\title{
Integrating Renewable Energy Requirements into Building Energy Codes
}

\author{
JR Kaufmann \\ JR Hand \\ MA Halverson
}

July 2011

\section{Pacific Northwest}

NATIONAL LABORATORY

Proudly Operated by Battelle Since 1965 


\title{
DISCLAIMER
}

This report was prepared as an account of work sponsored by an agency of the United States Government. Neither the United States Government nor any agency thereof, nor Battelle Memorial Institute, nor any of their employees, makes any warranty, express or implied, or assumes any legal liability or responsibility for the accuracy, completeness, or usefulness of any information, apparatus, product, or process disclosed, or represents that its use would not infringe privately owned rights. Reference herein to any specific commercial product, process, or service by trade name, trademark, manufacturer, or otherwise does not necessarily constitute or imply its endorsement, recommendation, or favoring by the United States Government or any agency thereof, or Battelle Memorial Institute. The views and opinions of authors expressed herein do not necessarily state or reflect those of the United States Government or any agency thereof.

\author{
PACIFIC NORTHWEST NATIONAL LABORATORY \\ operated by \\ BATTELLE \\ for the \\ UNITED STATES DEPARTMENT OF ENERGY \\ under Contract DE-AC05-76RL01830 \\ Printed in the United States of America \\ Available to DOE and DOE contractors from the \\ Office of Scientific and Technical Information, \\ P.O. Box 62, Oak Ridge, TN 37831-0062; \\ ph: (865) 576-8401 \\ fax: (865) 576-5728 \\ email: reports@adonis.osti.gov

\begin{abstract}
Available to the public from the National Technical Information Service, U.S. Department of Commerce, 5285 Port Royal Rd., Springfield, VA 22161 ph: (800) 553-6847 fax: (703) 605-6900

email: orders@ntis.fedworld.gov

online ordering: http://www.ntis.gov/ordering.htm
\end{abstract}

This document was printed on recycled paper.

$(9 / 2003)$ 


\section{Integrating Renewable Energy Requirements into Building Energy Codes}

JR Kaufmann

JR Hand

MA Halverson

July 2011

Prepared for

U.S. Department of Energy

under Contract DE-AC05-76RL01830

Pacific Northwest National Laboratory

Richland, Washington 99352 



\section{Executive Summary}

This paper summarizes PNNL's preliminary recommendations to DOE on the implementation of renewable energy requirements in the model building energy codes. This document provides a summary of many of the issues associated with a renewable energy requirement and provides a roadmap for short- and long-term adoption of a requirement.

The inclusion of a renewable energy requirement in the model building energy codes has the potential to dramatically increase the volume of renewable energy installations in the US in the next 10-20 years. However, if a renewable energy requirement is not implemented carefully the requirement may have a negative impact on the perception of renewable energy for many years. The complexity of this issue is summarized in this document.

The overall strategy advised is consistent with the figure, below. As the price of renewable energy, specifically photovoltaic (PV) is reduced the stringency of the renewable requirement should be increased based on cost effectiveness. The requirement could also be increased as the efficiency of PV systems increase.

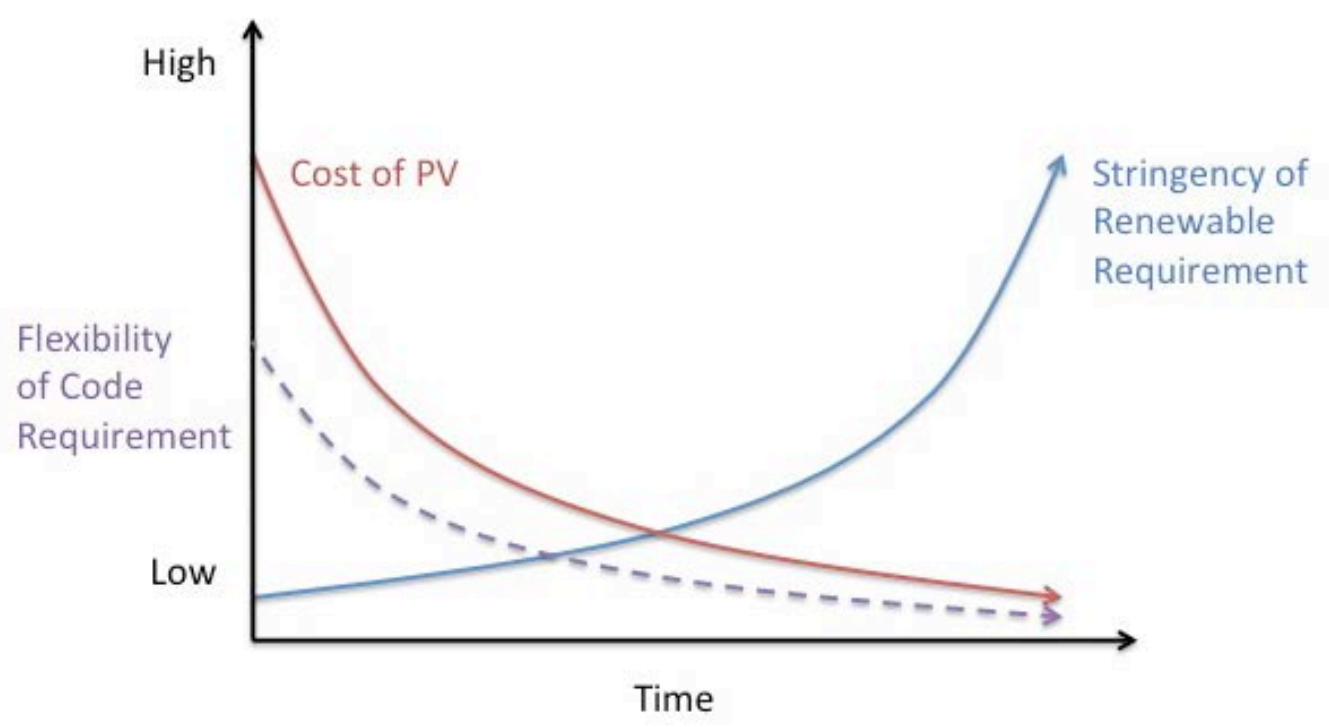

At the same time the flexibility of any renewable energy requirement must initially be very high and may be slowly reduced as public acceptance increases and renewable energy becomes pervasive. This flexibility is important to build confidence in the technology and will allow the repercussions to the national electric grid and renewable markets to be monitored.

Section 3.0 of the report provides an overview of the existing renewable requirements in US and global jurisdictions. The examples found include incentive programs and mandatory requirements. The research indicates there is significant diversity in the language, requirements, and implementation among the existing requirements, with Spain and Germany's requirements being the most advanced. 
A stakeholder survey of renewable energy is presented in Section 4.0, which indicated that most respondents believe reducing cost is the best way to improve on-site renewable integration. The survey also contains insights about specific structure of a possible code requirement and advice from respondents about how to allow trade-offs.

Section 5.0 of the report provides a summary of possible renewable energy technologies and discussion to support a renewable requirement based on rooftop photovoltaics (PV). Modeling suggests that requirements above $4.0 \mathrm{Watts} / \mathrm{ft}^{2}$ of roof area or $0.5 \mathrm{Watts} / \mathrm{ft}^{2}$ of conditioned floor area will be impractical due to roof size limitations in commercial buildings.

The modeling work explored requirements by roof area and by conditioned floor area and found the latter to be more consistent in the percentage of building load provided by PV. For roof area a requirement of $1 \mathrm{Watt} / \mathrm{ft}^{2}$ could provide between $0.3-24 \%$ of the building energy needs depending on location and building type. Warehouses, retail, and schools would have the largest projected energy offset (Table 5.1). If the requirement is based on conditioned floor area the same requirement provides $0.3-9 \%$ of the building energy needs and the distribution is more equitable between building types (Table 5.2).

The issues associated with a renewable energy requirement are addressed in Section 6.0. This section also outlines a recommended approach for each issue. Some of the issues evaluated include electric versus thermal requirements, alternatives if the use of renewable energy is infeasible, a possible requirement structure, allowing trade-offs with the requirement, renewableready requirements.

Section 7.0 provides the overarching strategy for dealing with the phase-in of the renewable requirements. The key strategies include the following.

- Priority should continue to be given to energy efficiency. A renewable requirement should be additive or complementary to energy efficiency, not a substitute for it.

- Renewable energy requirements in building energy codes should be part of a broader national renewable energy strategy. The broader strategy includes such things as financial incentives, grid policies, and renewable portfolio standards. All key stakeholder groups should clearly understand the goal, the role of building codes in helping to achieve the goal, and how each of the pieces of the broader strategy complement each other.

- A national forum representative of key stakeholder interests should be convened to help guide and coordinate efforts to integrate renewable energy requirements into codes.

- Where possible, renewable energy requirements should be introduced through voluntary programs and standards first, such as LEED, ASHRAE 189.1, the IGCC, before being rolled into codes.

- The Federal, state, and local governments should consider renewable energy requirements for new public buildings as a way to gain experience and build acceptance.

- Requirements should start small and gradually increase over time. Renewables should begin as part of an options package. The value and effectiveness of renewable-ready requirements has not been established.

- The principle fault line over whether codes should require the use of renewable energy is cost-effectiveness. Most think renewables should be cost-effective before they are 
required by codes, but many believe there are other critical objectives that must be considered as well. Discussions should be ongoing, and "muddling through" may be the default solution. An options approach and requirements for public buildings help sidestep this issue for the time being.

- Renewable energy requirements may be acceptable if introduced slowly, flexibly, and equitably.

- Solar water heating should be considered as a part of a water heating options package, not a renewable energy options package. In the long-term, a renewable energy requirement should apply to on-site electric generation - once efficiency requirements for building energy systems (HVAC, lighting, envelope, hot water) are maximized, only renewable electricity will be additive.

- If and when building codes transition to more performance- or outcome-based approaches, a separate renewable energy carve-out may still be appropriate to ensure some level of market development.

Section 8.0 provides recommendation by building type including commercial, residential, and public sector buildings. The important recommendations are summarized by building type below.

Commercial Recommendations:

- Initial renewable electricity requirements should be structured first as an options package, then transition to prescriptive requirements.

- A target renewable electricity requirement is suggested in the range of 0.5 to $4 \mathrm{Watts} / \mathrm{ft}^{2}$ of total roof area for commercial buildings.

- RECs should be included as an alternative compliance method if questions of building life and trade-off equity can be resolved. This is part of a separate ongoing task.

- Solar water heating systems should be included as a package option as a separate water heating requirement.

- Federal, state and local governments should consider a renewable energy requirement for public buildings.

Residential Recommendations:

- Renewable electricity requirements should be structured as an options package until the price of PV is low enough to make residential requirements appropriate.

- Because of issues like shading and the infeasibility of purchasing renewable energy certificates (RECs) as an alternative, a mandatory requirement even in the future is highly problematic. A program like Aspen’s Renewable Energy Mitigation Program may provide may have potential to address this issue, but requires local consensus and coordination.

- Solar water heating systems should be included as a package option in a separate water heating requirement. Luxury water heating applications like pool heaters should be considered as a possible way to aid solar market penetration.

- If alternative compliance paths are required they should focus on community solar approach rather than RECs which will be less feasible in the residential sector. 
- Passive solar design should not be added as a renewable energy code requirement. It may be acceptable as part of an options package in the short-term, but in the long-term it may not provide additionality.

Section 9.0 then provides details about how to engage stakeholders in the development of code language and specific requirement options. The plan calls for presenting the findings and recommendations of this report to key organizations and soliciting their input. In addition, a separate forum should be convened whose specific focus will be on renewable energy requirements, to make recommendations and otherwise inform discussions on model codes. In addition to the standards-development organizations like ASHRAE and ICC, it should include engineers, architects, code officials, solar equipment manufacturers and installers, builders, energy code advocacy groups, utilities, state and local officials, utilities, and others.

Based on this high level document about renewable energy requirements several future efforts are proposed as logical next steps.

- Identify a practical target price point for PV which will make an energy code requirement based on solar cost effective. A deeper analysis of this issue considering cost changes over time is needed to understand the best code structure and address the issue of cost effectiveness.

- Perform detailed energy and cost analysis to determine which alternative compliance methods including high efficiency and RECs may be energy equivalent and cost-effective in the short term. A separate task is currently doing a more detailed analysis of the REC options.

- Determine a specific trade-off level for high efficiency options and the renewable requirement which would be reasonable to put in place in the next 1-2 code cycles as a base for future requirements. Specific code language should be drafted and stakeholder input collected on the requirement.

- Develop a set of possible phased longer term approaches to including renewable requirements in the building energy code based on the discussion in this document. A separate strategy should be provided for both residential and commercial energy codes in recognition of the different stakeholders and compliance issues. Solicit feedback from the stakeholders on these possible strategies and determine the most appropriate path forward in the model energy codes.

- Gather a group of strategic stakeholders from the grid, code, and utility arenas who can aid in coordination of the renewable energy requirements, transmission impacts, and provide feedback on specific code levels. This could be accomplished in part using a DOE sponsored electronic forum.

- Conduct a more detailed analysis of how much energy PV requirements based on floor area and roof area would provide for each building types and climate zones. 


\section{Contents}

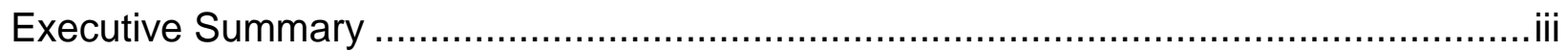

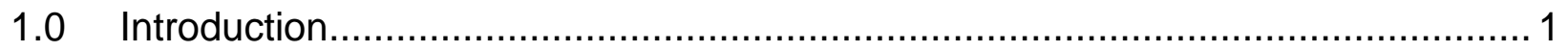

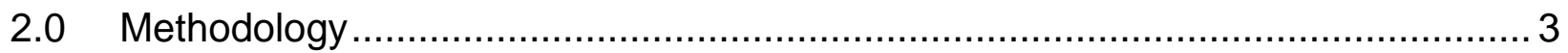

3.0 Summary of National//nternational Precedents ….......................................... 5

4.0 Summary of Renewables Integration Survey ................................................ 17

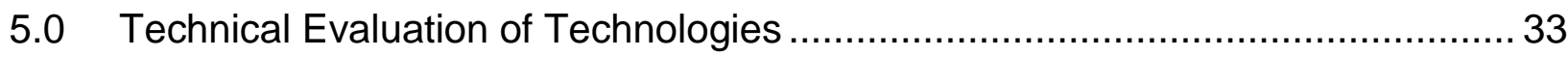

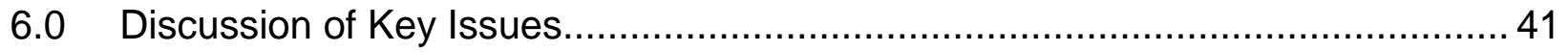

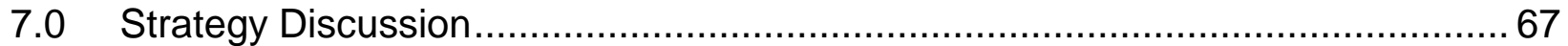

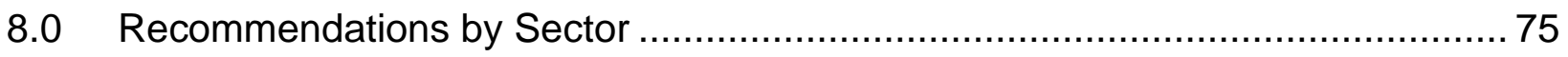

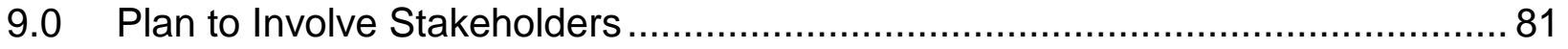

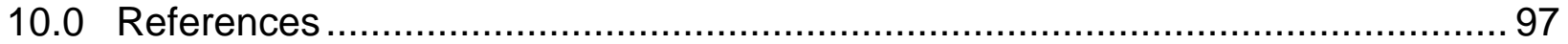

11.0 Acronyms of Organizations Referenced in This Report................................... 99

Appendix A: Annotated Bibliography of National/International Precedents ..................1

A1: National (U.S.) Model Codes and Standards .................................................

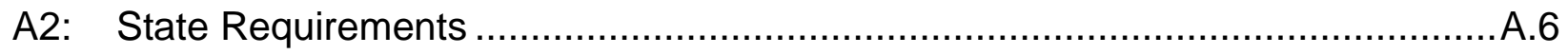

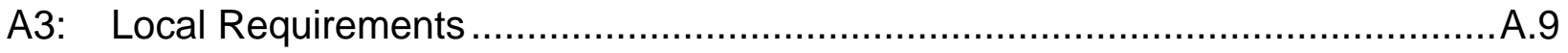

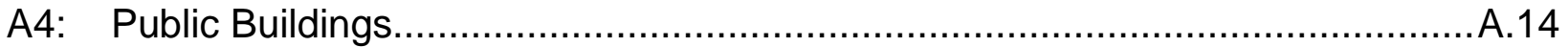

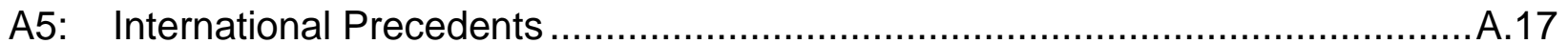

Appendix B: Complete Results of Renewables Integration Survey .............................1 


\section{Figures}

Figure 7.1: Current state of renewable energy requirements ................................. 70

Figure 7.2: Potential near-to-mid-term renewable energy requirements ..................... 71

Figure 7.3: Potential long-term renewable energy requirements ............................... 71

\section{Tables}

Table 3.1: Summary of Jurisdictions with Renewable Energy Code Requirements ........ 6

Table 5.1: Results of Potential Requirement Based on Roof Area .............................. 38

Table 5.2: Results of Potential Requirement Based of Conditioned Floor Area ........... 39

Table 9.1: Impacts of Recommendations on Stakeholder Involvement........................ 91

Table 9.2: Level of Involvement of Stakeholder Groups.......................................... 92 


\subsection{Introduction}

This report was completed by the Pacific Northwest National Laboratory's (PNNL) for the U.S. Department of Energy's (DOE) Building Technologies Program. The mission of DOE's Building Technologies Program (BTP) is to develop technologies, techniques, and tools, including building energy codes, for making residential and commercial buildings more energy efficient, productive, and affordable. PNNL, through its Building Energy Codes Program (BECP), provides support and assistance to DOE in this effort.

One approach to making buildings more energy-efficient is to require the use of renewable energy systems capable of generating power or energy that can be used by the building occupants. DOE's Energy Information Administration defines renewable energy as "Energy resources that are naturally replenishing but flow-limited. They are virtually inexhaustible in duration but limited in the amount of energy that is available per unit of time. Renewable energy resources include: biomass, hydro, geothermal, solar, wind, ocean thermal, wave action, and tidal action." ${ }^{1}$ Buildings that generate their own energy may not need to purchase energy from their local utilities.

Because of increased energy and climate concerns, interest in speeding the development and deployment of renewable energy resources in the U.S., and the effectiveness of building energy codes in delivering energy efficiency, DOE tasked PNNL with developing recommendations on how to best integrate renewable energy requirements into building energy codes. DOE also requested a plan to involve stakeholders as part of this work.

To date, because of high energy costs, the approach to renewable energy in building codes has been permissive - renewables are allowed by codes, but not required. Initial effort in the 1970s and 1980s was focused on ensuring the safety of renewable energy equipment and addressing barriers to the use of renewable energy equipment in structural, plumbing, mechanical, electrical, fire, and building codes. This task has been largely, although not totally. Some new barriers continue to be identified as new technology is developed and deployed, such as fire access and service issues on roofs occupied with renewable energy equipment. These issues must continue to be addressed. However, codes do not prohibit the use of renewable energy or pose a major barrier to the widespread deployment of renewable energy as earlier codes may have done. In addition, all of the code organizations - the American Society of Heating, Refrigerating, and Airconditioning Engineers (ASHRAE), International Code Council (ICC), International Association of Plumbing and Mechanical Officials (IAPMO), and National Fire Protection Association (NFPA) - have adopted policies to support the use of renewable energy, and procedures are in place to handle and resolve these issues as they come up. Thus addressing code barriers to the use of renewable energy was not the main focus of this evaluation.

The focus of this report is on how requirements related to the use of renewable energy could be incorporated into building energy codes. The basic goals were to: (1) provide a rough guide of how to get there; (2) identify key issues that need to be considered, including a discussion of

\footnotetext{
${ }^{1}$ See http://www.eia.gov/cneaf/solar.renewables/page/mswaste/msw_report.html.
} 
various options, to help inform code deliberations; and (3) to help foster alignment among energy code-development organizations, such as the American Society of Heating, Refrigeration and Air-conditioning Engineers (ASHRAE) and the International Code Council (ICC), as well as other key stakeholder groups. Section 9.0 of this document outlines a plan to involve stakeholders provides guidance on which organizations should be involved.

This report does not evaluate whether the use of renewable energy should be required on buildings. That is a key question around which there likely are many strong opinions, mostly centering around the issue of cost-effectiveness. It is a political issue that needs to be considered by DOE and may be an appropriate focus of future work. Numerous organizations and jurisdictions have already started to integrate renewable energy requirements into codes and standards. 


\subsection{Methodology}

This section describes the methodology and research techniques used in this effort.

\subsection{Search for models and precedents}

The first step of the research for this report was to conduct a search for national and international precedents of local and national governments that have adopted renewable energy requirements. . In most cases the actual code language was available. In some cases, however, a news article or report about a requirement was located, but with the actual code requirement was not available. In addition, some sources were not available in English. The authors had a few source documents translated into English to confirm press accounts; however, they were not officially sanctioned by the host jurisdiction and are not available to the public. The Annotated Bibliography of National and International Precedents in Appendix A contains citations and links to the source documents.

\subsection{Identify key stakeholders}

As part of the overall study, the authors sought to get input from key stakeholder groups. As a first step to getting that input, we began by identifying the key categories of stakeholder groups, defined as groups with expertise in the area of building energy codes and renewable energy (or both) and/or groups that would be significantly affected by renewable energy requirements in building codes. This included, but was not limited to, state and local code officials, standardssetting organizations, design professionals, homebuilders and contractors, energy efficiency and codes advocacy groups, the renewable energy industry and renewable energy advocacy groups, and utilities.

The search for international and, especially, national precedents yielded the names of numerous organizations and contacts. In addition, organizations and personnel involved with codes were obtained from PNNL's Building Energy Codes Program (BECP) mailing and resource lists, as well as from general web searches for leading organizations in each of the fields described above.

\subsection{Identify key issues}

Staff developed a list of some of the key issues they thought needed to be addressed in developing a strategy to integrate renewable energy requirements into codes. These issues were vetted internally first and then with a few key stakeholders. They are discussed in Section 6.0, Discussion of Key Issues.

\subsection{Survey of stakeholders}

PNNL developed a questionnaire as a means to obtain input from stakeholders on the key issues and possible strategies. The intent of the questionnaire was to solicit qualitative input, not to take a quantitative poll. While most of the questions provided for 'yes-no' or 'multiple-choice' answers, every question provided a comment box and asked respondents to explain their answers or provide other information. The survey consisted of 29 questions, not including basic 
information. The survey was developed and vetted internally at PNNL to ensure the survey was neutral in tone and phrased in such a manner as to elicit the most useful information.

The survey was sent to 160 persons from the key stakeholder and other groups. . People had a month to respond, and a reminder was sent out at the end of the third week. Depending on the depth of qualitative comments and explanations provided, the survey took about 1 hour to complete. There were 75 responses - 56 complete responses and 19 partial. The respondents represented a diversity of interests. PNNL conducted follow-up phone calls with 15 respondents to explore their answers and some of the key issues in greater depth. These interviews did not use an established format, but were open-ended based on the answers the respondent provided in the survey.

The results of the survey are summarized in Section 4.0, Summary of Survey. The entire survey results are included as Appendix B, Renewables Integration Survey.

\subsection{Quantitative analysis}

The authors conducted a brief review to estimate how much energy could reasonably be produced by an on-site renewable energy system. While there are a handful of renewable energy technologies that can be used in buildings, photovoltaics (PV) and solar hot water are the most practical to become part of a code requirement; however, solar water heating is more likely to be required as high-efficiency water heating option. ${ }^{2}$ The purpose of this review was to provide guidance on how much energy a photovoltaic requirement in building energy codes could provide.

The National Renewable Energy Laboratory (NREL) conducted an "Assessment of the Technical Potential for Achieving Net Zero-Energy Buildings in the Commercial Sector" in 2007 (Griffith, 2007), which included the use of photovoltaics on $50 \%$ of the roof area. The results of that report are summarized in Section 5.0, Technical Evaluation, with a discussion of additional analysis PNNL conducted on available roof area and framing the photovoltaic contribution in terms of per square foot of roof area, per square foot of conditioned floor area, and percentage of building load for each of DOE's main building prototypes.

\subsection{Development of recommended strategy and stakeholder involvement plan}

The recommendations of this report and the stakeholder involvement plan were developed after consideration of the information described above. The authors developed the recommendations and had them reviewed internally by other staff in PNNL's Building Energy Codes Program. The final recommendations reflect the opinions and judgment of the authors.

\footnotetext{
${ }^{2}$ See Recommendation 6 in Section 7.0 Recommended Actions for discussion of why PV is one of the most likely candidates to be included as a stand-alone requirement in an energy code.
} 


\subsection{Summary of National/International Precedents}

One of the first steps in determining how to integrate renewable energy requirements into building energy codes was to review other groups that have already implemented a requirement. The authors conducted a web-search to identify what local, state, or national governments have adopted renewable energy requirements. Broadly speaking, there are few renewable energy requirements either globally or within the United States. Most code jurisdictions are permissive they allow use of renewable energy equipment - but few have mandatory requirements.

Many jurisdictions try to incentivize renewable energy rather require it. These jurisdictions provide incentives, such as rebates, tax credits, or loans. In Europe incentives often take the form of feed-in tariffs (FITs), where the utility pays the customer for each kilowatt-hour (kWh) produced over the course of a number of years. In addition, many jurisdictions have net-metering requirements to allow customers to sell unneeded power to utilities for the same price they pay when they need backup power; the alternative would be to store unneeded power from a renewable energy system in a battery for use when it is needed, which may not be economically efficient for the customer.

For those jurisdictions that do use building codes to promote or require the use of renewable energy, requirements take numerous forms. On one end of the spectrum, communities may require that buildings be made 'renewable-ready,' meaning they require builders to offer solar to home buyers, or offer non-monetary code-based incentives such as expedited permitting. On the other end of the spectrum are jurisdictions that mandate the use of photovoltaics or solar water heating for all new buildings and remodels. In the center of the spectrum are voluntary leadership programs, standards that rely on points and trade-offs, and renewable energy requirements specific to public buildings.

Most requirements apply to renewable energy broadly, or to photovoltaics (PV) and solar water heating (SDHW) specifically. A few requirements include passive solar design or daylighting. None apply directly to wind, geothermal, or biomass, although they may be permitted as alternatives.

\subsection{Summary descriptions}

Table 3.1 identifies and categorizes the major code provisions that were found. They are ordered from what the authors judged to be least stringent to most stringent. Below the table is a written summary of the examples. More detailed descriptions, links, and citations for each may be found in Appendix A. 
Table 3.1: Summary of Jurisdictions with Renewable Energy Code Requirements

\begin{tabular}{|c|c|c|c|}
\hline CATEGORY & $\begin{array}{c}\text { GENERAL } \\
\text { RENEWABLES }\end{array}$ & PHotovoltaics & $\begin{array}{c}\text { SOLAR WATER } \\
\text { HEATING }\end{array}$ \\
\hline Non-monetary incentives & $\bullet$ Chicago & - Greece & \\
\hline Renewable-ready & $\begin{array}{c}\bullet \text { Ohio (schools) } \\
\bullet \text { Vancouver, B.C. } \\
\bullet \text { Santa Fe } \\
\bullet \text { West Hollywood, CA } \\
\bullet \text { ASHRAE Standard 189.1 }\end{array}$ & & \\
\hline $\begin{array}{l}\text { Model codes and } \\
\text { leadership standards }\end{array}$ & $\begin{array}{l}\text { • New Buildings Core } \\
\text { Performance Guide } \\
\text { • ICC Green Code (IGCC) } \\
\text { - National Green Building } \\
\text { Standard (ICC-700) } \\
\text { - ASHRAE Standard 189.1 } \\
\text { • USGBC-LEED } \\
\text { • } 2012 \text { IECC }\end{array}$ & & \\
\hline Points & $\begin{array}{c}\bullet \text { Boulder } \\
\bullet \text { Tucson } \\
\bullet \text { Pima County, AZ } \\
\bullet \text { Long Island (10 towns) } \\
\bullet \text { Austin } \\
\bullet \text { Scottsdale, AZ } \\
\text { - Numerous requirements for } \\
\text { public buildings }\end{array}$ & & \\
\hline $\begin{array}{l}\text { Requirements for } \\
\text { outdoor systems - e.g., } \\
\text { pools, spas, snowmelt }\end{array}$ & $\begin{array}{l}\text { - Barcelona (pools) } \\
\text { - Albuquerque (pools) } \\
\text { - Aspen and Pitkin County, } \\
\text { Colo. (snowmelt, spas) }\end{array}$ & & \\
\hline $\begin{array}{l}\text { Must offer renewable } \\
\text { energy to customer }\end{array}$ & • Colorado (residential) & & \\
\hline $\begin{array}{l}\text { Public buildings (if cost- } \\
\text { effective) }\end{array}$ & $\begin{array}{c}\bullet \text { Federal (EPACT 2005) } \\
\bullet \text { California } \\
\bullet \text { Arizona } \\
\bullet \text { Florida } \\
\bullet \text { Several other states } \\
\bullet \text { Chandler, AZ }\end{array}$ & & • Hawaii \\
\hline $\begin{array}{l}\text { Public buildings } \\
\text { (mandatory) }\end{array}$ & $\begin{array}{l}\text { - Minnesota } \\
\text { - Oregon }\end{array}$ & & $\begin{array}{c}\bullet \text { Cyprus } \\
\bullet \text { Florida (schools) }\end{array}$ \\
\hline $\begin{array}{l}\text { Stretch/reach codes } \\
\text { (local option) }\end{array}$ & $\begin{array}{l}\bullet \text { California } \\
\bullet \text { Massachusetts } \\
\bullet \text { Oregon }\end{array}$ & & \\
\hline $\begin{array}{l}\text { Choice of required } \\
\text { options }\end{array}$ & - Germany (thermal) & - Oregon (residential) & $\begin{array}{l}\bullet \text { Oregon (residential) } \\
\bullet \text { Australia }\end{array}$ \\
\hline Required & $\begin{array}{c}\text { • England (require local RE } \\
\text { targets) } \\
\text { - England (Merton, other local } \\
\text { jurisdictions) } \\
\text { - Ireland (bldgs }>1000 \mathrm{~m}^{2} \text { ) }\end{array}$ & $\begin{array}{c}\bullet \text { Spain } \\
\bullet \text { Barcelona (complements } \\
\text { national law) }\end{array}$ & $\begin{array}{c}\text { • Spain } \\
\bullet \text { Barcelona } \\
\bullet \text { Portugal } \\
\bullet \text { Greece } \\
\bullet \text { Sao Paulo, Brazil } \\
\bullet \text { Israel } \\
\bullet \text { Marburg, Germany } \\
\bullet \text { Hawaii } \\
\bullet \text { India (local) }\end{array}$ \\
\hline $\begin{array}{l}\text { Aggressive performance } \\
\text { requirements (making } \\
\text { RE more likely) }\end{array}$ & $\begin{array}{c}\text { European Union (Directive) } \\
\bullet \text { Japan } \\
\bullet \text { Greece }\end{array}$ & & \\
\hline
\end{tabular}


A description of the major approaches and the leading examples of each are provided below. There is some overlap between categories, because they are not mutually exclusive and some local codes could be put in two categories.

\subsubsection{Non-monetary incentives}

Many jurisdictions offer monetary incentives to use renewable energy, but they are independent of building code requirements and are not addressed here. A few, however, have put some nonmonetary incentives within the building code structure. Examples include expedited processing of permit applications, fee reductions, awards or recognition (for marketing purposes), construction site signs, or technical assistance.

- Chicago offers expedited permitting and fee reductions for buildings that use solar energy, while Greece offers streamlined processing for buildings that use photovoltaic panels.

- Chandler, Arizona offers several of these non-monetary incentives for buildings receiving various levels of LEED certification.

\subsection{2 'Renewable-ready'}

This approach preserves the option to use solar energy equipment at a future date. It includes installing some infrastructure or reserving space for installation of solar and associated electrical equipment.

- New schools in Ohio have requirements for orientation, solar access, structural integrity, and electrical system access to accommodate photovoltaics in the future.

- Vancouver, Canada, requires new homes to be equipped with solar-ready pipe from the attic to the service room.

- Santa Fe requires sleeved penetrations.

- West Hollywood requires 300 square feet of south roof area clear of vent pipes or other obstructions, increasing structural capacity of the roof by 4 pounds per square foot, and installing 0.75 inch or larger conduit, with pull boxes as needed, from the roof to the electrical room (or electrical panels).

\subsubsection{Model codes and 'leadership' standards}

Numerous organizations have developed high performance standards for sustainable or 'green' design. These standards are voluntary and are meant to lead practice by setting a benchmark higher than code. The standards may be used by builders or designers to provide an accepted benchmark, or as the basis for building code requirements by some jurisdictions wishing to go further than standard requirements. Leadership standards are mostly performance-based - while credit is given for the use of renewable energy, it generally is not required.

- ASHRAE Standard 189.1 is a standard for the design of high-performance green buildings. It is a design standard for engineers and tends to be performance-based, although it does have some mandatory prescriptive requirements. It is not intended nor promoted for adoption by local jurisdictions, although it could be used as such. 
ASHRAE 189.1 requires that building project design show allocated space and pathways for future installation of on-site renewable energy systems and associated infrastructure. In addition, buildings must meet either an energy performance option that does not specifically require the use of renewable energy, or a prescriptive option that does. Because single-story buildings have more roof area per conditioned floor area, the prescriptive standard is $6 \mathrm{kBtu} / \mathrm{ft}^{2}\left(20 \mathrm{kWh} / \mathrm{m}^{2}\right)$ multiplied by the total roof area in $\mathrm{ft}^{2}$ $\left(\mathrm{m}^{2}\right)$ compared to $10 \mathrm{kBtu} / \mathrm{ft}^{2}\left(32 \mathrm{kWh} / \mathrm{m}^{2}\right)$ multiplied by the total roof area in $\mathrm{ft}^{2}\left(\mathrm{~m}^{2}\right)$ for other buildings.

- The International Code Council's (ICC) 2012 International Energy Conservation Code (IECC) was amended as a prescriptive option along the lines of the Oregon residential energy code, except that it applies only to commercial buildings and multi-family buildings 4-stories or taller. In addition to the mandatory requirements of the IECC, applicants must choose one of three prescriptive options: high-efficiency equipment, high-efficiency lighting, or the renewable energy requirements below. The amendment would require installation of an on-site renewable energy system that provides not less than 1.75 Btus or 0.50 watts per square foot of conditioned floor area, or not less than $3 \%$ of the energy used within the building for building mechanical and service water heating equipment and lighting. Numerous jurisdictions in the U.S. adopt the IECC as their energy code.

- The ICC's International Green Construction Code (IGCC) ${ }^{2}$, unlike ASHRAE Standard 189.1, is written in code language so that it can be adopted as a code but it will probably be adopted as a stretch code or voluntary sustainable design code. (At the time of writing, only Richland, Washington, has adopted it on a non-mandatory basis.) The IGCC requires that buildings be equipped with a renewable energy system. Photovoltaic systems must provide at least "two percent of the total calculated annual energy use of the building" and have a rating of at least $0.50 \mathrm{~W} / \mathrm{ft}^{2}$ of conditioned floor area. A solar water heating system shall be capable of meeting at least $10 \%$ of the building's annual estimated hot water energy usage. Other renewable energy systems must provide at least $2 \%$ of the total calculated annual energy use of the building, or have a rating of at least $1.75 \mathrm{Btu} / \mathrm{hr}$ or at least $0.50 \mathrm{~W} / \mathrm{ft}^{2}$. It also includes any system that derives its energy from solar radiation, wind, waves, tides, landfill gas or biomass. All systems must be separately metered. Energy savings from on-site renewable energy may be deducted when calculating building total annual net energy use for purposes of meeting the building's total energy performance target. Renewable energy credits may be used where there is at least a 10 -year commitment for $4 \%$ of the total annual building energy consumption.

- The U.S Green Building Council’s Leadership in Energy and Environmental Design (LEED) program and the National Green Building Standard (ICC-700) are point-based. They are voluntary and do not require the use of renewable energy sources, but provide points toward the required energy credits. LEED New Construction (NC) applies to new commercial buildings, and LEED Existing Buildings (EB) applies to renovations of

\footnotetext{
${ }^{3}$ The IGCC has been released in two versions so far - Public Version 1 (PV1) and Public Version 2 (PV2). The comments on the IGCC refer to PV2. The IGCC is undergoing a series of hearings in 2011 to generate the 2012 IGCC and the contents of that version may be different when finally published.
} 
existing commercial buildings. The National Green Building Code applies to residential construction.

- The New Buildings Institute (NBI) Core Performance Guide establishes prescriptive guidelines for small and medium-sized commercial buildings. Similar to the Prescriptive Options described in Section 3.1.10, the Guide lists several enhanced performance options from which the applicant must choose. One of the enhanced options is that onsite renewable energy must supply at least $10 \%$ of building loads. The USGBC has adopted the Core Performance Program into its LEED NC program in lieu of performance modeling. Chapter 5 of the 2012 IECC code, and the Massachusetts "Stretch Code" were developed from NBI's Core Performance program.

\subsubsection{Point-based codes}

Buildings must achieve a specified level of energy performance, with points available for use of renewable energy. Several communities, especially in the Southwest, have codes based on points, much like LEED and the National Green Building Standard (ICC-700) referenced above.

\subsubsection{Requirements for outdoor systems}

Aspen and Pitkin County, Colorado, impose renewable energy requirements on exterior energy use, such as swimming pools, spas, and snowmelt systems. Some people refer to these uses outdoor applications as 'luxury’ uses.

- Aspen and Pitkin County require that for houses greater than 5,000 square feet, $50 \%$ of the energy for these outdoor systems be supplied from on-site renewable energy. In lieu of this, homeowners may pay a fee to the Renewable Energy Mitigation Fund (REMP) for energy-efficiency and renewable energy projects elsewhere in the community.

- Barcelona is requires $100 \%$ of swimming pool heating must be from solar.

- Albuquerque requires that the primary source of energy for heating swimming pools shall come from solar collectors.

\subsubsection{Must offer renewable energy at time of sale}

- Colorado requires builders of single family homes to offer the buyer either a photovoltaic (PV) system or a solar water heating system installed on their new home, or to have all the necessary wiring and/or plumbing installed so that they can easily add a solar system at a later date. The builder must also provide the buyer with a list, maintained by the Governor's Energy Office, of every solar installer in the area.

\subsubsection{Public buildings (if cost-effective)}

Numerous cites, states, and even countries impose renewable energy requirements on public buildings under their own jurisdiction. This allows local contractors to gain experience and demonstrates feasibility before requiring it on other buildings.

- California, Florida, Hawaii, and Arizona require the consideration and use of renewable energy if cost-effective; numerous other states have sustainable design requirements, under which renewable energy is allowed but not specifically required. 
- In the U.S., Federal agencies, to the extent economically feasible and technically practicable, must ensure that not less than $3 \%$ of the total electricity consumed by the Federal Government in 2007-2009, not less than 5\% in 2010-2012, and not less than $7.5 \%$ in 2013 and thereafter, comes from renewable energy. This requirement applies to an agency's entire portfolio of buildings, and may include the purchase of renewable energy certificates (RECs). However, coupled with aggressive energy-efficiency requirements, many new Federal buildings are in the forefront in renewable energy use.

- In addition, new Federal buildings and major renovations of Federal buildings must meet $30 \%$ of their hot water demand from solar water heaters, if life-cycle cost-effective.

\subsubsection{Public buildings (mandatory)}

A handful of governments go the next step and require the use of renewable energy in public buildings. Minnesota and Oregon require the use of renewable energy in public buildings.

- Oregon requires that $1.5 \%$ of the project costs for public buildings be dedicated to the purchase and installation of solar energy equipment.

- Minnesota requires state agencies to provide at least 2\% of a new building's anticipated energy needs from on-site renewable energy resources, or supply a full cost and carbon analysis explaining why renewables would not be cost-effective.

- Florida requires schools to install solar water heating if hot water demand exceeds 1,000 gallons per day.

- Outside the U.S., Cyprus has required solar water heaters on public buildings for many years.

\subsubsection{Stretch I reach codes}

'Stretch'codes, also known as 'reach" codes, are high-performance requirements that may be adopted by jurisdictions wanting more aggressive requirements than those provided by the standard code. The two leading stretch codes in the U.S. are California and Massachusetts.

- The California Green Building Code (CalGreen) was developed by the State of California as a model code for jurisdictions, in an attempt to establish a benchmark and to ensure some consistency among jurisdictions. CalGreen operates much like the leadership standards described above. In energy, applicants must choose 4 of 21 electives to qualify as Tier 1 , and 6 electives for Tier 2. Of the 21 electives, 4 relate to renewable energy solar water heating, photovoltaics, and two solar-ready alternatives. Numerous communities in California have adopted 'beyond code' requirements, but most have deviated from CalGreen.

- In Massachusetts, if communities wish to go beyond the state code, they must adopt the Massachusetts Stretch Code. As of May, 2011, 88 jurisdictions have adopted the Massachusetts Stretch Code. The stretch code does not have a specific renewable energy requirement. 


\subsubsection{Prescriptive options}

Prescriptive options require applicants to choose from among a specified set of additional prescriptive requirements that exceed other energy-related requirements, with renewable energy being among the options. It is similar in many respects to the California Green Building Code and ASHRAE Standard 189.1 for High-Performance Green Buildings, except that the code is mandatory. The Oregon Residential Energy Code is the best example of this approach.

- Germany's Renewable Energies Heat Act of 2008 requires the use of renewable energy to meet a percentage of a building's thermal energy demand. It is important to note that energy-savings measures and heat pumps, including both ground source and air-to-air heat pumps, may satisfy the requirements. The requirements apply to both residential and non-residential buildings. The required percentage varies by renewable energy source. Solar thermal must provide $15 \%$ of a commercial building's thermal demand, or $0.04 / \mathrm{m}^{2}$ per of heated floor area for residential. Except for residential solar thermal systems, the requirements are performance-based; applicants must submit calculations of the building's thermal load and proof that the renewable energy system will provide the required percentage of that load.

- Oregon has long had some of the most energy-efficient residential energy requirements in the U.S. In addition to the base code requirements, since 2008 builders must select one prescriptive option from a list of nine advanced options. Two of the options include installation of a solar water heating system 40 square feet or larger, or a photovoltaic system of at least 1 watt per square foot times the conditioned floor area. Other options include high-efficiency equipment, lighting, heat pump water heater, duct sealing, a highperformance envelope, and combinations thereof. Most builders choose one of the nonrenewable energy options. Oregon eventually plans to require builders to choose two options, then three.

- Under the Massachusetts Stretch Code, homes must receive a rating of 70 or less (65 or less for homes larger than 3,00 square feet) using the Home Energy Rating System (HERS), where a rating of 100 is a home built to the IECC 2006 code and 0 is a zero netenergy home. Builders may use renewable energy to help achieve the rating, but are not required to do so. Commercial buildings larger than 100,000 square feet must meet a performance standard set at $20 \%$ below the estimated energy use of a building designed to meet ASHRAE 90.1-2007, with no specific renewable energy requirement. Mediumsized commercial buildings less than 100,000 square feet have the same option, or they may use a simplified, prescriptive energy code based on Chapter 5 of the IECC 2009 energy code with additional efficiency improvements. The improvements include a choice of high-efficiency heating, ventilation and air conditioning (HVAC) equipment, further lighting energy reductions, or on-site renewable energy. This prescriptive option for commercial buildings was developed from the Core Performance program of the New Buildings Institute.

- The Australian national building code requires the use of low emissions systems for domestic water heating, such as high-efficiency natural gas, heat pumps, or solar water heating. If used, the solar water heater must provide $40 \%$ of the hot water load for a small building ( 1 or 2 bedrooms), and $60 \%$ of the hot water demand for a large building ( 3 or more bedrooms). Renewable energy certificates are an acceptable alternative, with the 
number of RECs dependent on the number of bedrooms - 14 RECs for one or two bedrooms, 22 RECs for three or four bedrooms, and 28 RECs for five bedrooms or more..

- $\quad$ Seattle currently is considering a proposal to include on-site renewable energy systems as a prescriptive option in the amount of $500 \mathrm{Btu} / \mathrm{ft}^{2}$ of gross conditioned area, 1/12 the level in ASHRAE Standard 189.1. However, Seattle allows RECs as an alternative at the same level as ASHRAE Standards $189.1-7 \mathrm{kWh} / \mathrm{ft}^{2}$ of conditioned space each year until the cumulative purchase totals $70 \mathrm{kWh} / \mathrm{ft}^{2}$. Thus, the cost of RECs as an alternative is expected to be roughly equivalent to, or slightly more than, the cost of installing the renewable energy system.

\subsubsection{Renewable energy requirement}

A few communities, mostly in Europe, require the use of renewable energy outright in all residential and/or commercial buildings (reasonable exemptions allowed). In general the requirements start small, but are required nonetheless. Several of the European requirements are complemented by feed-in tariffs, which improve the economics of renewable energy systems for builders and owners.

- $\quad$ Spain's National Building Code requires the use of photovoltaics on large commercial buildings. The applicable building size varies by occupancy type. The country is divided into five solar climate zones representing 10\% increments in the solar resource - zones with a better solar resource have to install larger solar systems. The minimum photovoltaic system size is $5 \mathrm{~kW}$. Spain's PV requirement is the only photovoltaic requirement that the researchers found. It must be noted that the requirement is 'greased' by a national feed-in tariff.

- $\quad$ Spain also requires the installation of a solar water heater on new and renovated buildings in which there is a demand for domestic hot water and/or the conditioning of a covered swimming pool. System size varies by climate zone and the hot water load of the building, on a sliding scale ranging from $50 \%$ to $70 \%$ if the backup energy source is electricity, and $30 \%$ to $70 \%$ of the demand if the backup energy source is natural gas, propane, and other. The law specifies the minimum water heating load to be used for design purposes for about 20 categories of residential and nonresidential buildings.

- In addition to the national requirement, Barcelona requires that new buildings and major renovations use solar energy for $60 \%$ of their hot water demand. The Barcelona model has been adopted in Madrid, Seville, and other communities.

- Hawaii requires solar water heaters to be installed on the new single-family dwellings, starting in 2010. It is the only requirement in the U.S. (aside from some requirements for public buildings and outdoor uses).

- $\quad$ Portugal requires 1 square meter ( 10 square feet) of collector area per person of solar water heating on all new and renovated buildings.

- In 2004, the Borough of Merton, England adopted a local planning policy that requires new developments to generate at least $10 \%$ of their energy needs from on-site renewable energy sources. In 2008, the English government's Planning Policy Statement - Planning and Climate Change - PPS1 required local planning authorities to consider renewable energy targets for new developments. Numerous local authorities have subsequently 
adopted requirements similar to the 'Merton rule.' The Merton rule covers all buildings, not just homes. The most commonly accepted threshold is 10 homes or $1,000 \mathrm{~m}^{2}$ of nonresidential development.

- Sao Paulo, Brazil, requires a solar water heating system for both residential and nonresidential buildings approved after July 2008. The systems shall provide at least $40 \%$ of the annual hot water demand. The buildings covered are those intended for commercial, industrial (if hot water is needed for the industrial process or if showers are to be installed for the staff), and, in general, any other use that entails the presence of dining rooms, kitchens or collective laundries.

- Ireland requires that new dwellings be designed and constructed so that a reasonable proportion of the energy consumption of the dwelling is provided by renewable energy sources. They have defined this as " $10 \mathrm{kWh} / \mathrm{m}^{2} /$ year contributing to energy use for domestic hot water heating, space heating or cooling; $4 \mathrm{kWh} / \mathrm{m}^{2} /$ year of electrical energy, or a combination of these which would have equivalent effect.” Buildings larger than $1,000 \mathrm{~m}^{2}$ shall consider the use of decentralized (on-site) renewable energy, but there is no mandatory requirement to use renewables.

- Israel has required solar water heaters for new homes since 1980, and for all residential buildings since the early 1990s. Israel estimates that solar water heaters are installed on about $85-90 \%$ of Israeli homes and meet about $4 \%$ of Israel's total energy demand.

- As of January 2011, Greece requires all new buildings to meet at least $60 \%$ of their domestic hot water demand from solar technology. This regulation is in response to the European Energy Performance of Buildings Directive (EPBD). Greece already has a significant penetration of solar water heaters.

- Marburg, Germany, requires 1 square meter of solar panel for every 20 square meters of heated floor space, with a minimum size of 4 square meters $\left(43 \mathrm{ft}^{2}\right)$. The City may impose a fine of $€ 1,000$ on those who do not comply. Exempt from the new law are buildings with an existing district heating system, a combined heat and power generator, or a wooden pellet oven. At the time that this report was written the law was not being enforced because of a legal challenge.

- Several jurisdictions in India (Karnataka, Chandigarh Union Territory, others) require the use of solar water heaters for industries where hot water is required., as well as for housing complexes and residential buildings greater than $600 \mathrm{ft}^{2}$ of floor area. At the national level a similar requirement is being considered. The requirement would vary based on occupancy type. For example, 100 liters per day must be provided for every 200 $\mathrm{m}^{2}$ of single-family residential floor area; for every four beds in a nursing home or hospital; every three rooms in hotels; every $40 \mathrm{~m}^{2}$ of restaurant seating area; and every 50 workers in an industrial canteen. A 3 year lead-time is recommended before the law takes effect. It is recommended to cover all types of residential and commercial buildings, but a compromise would be to require solar water heating in commercial buildings first, while providing incentives for residential buildings. For maximum effect, the report recommends adoption of "flanking" measures such as bureaucratic streamlining and provision of loans and incentives. 


\subsubsection{Aggressive energy performance requirements}

The last approach identified is the adoption of very aggressive energy performance requirements such that renewable energy may be needed to meet the performance-based target. Aggressive energy performance targets, with post-occupancy verification that the targets are being achieved, has been discussed by energy code professionals as the possible direction for high-performance codes in the future. Under such an approach, a specific renewable energy requirement may be irrelevant. (Specific renewable requirements in conjunction with a performance-based approach are evaluated in Section 6.0, Discussion of Key Issues.)

It is unclear whether any community has adopted this approach already. Several codes are performance-based and fairly aggressive. However, it is not clear whether they are aggressive enough to drive the use of renewable energy systems.

- Chief among these is the European Union (EU) Directive on the Energy Performance of Buildings, 2010/31/EU. The recast calls for member states to ensure that all new buildings are nearly zero-energy buildings by 31 December 2020, and that new buildings occupied and owned by public authorities are nearly zero-energy buildings by 31 December 2018. This will drive the use of renewable energy as well as energy efficiency, whether implemented as performance-based or prescriptive codes.

- Greece's solar water heating law was in response to the EU Directive. More importantly, perhaps, Greece also adopted a provision that all new public buildings must cover the total of their primary energy consumption with energy supplied from renewable energy sources, combined heat and power (CHP) systems, district heating on a large area scale, and heat pumps by 2015, and all new buildings by 2020. This is expected to drive the use of renewable energy.

- Japan has a performance-based code and has progressively ratcheted the target since first adopted in 1979. Japan has a significant penetration of residential solar water heaters and an increasing number of photovoltaic systems. How much of the market penetration is driven by the code or other factors was unclear. Demand water heaters are also common in Japan.

- The Energy Independence and Security Act of 2007 passed by the U.S. Congress requires that new Federal buildings (and major renovations) reduce fossil-fuel-generated energy consumption by 55\% from a baseline defined by the Commercial Building Energy Consumption Survey (CBECS) beginning in 2010, 65\% in 2015, 80\% in 2020, 90\% in 2025 , and $100 \%$ in 2030 . Rather than counting reductions, the proposed rule would establish a Maximum Allowable Fossil Fuel Energy Consumption target. In addition to deep energy-efficiency improvements, Federal agencies likely will have to install on-site renewables and/or purchase renewable energy certificates to meet these targets.

We were not able to identify an exact progression from more lenient to more aggressive codes in the examples found. This may be because there are not many communities that have any requirements at all, and what requirements that do exist are so recent there has not been time for them to progress.

The one thing that is relatively consistent, however, is that most of the communities with renewable energy requirements have a strong history of aggressive energy-efficiency 
requirements in their codes. California, Florida, Massachusetts, Oregon, Boulder, Austin, and others in particular have long been leaders in energy-efficient codes.

\subsection{Requirements not included in this summary}

Several code jurisdictions we found purport to require the use of solar energy. However, they allow other measures to be readily substituted such that the solar energy requirement, in our opinion, is moot; in most cases we expect that most people use the alternatives, which are generally less expensive than solar. Hence, we have not listed them as code requirements in the table.

A common approach to advancing renewable energy and sustainable design requirements applies to public buildings. Many jurisdictions require public buildings to meet point-based sustainable design or 'green building' standards, such as the U.S. Green Building Council's Leadership in Energy and Environmental Design (LEED) and similar programs. However, these programs allow points for energy efficiency, including the use of renewable energy systems, but do not require the use of renewable energy. Still other jurisdictions require the government agencies to obtain a minimum amount of power through the purchase of renewable energy certificates (RECs, or 'green tags'). None of these are considered code requirements for our purposes, because they do not effectively require the use of on-site renewable energy. 


\subsection{Summary of Renewables Integration Survey}

PNNL developed a questionnaire obtain input from stakeholders on the key issues and possible strategies for integrating renewable energy requirements into building energy codes. The survey consisted of 29 questions, beyond basic information. It was sent to 160 stakeholders representing a diversity of interests. There were 56 complete responses and 19 partial responses, for a total of 75 responses. Forty percent of the respondents serve on an ASHRAE or ICC committee, which are the most likely avenues by which renewable energy requirements will be introduced into national codes and standards.

Important note about the survey: The goal of the questionnaire was to get a sense of professional opinion about the issue and to solicit qualitative input. It was not intended as a statistically valid quantitative poll, where the conclusions and recommendations would reflect the majority opinion. Rather, PNNL intended the survey as a way to solicit ideas - arguments for and against various strategies and approaches, and creative ways to address the key issues. The sample size was relatively small and the sample set, focusing on people with experience in energy codes, was not necessarily representative. Thus the results were not analyzed for statistical validity, and readers are cautioned about interpreting the numerical results in that manner.

While most of the questions provided for 'yes-no' or 'multiple-choice' answers, every question provided a comment box and asked respondents to explain their answers or provide other information. The recommendations developed by PNNL for this report do not necessarily reflect the quantitative results of the survey. PNNL staff looked at the accompanying comments provided by survey respondents in evaluating the key issues, and made recommendations based on their professional assessment of the strength of the comments and explanations provided.

Selected explanatory comments that accompanied the survey responses are included in the summary below. We have tried to provide a flavor for some of the common comments or comments the authors thought were insightful, while trying to avoid bias in doing so. Readers are referred to Appendix B for a full listing of comments provided by survey respondents.

\subsection{Summary of survey results}

The first two questions concerned barriers to the use of on-site renewable energy. Forty-one percent of respondents said there are significant remaining electrical, plumbing, fire, building, mechanical or other code barriers to the use of renewable energy, 27 percent said those issues have mostly (not totally) been resolved, and 32 percent said they don't know. The most common barrier cited in comments was fire code issues. However, overall it was ranked medium-to-low in comparison with other barriers. 


\begin{tabular}{|c|c|c|c|}
\hline \multicolumn{4}{|c|}{$\begin{array}{l}\text { Question 1: Are there any electrical, plumbing, fire, building, mechanical or other } \\
\text { code issues that you think are significant barriers to the use of renewable energy } \\
\text { systems or have they mostly been addressed by IAPMO, ICC, I PC, IEC, I BC, ASME, } \\
\text { ASTM, NFPA, and other standards? }\end{array}$} \\
\hline Response & Chart & Frequency & Count \\
\hline Mostly been resolved & & $27.4 \%$ & 20 \\
\hline $\begin{array}{l}\text { Significant remaining issues } \\
\text { (please describe) }\end{array}$ & & $41.1 \%$ & 30 \\
\hline Don't know & & $31.5 \%$ & 23 \\
\hline
\end{tabular}

Addressing high costs and access to financing was overwhelmingly ranked as the most important action that could lead to the widespread use of renewable energy today. Installation quality and interconnection standards were tied for second, followed by siting issues such as ensuring solar access and addressing homeowner association restrictions. Requiring the use of renewables through building codes, better consumer awareness and image, and improved information for design professionals ranked in the middle, followed by other code (electrical, plumbing, fire, etc.) issues, grid integration, commissioning of renewable systems, and improved inspections and enforcement.

\begin{tabular}{|c|c|c|c|c|c|}
\hline \multicolumn{6}{|c|}{$\begin{array}{l}\text { Question 2: Please rank, in order of importance, the actions you think best lead to } \\
\text { widespread use of on-site renewable energy resources. Rank at least five, with } 1 \\
\text { representing the most important action. }\end{array}$} \\
\hline Response & First & Second & Third & Fourth & Fifth \\
\hline $\begin{array}{l}\text { Reduce costs, improve } \\
\text { financing }\end{array}$ & 37 & 11 & 3 & 4 & 2 \\
\hline $\begin{array}{l}\text { Address utility inter- } \\
\text { connection standards and } \\
\text { net-metering }\end{array}$ & 9 & 10 & 9 & 5 & 9 \\
\hline Ensure quality installations & 2 & 18 & 7 & 13 & 6 \\
\hline Address siting issues & 7 & 9 & 9 & 9 & 4 \\
\hline $\begin{array}{l}\text { Require use of RE through } \\
\text { building codes }\end{array}$ & 8 & 6 & 4 & 8 & 3 \\
\hline $\begin{array}{l}\text { Improve image, consumer } \\
\text { awareness }\end{array}$ & 4 & 8 & 9 & 5 & 7 \\
\hline $\begin{array}{l}\text { Improve info for design } \\
\text { professionals }\end{array}$ & 1 & 7 & 14 & 10 & 4 \\
\hline Address code issues & 6 & 4 & 6 & 6 & 10 \\
\hline $\begin{array}{l}\text { Resolve grid integration } \\
\text { issues }\end{array}$ & 3 & 4 & 11 & 4 & 4 \\
\hline $\begin{array}{l}\text { Improve code inspections } \\
\text { and enforcement }\end{array}$ & 3 & 2 & 6 & 5 & 13 \\
\hline Commission RE systems & 1 & 7 & 4 & 6 & 5 \\
\hline
\end{tabular}

By a 64-36 percent margin, respondents said renewables should not be required if they are not cost-effective. Individual comments against requiring renewables if not cost-effective ranged from "criminal”, "it will pave the way for backlash," and "you may grow resentment rather than 
acceptance," to "codes are a minimum and thus should be cost-effective," "codes are not the appropriate vehicle to push renewable energy," and "require energy efficiency before renewable energy - why install PV if you have T12 lighting and no insulation?”

In support of requiring renewables even if not cost-effective were comments such as "this is one of the best methods of market transformation," "codes require many things that are not "costeffective'," "it forces builders to think about how to do it for the lowest cost," and "a diet of all potatoes might be cost-effective from a short-term financial analysis, but we need diversity; a diet rich in fruits and vegetables may be more expensive, but it also means lower costs in other budget areas." A few comments said it would be fine if renewables were "slightly" non-costeffective, but at $\$ 0.25 / \mathrm{kWh}$, it would be irresponsible.

This was a key question in the survey. Answers to several subsequent questions were reasonably well correlated with the answer to this question. However, even though the majority opposed a renewable energy requirement if renewables aren't cost-effective, answers to questions \#16 and \#26, as well as several other questions, suggested there may be a little more room for acceptance of a requirement than this question alone would indicate, depending on the specifics of the approach taken.

\begin{tabular}{|c|c|c|c|}
\hline \multicolumn{4}{|c|}{$\begin{array}{l}\text { Question 3: Should the use of on-site renewable energy be considered as a code } \\
\text { requirement even if it doesn't meet standard tests of cost-effectiveness? }\end{array}$} \\
\hline Response & Chart & Frequency & Count \\
\hline Yes & & $36.1 \%$ & 26 \\
\hline No & & $63.9 \%$ & 46 \\
\hline
\end{tabular}

Respondents preferred outcome-based codes, performance-based codes, and prescriptive requirements in that order. Arguments in favor of prescriptive codes are simplicity, enforceability, and that they have a better chance of becoming standard practice. Arguments for performance-based codes were that they are more flexible and allow for innovative design. Outcome-based codes are based on actual performance of a building, not design intent. Individual comments reflected that outcome-based codes are still some years away. There was a reasonable correlation between those who think codes should not require renewables if they are not cost-effective and preference for performance- or outcome-based codes.

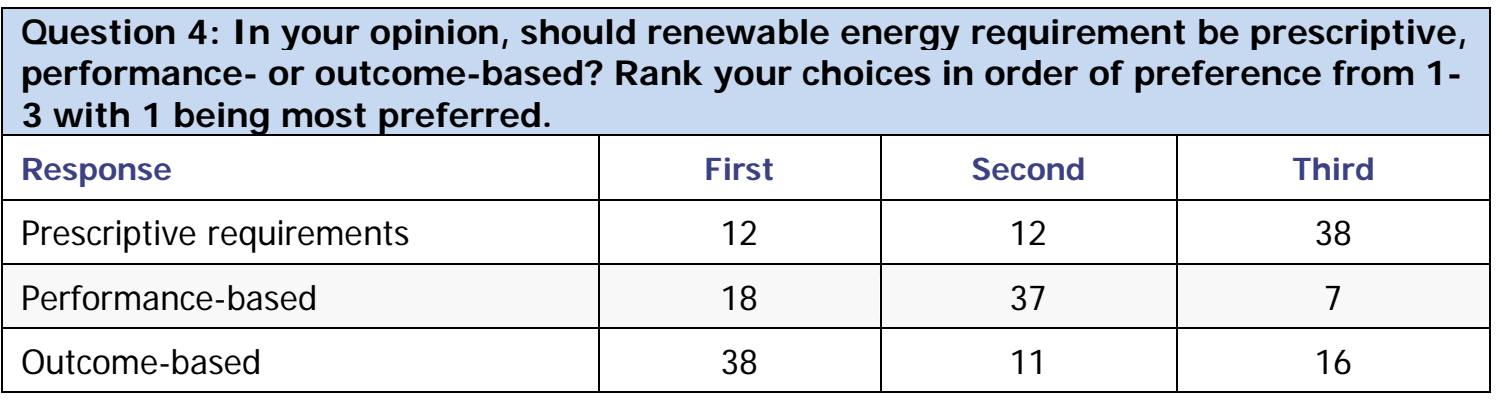

Half of respondents thought a renewable energy requirement should be based on total building loads. This likely reflected the interest in performance- or outcome-based codes as opposed to 
the prescriptive requirements. Comments pointed out the disadvantages of basing a requirement on either roof area or floor area.

\begin{tabular}{|c|c|c|c|}
\hline \multicolumn{4}{|c|}{$\begin{array}{l}\text { Question 5: If prescriptive or performance-based on-site renewable } \\
\text { energy requirements were implemented, on what should siting requirements be } \\
\text { based? }\end{array}$} \\
\hline Response & Chart & Frequency & Count \\
\hline Floor area & & $7.2 \%$ & 5 \\
\hline Roof area & & $13.0 \%$ & 9 \\
\hline Building type/occupancy & & $11.6 \%$ & 8 \\
\hline $\begin{array}{l}\text { Building load regulated by } \\
\text { current codes (i.e., } \\
\text { mechanical and lighting) }\end{array}$ & & $8.7 \%$ & 6 \\
\hline $\begin{array}{l}\text { Total building load (including } \\
\text { estimated plug loads) }\end{array}$ & & $40.6 \%$ & 28 \\
\hline Capital construction costs & & $1.4 \%$ & 1 \\
\hline Other (please specify) & & $17.4 \%$ & 12 \\
\hline
\end{tabular}

As expected, the majority of respondents thought performance- or outcome-based codes should not include a separate renewable energy requirement. Most thought that the idea of performancebased codes was to allow flexibility on how to best meet the target. As one response said, 'Energy improvement designs should be cost-driven.” What the authors thought was interesting, however, was that almost 40 percent still thought that a performance- or outcome-based code should include a renewable energy 'carve-out.' The main justification for this was that it may be necessary to give a slight push to renewable energy or it won't be used.

\begin{tabular}{|l|l|c|c|}
\hline $\begin{array}{l}\text { Question 6: If codes move toward being less prescriptive and more performance- or } \\
\text { outcome-based, should they include a separate renewable energy requirement to } \\
\text { ensure people become familiar and experience renewable energy systems, or } \\
\text { should the builder/ owner be able to decide how best to meet the target? }\end{array}$ \\
\hline $\begin{array}{l}\text { Response } \\
\text { Chart }\end{array}$ & Frequency & Count \\
\hline $\begin{array}{l}\text { Include a separate renewable } \\
\text { energy requirement; it will } \\
\text { help develop experience with } \\
\text { renewables and spur the } \\
\text { market }\end{array}$ & & $37.9 \%$ & \\
\hline $\begin{array}{l}\text { A renewable requirement is } \\
\text { unnecessary and conflicts } \\
\text { with the intent of an } \\
\text { outcome-based code; leave it } \\
\text { to the builder/owner to } \\
\text { decide how to meet the } \\
\text { target }\end{array}$ & & & \\
\hline
\end{tabular}


On the theme of allowing flexibility, almost 3/4 of respondents thought a renewable energy requirement should not be specific to electric (i.e., photovoltaics) or thermal (solar water heating) systems.

\begin{tabular}{|l|l|c|c|}
\hline $\begin{array}{l}\text { Question 7: Assuming the goal is to reach zero net-energy by some future date, and } \\
\text { that electricity will still be needed for lights and miscellaneous end-use (plug) } \\
\text { loads, does it make sense to require installation of renewable energy systems that } \\
\text { generate electricity as opposed to systems that meet thermal loads? }\end{array}$ \\
\hline Response & Chart & Frequency & Count \\
\hline $\begin{array}{l}\text { Require renewable thermal as } \\
\text { a pre-cursor to a renewable } \\
\text { electric requirement }\end{array}$ & & $13.6 \%$ & 8 \\
\hline $\begin{array}{l}\text { Require renewable energy, let } \\
\text { owner decide whether } \\
\text { thermal or electric }\end{array}$ & & $72.9 \%$ & 43 \\
\hline $\begin{array}{l}\text { Require a minimum of each } \\
\text { (renewable thermal and } \\
\text { renewable electric) }\end{array}$ & & $6.8 \%$ & 4 \\
\hline $\begin{array}{l}\text { Require renewable electric } \\
\text { only }\end{array}$ & & $6.8 \%$ & 4 \\
\hline
\end{tabular}

Fifty-nine percent of respondents to this question, representing half the sample of 75, thought that renewable energy requirements should start soon, in tandem with energy efficiency requirements. It is important to note that only 26 respondents in question \#3 favored a renewable energy requirement even if renewables were not cost-effective. Because most, if not all, of those 26 respondents presumably supported beginning now or soon, that means at least 12 respondents who thought codes should not require renewables if they are not cost-effective also supported beginning now or soon if there were to be a code requirement. 


\begin{tabular}{|c|c|c|c|}
\hline \multicolumn{4}{|c|}{$\begin{array}{l}\text { Question 8: When should renewable energy requirements begin to be integrated } \\
\text { into code? }\end{array}$} \\
\hline Response & Chart & Frequency & Count \\
\hline $\begin{array}{l}\text { Beginning now (or soon), in } \\
\text { tandem with improvements to } \\
\text { energy efficiency } \\
\text { requirements }\end{array}$ & & $59.4 \%$ & 38 \\
\hline $\begin{array}{l}\text { Later; take wait-and-see } \\
\text { approach; wait until costs } \\
\text { drop }\end{array}$ & & $0.0 \%$ & 0 \\
\hline $\begin{array}{l}\text { Only when renewable energy } \\
\text { has become cost-effective }\end{array}$ & & $12.5 \%$ & 8 \\
\hline $\begin{array}{l}\text { Only after all more cost- } \\
\text { effective energy efficiency } \\
\text { has been adopted }\end{array}$ & & $14.1 \%$ & 9 \\
\hline 2030 & & $3.1 \%$ & 2 \\
\hline Never & & $10.9 \%$ & 7 \\
\hline
\end{tabular}

Sixty percent of respondents favored putting a renewable energy requirement into voluntary green rating programs like the LEED and Green Globes, or voluntary standards like ASHRAE 189.1 and the IGCC, or both, before moving the requirement into building codes. Forty percent didn't think it was essential to do so. Virtually all of the respondents who said it wasn't necessary supported requiring renewable in codes even if it wasn't cost-effective. (It is important to note that this process of incorporating renewable energy requirements into these programs and standards has already begun.)

\begin{tabular}{|c|c|c|c|}
\hline \multicolumn{4}{|c|}{$\begin{array}{l}\text { Question 9: Should renewable energy requirements be introduced into voluntary } \\
\text { "green" or "stretch" codes and programs first (i.e., LEED, GBI, ASHRAE 189.1, I GCC, } \\
\text { etc.)? }\end{array}$} \\
\hline Response & Chart & Frequency & Count \\
\hline $\begin{array}{l}\text { EITHER voluntary programs } \\
\text { (i.e., LEED, GBI) OR } \\
\text { voluntary standards (i.e., } \\
\text { ASHRAE 189.1, IGCC, stretch } \\
\text { codes) for at least three years }\end{array}$ & & $17.2 \%$ & 10 \\
\hline $\begin{array}{l}\text { BOTH voluntary programs } \\
\text { (i.e., LEED, GBI) AND } \\
\text { voluntary standards (i.e., } \\
\text { ASHRAE 189.1, IGCC, stretch } \\
\text { codes) for at least three years } \\
\text { each }\end{array}$ & & $43.1 \%$ & 25 \\
\hline Good idea, but not essential & & $20.7 \%$ & 12 \\
\hline $\begin{array}{l}\text { No, don't bother; just require } \\
\text { it }\end{array}$ & & $19.0 \%$ & 11 \\
\hline
\end{tabular}

${ }^{4}$ ASHRAE 189.1, the IGCC, and the 2012 IECC have begun to incorporate renewable energy requirements. 
Respondents supported leading with alternative prescriptive options to other renewable energy requirements by a wide margin, 79 percent to 21 percent. Some favored this because they felt renewables should not be required; others because they supported more flexibility than an outright requirement.

\begin{tabular}{|c|c|c|c|}
\hline \multicolumn{4}{|c|}{$\begin{array}{l}\text { Question 10: Prior to requiring the use of renewable energy, should renewable } \\
\text { energy systems be included as an eligible alternative compliance option (i.e., under } \\
\text { a point-based system or as an alternative prescriptive measure)? }\end{array}$} \\
\hline Response & Chart & Frequency & Count \\
\hline Yes & & $78.7 \%$ & 48 \\
\hline No & & $21.3 \%$ & 13 \\
\hline
\end{tabular}

By a smaller margin, respondents favored some kind of renewable-ready requirement prior to requiring installation of a renewable energy system. Comments from supporters of renewableready requirements said it's easier and cheaper to build-in the ability to use renewables at time of construction, and will reduce costs and complexity of installing renewables later. Opponents said it's just a delaying action of marginal benefit that wastes people's money. They were also concerned about knowing what to pre-plan for, and that future installers would avoid the high risk of relying on someone else's earlier work. Several comments said such a requirement should provide space and pathways, and perhaps conduit, to accommodate renewables in the future.

\begin{tabular}{|c|c|c|c|}
\hline \multicolumn{4}{|c|}{$\begin{array}{l}\text { Question 11: Would it be meaningful to require pre-wiring for solar electric (PV) } \\
\text { and/ or pre-plumbing for solar water heating as a first step, or would that provide } \\
\text { too marginal of a benefit to mandate? }\end{array}$} \\
\hline Response & Chart & Frequency & Count \\
\hline Meaningful first step & & $55.7 \%$ & 34 \\
\hline $\begin{array}{l}\text { Too marginal to bother with; } \\
\text { too few will use it, and it's } \\
\text { easy enough to plumb or wire } \\
\text { it later }\end{array}$ & & $44.3 \%$ & 27 \\
\hline
\end{tabular}

A slight majority of respondents (55 percent) thought it would be reasonable to require the use of renewable energy for outdoor uses such as swimming pools, spas, and snowmelt systems as a first step. The most common comment was that these uses represent a waste of energy, so a requirement is not unreasonable. A few comments said being wealthy is "no excuse for wanton consumption or waste," that people who owned such systems can better afford a renewable energy system, and that such a requirement served as a "luxury tax." Forty-five percent thought it should not be required. Opponents did not provide as many explanatory comments. 


\begin{tabular}{|l|l|c|c|c|}
\hline $\begin{array}{l}\text { Question 12: Would it be meaningful to require the use of renewables on outdoor or } \\
\text { "Iuxury uses" as a first step, such as swimming pools, spas, snowmelt systems? }\end{array}$ \\
\hline Response & \multicolumn{2}{|l|}{ Chart } & Frequency & Count \\
\hline Yes, it is a good first step & & $55.0 \%$ & 33 \\
\hline $\begin{array}{l}\text { No, it doesn't affect most } \\
\text { buildings and sends a } \\
\text { message that renewables are } \\
\text { for the wealthy }\end{array}$ & & $45.0 \%$ & 27 \\
\hline
\end{tabular}

Almost 60 percent of respondents thought that government should "lead by example" by requiring the use of renewable energy in public buildings ${ }^{5}$, and another 30 percent thought it would be a good idea, although not critical. Only 10 percent thought requirements should be imposed on all buildings simultaneously.

\begin{tabular}{|c|c|c|c|}
\hline \multicolumn{4}{|c|}{$\begin{array}{l}\text { Question 13: Should government "lead by example" by requiring the use of } \\
\text { renewable energy in public buildings before it is required in other buildings through } \\
\text { codes? }\end{array}$} \\
\hline Response & Chart & Frequency & Count \\
\hline Yes, absolutely & & $58.3 \%$ & 35 \\
\hline Yes, good idea but not critical & & $31.7 \%$ & 19 \\
\hline $\begin{array}{l}\text { No, impose requirements on } \\
\text { all buildings simultaneously }\end{array}$ & & $10.0 \%$ & 6 \\
\hline
\end{tabular}

Fifty-eight percent of respondents thought, for various reasons, that solar water heating requirements will not necessarily lead to the adoption of photovoltaic requirements. The most common reason, endorsed by 35 percent of the respondents, was that there are other water heating options that could be used instead of solar hot water systems. One comment noted that heat pump water heaters are likely to make solar water heating irrelevant. A few explanatory comments said that solar water heating has a "higher potential for installation and O\&M problems," and that requiring it could "result in another 1980s black eye” - even though no respondents checked that alternative to the question. Other comments simply said that people should have the flexibility to decide whether to install a solar water heating or photovoltaic system. On the flip side, several comments in support of leading with a solar water heating requirement said solar water heating is more cost-effective than photovoltaics. One comment said that after people see that "solar water heating can be safe and dependable, they will be more open to renewable electric options.”

\footnotetext{
${ }^{5}$ See Section 3.0 National and International Precedents for a description of governments that have already adopted renewable energy requirements for their own buildings.
} 


\begin{tabular}{|c|c|c|c|}
\hline $\begin{array}{l}\text { Question 14: Solar water h } \\
\text { photovoltaics today. Shoul } \\
\text { requiring PV so people beg } \\
\text { though it wouldn't help me } \\
\text { eventually to achieve zero }\end{array}$ & $\begin{array}{l}\text { aters } \\
\text { solar } \\
1 \text { to ac } \\
\text { et misc } \\
\text { et-ene }\end{array}$ & $\begin{array}{l}\text { effective th } \\
\text { ed as a prec } \\
\text { requiremen } \\
\text { trical) load: }\end{array}$ & $\begin{array}{l}\text { to } \\
\text { essary } \\
\text { en }\end{array}$ \\
\hline Response & Chart & Frequency & Count \\
\hline $\begin{array}{l}\text { Yes, it will help people gain } \\
\text { experience with installing } \\
\text { renewable energy systems }\end{array}$ & & $17.3 \%$ & 9 \\
\hline $\begin{array}{l}\text { Yes, it will help people adapt } \\
\text { to and accept renewable } \\
\text { energy requirements }\end{array}$ & & $25.0 \%$ & 13 \\
\hline $\begin{array}{l}\text { No, there are other water } \\
\text { heating alternatives }\end{array}$ & & $34.6 \%$ & 18 \\
\hline $\begin{array}{l}\text { No, solar water heating still } \\
\text { has a poor reputation from } \\
\text { 1980s experiences }\end{array}$ & & $0.0 \%$ & 0 \\
\hline $\begin{array}{l}\text { No, it won't help people gain } \\
\text { experience or otherwise } \\
\text { accept renewable energy }\end{array}$ & & $11.5 \%$ & 6 \\
\hline $\begin{array}{l}\text { No, solar water heaters } \\
\text { reduce thermal loads, they } \\
\text { don't provide electricity } \\
\text { which should be the end goal }\end{array}$ & & $11.5 \%$ & 6 \\
\hline
\end{tabular}

Sixty-two percent of respondents favored allowing the purchase of renewable energy certificates (RECs) as an option to meet a renewable energy requirement. However, most of the individual comments accompanying answers to this question were negative toward allowing RECs.

\begin{tabular}{|c|c|c|c|}
\hline $\begin{array}{l}\text { Question 15: Should the pu } \\
\text { allowed as an option to me }\end{array}$ & $\begin{array}{l}\text { chase } \\
\text { ta ren }\end{array}$ & $\begin{array}{l}\text { ertificates } \\
\text { nent? }\end{array}$ & be \\
\hline Response & Chart & Frequency & Count \\
\hline $\begin{array}{l}\text { Yes, RECs should be a } \\
\text { general option in all buildings }\end{array}$ & & $27.6 \%$ & 16 \\
\hline $\begin{array}{l}\text { RECs should be an option } \\
\text { only if use of on-site } \\
\text { renewables is not feasible }\end{array}$ & & $34.5 \%$ & 20 \\
\hline $\begin{array}{l}\text { No, RECs should not be an } \\
\text { allowable option }\end{array}$ & & $37.9 \%$ & 22 \\
\hline
\end{tabular}

Results of the preferred way to phase in a renewable energy requirement were mixed. The preferred approaches were to allow renewables as an alternative to another energy code requirement, or to include renewables on a list of prescriptive options. The only approach that was clearly not favored was requiring renewables, but allowing a buy-out to purchase offsets on other buildings. Preference for other approaches was more mixed and difficult to draw a conclusion. 


\begin{tabular}{|c|c|c|c|c|c|}
\hline \multicolumn{6}{|c|}{ Question 16: What is the best way to phase in a renewable energy requirement? } \\
\hline & $\begin{array}{c}1 \text { Yes, } \\
\text { preferred }\end{array}$ & 2 Maybe & $\begin{array}{c}3 \\
\text { Indifferent/ } \\
\text { no opinion }\end{array}$ & $\begin{array}{c}4 \text { No, not } \\
\text { appropriate }\end{array}$ & Total \\
\hline $\begin{array}{l}\text { Include renewables on a } \\
\text { list of alternative } \\
\text { prescriptive measures, of } \\
\text { which } x \text { (number) must be } \\
\text { required }\end{array}$ & $\begin{array}{c}19 \\
(31.1 \%)\end{array}$ & $\begin{array}{c}27 \\
(44.3 \%)\end{array}$ & $\begin{array}{c}6 \\
(9.8 \%)\end{array}$ & $\begin{array}{c}9 \\
(14.8 \%)\end{array}$ & 61 \\
\hline $\begin{array}{l}\text { Allow renewables as } \\
\text { alternative to another } \\
\text { requirement }\end{array}$ & $\begin{array}{c}22 \\
(36.7 \%)\end{array}$ & $\begin{array}{c}25 \\
(41.7 \%)\end{array}$ & $\begin{array}{c}2 \\
(3.3 \%)\end{array}$ & $\begin{array}{c}11 \\
(18.3 \%)\end{array}$ & 60 \\
\hline $\begin{array}{l}\text { Solar ready requirement } \\
\text { (pre-plumbing or pre- } \\
\text { wiring to accommodate } \\
\text { solar) }\end{array}$ & $\begin{array}{c}21 \\
(34.4 \%)\end{array}$ & $\begin{array}{c}15 \\
(24.6 \%)\end{array}$ & $\begin{array}{c}10 \\
16.4 \%\end{array}$ & $\begin{array}{c}15 \\
(24.6 \%)\end{array}$ & 61 \\
\hline $\begin{array}{l}\text { Require renewables for } \\
\text { outdoor or luxury uses } \\
\text { (pools, spas, snowmelt } \\
\text { systems) }\end{array}$ & $\begin{array}{c}15 \\
(25.0 \%)\end{array}$ & $\begin{array}{c}18 \\
(30.0 \%)\end{array}$ & $\begin{array}{c}7 \\
(11.7 \%)\end{array}$ & $\begin{array}{c}20 \\
(33.3 \%)\end{array}$ & 60 \\
\hline $\begin{array}{l}\text { Require renewables, with } \\
\text { trade-offs allowed }\end{array}$ & $\begin{array}{c}12 \\
(20.0 \%) \\
\end{array}$ & $\begin{array}{c}21 \\
(35.0 \%) \\
\end{array}$ & $\begin{array}{c}5 \\
(8.3 \%) \\
\end{array}$ & $\begin{array}{c}22 \\
36.7 \%) \\
\end{array}$ & 60 \\
\hline $\begin{array}{l}\text { Minimal requirements, few } \\
\text { exceptions }\end{array}$ & $\begin{array}{c}17 \\
(27.9 \%)\end{array}$ & $\begin{array}{c}12 \\
(19.7 \%)\end{array}$ & $\begin{array}{c}10 \\
(16.4 \%)\end{array}$ & $\begin{array}{c}22 \\
(36.1 \%)\end{array}$ & 61 \\
\hline $\begin{array}{l}\text { Require renewables, with a } \\
\text { buy-out dedicated to } \\
\text { purchase of offsets on } \\
\text { other buildings }\end{array}$ & $\begin{array}{c}2 \\
(3.4 \%)\end{array}$ & $\begin{array}{c}13 \\
(22.0 \%)\end{array}$ & $\begin{array}{c}12 \\
(20.3 \%)\end{array}$ & $\begin{array}{c}32 \\
54.2 \%)\end{array}$ & 59 \\
\hline
\end{tabular}

There was strong sentiment (68 percent) to allow all renewable energy systems, including systems such as passive solar heating and daylighting whose output is difficult to quantify, as eligible to meet a renewable energy code requirement. Comments supporting inclusion of daylighting and passive solar design were flexibility and they reduce load. Comments opposed were that they are difficult to measure and enforce, they would serve as loopholes, and they are building load reduction strategies rather than load satisfaction or renewable energy strategies. A few comments supported allowing passive solar design but not daylighting. 


\begin{tabular}{|c|c|c|c|}
\hline \multicolumn{4}{|c|}{$\begin{array}{l}\text { Question 17: Should systems whose contribution is more difficult to measure } \\
\text { (daylighting, passive solar design, possibly renewable thermal systems) be allowed } \\
\text { to meet a renewable energy requirement? Or should the requirement apply only to } \\
\text { renewable electric systems whose output can more easily be measured? }\end{array}$} \\
\hline Response & Chart & Frequency & Count \\
\hline $\begin{array}{l}\text { Allow all renewables (electric, } \\
\text { daylighting, passive solar, } \\
\text { and solar water heating) }\end{array}$ & & $67.8 \%$ & 40 \\
\hline $\begin{array}{l}\text { Allow solar electric and solar } \\
\text { water heating; do not allow } \\
\text { daylighting or passive solar }\end{array}$ & & $27.1 \%$ & 16 \\
\hline $\begin{array}{l}\text { Allow solar electric systems } \\
\text { only; do not allow } \\
\text { daylighting, passive solar, or } \\
\text { solar water heating }\end{array}$ & & $5.1 \%$ & 3 \\
\hline
\end{tabular}

As one would expect, virtually everybody regards solar water heating, photovoltaics, and wind energy systems as renewable energy systems for code purposes. Micro-hydro was close behind at 85 percent, while geothermal direct heat and biomass CHP and biomass boilers had 70+ percent support. In line with the previous question, more than 60 percent of respondents consider daylighting and passive solar design as renewable energy technologies, and fuel cells weighed in at 59 percent. Ground source heat pumps had 54 percent support, while air-to-air heat pumps came in with 35 percent support. Woodstoves filled out the list at 35 percent, but they were not specified as "efficient" woodstoves. 


\begin{tabular}{|c|c|c|}
\hline \multicolumn{3}{|c|}{$\begin{array}{l}\text { Question 18: What technologies should be considered as eligible (complying) } \\
\text { renewable energy systems? }\end{array}$} \\
\hline & Yes & No \\
\hline $\begin{array}{l}\text { THERMAL } \\
\text { Air-to-air heat pump }\end{array}$ & $20(35.1 \%)$ & $37(64.9 \%)$ \\
\hline Daylighting & $36(62.1 \%)$ & $22(37.9 \%)$ \\
\hline Geothermal direct heat & $44(73.3 \%)$ & $16(26.7 \%)$ \\
\hline Ground source (or water source) heat pump & $32(54.2 \%)$ & $27(45.8 \%)$ \\
\hline On-site biomass boiler & $41(70.7 \%)$ & $17(29.3 \%)$ \\
\hline Passive solar heating & $39(66.1 \%)$ & $20(33.9 \%)$ \\
\hline Solar water heater & $59(96.7 \%)$ & $2(3.3 \%)$ \\
\hline Woodstove & $20(34.5 \%)$ & $38(65.5 \%)$ \\
\hline $\begin{array}{l}\text { ELECTRIC SYSTEMS } \\
\text { BiomasS CHP }\end{array}$ & $41(77.4 \%)$ & $12(22.6 \%)$ \\
\hline Fuel cell & $35(59.3 \%)$ & $24(40.7 \%)$ \\
\hline Micro-hydro & $52(85.2 \%)$ & $9(14.8 \%)$ \\
\hline Solar (photovoltaics) & $61(98.4 \%)$ & $1(1.6 \%)$ \\
\hline Wind & $60(96.8 \%)$ & $2(3.2 \%)$ \\
\hline
\end{tabular}

Availability of the solar resource, whether because of the regional solar resource or on-site shading, constituted the main grounds for waiver from a renewable energy requirement. What surprised the authors was that only 18 percent of respondents said high costs should be grounds for a waiver, considering the large number that said renewable energy should not be required if it is not cost-effective. They apparently think that if there is going to be a requirement, high costs shouldn't be grounds for a waiver because it would be self-defeating - many people would use the waiver, so why require renewables in the first place? 


\begin{tabular}{|c|c|c|c|}
\hline \multicolumn{4}{|c|}{$\begin{array}{l}\text { Question 19: What would constitute grounds for a waiver from a renewable (solar } \\
\text { energy requirement? (Choose all that apply) }\end{array}$} \\
\hline Response & Chart & Frequency & Count \\
\hline $\begin{array}{l}\text { Local solar resource (northern } \\
\text { or cloudy climate exemption) }\end{array}$ & & $68.3 \%$ & 41 \\
\hline On-site shading & & $63.3 \%$ & 38 \\
\hline Roof pitch in wrong direction & & $26.7 \%$ & 16 \\
\hline $\begin{array}{l}\text { Small roof-to-area ratio (as } \\
\text { on a tall building) }\end{array}$ & & $43.3 \%$ & 26 \\
\hline High costs & & $18.3 \%$ & 11 \\
\hline Off-grid & & $26.7 \%$ & 16 \\
\hline $\begin{array}{l}\text { No thermal or electric load in } \\
\text { the building }\end{array}$ & & $66.7 \%$ & 40 \\
\hline Other & & $11.7 \%$ & 7 \\
\hline
\end{tabular}

If solar access is not available (assuming a renewable energy requirement is effectively a solar energy requirement), additional energy efficiency was the preferred alternative by 57 percent of the respondents. And despite reasonable support for renewable energy certificates (RECs) in question \#15, only 11 percent identified RECs as the preferred option here. Presumably additional efficiency should be considered first if the use of on-site renewable energy is not feasible, and RECs as a last resort. A few comments confirmed this. One respondent suggested a 200 percent energy efficiency offset and a 150 percent RECs offset.

\begin{tabular}{|l|l|c|c|c|}
\hline \multicolumn{2}{|l|}{ Question 20: If solar access is not available, what is the best alternative? } \\
\hline Response & \multicolumn{2}{|l|}{ Chart } & Frequency & Count \\
\hline Waiver & & $5.4 \%$ & 3 \\
\hline $\begin{array}{l}\text { Another renewable energy } \\
\text { technology }\end{array}$ & \multicolumn{1}{|l|}{} & $16.1 \%$ & 9 \\
\hline Purchase of RECs & & $10.7 \%$ & 6 \\
\hline $\begin{array}{l}\text { Purchasing offsets (i.e., } \\
\text { transferable renewable rights) }\end{array}$ & & $0.0 \%$ & 0 \\
\hline Additional energy efficiency & & $57.1 \%$ & 32 \\
\hline Other (please specify) & & $10.7 \%$ & 6 \\
\hline
\end{tabular}

Sixty-five percent of respondents opposed having a building owner pay for an equivalent-sized renewable energy system on another building in the same code jurisdiction if the use of renewables is infeasible on their own site. The accompanying explanatory comments were overwhelmingly negative toward the idea, such as "fuzzy math," "moving into the realm of property rights,” "administrative nightmare,” and "just not practical.” 


\begin{tabular}{|c|c|c|c|}
\hline \multicolumn{4}{|c|}{$\begin{array}{l}\text { Question 21: If it is impracticable to install renewable energy on a particular } \\
\text { building, and in lieu of purchasing RECs, would it be reasonable to require the } \\
\text { owner to cause to have installed an equivalent-sized renewable energy system on } \\
\text { another (new or existing) building within the same code jurisdiction? }\end{array}$} \\
\hline Response & Chart & Frequency & Count \\
\hline Yes & & $35.1 \%$ & 20 \\
\hline No & & $64.9 \%$ & 37 \\
\hline
\end{tabular}

There was broad support for crediting off-building renewable energy systems (94 percent), as long as the systems remain under the same ownership as the building. Of those, $1 / 2$ said it should be on the same site, $1 / 4$ said it could be located at another site within the same code jurisdiction, and $1 / 4$ said would presumably allow it in a different jurisdiction so long as it's the same owner. In accompanying comments, common themes were "who cares where it's located.” Some ideas suggested included parking lots, pole mounts, and utility-owned neighborhood systems.

\begin{tabular}{|l|l|l|c|c|}
\hline \multicolumn{2}{|l|}{ Question 22: Should use of off-building renewable energy resources be allowed? } \\
\hline Response & \multicolumn{2}{|l|}{ Chart } & Frequency & Count \\
\hline $\begin{array}{l}\text { Yes, as long as it's on the } \\
\text { building site }\end{array}$ & & $46.2 \%$ & 24 \\
\hline $\begin{array}{l}\text { Yes, as long as the alternative } \\
\text { site is under the same } \\
\text { ownership as the building }\end{array}$ & & $23.1 \%$ & 12 \\
\hline $\begin{array}{l}\text { Yes, as long as the alternative } \\
\text { site is under the same } \\
\text { ownership as the building, } \\
\text { and within the same code } \\
\text { jurisdiction }\end{array}$ & & $23.1 \%$ & 12 \\
\hline No, it should not be allowed & & $7.7 \%$ & 4 \\
\hline
\end{tabular}

Half of respondents favored separate renewable energy requirements for new buildings and remodels or tenant improvements of existing buildings; $1 / 4$ supported the same requirement, while $1 / 4$ favored not worrying about existing buildings until requirements are implemented for new buildings first. Comments ranged from "we can’t ignore the $90 \%+$ of existing buildings” on the one hand, to "this is extremely hard," "we're getting ahead of ourselves," and "it will take a lot of minds a long time to figure it out." One comment said "we can't even do remodels or tenant improvements with the energy codes we have now." 


\begin{tabular}{|c|c|c|c|}
\hline \multicolumn{4}{|c|}{$\begin{array}{l}\text { Question 23: What can be done for remodels or tenant improvements of existing } \\
\text { buildings to ensure they begin to use renewables and ensure some level of equity? }\end{array}$} \\
\hline Response & Chart & Frequency & Count \\
\hline $\begin{array}{l}\text { Apply the same basic } \\
\text { requirements, depending on } \\
\text { the extent of the remodel }\end{array}$ & & $26.4 \%$ & 14 \\
\hline $\begin{array}{l}\text { Develop separate } \\
\text { requirements to reflect } \\
\text { different circumstances, } \\
\text { limitations (please use box } \\
\text { below for suggestions) }\end{array}$ & & $49.1 \%$ & 26 \\
\hline $\begin{array}{l}\text { Ignore; focus on new } \\
\text { construction first }\end{array}$ & & $24.5 \%$ & 13 \\
\hline
\end{tabular}

Seventy-eight percent of respondents favored commissioning of renewable energy systems as part of a renewable energy requirement. The authors believe the broad support is partly explained by the growing support for outcome-based codes, as evidence by question \#4.

\begin{tabular}{|l|l|c|c|}
\hline \multicolumn{2}{|l|}{ Question 24: Should a renewable energy requirement also require systems to be } \\
commissioned?
\end{tabular}

Question \#25 asked for recommended pathways to move renewable energy requirements into building codes. No one recommendation stood above others in terms of the number of mentions, and there were no new recommendations that hadn't already been addressed by previous questions. Readers are referred to Appendix B to see the comments that were submitted.

Despite opposition to renewable energy requirements in codes expressed in earlier questions, a large majority of respondents (69 percent) said people will accept renewable energy requirements if done slowly, equitably, and flexibly. Some example comments in favor included "equitability and flexibility will soften the reality," "its time has come," "start with a small target that few can object to," and "people are not good at calculating costs and values. If they see systems working, they will be positive. If not, they will revolt.” Thirty-two percent remained opposed. Examples of comments included "developers are bottom line people and generally resent being told what to do," and "unfortunately people will accept it, but not because it is a good thing to do.” 


\begin{tabular}{|l|l|c|c|}
\hline $\begin{array}{l}\text { Question 26: How will people accept a renewable energy requirement? What do } \\
\text { you think will be the response? }\end{array}$ & Chart & Frequency & Count \\
\hline Response & & $31.5 \%$ & 17 \\
\hline $\begin{array}{l}\text { It will never pass as long as } \\
\text { renewables are not cost- } \\
\text { effective }\end{array}$ & & $68.5 \%$ & 37 \\
\hline $\begin{array}{l}\text { People will accept it if done } \\
\text { slowly, equitably, and flexibly }\end{array}$ & & & \\
\hline
\end{tabular}

Builders and contractors and building owners were judged to be most resistant to adopting renewable energy requirements into building codes. However, the survey failed to distinguish whether the resistance was primarily on the residential side (i.e., home builders and home owners), or whether it applied equally as well to non-residential contractors and building owners. Utilities, the design community, and especially code professionals were perceived to have less resistance. The question also asked what respondents might suggest to help overcome the resistance. The main recommendations were to start slowly, to make renewables cost-effective, and more education and training.

\begin{tabular}{|c|c|c|c|c|c|}
\hline \multicolumn{6}{|c|}{$\begin{array}{l}\text { Question 27: Rank, in order of significance, where you think the most resistance to } \\
\text { renewable energy requirements will come from. Rank at least three, with } 1 \\
\text { representing the greatest resistance. }\end{array}$} \\
\hline Response & First & Second & Third & Fourth & Fifth \\
\hline Builders, contractors & 18 & 17 & 10 & 2 & 1 \\
\hline Building owners & 23 & 18 & 7 & 5 & 1 \\
\hline Code professionals & 2 & 9 & 13 & 7 & 7 \\
\hline Design community & 5 & 16 & 7 & 8 & 3 \\
\hline Utilities & 12 & 7 & 13 & 3 & 9 \\
\hline
\end{tabular}

Questions \# 28 and \#29 were more open-ended, and asked for key issues that were missed and any additional comments respondents wished to make. There was nothing significantly new that hadn't already been addressed. The comments are too numerous and varied to list here. Readers should see Appendix B for detailed listing of these comments. 


\subsection{Technical Evaluation of Technologies}

There are a number of mature and developing renewable energy technologies; however, many technologies are not necessarily appropriate for use on individual buildings or building sites. Also, some technologies that could be used on buildings could not easily be included as prescriptive code requirements. The text below describes how various technologies may fit into the code. In addition, the "Potential Impact of Code Requirements," below, provides estimates of the potential impact of renewable energy requirements.

\subsection{Technologies}

\subsubsection{Photovoltaic (PV)}

PV systems are typically roof-mounted or ground-mounted, although they can also be integrated into vertical walls or roofing materials. The panels may be fixed or they may track the sun, which increases both generation and installed costs. Module efficiencies typically range from about $7 \%$ to close to $20 \%$, depending on the technology (Kreutzmann 2008). Code requirements would not exclude any specific PV technologies or applications.

PV systems have been successfully installed throughout US. Most commercial buildings could install PV systems. Residential buildings, on the other hand, often have shaded roofs or poor building orientation (i.e. roof slopes face east-west).

Because PV is an available option for so many buildings, it is the main focus of renewable energy requirements. An electric renewable energy requirement would likely be based on a roofmounted PV system. While other technologies might be allowed, PV is available for the greatest number of sites and the requirement must be designed such that a compliant PV system would fit on any roof. While PV could be installed on the ground or walls, these systems would not be practical for many sites.

The drawback of PV systems is that they are relatively expensive and payback periods are quite long. One source estimated that the cost of electricity, not including government incentives, from small (2-5 kW) rooftop systems is $\$ 0.20-0.80$ per $\mathrm{kWh}$ (worldwide range), considerably higher than most electric rates (REN21 2008). Generous subsidies make PV cost-effective in certain cases, but code requirements generally do not rely on subsidies. PV module prices have decreased substantially in recent years. If installed costs continue to decrease while electricity costs increase, PV may become may become broadly cost-effective, in which case prescriptive requirements should be strongly considered.

One advantage of PV and some other electric renewable energy systems is that they can be netmetered. Net-metering allows surplus electricity to be banked and credited on a building's monthly energy bill. Net-metering allows building owners to receive retail electric rates for their PV output. Net-metering means larger PV systems can be installed without wasting any energy or installing battery storage for excess electricity. This is quite different than solar hot water, where hot water must be used immediately or temporarily stored. Tanks have a finite amount of 
storage and if the hot water demands are not high enough, the system may not utilize some of the available thermal energy.

\subsubsection{Solar water heaters}

Solar water heaters use the sunlight to heat water for service hot water demands. Systems vary based on the design goals, the need for freeze protection, and the hot water demands. Solar water heaters typically include roof-mounted panels or evacuated tubes, an insulated storage tank, pipes, pumps, and controls. Solar water heaters can be one of the most cost-effective on-site renewable options.

One significant difference between PV and solar hot water is that solar hot water systems are limited by building characteristics. The most important characteristic is the hot water demand. In buildings that use very little hot water, solar hot water is impractical. Solar hot water may be impractical in buildings with several small distributed hot water systems, like apartments. Furthermore, solar water heating systems are generally designed to supply no more than $70 \%$ of the annual hot water demand. If the system is any larger, it will produce too much hot water in the summer and the system must be shut off or dump excess heat.

This leads to an important distinction between PV and SHW; unlike PV, solar hot water systems cannot export or 'bank' energy. Solar hot water systems essentially reduce the building's overall hot water load. It should be noted that other technologies could perform the same role. Heat recovery, heat pump water heaters, and even condensing gas water heaters can achieve similar results. For these reasons, we believe that solar hot waters should be included in water heating sections of the code. For example, the code could require the selection of an 'advanced water heating measure' from a list that would include, among others, solar hot water. We believe that this structure makes more sense than allowing trade-offs between solar hot water, PV, and other renewable energy systems.

\subsubsection{On-site or building-integrated wind}

The wind industry has grown substantially over the last decade. However, the vast majority of wind energy is generated by commercial scale wind farms located in remote, windy regions with multiple 1+ MW wind turbines. Building-integrated wind energy, on the other hand, is still extremely rare. There have been a many small scale wind technologies developed. Some building-integrated wind projects have also been implemented. However, the actual performance of building-integrated wind is often lower than expected (Wilson 2009). There are many legitimate concerns regarding noise and vibrations caused by building-integrated wind systems. The cost-effectiveness of building-integrated wind is not nearly as good as commercial scale wind and is often worse than on-site PV systems. For a more thorough discussion of buildingintegrated wind systems, see “The Folly of Building-Integrated Wind” by Alex Wilson (Wilson 2009).

For the reasons discussed above, we believe that on-site wind would rarely be used to meet a renewable energy code requirement. As such, we do not recommend including on-site wind in prescriptive requirements or options. However, if designers wish to pursue building-integrated wind and can prove that the systems are safe and reliable, they should be able to receive credit in the performance path or as an alternative compliance measure. Because on-site wind is rare and 
the systems add considerable complexity, we do not believe that it would be an unfair burden for designers to model the building and use the performance compliance path (of course, the prescriptive path could be used if the wind energy is not needed for compliance).

\subsubsection{Ground source heat pumps}

Ground source heat pumps (GSHPs) can provide very efficient HVAC systems by using the ground to extract and reject heat. By using the ground as a source and sink, GSHPs take advantage of the fact that the ground temperature is often warmer than the air temperature in the winter and cooler then the air temperature in the summer. Although GSHPs are occasionally classified as renewable energy (geothermal), we believe that they are more accurately described as a high efficiency heating and cooling system. GSHPs use heat from the ground in the same way that air source heat pumps use heat from the air. As such, we do not recommend classifying GSHPs as 'renewable energy' in energy codes.

On the other hand, GSHPs are capable of providing higher efficiencies than most other heating and cooling systems. So, GSHPs could be treated as an 'advanced energy measure.' In an 'advanced energy options approach,' GSHPs could provide an alternative to PV and other advanced energy measures. However, if GSHPs are used, the code should ensure that the compliant GSHP system would provide substantial gains in efficiency over standard heating and cooling options. If a GSHP provides the same efficiency as a standard air source heat pump, it should obviously not qualify as an advanced energy measure. The requirement may be written by specifying that the GSHP system have a COP (or other measure of efficiency) of at least 10-30\% better than a standard HVAC system.

\subsubsection{Combined Heat and Power (with biomass or other feedstock)}

Combined heat and power (CHP) systems produce electricity the same way conventional power plants do. However, the waste heat, which is a byproduct of all thermal power plants, is captured and used for space or water heating rather than being rejected to air or water. CHP systems provide impressive efficiencies and, when they use a renewable feedstock such as biomass, they produce renewable electricity and heat. However, CHP systems are still relatively rare in the US. The main issue with CHPs is that they require a steady demand for heat. If space or water heating is only needed a small fraction of the year, the unit will not produce electricity (or will produce electricity but will not utilize the CHP system) and the added costs of the system will not be justified. CHPs tend to work in large buildings with large demands for heat, such as hospitals, campuses, or industrial facilities.

Although CHP system should certainly be encouraged, we believe that it would be very difficult to write a CHP requirement into an energy code. CHP systems are quite complex and very building-specific. As such, our recommendation is to give credit to CHP systems in the performance compliance path, but to not include CHPs in any potential prescriptive renewable energy requirements.

\subsubsection{Passive Solar (for residential buildings)}

Passive solar design utilizes sunlight to reduce heating energy use. Passive solar heating is much more common in residential construction, and in climates where heating loads are dominant. In commercial buildings, cooling loads often dominate for much of the year, so there is less benefit 
from passive solar design. To fully utilize passive solar, buildings must be carefully designed to absorb winter sun, but also to store thermal energy. Thermal mass is used to reduce large temperature swings between day and night that can occur in poorly designed passive solar buildings. Needless to say, it is unlikely that an energy code could require full passive solar design. However, there more moderate passive solar features that would be more realistic for energy codes. These would primarily include positioning of glazing and building orientation. For example, buildings in cold northern climates benefit from locating more of their glazing on the south side of the building. These measures can have benefit, but the benefits are building and location specific and are generally quite small.

While there are clear benefits to passive solar design and it should be encouraged wherever practical, it is unlikely that a prescriptive requirement could include passive solar design. Optimum passive solar design varies substantially by location and climate. Attempts to model savings from passive solar demonstrate the difficulty of applying a prescriptive requirement to all buildings. One NREL study states that passive solar design features are "complicated because good solutions depend on the load profile and the climate and simple rule-based approaches have not been developed that can make proper design decisions" (Griffith 2007). Furthermore, there would be many opponents to glazing restrictions. The requirement would not be popular for homeowners with good views in one direction or for developments with homes built close to lot lines. Passive solar design is complex and building modeling is essential. As such, prescriptive requirements should be avoided but passive solar design could be considered for credit in performance compliance paths.

\subsection{Potential impact of code requirements}

There are a many technologies that could be considered as 'renewable energy' in an energy code. However, most of the technologies are very building or site-specific and could only be used in a small fraction of buildings. One renewable energy technology that can be applied to the majority of buildings and produce a significant amount of energy is PV. It is generally accepted that PV (in addition to efficiency technologies) will be necessary to achieve very low energy buildings.

The National Renewable Energy Laboratory conducted an “Assessment of the Technical Potential for Achieving Net Zero-Energy Buildings in the Commercial Sector" in 2007 (Griffith, 2007), which provides estimates of energy use by buildings and potential PV production in current and projected future buildings. The study estimates that on average, new buildings meeting ASHRAE Standard 90.1-2004 use $70.7 \mathrm{kBtu} / \mathrm{ft}^{2} / \mathrm{yr}$. NREL also predicted that buildings utilizing technology available in 2025 could reach an average energy use intensity (EUI) of 40.3 $\mathrm{kBtu} / \mathrm{ft}^{2} / \mathrm{yr}$. Assuming 20\% module efficiency, 95\% inverter efficiency, and 50\% roof coverage, NREL estimated that PV systems on commercial buildings could, on average, produce 28.1 $\mathrm{kBtu} / \mathrm{ft}^{2} / \mathrm{yr}$, lowering average EUIs to $12.2 \mathrm{kBtu} / \mathrm{ft}^{2} / \mathrm{yr}$. The report also estimates that $62 \%$ of commercial buildings and $47 \%$ of commercial floor area could reach net zero energy levels (using the PV and 2025 design practice assumptions described above). The report also showed large discrepancies between building types. For example, average office buildings need to reduce energy use by $67 \%$ in order for on-site PV to be able to bring the building to net zero. By contrast, warehouse buildings need $6 \%$, educational facilities need $43 \%$, and retail stores need $45 \%$ reductions in energy use in order to reach net zero (with on-site PV). 
The results of the NREL study suggest that renewable energy is needed if buildings are to reach, on average, EUIs of less than about $40 \mathrm{kBtu} / \mathrm{ft}^{2}$ (and both renewable energy and additional energy efficiency is needed to achieve net zero buildings). The results of the study can also be used to provide a rough estimate of the potential impact of a renewable energy requirement. In the US, commercial buildings are added at a rate of about 1.6 billion square feet per year (DOE 2008). If a requirement were put into effect that resulted in $20 \%$ efficient modules, $95 \%$ efficiency inverters, and PV systems covering 50\% of roof area, buildings would produce about $28 \mathrm{kBtu} / \mathrm{ft}^{2} / \mathrm{yr}$, or 18,000 GWh of electricity annually. According to the Solar Energy Industries Associate, there are $2.1 \mathrm{GW}$ of installed PV capacity in the US (SEIA 2010). Assuming average production of $1400 \mathrm{kWh}$ per $\mathrm{kW}$, the US currently generates approximately 2,940 GWh annually from PV. As you can see, a full-scale, strong PV requirement for new commercial buildings would significantly affect the PV market. Note, however, that the technology assumptions used by NREL (20\% module efficiency, 95\% efficient inverters) are high compared to most current installations. Also, $50 \%$ of roof area coverage would be an extremely ambitious requirement. These assumptions should be considered an upper limit of a potential PV requirement. We expect any actual requirements to result in much lower production.

PNNL performed additional analysis, using prototypes of typical building types, to help understand the limits that space constraints put on PV requirements. Requirements will likely be written (though not necessarily) as a specific amount of watts per $\mathrm{ft}^{2}$ of roof or conditioned floor area. Our analysis assumed 13\% module efficiency, and suggests that requirements above 4.0 $\mathrm{Watts} / \mathrm{ft}^{2}$ of roof area or $0.5 \mathrm{Watts} / \mathrm{ft}^{2}$ of conditioned floor area will be impractical. At these requirement levels, PV systems for some building types become too large for the roof (assuming typical module spacing and location of mechanical equipment). Designers could use higher efficiency modules, relocated roof obstructions (i.e. mechanical equipment), or install wall or ground-mounted systems. However, these alternatives are often more expensive or impractical. As such, we believe that $4.0 \mathrm{Watts} / \mathrm{ft}^{2}$ roof area or $0.5 \mathrm{Watts} / \mathrm{ft}^{2}$ of conditioned floor area is the upper limit for a prescriptive PV requirement, unless additional sizing conditions are given. For example, a requirement could specify $0.5 \mathrm{Watts} / \mathrm{ft}^{2}$ of conditioned floor area, not to exceed $50 \%$ of gross roof area. The ' $50 \%$ of roof area' provision provides an option for buildings types that may not be able to fit $0.5 \mathrm{Watts} / \mathrm{ft}^{2}$ conditioned floor area on their roof.

Our analysis also helps illustrate how requirement structures affect various building types. As an example, we applied the two requirement structures to the prototype buildings. The values for the requirements were assumed to be $1.0 \mathrm{~W} / \mathrm{ft}^{2}$ of roof area and $0.4 \mathrm{~W} / \mathrm{ft}^{2}$ of conditioned floor area (these values are somewhat arbitrary, but they were selected because they result in systems that are roughly equivalent overall). Table 5.1 and Table 5.2, below show the estimated percentage of site energy use covered by the code-compliant PV system for each building type. This analysis suggests that a requirement structure based on roof area will result in substantial variation in the percentage of building load supplied by PV; from about $0.4 \%$ for fast food restaurants and large hotels to $24 \%$ for warehouses in certain climates. The requirement structure based on conditioned floor area also leads to variation among building types, but not nearly as much; from $0.3 \%$ for fast food restaurants to $9 \%$ for warehouses in certain climates. One additional observation is that a requirement based on conditioned floor area tends to be harder on multistory buildings. For example, PV systems on high rise apartments would only cover $2 \%$ of the 
building load in El Paso if the requirement were based on roof area but would cover $6 \%$ of building load if the requirement were based on conditioned floor area.

Table 5.1: Results of Potential Requirement Based on Roof Area

\begin{tabular}{|c|c|c|c|c|c|c|}
\hline \multirow{3}{*}{$\begin{array}{l}\text { Prototype Bldg. } \\
\text { Loc: }\end{array}$} & \multicolumn{6}{|c|}{$1.0 \mathrm{~W} / \mathrm{ft}^{2}$ of roof area requirement } \\
\hline & \multicolumn{6}{|c|}{$\begin{array}{l}\text { Percentage of Building Site Energy Use Supplied by Potential } \\
\text { Code-Required PV systems }\end{array}$} \\
\hline & El Paso & Boise & Memphis & Salem & Baltimore & Burlington \\
\hline $\begin{array}{l}\text { Restaurant Fast } \\
\text { Food }\end{array}$ & $0.6 \%$ & $0.5 \%$ & $0.5 \%$ & $0.4 \%$ & $0.4 \%$ & $0.4 \%$ \\
\hline $\begin{array}{l}\text { Sit Down } \\
\text { Restaurant }\end{array}$ & $1 \%$ & $1 \%$ & $1 \%$ & $1 \%$ & $1 \%$ & $1 \%$ \\
\hline Small Office & $8 \%$ & $7 \%$ & $6 \%$ & $6 \%$ & $6 \%$ & $6 \%$ \\
\hline Retail Stripmall & $9 \%$ & $8 \%$ & $7 \%$ & $6 \%$ & $6 \%$ & $6 \%$ \\
\hline Stand alone Retail & $9 \%$ & $8 \%$ & $7 \%$ & $7 \%$ & $6 \%$ & $7 \%$ \\
\hline $\begin{array}{l}\text { Mid rise } \\
\text { Apartment }\end{array}$ & $4 \%$ & $4 \%$ & $3 \%$ & $3 \%$ & $3 \%$ & $3 \%$ \\
\hline $\begin{array}{l}\text { Outpatient } \\
\text { HealthCare }\end{array}$ & $2 \%$ & $1 \%$ & $1 \%$ & $1 \%$ & $1 \%$ & $1 \%$ \\
\hline Small Hotel & $2 \%$ & $2 \%$ & $2 \%$ & $2 \%$ & $2 \%$ & $2 \%$ \\
\hline Warehouse & $24 \%$ & $21 \%$ & $19 \%$ & $18 \%$ & $17 \%$ & $17 \%$ \\
\hline Medium Office & $5 \%$ & $4 \%$ & $4 \%$ & $3 \%$ & $3 \%$ & $3 \%$ \\
\hline Primary School & $9 \%$ & $8 \%$ & $7 \%$ & $7 \%$ & $7 \%$ & $7 \%$ \\
\hline $\begin{array}{l}\text { High rise } \\
\text { Apartment }\end{array}$ & $2 \%$ & $1 \%$ & $1 \%$ & $1 \%$ & $1 \%$ & $1 \%$ \\
\hline Large Hotel & $0.4 \%$ & $0.4 \%$ & $0.3 \%$ & $0.3 \%$ & $0.3 \%$ & $0.3 \%$ \\
\hline Secondary School & $6 \%$ & $5 \%$ & $5 \%$ & $4 \%$ & $4 \%$ & $4 \%$ \\
\hline Hospital & $0.6 \%$ & $0.5 \%$ & $0.5 \%$ & $0.4 \%$ & $0.4 \%$ & $0.4 \%$ \\
\hline Large Office & $1.1 \%$ & $1.0 \%$ & $0.9 \%$ & $0.8 \%$ & $0.8 \%$ & $0.8 \%$ \\
\hline Minimum & & & & $0.3 \%$ & & \\
\hline Maximum & & & & $24 \%$ & & \\
\hline
\end{tabular}


Table 5.2: Results of Potential Requirement Based of Conditioned Floor Area

\begin{tabular}{|l|c|c|c|c|c|c|}
\hline \multirow{2}{*}{\begin{tabular}{l}
\multirow{2}{*}{$\begin{array}{l}\text { Prototype Bldg. } \\
\text { Loc: }\end{array}$} \\
\cline { 2 - 7 }
\end{tabular}} & \multicolumn{5}{|c|}{ O.4 Wercentage of Building Site Energy Use Supplied by Potential } \\
Cl Pode-Required PV systems \\
\cline { 2 - 7 } $\begin{array}{l}\text { Restaurant Fast } \\
\text { Food }\end{array}$ & $0.5 \%$ & $0.4 \%$ & $0.4 \%$ & $0.3 \%$ & $0.3 \%$ & $0.3 \%$ \\
\hline $\begin{array}{l}\text { Sit Down } \\
\text { Restaurant }\end{array}$ & $1 \%$ & $1 \%$ & $1 \%$ & $0 \%$ & $0 \%$ & $0 \%$ \\
\hline Small Office & $6 \%$ & $6 \%$ & $5 \%$ & $5 \%$ & $5 \%$ & $5 \%$ \\
\hline Retail Stripmall & $3 \%$ & $3 \%$ & $3 \%$ & $3 \%$ & $2 \%$ & $3 \%$ \\
\hline Stand alone Retail & $4 \%$ & $3 \%$ & $3 \%$ & $3 \%$ & $3 \%$ & $3 \%$ \\
\hline $\begin{array}{l}\text { Mid rise } \\
\text { Apartment }\end{array}$ & $6 \%$ & $5 \%$ & $5 \%$ & $4 \%$ & $4 \%$ & $4 \%$ \\
\hline $\begin{array}{l}\text { Outpatient } \\
\text { HealthCare }\end{array}$ & $2 \%$ & $2 \%$ & $1 \%$ & $1 \%$ & $1 \%$ & $1 \%$ \\
\hline Small Hotel & $4 \%$ & $3 \%$ & $3 \%$ & $3 \%$ & $3 \%$ & $3 \%$ \\
\hline Warehouse & $9 \%$ & $9 \%$ & $8 \%$ & $7 \%$ & $7 \%$ & $7 \%$ \\
\hline Medium Office & $5 \%$ & $5 \%$ & $4 \%$ & $4 \%$ & $4 \%$ & $4 \%$ \\
\hline Primary School & $4 \%$ & $3 \%$ & $3 \%$ & $3 \%$ & $3 \%$ & $3 \%$ \\
\hline $\begin{array}{l}\text { High rise } \\
\text { Apartment }\end{array}$ & $6 \%$ & $5 \%$ & $5 \%$ & $4 \%$ & $4 \%$ & $4 \%$ \\
\hline Large Hotel & $1.2 \%$ & $1.1 \%$ & $1.0 \%$ & $0.9 \%$ & $0.9 \%$ & $0.9 \%$ \\
\hline Secondary School & $4 \%$ & $3 \%$ & $3 \%$ & $3 \%$ & $3 \%$ & $3 \%$ \\
\hline Hospital & $1.4 \%$ & $1.3 \%$ & $1.1 \%$ & $1.0 \%$ & $1.0 \%$ & $1.0 \%$ \\
\hline Large Office & $5.7 \%$ & $5.1 \%$ & $4.5 \%$ & $4.2 \%$ & $4.0 \%$ & $4.1 \%$ \\
\hline & & & & $0.3 \%$ & & \\
\hline & & & & $9 \%$ & & \\
\hline
\end{tabular}




\subsection{Discussion of Key Issues}

When considering the addition of renewable energy requirements into building energy codes, there are several issues to be addressed. The following sections provide a discussion of each important issue. The discussions describe some of the key options with pros and cons and provide recommendations for each issue. The sections below apply to both commercial and residential buildings, except where noted.

In both the commercial and residential code it is important that any renewable energy requirement be structured so existing core requirements (like building envelope) may not be traded directly against a renewable requirement. This is critical because small additions of high performance items like PV or a geothermal heat pump may lead to disproportionate reductions in insulation or mechanical equipment which is counter-productive over the life of the building.

\subsection{Electric versus thermal or direct use systems}

On-site renewable energy systems can be broadly categorized as either electric or direct use systems. Direct use systems, like solar hot water or daylighting, harness a renewable resource and use it to reduce building energy loads. Although the energy does not need to be used instantly (in the case of solar hot water), the energy collected is always used on-site. Electric systems also reduce building energy loads. However, electric systems have an advantage over direct use systems in that they can send surplus energy to the electric grid. If the electric renewable energy system is net-metered, as many are, any surplus energy can be used during other parts of the month.

The ability to produce electricity on-site and send back surplus energy to the grid is essential to reducing that further. Although energy efficiency can greatly reduce building energy loads, there will always be some site electricity use in buildings (for plug loads, etc). The site electricity use will need to be 'offset' with renewable energy systems that can 'bank' electricity. This poses the question, should codes require only electric renewable energy systems, only thermal (direct use) systems, a choice between the two, or both?

\subsubsection{Require electric only:}

Pros: At some point additional energy efficiency will begin to yield diminishing returns. An analysis by the National Renewable Energy Laboratory (NREL) concluded that the average Energy Use Intensity (EUI) for commercial buildings could be reduced to as little as 40.3 $\mathrm{kBtu} / \mathrm{ft}^{2}$ ·yr using a comprehensive package of technologies and practices termed "Max Tech." (Griffith et al. 2007) No matter how efficient the building envelope, lighting, and mechanical systems that are installed, it is unlikely that energy use can be reduced to zero. In addition, energy will continue to be needed for equipment and appliance loads and nighttime lighting. Thus, at some point on-site electric renewable energy systems will be needed to meet these needs and further reduce the need for purchased power. Another advantage of electric renewable energy systems is that it is often easier to measure their output and demonstrate compliance. 
Cons: Direct renewable energy systems (like solar hot water, solar air heating, biomass boilers, etc.) are often more cost-effective than photovoltaics (PV). Giving designers and builders more options, especially options with lower upfront investments, will reduce resistance to renewable energy requirements. Certain industries would argue against electric-only requirements because they would essentially pick PV as the 'technology winner' over other renewable energy options. Furthermore, current energy codes are not very close to net zero buildings. At this point in time, the energy code should focus on reducing all site energy, rather than trying to offset electric use.

\subsubsection{Require thermal (direct use):}

Pros: The advantage of requiring only thermal systems (solar hot water, biomass boilers, etc.) is that they generally are more cost-effective than PV. There will likely be less opposition to a thermal requirement, especially in areas that have good solar resource.

Cons: Thermal systems have their own shortcomings, so it does not make sense to specifically require renewable thermal systems. For example, there are buildings where thermal systems are not practical to install (buildings with very low hot water demands). Also, there are alternatives to thermal renewable energy systems that would have the same effect. For example, the benefits of a solar hot water system could also be obtained using a heat pump water heater, heat recovery (desuperheater), or drain water heat recovery.

\subsubsection{Require a choice between thermal and electric:}

Pros: Requiring a choice between renewable thermal and renewable electric systems gives designers flexibility to choose the most cost-effective renewable energy system or the system that best fits their needs.

Cons: Designers will rarely choose PV systems because there are usually cheaper or more costeffective options. In the long run, if we would like to continue reducing building energy use, buildings will need electricity-producing systems. Allowing a choice of renewable energy systems will limit the amount that building energy use can be reduced.

\subsubsection{Require both electric and thermal renewable energy systems:}

Pros: This may be the best approach for the long-term. In the short-term, renewable energy requirements will likely use an options approach, where it may make more sense to separate the requirements. For example, solar hot water systems could be part of a high-efficiency water heating options requirement, while electric renewable energy could be part of an advanced energy measure options requirement.

Cons: The downside of separately requiring both systems is that they cannot be traded against each other, and there will continue to be reasonable alternatives to solar water heaters or other renewable thermal systems. Also, if solar hot water and PV are both used, space constraints may need to be considered (although this should rarely be a problem). 
Commercial Recommended Approach: In the next few code cycles, proposed renewable energy requirements will use an 'options' approach that allows both electric renewable energy as well as other advanced energy options. Direct use renewable energy systems, such as solar hot water, should be treated separately and included in relevant sections of the code (i.e., solar hot water in the water heating section). Designers would be required to choose one or more measures from a package of options. Initially, the options may also include additional efficiency measures. This requirement structure will help support renewable energy industries and reduce building energy use, while still allowing design flexibility.

After several code cycles, when building energy loads have been reduced to the point where there are few efficiency measures that could be included in the options package, an electric-only renewable energy requirement could be considered. Other renewable energy technologies would be required or encouraged in the appropriate section of the code. For example the water heating equipment section would require one of several high efficiency options (solar hot water system, heat pump water heater, tankless water heater, etc.).

Our recommended approach allows for design flexibility and cost-effective technology in the short-term. In the long-term, it sets up electric-only renewable energy requirements that could be strengthened over time.

Residential Recommended Approach: For residential buildings, our recommendation is slightly different. The options approach described above should be used. Similarly, PV should be part of an advanced energy measures options package, and solar hot water should be part of a high efficiency water heating package. Over time, the measures in the options packages should be strengthened. However, unlike the commercial code, we do not believe that a prescriptive requirement (i.e., a requirement without options or exceptions) for renewable energy will ever be accepted into the residential energy code because of upfront costs; in addition, solar access and orientation issues are much more problematic for residential buildings than commercial buildings due to lower heights, smaller lots and building footprints, smaller setbacks, and more trees.

\subsection{Requirement structure}

On-site renewable energy requirements could be structured in many ways, but the code must clearly define the size of the required system. The size would likely be expressed in units of capacity, such as kWs or Btus/hr, or annual energy production, such as kWhs or Btus. The size of the required system would vary from building to building (a flat size requirement for residential systems is unlikely to be accepted, but it could also work). The required system size could be based on a variety of building characteristics, like building energy load, conditioned floor space, or roof area. The merits of these alternatives are discussed below.

\subsubsection{Option 1: Renewable energy size requirement based on building energy use}

Pros: Basing the system size on the estimated building energy load is probably the most equitable requirement structure. Each building would simply supply a percentage of their load with on-site renewable energy (for reference, the requirement would likely start at between 1 and $5 \%$ of building load, and then gradually increase). It would be difficult for building owners to argue that their building type is being unfairly burdened. Another benefit is that this requirement 
structure incentivizes energy efficiency. By designing a building with lower energy loads, designers could reduce the size of the required renewable energy system and the associated cost burden.

Cons: To base the size of the renewable energy system on building energy load, energy modeling must be performed. While energy modeling is often useful, it is an additional cost burden. Residential and small commercial buildings, which often use prescriptive compliance paths, would not otherwise perform sophisticated whole-building energy modeling. In addition, energy modeling has inherent shortcomings and inaccuracies. Basing the requirement on modeled energy use would not necessarily result in renewable energy systems that produced the desired percentage of energy load. One potential approach to avoid the need for energy modeling is to base the renewable energy requirement on the building electrical service load. Smaller buildings could be allowed to use this option, while larger and more costly buildings could be required to do energy modeling.

The other problem with basing the requirement on building energy use is that some buildings with high energy use per square foot may not have enough roof space for their required renewable energy systems. There could be exemptions for those buildings. Alternatively, ground-mounted or façade-integrated solar technologies could be pursued to meet the requirement.

\subsubsection{Option 2: Renewable energy size requirement based on conditioned floor space}

Pros: One advantage of basing the renewable energy size requirement on conditioned floor space is that no modeling or complex calculations are required. The code would specify the size of the system per square foot, which designers would simply multiply by the conditioned floor space $\left(\mathrm{ft}^{2}\right)$ to determine the required system size. The simplicity of this approach reduces the burden on designers as well as code officials, who could easily determine compliance. Also, while the requirement would not directly incentivize lower building loads, it would encourage designers to minimize the conditioned floor area, which could in turn lower energy use. Note that this incentive is not expected to be a motivating factor when designing the size of the building, but it could become more relevant as renewable energy requirements increase in stringency.

Basing a requirement on conditioned floor provides reasonable equitability. Generally, for any particular building type, energy use increases with floor area. In particular, larger homes use more energy in total than smaller homes (even though they may use less per square foot), so a requirement based on floor area ensures that larger homes install larger systems.

Cons: Some designers, builders, or building owners may object to this structure because it does not take energy use into account. For example, a 10,000 $\mathrm{ft}^{2}$ warehouse and a 10,000 $\mathrm{ft}^{2}$ office building would be required to install the same size system, even though the office building would likely consume significantly more energy than the warehouse. The owners of the warehouse may claim that the requirement is unfair because it burdens their building, which uses less energy and costs less than other buildings. 
Another issue that arises is available roof area. For many non-residential buildings, PV or solar hot water will be the only practical technologies that could be used to meet the requirement. Both of these technologies require roof area. In tall buildings, there may not be enough roof space for the required renewable energy system. Note that in some cases, these systems could be mounted on vertical walls or ground-mounted. Alternatively, the code could allow RECs, technologies like ground source heat pumps and biomass boilers, or additional energy efficiency measures to help meet the renewable energy requirement.

\subsubsection{Option 3: Renewable energy size requirement based on roof area}

Pros: A requirement based on roof area, like a requirement based on conditioned floor space, has the advantage of simplicity. No complex calculations or modeling would be needed to determine the size of the required system. Another advantage of a requirement based on roof area is that the required system would never be too large for the roof (assuming that shading is not severe and there are no excessive roof obstructions).

Also, the requirement may, depending on the stringency and structure, encourage taller buildings with smaller footprints and roofs. By designing taller buildings, designers could maintain the desired amount of floor space while decreasing the required renewable energy system size. Taller buildings and denser, urban construction could be considered an environmental benefit, although it is unlikely that the renewable energy requirement would have any significant impact on construction density.

Cons: Similar to Option 2, some may consider this requirement structure unfair. For example, a 10 -story building with a $5,000 \mathrm{ft}^{2}$ roof would have the same size system as a 1-story building with a 5,000 $\mathrm{ft}^{2}$ roof, even though the first building has about ten times as much conditioned floor space and probably uses significantly more energy (as a result, this structure places a larger burden on low-rise or 1-story building owners and designers).

Recommended Approach \#1: Any renewable energy code requirement needs to be relatively simple and easily understood to minimize unnecessary burdens on designers and code officials. As such, the requirement should be based on an easily measureable building feature like conditioned floor space or roof area. Of these two options, a requirement based on conditioned floor space would probably be considered more equitable. However, if such a structure is used, exceptions or options must be provided so that buildings with insufficient roof space can meet the requirement. (See the Lack of Resource Availability and the Renewable Energy Certificates sections for more details on exceptions and options)

Recommended Approach \#2 (only relevant for commercial buildings): An alternative approach is to base the requirement on the roof area of the building but have different requirement levels or a cap depending on the number of stories of the building and the building type. Because taller buildings would typically use more energy per square foot of roof area, they would be required to install a larger system per square foot of roof area. This makes the requirement slightly more equitable. Also, by basing the requirement on roof area, the code can ensure that there is adequate roof space for renewable energy systems on most buildings. To do this, the numeric values for the requirement (i.e., number of $\mathrm{kW}$ or $\mathrm{kWh}$ per $\mathrm{ft}^{2}$ of roof area) 
should be based on the percentage of the roof that will be cover with PV. For example, for multistory buildings, the requirement could be based on covering $20 \%$ of the roof with PV. By assuming typical conversion efficiencies, the $20 \%$ coverage could be converted into a capacity or annual output per square foot of roof area. The requirement should be calculated in this way because it prevents code proposals from making impractical requirements. Basing the requirements on building type would allow the code to discriminate between a 100,000 $\mathrm{ft} 2$ single story warehouse and a 100,000 ft2 single story office building with high internal loads. These buildings have significantly different needs and could be required to have significantly different renewable energy requirement, even though they have the same roof area available for installation of a PV system.

Residential Approach: Our recommendation for residential requirements is essentially the same as Recommended Approach \#1, above. Because residential construction is generally one or two stories, the requirement could just be based on the floor area. This would be more equitable than basing a requirement on roof area. Of course, roof orientation and shading are major constraints for residential solar systems, so either alternative options or exceptions must be included in any residential renewable energy requirement.

\subsection{Differentiating renewable energy requirements by building type}

If the size of renewable energy requirements is based on the building energy use, that requirement can be used for any building (as long as there is a way to model or estimate the energy use). However, if the size of required systems is based on the floor area of the building, the area of the roof, the number of floors, or other building attributes, the requirement will inevitably be seen as inequitable or unfair by some. One possible way to alleviate these concerns is to adjust the requirement based on the type building. The question is whether renewable energy requirements should vary by building type.

Pros: The advantage of differentiating by building type is that it may be more equitable. In fact, it would be similar to basing the system size on annual energy use, except the designer would not have to model the building to calculate the annual energy use (it also avoids accuracy issues associated with modeling). This structure would maintain the simplicity of a prescriptive requirement while avoiding some of the pitfalls of a 'one size fits all' approach. Consider a code that requires a renewable energy system rated at $\mathrm{X}$ watts per square foot of floor space. In a $10,000 \mathrm{ft}^{2}$ warehouse building, the requirement may result in a renewable energy system that provides $10 \%$ of the annual building energy use. Meanwhile, a $10,000 \mathrm{ft}^{2}$ office would have to install the same size system, but it may only produce $2 \%$ of the annual building energy use. In this example, the owner of the warehouse may view the requirement as unfair. In general, this requirement penalizes buildings with low energy intensity relative to buildings with high energy intensity. One way to avoid the issue illustrated above is to differentiate the requirement based on building type. See Spain and India in Section 3.0 on National and International Precedents for examples where this has been adopted.

Cons: The shortcoming of this approach is that it adds complexity to an otherwise simple prescriptive requirement. Also, there are many buildings that do not easily fit into typical building categories or that combine several building types. 
Recommended Approach: At this time, we do not recommend varying renewable energy requirements by building type. The added complexity of setting requirement levels for each building type would be challenging and contentious. However, as renewable energy requirements become more stringent, especially when they begin to approach limits such as available roof space or zero energy use, codes should consider separate requirements based on building type.

\subsection{Sequencing renewable energy requirements}

When should renewable energy requirements be introduced into building energy codes and how should they evolve over time? There are two broad strategies that should be considered. First, small renewable energy requirements could be added to the code soon. Over the course of the next few codes cycles, the requirements would be gradually increased in tandem with energy efficiency requirements. Alternatively, renewable energy requirements could be left out of the next few code cycles while energy efficiency requirements increase until there are few efficiency measures remaining. Then, renewable energy requirements would be introduced and quickly increased to continue to decrease building energy use. The benefits and drawbacks of each approach are discussed below.

Pros: Introducing a renewable energy requirement in the 2012 IECC using an options approach will help support and grow renewable energy industries (manufacturers, installers, distributers, etc.). It will help designers, builders, and owners get used to the idea and provide them with some experience. The consistent demand for renewable energy systems and increased scale may help to drive down installed costs. Also, starting small and slowly increasing the requirement will help avoid a shock to the renewable energy industries, the building industries, and utilities. Without consistent demand for renewable energy systems, the rate of new renewable energy installations may stagnate, and the success of renewable energy industries will continue to depend largely on the ebb and flow of energy prices and government subsidy programs.

In addition, renewable energy requirements may be necessary to continue achieving additional energy code savings in the near-term. For prescriptive compliance paths, there are not very many additional measures that can be added to substantially reduce energy use. So, in the next few code cycles, renewable energy systems may need to become part of the prescriptive requirements (if additional energy improvements are to be achieved). However, they will not necessarily be a mandatory requirement, because performance compliance paths can still realize additional savings by setting energy targets lower. At some point, if codes continue to become more stringent, the targets will be low enough such that renewable energy systems are an implicit requirement.

Cons: The main argument against this strategy is that for the next few code cycles, there may be additional energy efficiency requirements that provide more cost-effective energy savings than renewable energy systems would (although this may not be the case for prescriptive codes). It is logical to implement the most cost-effective measures first, delaying other requirements until the costs have come down and energy prices have increased. Also, many sources of on-site renewable energy have high capital costs and are not currently cost-effective without subsidies. There will be less resistance from building owners, designers, and builders once renewable energy system costs have come down and energy prices have increased. 
Also, in the coming decades, there may be breakthroughs in renewable energy technologies and new technologies may be developed and commercialized. Requiring a specific set of renewable energy technologies now may inadvertently provide a push to some particular technologies, which could cause "lock-in" and discourage the development of emerging technologies.

Recommended Approach: There are substantial benefits to integrating renewable energy requirements with codes soon, even if the requirements are small or part of an options approach. Not only will such a requirement reduce building energy use, it will help support renewable energy industries by providing steady demand and may drive down the installed cost of renewable energy systems. While capital costs are still a barrier for many renewable technologies, they are falling and are often reduced through government subsidies. In the next few code cycles, renewable energy requirements could be adopted into both stretch and model codes, with the expectation that progressive states and jurisdictions will adopt the requirements a few years before the majority of states.

\subsection{Allowing trade-offs between renewable energy and energy efficiency}

Renewable energy requirements will most likely contain alternatives for buildings with poor renewable energy resources (shading, lack of wind resource, etc.). The alternatives may include the purchase of RECs (see RECs discussion below) or other feasible energy efficiency technologies when a site has a poor renewable resource. Another alternative that should be considered is to allow additional energy efficiency measures as a general option, in lieu of renewable energy systems (meaning that designers choose either renewable energy or an energy efficiency measure). An example is the Oregon energy code, which requires that builders select one of nine 'additional measures.' The measures include PV, solar hot water, and a variety of HVAC, envelope, lighting, and hot water energy efficiency measures.

\subsubsection{Should energy efficiency be allowed as a general option?}

Pros: The advantage of allowing energy efficiency as an exception is that it gives designers and builders more options. In general, options and flexibility is appreciated by the design community (as long as the options are not vaguely defined). Also, energy efficiency investments often have lower upfront and life-cycle costs than renewable energy investments (of course, this is not always the case). Including energy efficiency exceptions in code proposals will reduce the amount of resistance to renewable energy requirements.

Cons: Part of the reason for requiring renewable energy is to build the industry and to drive down installed cost through economies of scale and a consistent market for renewable energy systems. By allowing alternatives that are less expensive than renewables, the requirement would not meet these goals. Another issue with energy efficiency options is that as energy codes become increasingly stringent, there are fewer and fewer building systems that can be improved through prescriptive requirements. As a result, there may not be energy efficiency measures available to use as options. However, this will probably not be a problem for the next few code cycles. 


\subsubsection{Should more energy efficiency be required if on-site renewable energy is not feasible?}

Pros: This approach gives priority to renewable energy systems over other advanced energy measures. It ensures that a substantial number of renewable energy systems are implemented. It also ensures that in cases where the building is shaded or has a poor solar resource, other energysavings measures are implemented. This is preferable to full exceptions, where no savings would be realized.

Cons: One downside of allowing energy efficiency as an exception is that code officials would have to determine whether buildings qualify for the exceptions. Code officials are not necessarily qualified to determine a site's solar resource. However, this can be addressed through wellthought out exceptions in the code. The codes already have these for cool roofs (essentially if the roof is shaded for any period of time you can exempt the roof system). Furthermore, building industry groups may object to the requirement if it appears to favor renewable energy. For example, if the energy efficiency measures save the same amount of energy as the renewable energy system would produce, it seems unreasonable to prioritize renewable energy (of course, proponents of the requirement would say that supporting renewable energy has additional benefits that justify its prioritization).

Recommended Approach: Initially, energy efficiency upgrades should be allowed as options to make the requirement more palatable. Allowing energy efficiency as an option, rather than an exception for poor solar resource keeps the requirement simple and reduces the burden on code officials. For commercial buildings, the best course of action may be to allow energy efficiency options for the first 1 or 2 code cycles with renewable energy requirements, then limit the requirement to renewable energy only. For residential buildings, renewable energy requirements will need to offer energy efficiency measures as alternative options. We doubt that a prescriptive requirement will be accepted into residential codes, even if costs are reduced in the future. Another important consideration is the stringency of the energy efficiency options relative to the renewable energy option.

Option \#1: If the energy efficiency options are designed to save about the same amount of energy as would be saved by the renewable energy systems, the energy efficiency options will likely be cheaper to install. As a result, few builders or designers will choose the renewable energy systems (depending on financial incentives). Then over time, the energy efficiency requirements would be strengthened or designers would have to choose multiple options. This way, designers can have the flexibility to choose low-cost technologies for their building (while still using a prescriptive compliance path).

Option \#2: If one of the primary goals of the requirement is to drive renewable energy adoption, the energy efficiency options should be stricter. Stricter energy efficiency options would save more energy but would cost more and may have longer payback periods. This would put the energy efficiency on more of a level ground with renewable energy systems, helping to drive the renewable energy industry and increase its scale. 


\subsection{Cost-effectiveness}

Cost will be the biggest impediment to widespread acceptance of renewable energy requirements. Requiring renewable energy systems will clearly provide environmental benefits. In addition, it may help drive down installed costs and increase cost-effectiveness over time. In the short-term, however, the main barriers to the use of renewable energy by builders, building owners, engineers, and architects are high capital costs and lack of cost-effectiveness. As such, requiring renewable energy systems is bound to be contentious.

\subsubsection{Is it justifiable to require renewable energy systems that are not necessarily cost-effective?}

Pros: The obvious advantage of requiring renewable energy systems is that it would greatly increase the volume of renewable energy installations. Aside from environmental benefits, a larger volume of installations would help sustain renewable energy industries and would likely drive down the installed costs.

At the moment, there are various government and utility subsidies that improve the economics of renewable energy systems. Unfortunately, there is some evidence that renewable energy rebates actually inflate the installed cost charged by contractors (Wiser et al. 2006). Although incentives encourage renewable energy systems, the majority of the incentives are often absorbed by the contractor, rather than the building owner. So, while renewable energy industries rely heavily on incentives, the incentives may actually prevent substantial reductions in the pre-incentive price of renewable energy.

If, on the other hand, renewable energy systems were required, the increased scale and competition amongst installers would likely lead to lower installed costs. A requirement could drive businesses to find to lowest cost solution.

The argument can also be made that some renewable energy systems would be cost-effective if the externalities associated with fossil fuels were priced appropriately. Until energy is priced according to true costs, some states and jurisdictions may use energy codes as a way of encouraging environmental and national security goals, even if some measures are not costeffective.

Cons: Many energy codes are based on the cost-effectiveness of measures. Certain industry groups, as well as building owners, will object to requirements that are not cost-effective. Realistically, though, these groups might object to renewable energy requirements even if they were cost-effective because the requirement would increase capital costs. Other groups may object because more energy savings could be achieved if the money were spent on energy efficiency measures or large scale renewable energy projects. Some of these groups would be appeased if the requirement had sufficient options such that designers could choose the lowest first cost or most cost-effective measure.

Recommended Approach: In commercial buildings, renewable energy requirements do not necessarily need to pass a life-cycle cost-effectiveness test, especially if they are part of an options package. Technology options will allow designers to use systems that are the most cost- 
effective for the individual building. Renewable energy doesn't necessarily need to be costeffective before many will accept a requirement, but it should probably be more cost-effective than it is today. To reduce resistance to a mandatory renewable requirement, it is also important for the required renewable energy systems to have a relatively low upfront cost. The size of the required system (meaning the capacity or annual energy output) should start small. Starting with a small requirement will keep the capital cost burden relatively low, a crucial requirement for many builders and designers. The survey indicated that most people felt that requirements would be accepted if they are flexible, equitable, and introduced slowly, even if the technology is not cost-effective.

For residential buildings, we believe that upfront costs and cost-effectiveness are more of an impediment. While renewable energy systems could certainly be included in options packages, it is unlikely that a prescriptive renewable energy requirement could be implemented, even if the cost-effectiveness of renewables improves.

\subsection{Lack of resource availability}

The most common physical constraint encountered for on-site renewable energy systems will likely be shading. Buildings, especially residential buildings, may be shaded by trees, buildings, or other objects. (Shading is typically not on issue on commercial buildings because of height, fewer nearby tree, and buffer zones such as parking lots.) Obviously, buildings that are substantially shaded should not be required to install solar systems. So, any renewable energy requirement must have either options or exceptions when shading occurs. The benefits and drawbacks of these approaches are discussed below. Note that this discussion could also be applied to locations with very poor solar resource.

\subsubsection{Exceptions for poor solar resource:}

Pros: Building owners should not be forced to build solar systems that have poor energy output and are uneconomic.

Cons: If there is a full exception for shading (i.e., shaded buildings have no obligation to install renewable energy or other measures), no renewable energy or energy reduction benefits will be realized for buildings that are shaded. This would be unfair to other owners who must comply with the requirement. In addition, builders and designers will have an incentive to claim that their site is shaded or to select sites that are shaded. Furthermore, it can be difficult to define what constitutes a 'shaded site.' One could specify the number of shaded hours per year (or percent of the sunlit hours that are shaded), but there is often room for interpretation in these calculations. For example, one section of a roof may receive more shading than the rest of the roof. Designers could use the shaded section to claim the exception. The bottom line is that if an exception exists, many designers may claim it and code officials will not necessarily have the time or technical expertise to determine if the exceptions are justified.

\subsubsection{Allowing alternative options for poor solar resource:}

Pros: The obvious advantage of offering options other than solar renewable energy systems is that some of the benefits will be realized even if the building has a poor solar resource. Also, if 
an option approach is taken (rather than exceptions), there is no burden on the code official to verify that a site does or does not have an adequate solar resource. The designer simply chooses the option that best meets their economic and design criteria. It also ensures equity in that all buildings are treated the same.

Cons: The allowable options must be carefully designed to avoid unintended consequences. For example, if RECs are allowed as an option, the majority of designers may choose to purchase RECs (depending on how the requirement is structured and the amount of RECs required). This could also happen if energy efficiency measures are allowed as an option. One of the goals of the renewable energy requirement is to grow and support on-site renewable energy system installers and distributed generation; allowing lenient RECs and efficiency options would prevent the requirement from meeting that goal.

Recommended Approach: If possible, full exceptions from renewable energy requirements should be avoided. Exceptions will inevitably be difficult to validate and may be abused, and will be seen as inequitable unless the options deliver the same amount of savings as the renewable energy requirement. Instead, renewable energy requirements should be designed to include options that are feasible for all buildings and that are either comparable in terms of capital requirements or energy production. Additional energy efficiency measures should be allowed as options. As long as renewable energy is part of an options package, users can choose another (energy efficiency) option if renewables are not feasible. If and when the use of renewable energy is mandatory, users should be required to choose an additional option from an options package. For commercial buildings, RECs may also be used as an option.

\subsection{Renewable energy certificates (RECs)}

Renewable energy certificates (RECs) are tradable commodities that represent the environmental attributes of renewable electricity. RECs are discussed here because there is a possibility that they could be purchased either as a substitute for renewable energy systems (in a package of options) or as part of an exception when a building has a poor solar resource.

In our opinion, the goals of a renewable energy requirement would be to reduce on-site nonrenewable energy consumption as well as to support and grow the industries that provide on-site renewable energy systems. In light of these goals, RECs are a slightly less desirable outcome than actual on-site renewable energy systems. However, depending on how the renewable energy requirement is designed, RECs may be a necessary alternative. For example, there may be situations where no renewable resources are available on-site. Some dense urban areas may be shaded by nearby buildings, lack sufficient space for ground source heat pumps, have no wind resource, etc. In the future, diminishing returns may make additional energy efficiency less viable alternative for cases where insufficient solar resource is available (i.e., shading). For these situations, there must be an alternative that would allow all building owners to comply with the requirement. RECs offer one such alternative.

However, there are several issues that must be considered when including RECs in a requirement. 


\subsubsection{Certification and verification}

RECs, which represent the environmental benefits associated with renewable energy (not the actual power), are currently purchased by a variety of customers. Some people or businesses purchase RECs voluntarily, while many utilities have mandates to meet Renewable Portfolio Standards. Independent organizations verify and certify RECs. Certification helps to ensure that RECs are not double-counted. One of the best known certification programs is the Green-e program (www.green-e.org). Green-e certification is required for RECs purchased to help meet the ASHRAE Standard 189.1. If RECs are allowed as an option for energy code compliance, certification should be required. Certification not only ensures valid RECs, it creates an easier and more standardized method for code officials to check compliance.

\subsubsection{Terms of RECs purchase}

If RECs are allowed as an option, how long (years) should building owners continue to purchase RECs? For a typical on-site renewable energy system, the system will continue producing energy for 20 years or longer. So, it may seem logical to require purchase of RECs for 20 years. The life of the building is even longer. In either case, however, the authority of code officials typically ends once the building passes inspection and is given a certificate of occupancy. It would be difficult to enforce the purchase of RECs in subsequent years. In addition, both buyers and sellers may be reluctant to enter into long-term contracts in a market with considerable uncertainty. A better strategy would be to require a larger purchase of RECs upfront, before the building is occupied, for the cumulative amount that would be otherwise purchased over the particular time horizon the jurisdiction decides is a reasonable to offset the on-site renewable energy system. An added benefit of this strategy is that it more closely resembles the structure of an investment in a renewable energy system (high upfront investment).

\subsubsection{Economics of RECs}

The exact amount of RECs required will depend on the size of the renewable energy system options and the desired outcome. The higher the RECs requirement, the more building owners will choose on-site renewable energy options. It should be noted that RECs, under most circumstances, would offer the lowest up-front cost option - RECs from large wind, biomass, and geothermal projects has a lower delivered price than PV. As a hypothetical example, consider a renewable energy requirement that stipulates a $2 \mathrm{~kW}$ PV system (note that these calculations are rough and only for illustrative purposes). Depending on the location, the system might produce about 2,400 kWh per year (in some locations, production would be considerably higher), or 48,000 kWh over 20 years. The PV system would typically cost between $\$ 12,000$ and $\$ 20,000$ before incentives. On the other hand, RECs can currently be purchased for roughly $2.5 \$$ per kWh. If the building owner had to purchase 48,000 kWh worth of RECs (20 years' worth), the cost would be $\$ 1,200$, considerably less than the installed PV costs.

Even though the PV system generates a return by producing energy each year and RECs do not, many building owners and developers would be tempted to choose the RECs (especially if they will not realize any revenue from the PV system). Keep in mind that PV is probably the most expensive form of renewable energy. Other on-site renewable energy systems could produce the same amount of energy for a lower upfront cost. (That's one reason why the RECs cost so much less in the example above - the energy is typically generated from large wind turbines, which is considerably less expensive than PV, the most likely on-site renewable energy option.) Even so, 
it is easy to see how a renewable energy requirement that allows RECs as an alternative could result in the purchase of many RECs but few on-site renewable energy systems.

Some would argue that on-site renewable energy systems have more value than RECs. RECs, for example, do not necessarily support local renewable energy contractors or installers. Also, there is some skepticism about the claimed benefits of RECs. The most legitimate argument along these lines is that some projects that sell RECs may have been implemented even in the absence of RECS. So, the sale of RECs for those projects did not 'create' any additional renewable energy, it simply improved the economics of a project that would have been implemented anyway. Supporters of RECs counter that demand for RECs sends a market signal to increase the supply of renewable energy. Taken as a whole, the RECs market clearly encourages the development of renewable energy.

If one of the goals of the code is to encourage on-site systems, codes could allow RECs as an alternative but require a larger amount of RECs than the renewable energy system would produce. The requirement could be designed such that cost of an on-site renewable energy system and the cost of RECs were roughly equivalent. The City of Seattle's code has a renewable energy requirement, although it has not yet taken effect. At one point, Seattle considered a structure that allowed RECs, but the amount of RECs required would have been equivalent to about 24 times the amount of the on-site renewable energy option. The reason for the large discrepancy was likely an attempt to 'level the playing field' between RECs and on-site renewable energy. Because on-site renewable energy would not be much cheaper than RECs, many designers will choose to install on-site renewable energy systems. Again, it should be noted that Seattle's requirement has not yet taken effect, and it is unclear whether RECs will be included in the final version.

\subsubsection{Potential problems with RECs}

One potential problem with allowing RECs in a renewable energy requirement is the uncertainty associated with RECs markets. RECs are sold into either compliance or voluntary markets. In compliance markets, RECs are bought to fulfill renewable portfolio standard (RPS) requirements. Terms placed on RECs vary widely in states with RPSs. It is likely that RECs purchased to meet building code requirements would come from the voluntary market. However, as more states develop strong RPS requirements, the voluntary market likely will be affected. Furthermore, the voluntary market is also affected by federal policies like tax incentives for wind and solar energy. These factors could affect the price and availability of RECs as an option to meet code requirements, and make it difficult to predict how designers will react to RECs options in renewable energy code requirements.

To illustrate the implications of variations in the price of RECs, consider an example where a renewable energy requirement was written such that RECs and the on-site renewable energy option cost about the same amount. The intended result would be that most designers install onsite renewable energy, while others purchase RECs. However, if state or federal policies (or other market forces) result in a slump in the price of RECs, RECs would have a significant price advantage and designers and building owners will all choose RECs over actual on-site renewable energy systems. 
While large price variations of RECs would still result in the expanded use of renewable energy (albeit off-site), it would be preferable to have more control over the outcome of the building code. To avoid problems, states may need to coordinate between the RECs provisions in their energy codes and their RPS requirements. Furthermore, as the RECs markets evolve, RECs provisions in building energy codes should be periodically assessed and updated as needed.

Recommended Approach: When renewable energy is part of an options approach, RECs are not necessary. The commercial code may eventually have prescriptive renewable requirements, in which case it is likely that RECs will be allowed. Our recommendation is to allow RECs as an option (or trade-off) alongside a site renewable energy requirement (rather than a fallback for buildings with no renewable energy resource). However, the RECs option should be large enough so that RECs do not have a significant cost advantage over on-site technologies. This will help ensure that at least some designers choose to install an on-site renewable energy system. Alternatively (as a second choice), RECs could be part of an exception when the site lacks an adequate renewable energy resource. This strategy could work fine, but may impose an additional burden on code officials in determining whether a site has an 'adequate' resource.

RECs should be certified through an independent program, such as Green-e. Also, only the broad certification requirements should be placed on RECs. The renewable energy requirement should not require RECs from specific technologies or locations, which could cause huge variations in RECs prices between states.

For residential buildings, we do not expect a prescriptive renewable energy requirement in the foreseeable future, so RECs should not be necessary. Furthermore, the purchase of RECs would be less palatable for home owners. The size of RECs purchased for residential requirements would be small, making it hard to justify the added complexity necessary to determine compliance with RECs purchases. Many utilities offer customers a green power package for a premium, which could serve as a local alternative. However, they vary in size, and do not represent a long-term contractual obligation like RECs - the customer can opt out at any time. The code jurisdiction would have to coordinate the code requirement with the utilities.

\subsection{Sale of RECs from on-site renewable energy system}

For buildings that comply with renewable energy code requirements by building on-site renewable energy systems, the code must be clear about whether building owners (or third party owners, see below) may sell, trade, or transfer the RECs. Typically, when utilities give rebates for solar systems, the RECs are transferred to the utility even though the building uses or gets credit for the electricity. Should building owners be allowed to sell the RECs created by a requirement renewable energy system?

Pros: It would be very difficult, and outside their typical responsibilities, for code officials to ensure that the associated RECs from on-site renewable energy systems are not stripped and sold, especially after the code inspection. Nor, would it seem, should it matter, because the desired outcome, the installation of an on-site renewable energy system, has been achieved. Also, many of the incentives available from utilities are contingent upon the transfer of RECs associated with the renewable energy project to the utility. Not being able to sell RECs would hurt the economics of on-site renewable energy systems. 
Cons: Some people would argue that selling RECs would go against the intent of the requirement. If the purchaser of the RECs gets to claim the environmental attributes associated with the renewable energy system, does the requirement actually ensure new production of renewable energy? Consider a situation where one building has an on-site PV system to meet the requirement, while another building does not have an on-site PV system but purchases RECs from the first building. In this situation, one renewable energy system is allowing two buildings to comply with the rule. (Note that, in most cases the RECs requirement would be larger than the on-site renewable energy production, so one PV system could not sell enough RECs to allow another building to comply). Does this meet the intent of the rule?

Recommended Approach: Despite concerns that the sale of RECs will allow other buildings or utilities to avoid building renewable energy systems, codes should be silent on the sale of RECs associated with an on-site renewable energy system required by code. Even if the RECs are sold, the electricity is still produced and will help reduce building energy loads. Also, RECs provide an important boost for the economics of on-site renewable energy systems. Perhaps the most important reason to allow the sale of RECs is that it would be difficult, if not impossible, for code officials to restrict their sale. The code compliance process will be simpler if no restrictions are placed on the sale of RECs from on-site renewable energy systems.

\subsection{Off-site generation}

It could be beneficial to allow building owners the option of installing renewable energy systems on off-site locations. As an example, consider a developer that is planning a set of residential buildings. Rather than installing a small PV system on each building, the developer could install a larger PV system on one building or on an open space nearby. Another example is a large company with multiple buildings in a jurisdiction that wishes to aggregate its renewable energy systems into one centralized facility.

Pros: The obvious advantage of allowing a renewable energy requirement to be met with an offsite system is that developers could take advantage of economies of scale by building larger, consolidated renewable energy systems. Building owners that are not developers could also build offsite renewable energy systems and could potentially make agreements with other building owners or renewable energy developers to achieve economies of scale.

Cons: The primary argument against allowing offsite generation is that it adds significant complexity to code compliance in individual buildings. Traditionally, code officials have no authority beyond the building site, so it would be difficult to enforce requirements offsite, especially if they are located on non-contiguous land. Even if code officials could enforce offsite generation, it would be complex and difficult to determine the portion of renewable energy systems that are 'assigned' to each building and to ensure that portions of the renewable energy system are not being double-counted. In addition, building owners could sell the renewable energy systems after the code inspection. Building-integrated systems are not as easy to move or sell.

If and when community energy usage can be considered, a simpler approach to renewable energy could be taken. A developer will know how many houses will be built in a planned development 
and also have a good idea of the size of the homes. They should be able to project how large of a PV system that will need to be installed to meet the needs of the houses. The installation is put in during site development and each house would need to be wired to accept power from the PV system as part of the condition to build in the development. This would only require an electrical inspection to see if the house meets the hook-up requirements.

Recommended Approach: Allowing off-site generation would be difficult to enforce and would create a significant burden on code officials. Allowing offsite generation is not recommended at this time.

\subsection{On-site power purchase or third party agreements}

Ownership of renewable energy systems and the sale of electricity from renewable energy systems can be complex. For example, some companies (often called solar services providers) offer to install, own, and operate PV systems on buildings that they do not own (the system may also be financed and owned by a third party). Under these Power Purchase Agreements (PPAs), the system may be leased to the building owner, or the electricity may be sold to the building owner at a predetermined rate for a set number of years. The advantage of this type of this agreement is that the building owner receives on-site renewable energy with little or no upfront cost. The solar services company or the financier retains the tax and depreciation benefits associated with the system and earns revenue from selling the electricity (and possibly the RECs). Should renewable energy code requirements allow these arrangements?

Pros: There are clear benefits to allowing these PPA arrangements. Building owners may not be able to afford the upfront investment of a renewable energy system. Also, some building owners cannot take advantage of incentives designed to help pay for renewable energy systems. For example, many building owners may not have a big enough tax appetite to take advantage of renewable energy tax credits. These arrangements are an important tool for renewable energy development.

The easiest and perhaps best solution would be to avoid placing any conditions on the ownership of the renewable energy system. This way, the system would simply comply if it is installed on the building and connected on the building-side of the electric meter. Placing conditions on the ownership of the system (or the sale of RECs, etc.) adds complexity and places an additional burden on code officials.

Cons: One downside of allowing third party agreements is that the building owner may not own the renewable energy system, or may eventually sell the building. That is not necessarily bad the system is on the building - but it is an unfamiliar situation and could prove confusing for code officials.

Recommended Approach: Renewable energy requirements should be kept as simple as possible. So, the system should be required to be located on the building site and connected to the building-side of the meter (for electric systems). This should ensure that the building owner either owns, leases, or purchases electricity from the renewable energy system. Also, structuring the requirement in this way minimizes the burden on the code inspector. 


\subsection{Solar-ready requirements}

Many existing buildings have features that add to cost, decrease performance, or prevent the installation of renewable energy systems. Proper building orientation and roof pitch, structural support for renewable energy systems, roof penetrations and chases, space for solar hot water equipment and inverters, and other similar requirements could make it simpler and cheaper to add renewable energy systems at a later time. Solar-ready requirements can be structured in many ways. For example, ASHRAE Standard 189.1-2009 has a mandatory provision requiring that the "building project design shall show allocated space and pathways for future installation of on-site renewable energy systems and associated infrastructure." Note that the requirement falls short of requiring any infrastructure. Solar-ready can also call for the installation of plumbing, electrical conduits or even electrical wiring for PV and solar hot water systems. See the Section 3.0, Summary National and International Precedent, for other renewable-ready examples. Are solar-ready requirements an appropriate first step towards renewable energy requirements?

Pros: Proponents of solar-ready requirements generally agree that solar systems are not costeffective at current energy and renewable energy system costs. (Of course, this is not always the case, especially when considering available incentives.) However, energy prices will increase over time, and renewable energy system costs seem to be decreasing as manufacturers achieve economies of scale and new technologies reduce costs. At some point, there will be a convincing financial case for the majority of building owners to install solar systems. Solar readyrequirements ensure that buildings can accommodate renewable energy systems once they become cost-effective.

Many building owners and designers prefer solar-ready requirements simply because they cost less to meet than installing actual renewable energy systems. As such, they can be viewed as a 'compromise' between advocates of renewable energy requirements and interest groups with cost concerns.

Solar-ready requirements also make designers think about renewable energy systems and possibly incorporate them into standard drawings and procedures. As such, solar-ready requirements prepare the design industry for future prescriptive renewable energy requirements. For example, ASHRAE 189.1's solar-ready requirement may eventually become a requirement for actual renewable energy systems. Requiring the design of space and pathways for the installation of renewable energy systems ensures that architects and engineers consider renewable energy systems as part of their standard design process. Familiarizing designers with these systems may help drive down costs once renewable energy systems are actually installed.

Cons: The shortcoming of solar-ready requirements is that they do not necessarily save or produce any energy. In addition, they impose costs, however minimal, on all buildings, even though many building owners may never take the next step of installing a renewable energy system. Also, it can be argued that solar-ready requirements will not substantially decrease the cost of renewable energy systems installed in future years. It is not an overwhelming burden to install renewable energy systems and associated equipment even in most existing buildings. Moreover, if buildings are pre-wired or pre-plumbed, they may not have the correct wiring or plumbing for systems installed 20 years later, and many engineers or installers would not trust 
wiring or plumbing that has not been used for 20 years, even if mechanical drawings can be found. At this time there is insufficient information available to determine whether solar-ready requirements, either pre-wiring and pre-plumbing or providing chases, conduit, and space, will have a significant effect in encouraging the future installation of renewable energy equipment.

Recommended Approach: Solar-ready requirements are not recommended. Rather, when states are ready, they should go directly to renewable energy option packages or requirements. While solar-ready requirements may be adopted by some states and jurisdictions, it seems unlikely that solar-ready requirements will be widely adopted and taken seriously enough to significantly affect future solar development.

\subsection{Commissioning renewable energy systems}

Building systems, including on-site renewable energy systems, can perform significantly worse than predicted if they are not functioning properly. Many problems and performance issues can be avoided if systems are commissioned before the building is occupied. Commissioning a building or a building system is a process by which the design, installation, and operation of a building or system is verified.

Pros: It is recommended that renewable energy code proposals should, to some degree, require commissioning for renewable energy systems. Commissioning helps avoid underperforming systems that could potentially create a backlash toward renewable energy. In fact, some codes and standards like ASHRAE Standard 189.1 already have provisions for commissioning building systems, including renewable energy systems.

Cons: The downside of commissioning is that it increases the cost of the project. Given the relatively poor economics of many renewable energy systems, added costs could prevent the development of renewable energy systems. Of course, poorly performing renewable energy systems would also have an impact on future development. In addition, it would seem like an unfair burden if renewable energy systems required commissioning but mechanical systems do not (although some codes have commissioning requirements already).

Recommended Approach: At this time, it is not essential to require commissioning of renewable energy systems. However, as commissioning requirements for other mechanical systems are strengthened, renewable energy requirements should eventually include provisions for commissioning the systems. Renewable energy systems are relatively simply compared to building HVAC systems. Therefore, commissioning should be straightforward in most cases and should not add substantially to the project costs. The detail with which renewable energy systems are commissioned may vary based on the technology used and should be determined as renewable energy code proposals are developed.

\subsection{Renovating existing buildings}

In general, model codes and standards require that renovations or alterations to existing buildings comply with the energy code. When alterations are made, sections or components of the building that are not altered do not need to comply with the current energy code. However, there is often confusion over what requirements are triggered when altering a building. There is also a legitimate concern that if compliance with the newest energy code is required when altering a 
building, the building owner may decide not make necessary improvements or investments in energy efficiency.

Discussion: Proposals for new renewable energy code requirements should carefully evaluate how renewable energy requirements would be applied to existing buildings. As an example, if there was a requirement for PV or solar hot water systems in an energy code, what type of (if any) alteration would trigger the requirement in existing buildings? Would repairing the existing roof trigger the solar requirement? After all, the roof would need to have sufficient structure support for a new solar system. Or, if the hot water tank was being replaced, would the solar hot water requirement be triggered? What if the hot water system was being replaced but the roof could not support solar panels?

The examples above illustrate some of challenges that would be encountered when applying renewable energy requirements to existing buildings. Because of these challenges, it is unlikely that any code proposal would intentionally require renewable energy systems when building systems or components are altered. A code proposal could be designed to trigger the requirement if large alterations involving multiple systems (hot water, HVAC, etc.) were planned. But again, triggering the renewable energy requirement must be balanced with the goal of encouraging practical (and affordable) investments in the energy efficiency of the existing building. This issue is not limited to renewable energy requirements. Energy efficiency requirements have become increasingly stringent. Strict energy efficiency (or structural, fire, seismic, etc.) code requirements could also prevent building owners from improving their buildings. One possible solution is to set different requirements in some sections of the code for new and existing buildings. However, these issues are unlikely to be fully resolved, and applying the code to existing buildings will always have inherent challenges.

Recommended Approach: Code proposals should be written such that the renewable energy requirement is leniently applied to existing buildings. Requiring renewable energy systems when sections of buildings or single systems are altered could prevent building owners from upgrading their buildings (and may therefore prevent potential efficiency upgrades). Requiring renewable energy systems during extensive renovations is an option but may also lead to problems. If the renewable energy requirements are not clearly defined for alterations and renovations, it will be the responsibility of the code officials to interpret the code.

\subsection{Public buildings}

Government can serve as a leader by using its own facilities as a model for the community. For example numerous communities throughout the U.S. and across the globe have adopted green building or sustainable design goals for their public buildings. Fewer have adopted renewable energy requirements.

Pros: Government buildings are widely used and visited, and can provide a visible demonstration of the renewable technology to the community and breakdown perceptual barriers. By seeing systems working, residents and businesses may come to view renewable energy as a viable option. Public models can also send a signal to the public of the importance of renewable energy to achieving larger national, energy and environmental goals. In addition, government 
adoption of renewable energy technology can help build markets for renewables that can help drive down costs and provide stability for local suppliers and installers.

Cons: Renewable energy is expensive, regardless of whether it involves private or public funds. Many people may object to their taxpayer money being used on something they regard as too expensive. It is also not a proven fact that visible public projects would encourage wider use of renewable energy in the community or help bring down costs.

Recommended Approach: We recommend that governments require the use of renewable energy on public buildings ahead of adopting such requirements into building energy codes for other (privately-owned) buildings. This is not an essential step, but we believe it would help build experience with renewable energy technology and requirements and help gain public acceptance. We recommend that all levels of government - Federal, state, and local - look to adopt the provisions of high performance green building codes and standards such as ASHRAE 189.1 or the International Green Construction Code (IGCC) as requirements for public buildings, to be rolled out to the public when those requirements are adopted into ASHRAE 90.1 or the International Energy Conservation Code (IECC). That way, public buildings would remain a cycle ahead of code requirements for other buildings.

\subsection{Interfacing with green building rating systems}

Buildings that use green building rating systems such as LEED and Green Globes typically go beyond energy codes. So, if codes begin requiring renewable energy systems, will it affect green building rating systems? Can rating systems give points for measures that are required by code and will there be enough energy measures left over to differentiate between code buildings and 'green' buildings?

Green building rating systems typically use points-based systems to rate buildings, although there are also minimum criteria that must be met. So, if a state adopts a strict code that requires renewable energy, buildings may automatically qualify for some LEED points. There is no inherent problem with this because buildings could still earn additional points by installing a larger renewable energy system than is required by code.

The U.S. Green Building Council develops the LEED tool in a completely separate process from building energy codes. Although the LEED tool may be influenced by tightening energy codes, they would not necessarily need to update the tool if renewable energy requirements were adopted. This is especially true in light of the fact that there will always be a wide variety in the strength of state energy codes.

A separate, perhaps more contentious issue, is whether green rating systems should put more emphasis on renewable energy systems. Currently, LEED-New Construction (NC) awards 1 point if the renewable energy system produces $1 \%$ of the building's energy code and additional points for larger systems. One way that green building rating systems could help prepare designers, engineers, and architects for renewable energy code requirements is to begin requiring a small renewable energy system as one of the minimum mandatory criteria needed to obtain a rating (points would still be given for larger systems). 
Pros: The obvious advantage of this approach is that all rated buildings will have an on-site renewable energy system. A requirement in green codes will serve as a valuable lead-in for mandatory energy codes. It will help prove that renewable requirements are feasible and could provide valuable data regarding how installed costs change when renewable energy is required. It could also help to gauge how strong opposition will be. Green rating systems are a good first step because unlike codes, the rating systems are voluntary, so designers can choose whether or not to pursue the rating. We doubt that a renewable energy requirement in a green building rating system would deter many designers from pursuing a rating - there are many other benefits to obtaining a green rating. Designers and building owners involved in green building rating systems tend to be more willing to make upfront investments in energy efficiency and renewable energy.

Cons: There will likely be opposition to this approach. One of the reasons that green building rating systems are appreciated is that designers are given a variety of options to achieve their desired rating. Requiring renewable energy systems would reduce the available options and may decrease the number of buildings that seek ratings. Furthermore, green rating systems must balance renewable energy with energy efficiency, indoor air quality, water conservation, and many other environmental concerns. Requiring renewable energy may be seen as unfairly favoring renewable energy over the many other components of green buildings.

Recommended Approach: If green building rating systems required small renewable energy systems as one of the minimum criteria, it would likely help model codes standards and states to adopt renewable energy requirements sooner. However, it is not essential for rating systems to require renewable energy. Renewable energy code requirements can still start to be implemented in states and jurisdictions that are more progressive, more willing to advance their building code, and that have better renewable energy resources and higher energy costs.

\subsection{Tradable allowances or offsets}

The Renewable Energy Mitigation Program (REMP) (see Section 3.0, Summary of National and International Precedents, for more information) offers an additional way to implement renewable energy while giving building designers and owners flexibility. The program requires buildings that exceed an 'energy budget' to either purchase renewable energy systems or to pay into a fund. The fund is generally used to pay for energy efficiency grants, although it could also fund renewable energy incentive programs. REMP or similar programs allow building owners that cannot, for whatever reason, install renewable energy systems, to instead help other buildings save energy. These programs are somewhat similar to the purchase of RECs to meet renewable energy requirements; however, the funds are controlled and dispersed locally, rather than going into regional or national RECs markets.

Pros: REMP, similar to the purchase of RECs, allows designers flexibility. Depending on site conditions and expected costs, some sites may decide that paying into the fund is the best option. The other advantage of REMP is that the funds generated are used locally or regionally. Local or state governments likely can choose to use the fund for programs that have the greatest impact.

Cons: One major problem with promoting REMP programs on a large scale is that they cannot easily be written into model energy codes. The issue is that each jurisdiction would likely have 
different ideas about how the REMP funds should be distributed. As a result, each jurisdiction would need to develop the infrastructure to collect and properly allocate funds. Another issue is that requiring some building owners to fund projects on other buildings would undoubtedly be contentious. Energy codes very rarely impose fees based on performance, and adjusting to the new structure would be difficult. The distribution of the funds could also be contentious, with various parties arguing over who should benefit from the fees, although there have been no major problems with this approach in Aspen or Pitkin County, Colorado.

Recommended Approach: We do not think that REMP-style programs should be pursued by model energy codes and standards. However, individual states or jurisdictions may be interested in setting up similar programs. At the least, case studies of the REMP program could be used to help interested states and jurisdictions. If DOE decides to pursue REMP-style programs further, we recommend tasking the national stakeholders forum or other groups with developing a generic REMP-style program for states and jurisdictions to adopt. The program would likely modify and add to the IECC and 90.1. Furthermore, the generic program would develop recommendations as to what amount of resources and staff are needed to run REMP-style programs and how the funds should be allocated.

\subsection{Electrical, plumbing, fire, building, and mechanical code barriers}

There do not appear to be any major code barriers that would undermine the adoption of renewable energy requirements into building energy codes. Initial effort in the 1970s and 1980s was to ensure the safety of renewable energy equipment and address barriers to the use of renewable energy equipment in structural, plumbing, mechanical, electrical, fire, and building codes. It is the authors' opinion that that task has been largely, although perhaps not totally, completed. The National Renewable Energy Laboratory conducted a review of 19 documents published in 2000-2006 to identify non-technical barriers to solar energy use (Griffith et al. 2007). From the summaries provided, only two of the documents mentioned codes and standards as possible barriers. The principle barriers were lack of government policy supporting renewable energy (13 of the 19 reports reviewed); lack of information (12); high costs (10); difficulty overcoming established energy systems (10); financing (10); failure to monetize environmental and other social benefits (8); inadequate workforce skills and training (7); interconnection and net metering (5); and aesthetics and poor public perception (4).

Some new barriers continue to be identified as new technology is developed and deployed, such as fire access and service issues on roofs occupied with renewable energy equipment. These issues must continue to be addressed. However, the barriers generally do not prohibit the use of renewable energy or pose a major barrier to the widespread deployment of renewable energy as some of the earlier barriers posed. As an example, there is some concern about roof-integrated PV systems, where the roof is 'live' and may pose a hazard when firemen respond to a fire. However, these systems are relatively rare compared to other types of building-integrated PV systems, and would not be expected to prevent the adoption of renewable energy requirements in codes.

In addition, all of the code-development organizations have adopted policies to support the use of renewable energy, and procedures are in place to handle and resolve these issues as they come up. 
Recommended Approach: Continue to address concerns through the existing structures and processes as issues arise.

\subsection{Effects of integrating widespread renewable energy with the electric grid}

By regulating certain electric end uses, building energy codes have always had an impact on the electric grid. However, buildings with large electric renewable energy systems can have a significantly different electric demand curve than a typical building. At some parts of the day, when the system is not producing energy, the building may have a load that is just as high as a typical building. However, when the renewable energy system is producing more electricity than the building is consuming, it actually exports electricity onto the grid.

As expected, widespread adoption of on-site renewable energy production could have an impact on the grid's overall electric demand. More importantly, it would impact the shape of the electric load throughout the day. Research has shown that if about $20 \%$ of homes (this study was based on the Western US electric grid) achieve a 'net zero' status with efficiency and on-site PV, the grid would be seriously impacted because the midday demand (when the PV systems peak) would be reduced to below the nighttime demand (Dirks 2010).

Nighttime demand (7:00AM was used in the study) essentially defines the minimum load, which can be met by cheap baseload power. So, at midday, PV generation would start to disrupt baseload generation, replacing it with more expensive peaking and intermediate load plants. While these impacts could be avoided or reduced by varying the design of PV systems and shifting building loads, the research illustrates an important point; caution must be used when designing energy code requirements that may have a substantial impact on the grid. Also, unless electric storage and load shifting becomes more prevalent, there could be a limit to the number of net-energy producing buildings that can be accommodated by the grid.

Interestingly, the research described above may actually provide an argument for adopting renewable energy requirements soon. If small renewable energy requirements are integrated into energy codes now, the overall impact of PV production on the grid will change gradually. Grid operators and utilities will have time to react and re-shape the load using electric storage, load shifting, or by petitioning to change energy codes.

Recommended Approach: The issue is not ripe for resolution at this time. Our only recommendation at this time is to continue to collect data and monitor the situation on a utility, state, and/or national scale. We have no specific recommendation relating to building energy codes. By the time enough on-site renewable energy systems begin to be installed, the issue may need to be revisited with fuller data as to the actual impacts and possible solutions.

\subsection{PV efficiency}

Photovoltaic modules vary in efficiency, depending on the materials used. PV made from lower efficiency materials would produce less electricity per square foot than modules made from materials with higher conversion efficiencies. On what level of PV efficiency should a renewable energy requirement be based? 
Discussion: So long as a renewable energy requirement is small enough that the roof would not need to be filled to capacity with PV, it would not matter whether the requirement assumes highor low-efficiency modules. One could install either to meet the requirement - the array of lower efficiency PV modules would have a larger footprint, but if sufficient area is available it wouldn't matter. Once the requirement becomes large enough, however, only high efficiency cells could fit in the limited space to satisfy the requirement (presuming most systems will be installed on the rooftop). This would help ensure maximum production. However, that would preclude the use of less efficient cells, which may be cheaper per watt, and could be seen as a restraint of trade. Ensuring the requirement remain small enough that either high- or lowefficiency modules could meet it would foster competition, which could help drive innovation or cost reductions or both.

Recommended approach: As renewable energy requirements ramp up in future years, they should not be so stringent as to preclude low-efficiency modules. Requirements should not exceed the maximum production that could be expected from a reasonably available class of low-efficiency modules.

\subsection{Limiting energy use/capacity}

One way to effectively require the use of renewable energy is indirectly by limiting the availability or use of non-renewable energy sources. These may take the form of hard limits on the capacities of equipment so as to ensure that nonrenewable resources are limited. Examples may include limits on the capacity of the electric panel ("amp rationing"), limits on the capacity of standard HVAC equipment (e.g., strict limits on the cooling capacity permitted per square foot of floor area), or limits on the storage volume of hot water. Another option might include charging highly-inverted rates to purchase electricity or natural gas. By limiting access to nonrenewable energy sources, designers will be driven to find ways to meet their power needs, including installation of renewable energy sources and technologies.

Pros: Limiting the use of non-renewable energy could be effective way to reduce energy use. It would force designers to find alternative ways to meet their power needs. Depending how tight the limitation is, it could include the use of renewable energy technologies. The drive for to find alternatives could spur innovation and help reduce costs.

Cons: Limiting the use of non-renewable energy sources will not necessarily lead to the increased use of renewable energy technologies - at least not until such time that the limitations can no longer be easily or affordably met by additional energy efficiency. To the extent it does drive the use of renewable energy, it does not address the issue of what to do if the use of renewables on a particular building is infeasible. Limiting capacity affects peak loads, but doesn't necessarily have the same effect on reducing energy use. Using inverted rates to discourage the use of energy and drive renewables may or may not be reasonable, but is outside the purview of building codes and is not evaluated here.

Recommended approach: This approach is indirect and would not necessarily lead to increased use of on-site renewable energy technologies. If renewables are to be required, the authors would recommend a more direct and transparent approach. 


\subsection{Strategy Discussion}

In order to ensure that future onsite renewable codes are integrated into building codes effectively, national policy measures must align with state initiatives, code development and stakeholder objectives. The following discussion outlines some strategies to consider when implementing onsite renewable code requirements. Generally, the discussion below focuses on national policy-orientated recommendations.

\subsection{Continue to pursue energy efficiency}

One of the strongest arguments against requiring the use of on-site renewable energy systems is that there are often more cost-effective energy efficiency measures available than renewable energy. Building energy codes should incorporate all cost-effective energy efficiency requirements before requiring renewable energy (although an options approach could use renewable energy and energy efficiency measures). Energy efficiency should continue to be aggressively promoted regardless of renewable energy. There should be no appearance that renewable energy is substituting for a being given priority over over energy efficiency. A renewable requirement should be additive or complementary to energy efficiency requirements.

\subsection{Bring Renewable Energy Requirements in Gradually as Returns for Energy Efficiency Diminish}

If code-compliant buildings are to reach very low energy use intensities over the coming decades, renewable energy code requirements will be necessary. Implementing an onsite renewable into the code requirement in the near future will allow the requirement to gradually be strengthened over the next few decades. Code requirements could be a driver for the renewable energy industry, helping to lower costs and improve the economics of renewable energy systems. Additionally, gradual increases could help avoid a shock to the renewable energy or building industries. Renewable energy requirements may be needed in the next few code cycles in order to continue decreasing energy use because prescriptive requirements can only be increased so far. Added efficiency requirements have diminishing returns and at some point in the near future, renewable energy systems may be the most cost-effective proposed code provision.

\subsection{Align and coordinate national policies}

By introducing renewable energy requirements into energy codes, two components of energy policy will begin to overlap: building energy codes and renewable electricity generation. These two policy areas must be aligned and complementary. In addition, it is critical that stakeholders understand that linkage and see renewable energy codes as part of a broader policy goal. DOE will need a simple and compelling explanation why renewable energy should be considered in building energy codes and how it can help meet critical national goals. 


\subsubsection{Utility-scale policy versus distributed renewable energy through building energy codes}

There are many avenues that DOE could use to encourage renewable energy. Using broader utility and grid-scale policies allows utilities and developers to take advantage of economies of scale, likely reducing the installed cost of renewable energy resources. Many feel that this is the proper avenue to spur development of renewables. However, there are also reasons to encourage renewable energy development through building energy codes. For example, building-integrated systems do not use additional land and do support local contractors. Distributed electric generation, like building-integrated PV, avoid transmission losses and may provide additional grid reliability. DOE should articulate the need for both grid-scale policy and renewable energy requirements in building energy codes. DOE needs to demonstrate how utility-scale power is being promoted and that distributed renewable energy through codes is not being promoted at the expense of pursuing utility power. The policies should be viewed as complementary, with building energy codes encouraging small distributed renewable energy while grid-scale policy drives large-scale renewable energy development to help achieve a common national goal.

Currently, many of the advantages of renewable energy are not considered during code development processes. Unless renewable energy code requirements are used as part of a broader renewable energy policy goal, such as a push for distributed or renewable energy generation, it is unlikely that mandatory codes will accept renewable energy requirements until they are consistently cost-effective.

\subsubsection{Financial incentives and other supporting measures and programs}

Experience in Europe suggests that a combination of mutually-supporting strategies provides good results. Spain, for example, requires PV on commercial buildings but 'greases' the requirement with its feed-in tariff. Without similar support, there would likely be a backlash against renewable energy requirements in the U.S., (there are incentives available in the U.S., but they tend to vary by year and location).

Renewable energy systems could certainly be used as part of an 'advanced energy measure' options package without too much resistance. In fact this strategy has been used in the 2012 IECC for commercial buildings, where applicants must choose one option from a menu of several advanced energy measures. When used in an options package, renewable energy systems do not always need to be cost-effective; they simply provide designers with an additional option to consider. However, if prescriptive requirements for renewable energy were introduced into codes, we believe that financial incentives or other support would be necessary to make the requirements palatable (at least for the next few code cycles).

The availability of incentives (e.g., tax credits, sales and property tax exemptions, low-interest loans, utility incentives) will make consideration of renewable energy code requirements more feasible. Without these incentives, the possibility of getting renewable energy requirements into codes and standards will be much more problematic. In addition, incentives for various energy efficiency measures are often withdrawn once the measures are adopted into codes. However, if renewable energy code requirements are adopted based on the availability of incentives for renewable energy technologies, those incentives cannot be withdrawn simply because renewable energy is required by code or their likely would be backlash. The two must be coordinated. 


\subsection{Foster or convene national stakeholders' forum}

It will likely take many years before renewable energy requirements are accepted into mandatory codes. However, over the next few code cycles, there will be a number of small steps towards renewable energy requirements. As such, it is important to have a long-term coordinated effort to progress renewable energy requirements in mandatory codes. We encourage DOE to support a national forum that would foster dialogue between key interests on code requirements to resolve many of the questions identified in Section 6.0, Discussion of Key Issues, and to gain wider acceptance of any renewable energy code requirements. This forum may be separate from or combined with existing code processes. The central goal of the group would be to discuss and eventually write and promote sensible code proposals that move renewable energy requirements forward. See Section 8.0, Plan to Involve Stakeholders, for a more detailed explanation.

ASHRAE and ICC committees have done laudable work on renewable energy requirements to date. However, the committees dealing with potential renewable requirements have many other priorities and may not have the time or the depth of experience needed to continue developing renewable energy requirements. We believe that renewable energy experts and advocates are needed in the discussions on how to address specific issues relating to renewable energy. A separate forum would ensure that adequate time and expertise are dedicated to solving some of the issues we identify in Section 6.0, Discussion of Key Issues. Note that the ICC committees have nothing to do with getting renewables into codes other than voting on specific code change proposals that have renewables included in them. The push to get renewables into the IECC has happened from outside interests and not from within ICC.

Involvement of the national forum could range from a group that DOE bounces ideas off to actually writing code proposals to submit into the ICC and ASHRAE processes. The forum should provide guidance on issues such as:

- The specific numeric requirements to be used in proposals for each code cycle

- How long mandatory codes need to wait until prescriptive requirements are feasible

- If RECs are allowed, the amount required and the allowable certification programs

- The actual language to be used in code proposals.

\subsection{Sequencing renewable energy requirements}

Strict renewable energy requirements in mandatory energy codes will face opposition because of (among other issues) added upfront costs and cost-effectiveness. It is important for DOE as well as ASHRAE and ICC to proceed slowly with renewable energy requirements to avoid a potential backlash. Renewable energy requirements should start small and gradually grow over time. We need to build acceptance rather than grow resentment. It is important to avoid mistakes technological failures, rigid application, or inequities could set back the cause of on-site renewables by years, if not decades.

Fortunately, there are several avenues that can be used to gradually promote renewable energy systems without strict requirements. These avenues include stretch codes and leadership standards. Other avenues include starting with renewable energy systems as part of an advanced energy measures 'options package' before actually requiring systems. 
Currently, stretch codes and standards like ASHRAE 189.1 and IGCC have RE-related provisions. In the near-term, their renewable energy provisions should be strengthened. Also, in order for the renewable energy requirements in 189.1 and IGCC to have any effect on the market, they need to be accepted in more jurisdictions (note that 189.1 is not intended for adoption by jurisdictions but it could be adopted by jurisdictions or adopted voluntarily by organizations, like the Army).

Stretch codes are an appropriate starting point for renewable energy requirements. As renewable energy requirements become more accepted and more cost-effective, the stretch code renewable energy requirements structures should eventually move into mandatory codes and standards (i.e., ASHRAE 90.1 and the IECC). In the near-term, mandatory codes will likely include renewable energy systems as part of a package of options, rather than an actual requirement. In fact, this has already happened in the 2012 IECC. The options in the 2012 IECC include renewable energy systems as well as additional efficiency measures. Because of cost and cost-effectiveness, it is unlikely that mandatory codes will have actual renewable energy requirements in the next few codes cycles. However, there are many 'shades of gray' between the options approach and actual requirements. For example, the other measures in an options package could be strengthened to the point where the many designers will choose the renewable energy option.

Figures 7.1, 7.2, and 7.3, below, show how renewable energy requirements may evolve over the coming decades. Note that there are many possible sequences. However, over time, the requirements will likely move from stretch codes to mandatory codes and from options packages to actual prescriptive requirements.

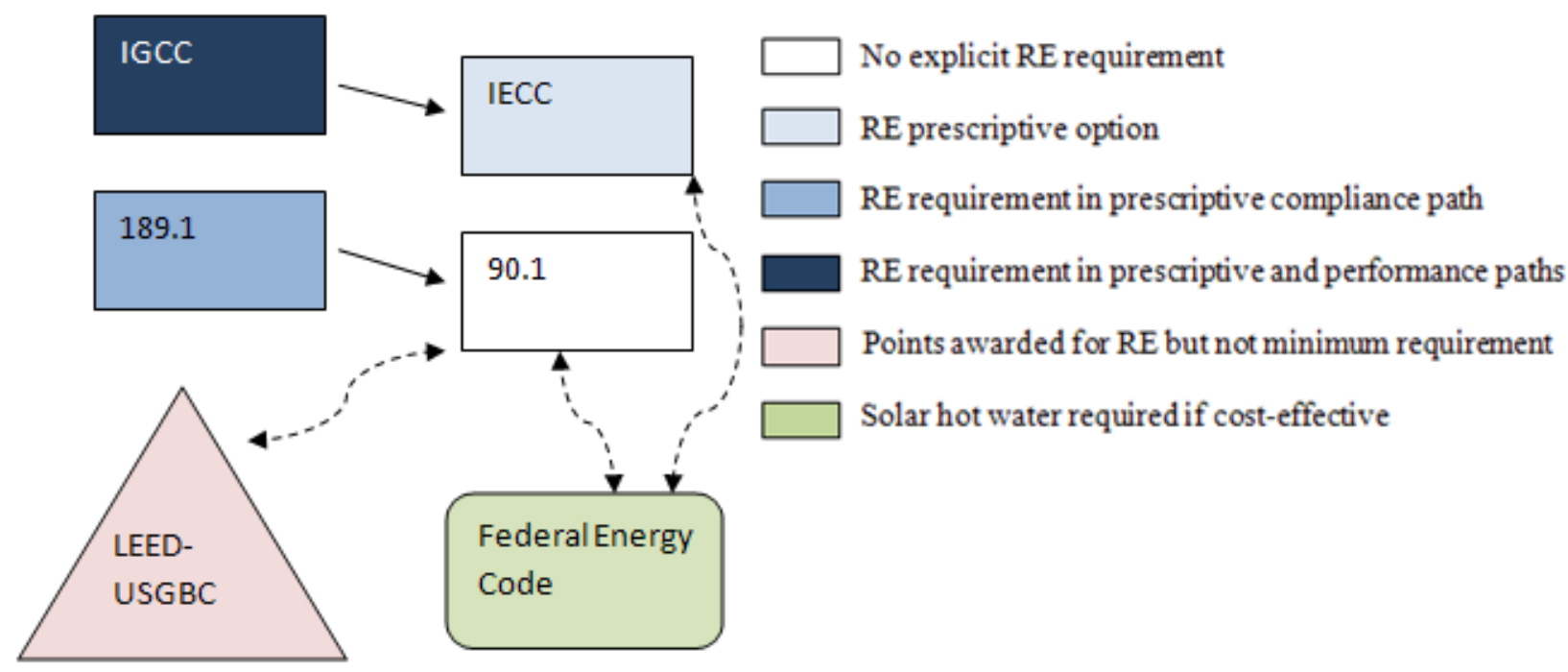

Figure 7.1: Current state of renewable energy requirements 


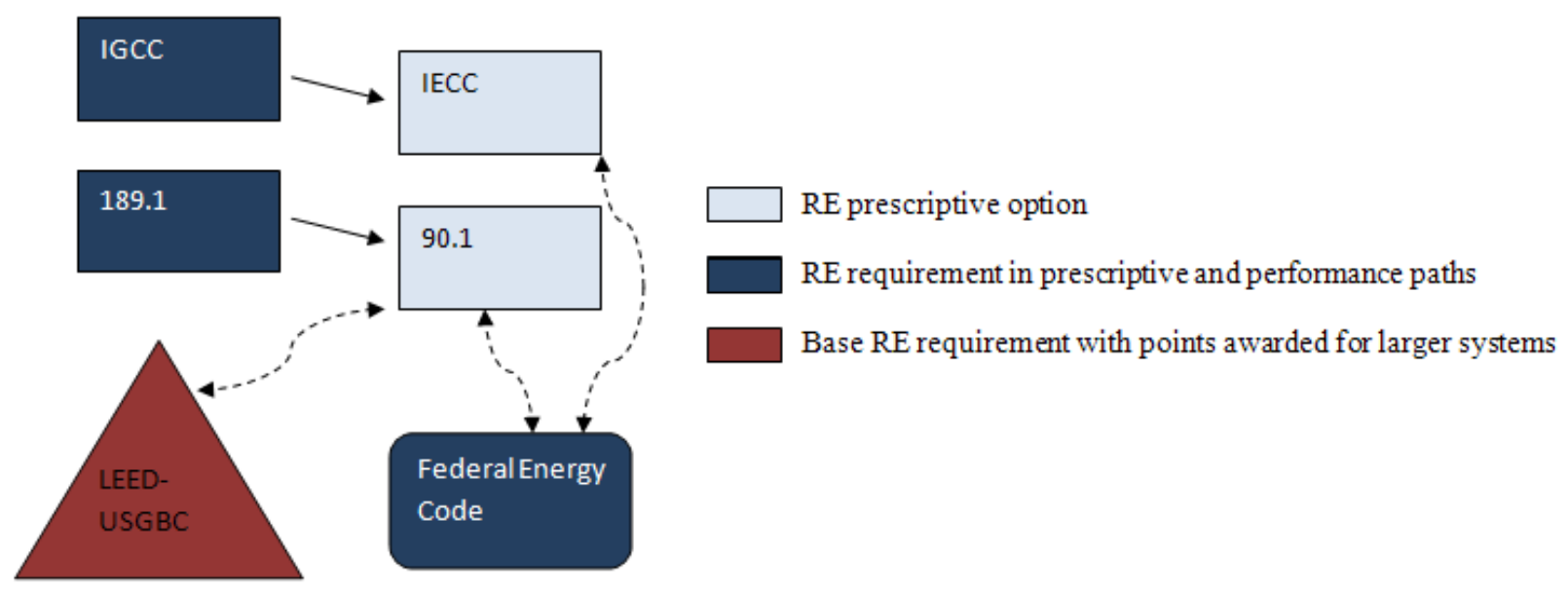

Figure 7.2: Potential near-to-mid-term renewable energy requirements

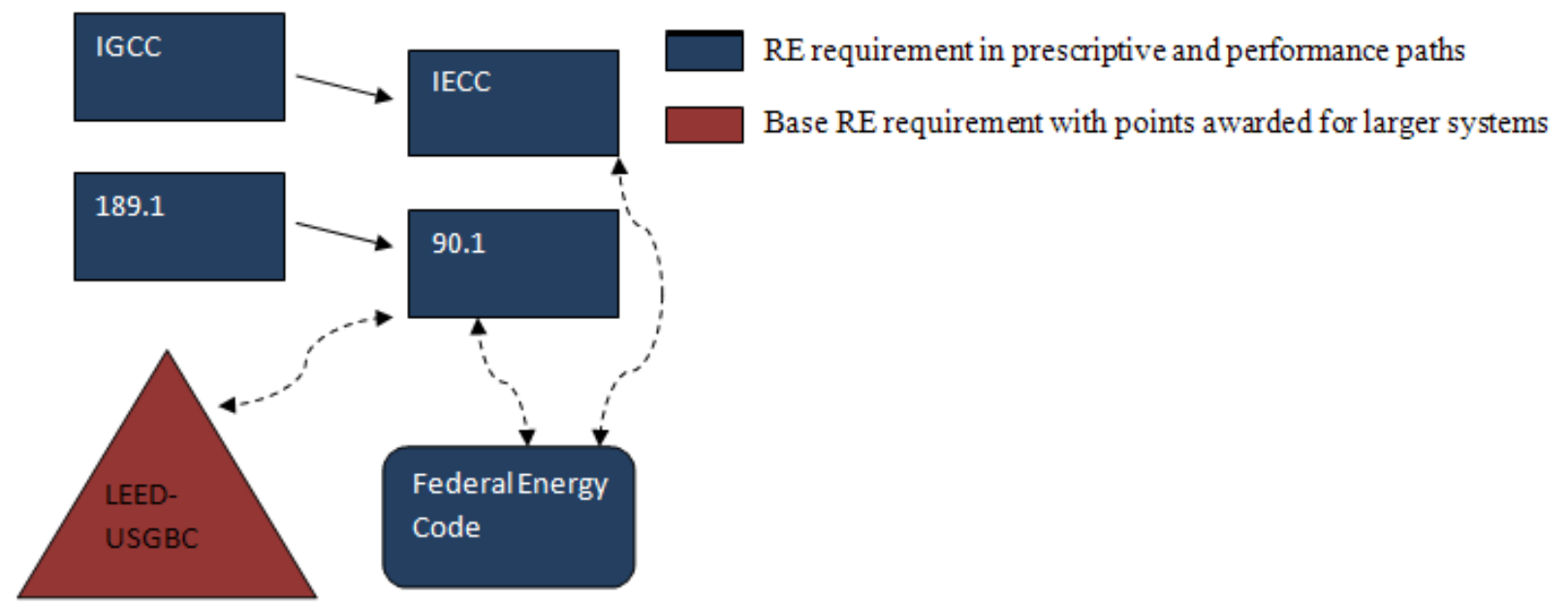

Figure 7.3: Potential long-term renewable energy requirements

Although the general levels of efficiency required by ASHRAE 90.1 and the IECC are quite similar, their code development processes are completely separate, and individual provisions are by no means equal. There should not be an expectation that they will accept equally stringent renewable energy requirements. Also, they will not necessarily accept renewable energy provisions on the same timeline. Although both 90.1 and the IECC tend to become increasingly stringent with each cycle, there are varying approaches and opinions on which measures should achieve new levels of efficiency.

Green building certification systems, such as the USGBC's LEED program, offer an additional path forward. LEED is quite different from codes and standards; it is voluntary and has certification levels based on a point-system. However, it also has what could be described as a 
'soft link' to mandatory codes and standards. For example, LEED uses ASHRAE standards as part of their baseline for energy efficiency. Projects must meet requirements related to ASHRAE 90.1 and points are given for going beyond 90.1. There is no minimum renewable energy requirement, but points are given for renewable energy systems (the larger the system, the more points). So, Standard 90.1 certainly has an effect on the LEED system. For example, if 90.1 were to require renewable energy systems, it would push LEED to increase its minimum requirements. Alternatively, LEED could have an impact on 90.1 (and the IECC). For example, LEED could require renewable energy systems as a minimum requirement for certification. While this would not directly impact mandatory codes and standards, it would demonstrate that renewable energy requirements are possible, and may encourage adoption of renewable energy requirements by 90.1 and the IECC. It may also indicate the amount of resistance that strict renewable energy code requirements in minimum codes and standards would face. Nevertheless, if LEED adopted a minimum renewable energy requirement, it would serve as a valuable guide for codes and standards.

Similar to LEED, the Federal building energy efficiency standards (10 CFR 433 and 10 CFR 435) are influenced by developments in 90.1. It is also influenced by the IECC for the Federal residential code (10 CFR 435). Currently, the Federal building energy efficiency standard is being updated to require solar hot water systems if they are cost-effective. There are also a number of requirements that may indirectly lead to renewable energy development. For example, another pending rule requires increasingly stringent reductions in fossil fuel use in new Federal buildings in the coming decades; eventually, designers may need to install renewable energy systems to help comply with the rule. In the long-term, the Federal building energy efficiency standards may adopt renewable energy requirements, either by adopting model energy codes with renewable energy requirements or by directly adopting renewable energy requirements through a rulemaking process. The key for the Federal building energy efficiency standards is to consider the interaction between renewable energy requirements and the numerous other requirements on Federal buildings and agencies in general. For example, rules already required that a certain amount of each agency's overall electricity use comes from RE. Depending on the stringency and success of those requirements, building-specific renewable energy requirements may not be necessary.

\subsection{Renewable energy technologies}

While there are a handful of renewable energy technologies that can be used in buildings, PV and solar hot water are most likely to be part of a code requirement. Technologies like on-site wind, geothermal electricity and heat, and combined heat and power (CHP) can be implemented. However, these technologies are somewhat rare because of either a lack of resource or, in the case of CHP, because they are only viable in buildings with specific characteristics (i.e., a relatively constant demand for heat and power). We recommend allowing these technologies as part of a performance compliance path. Given the complexity of CHP and geothermal energy systems, it is not unrealistic to expect designers to use the performance approach.

We also recommend separating solar hot water from PV requirements. The main reason is that there are other water heating technologies that could provide the same benefit as solar hot water. 
Like these other technologies (heat pump water heaters, waste water or condenser water heat recovery, etc.) solar water heating reduces the buildings energy load, whereas PV can actually export energy from the building. The renewable energy electric and hot water requirements are discussed further below.

\subsection{Additionality / electric-only requirement}

In the short-term, renewable energy should be an option. In that sense, it is not necessarily additional to the energy savings that might be gained from additional energy efficiency. The benefit of introducing renewable energy in this way is flexibility and building market share to gain experience and reduce costs. However, as energy efficiency options eventually reach diminishing returns, the benefit of renewable energy is to provide additional savings that cannot be achieved by energy efficiency - renewable energy will have to become additional. Solar water heating, daylighting, ground source heat pumps, and other thermal energy options are not additional - for example, solar water heating may not be practicable if one has already installed a heat pump water heater. However, the building will still require electricity for lighting, equipment, and some other uses. Thus to provide additionality, BECP suggests that renewable energy requirements in the long-term will probably have to focus on electricity production. For practical intent that means PV, with other renewable electric systems allowed in lieu of PV.

\subsection{Renewable-ready}

We do not recommend using renewable-ready requirements as an initial step. While some individual buildings may benefit from 'renewable-ready' design, we do not believe it is a worthwhile requirement for all buildings. Renewable-ready requirements impose a cost on buildings that may never install renewable energy systems and will not gain any benefits from the requirement. For this reason, we believe that renewable-ready requirements in mandatory energy codes may cause disdain and be viewed as a waste of resources. In addition, installing renewable energy systems on existing buildings is usually feasible even without renewable-ready features. Lastly, the codes are close enough to renewable energy requirements that renewableready provisions are not really needed; we recommend going straight to requirements. 


\subsection{Recommendations by Sector}

Key findings and recommendations for successfully integrating renewable energy requirements into energy codes are described below. Specifically, recommendations for integrating on-site renewable energy requirements in commercial, residential and public buildings are discussed. The recommendations outlined in this section are intended to help structure and inform future deliberations and foster alignment between DOE, ASHRAE, ICC and other stakeholders.

\subsection{Commercial buildings}

\subsubsection{Renewable electric requirement}

Because there are few technologies besides PV that could meet the renewable energy electric requirement, it may make sense to specifically identify PV.Initially, PV systems would be part of an options package. Eventually (not for a few code cycles), they would become prescriptive requirements.

Different building types must be treated equitably under renewable energy requirements, meaning that the requirement should not put a much larger burden on certain building types. There are several requirement structures that would help maintain a 'level playing field'. In the near-term, when PV is part of an options package, the requirement could be based on conditioned floor area (e.g., installed capacity must be X Watts/ft ${ }^{2}$ of conditioned floor area) or on roof area. If the requirement is based solely on roof area, the multi-story buildings should be required to install more watts per $\mathrm{ft}^{2}$ of roof area than single-story buildings (as an example, the requirements could be $0.75 \mathrm{Watts} / \mathrm{ft}^{2}$ for single-story and $1.0 \mathrm{Watts} / \mathrm{ft}^{2}$ for multi-story).

Requirements could also be based on a combination of building type, roof area, and number of stories as appropriate. In the long-term, if there is a strict PV requirement, it may need to be based only on roof area because strict requirements based on floor area will result systems too large to fit on the roof. One possible alternative, if the requirement is strict enough so that roof space is a problem, is to provide a cap based on the system size as a percentage of roof area. For example, the requirement could be $0.5 \mathrm{Watts} / \mathrm{ft}^{2}$ of floor area or a system that covers $50 \%$ of gross roof area.

Each potential requirement should be closely considered to understand the impacts on various types of buildings. System size relative to roof area must also be considered. The numeric requirements will depend on the intended stringency of the proposal, but they would likely be in the range of between 0.5 and $4 \mathrm{Watts} / \mathrm{ft}^{2}$ of total roof area. Below $0.5 \mathrm{Watts} / \mathrm{ft}^{2}$, many systems will impractically small. Above $4 \mathrm{Watts} / \mathrm{ft}^{2}$, designers will start running into roof space constraints. For similar reasons, requirements based on floor area should be between about 0.15 and $0.5 \mathrm{Watts} / \mathrm{ft}^{2}$ of conditioned floor area.

\subsubsection{Water heating requirement}

Solar water heating can be one of the most cost-effective renewable energy systems. However, the issue with specifically requiring solar water heating is that there are other technologies that could provide nearly identical benefits. As such, we recommend, at least for the next few code cycles, only including solar water heating as part of 'high efficiency water heating options 
package,' and not as an renewable energy prescriptive option. Other high efficiency water heating options may include measures like heat pump water heaters, condenser water heat recovery, desuperheaters, drain water heat recovery, tankless water heaters, and condensing gas water heaters. The solar hot water option would require a certain solar fraction, likely between $30 \%$ and $70 \%$. The solar fraction should be set based on the intended stringency of the requirement and the stringency of the other options.

\subsubsection{Renewable energy certificates (RECs)}

Depending on the structure of renewable energy requirements (see paragraphs below for descriptions), RECs may, at some point in the future, be part of the requirement. If RECs are included, they should be certified according to a nationally accepted program or standard (e.g. Green-e) and they should be purchased before occupancy. While it would be logical to allow building owners to purchase a small amount of RECs each year, it will be very difficult to enforce. Instead, the total amount of RECs should be purchased upfront as suggested by Seattle's code requirement.

Note that using RECs as part of a model code requirement will certainly pose some challenges. Identifying specific certification organizations may be contentious. Experience with RECs in the Federal sector indicates there are significant issues in the RECs markets that need to be addressed prior to a widespread code requirement. Also, most code officials will not be familiar with RECs, so training will be necessary to ensure compliance. Fortunately, RECs will probably not be necessary for at least a few code cycles, when prescriptive requirements are adopted. Beyond that time period, we can learn from jurisdictions that adopt stretch codes like the IGCC and ASHRAE 189.1, which already have provisions that include RECs.

The use of RECs in the code will depend on the requirement structure. In particular, it depends on whether the requirement uses an options approach or a prescriptive requirement.

\subsubsection{OPTIONS APPROACH}

In the near-term, renewable energy systems will mostly be included as part of an options package. As such, there is no need to offer RECs as an alternative for shaded buildings or regions with poor solar resource. Designers can determine whether the solar resource is suitable, and if it is not, they can simply choose a different option.

\subsubsection{PRESCRIPTIVE REQUIREMENT APPROACH}

If renewable energy systems are eventually required, RECs will likely need to be an option for buildings that are shaded or have a poor solar resource (note that we do not expect a prescriptive requirement for at least a few code cycles). We recommend allowing RECs as an alternative to the renewable energy system (rather than allowing RECs as part of an exemption if the site is shaded), but setting the RECs requirement high to encourage installing on-site systems. The amount required should be several times what a code-compliant on-site system would produce over the life of the system, so that RECs do not have a significant cost advantage over on-site systems. This approach encourages most designers to choose the on-site systems, while giving shaded sites an option. It also avoids exemptions for shaded sites, which means that code officials would not need to determine the solar resource or shading of a site. 


\subsubsection{Renewable-ready}

We do not recommend using renewable-ready requirements as an initial step. While some individual buildings may benefit from 'renewable-ready' design, we do not believe it is a worthwhile requirement for all buildings. Renewable-ready requirements impose a cost on buildings that may never install renewable energy systems and will not gain any benefits from the requirement. For this reason, we believe that renewable-ready requirements in mandatory energy codes may cause resentment and be viewed as a waste of resources. In addition, installing renewable energy systems on existing buildings is usually feasible even without renewable-ready features. Lastly, the codes are close enough to renewable energy requirements that renewableready provisions are not really needed; we recommend going straight to requirements.

\subsection{Residential buildings}

\subsubsection{Renewable electric requirement}

Similar to commercial buildings, PV is the only technology that could be consistently be used to meet an electric renewable energy requirement. However, we believe that strict renewable energy requirements are unlikely for residential buildings. Although the required systems would be small, the upfront cost would be a major concern. Also, residential buildings are much more likely to have shading or poor roof orientation. Thus, we recommend that PV be incorporated into energy codes only as part of a package of options. Other options would include measures like condensing furnaces, ground source heat pumps, higher insulation levels, and better glazing. Initially, few designers would choose PV systems. However, over time, the efficiency measures could be strengthened to the point where PV systems become one of the more attractive options.

\subsubsection{Water heating efficiency requirements}

Similar to our commercial recommendation, we recommend that solar hot water requirements be included in a 'high efficiency water heating options package.' The solar hot water option would likely require a certain solar fraction, probably between $30 \%$ and $70 \%$. The solar fraction required will depend on the intended stringency of the requirement and the stringency of the other options. Other options may include measures like heat pump water heaters, desuperheaters, drain water heat recovery, and high efficiency condensing gas water heaters (tank or tankless). Initially, the solar hot water system will likely be much more expensive than other options. However, the options could be strengthened over time to the point where solar hot water becomes attractive.

\subsubsection{Renewable energy certificates (RECs)}

We do not recommend including RECs in any residential energy requirements. Although RECs could be an alternative in the commercial code, we do not expect that the purchase of RECs will be palatable for homeowners. Homeowners will resent having to purchase RECs, which provide no direct benefit to the homeowner. While commercial building owners would oppose the added costs as well, we expect that REC requirements for homes would be more politically explosive. 
RECs alternatives like community solar could be explored for the residential sector. Also, the relatively small amount of RECs required would not justify the added burdens to code officials (for tracking REC purchases, etc.). Lastly, if renewable energy systems are always a part of option packages, there is no need for RECs; sites with shading or poor orientation for solar will simply choose another option.

\subsubsection{Passive solar design}

At this time, we do not recommend pursuing prescriptive requirements for passive solar heating. Passive design should be encouraged where possible, and passive features should certainly receive credit under the performance compliance path. But, while some energy savings are achieved with good solar design and orientation, these measures are very difficult to write prescriptively. Passive solar requirements would place requirements on the amount of glazing on each side of the house. While the requirements could be beneficial, homeowners, buildings, and developers would fight them. There are many cases, such as houses with attractive views or suburban houses in close proximity to neighbors, where glazing and orientation requirements would not be practical. Of course, passive solar design (and passive house standard) would be allowed in the prescriptive compliance path, but they would not receive explicit credit for passive solar design.

\subsubsection{Renewable energy mitigation program (REMP)}

Policies similar to the REMP program, which use fees charged to large inefficient buildings to fund energy efficiency and renewable energy projects, should not be actively pursued by model codes and standards. However, some jurisdictions may want to pursue REMP-style programs. Jurisdictions could study the Aspen and Pitkin County program. Alternatively, if DOE would like to pursue REMP-style programs, the national stakeholders' forum could be asked to develop a generic REMP-style program for interested jurisdictions to adopt as an add-on to a model energy code.

\subsubsection{Renewable-ready}

As for commercial buildings, we do not recommend using renewable-ready requirements as an initial step. In particular, residential buildings tend to have more problems regarding solar potential and shading due to height, roof orientation, proximity of vegetation, and other factors. This reduces the likelihood that a solar-ready requirement will lead to the use of solar energy in the future.

\subsection{Public buildings}

We recommend that public buildings (local, state, and Federal) serve as leaders by adopting onsite renewable energy requirements before they are adopted into mandatory codes for the private sector. Requirements for public buildings will help support renewable energy industries, provide experience for designers and local contractors, overcome public resistance to renewable energy requirements, and serve as a model for private codes. However, requirements for public buildings are not necessarily required to come before mandatory renewable requirements in 
model energy codes. They would serve as useful models, but model energy codes will likely continue to progress regardless of codes for public buildings.

Codes for public buildings could progress in a few ways. Public agencies could write and adopt renewable energy requirements into their existing energy codes. If this is the case, we recommend that they follow similar guidelines as outlined in our recommendations for commercial buildings (Recommendation \#8, above); start with an options approach that includes renewable energy, then progress to prescriptive requirements. Alternatively, local, state, or Federal agencies could simply adopt stretch codes and standards (i.e., the IGCC or ASHRAE 189.1) as they are updated. By adopting stretch codes, public buildings would stay ahead of energy codes for private buildings, which generally adopt ASHRAE 90.1 or IECC (although not always the most recent version). 


\subsection{Plan to Involve Stakeholders}

One of the most important aspects of getting renewable energy requirements into energy codes and standards is obtaining the buy-in of all interested parties in the building sector. Energy codes and standards are consensus documents, with all interested parties having some vote or influence on the development of codes and standards. Renewable energy requirements impact the organizations that develop codes, rate buildings, design buildings, enforce codes, supply power to buildings, own buildings, construct buildings, and promote energy efficiency in buildings. Section 9.1 looks at each of these building industry segments in turn. Section 9.2 outlines a plan for obtaining industry input and buy-in on the requirements proposed in the preceding chapters.

\subsection{Discussion of stakeholders, roles}

There are potentially hundreds of groups and individuals who may have opinions or thoughts on the role of renewable energy requirements in energy codes and standards in the US. Not all groups will be monolithic in the sense of having shared opinions. Because renewable energy requirements are not currently part of energy codes and standards, some groups may not have a formal opinion on this topic one way or another. However, because buildings are being built across the US with renewable energy systems, most groups can be expected to have some familiarity with the issue of renewable energy and how it might impact their particular aspect of the building industry. Putting renewable energy requirements into the national model energy codes and standards should focus their attention on this issue and lead to many insightful comments.

The groups below are listed in the broad categories of "code and standards developing organizations”, "high-performance green building rating organizations”, "professional design organizations”, the "code enforcement community”, "local and state officials”, "utility organizations", the "renewable energy industry”, "energy efficiency/renewable energy advocacy organizations", "builders and contractors”, and "building owners and managers”. Each category of organizations and each individual organization within a category may have a specific relevance to the issue of renewable energy in codes and standards and each individual organization may also have its own opinions on renewable energy.

\subsubsection{Code and Standards Developing Organizations}

The codes and standards developing organizations are those organizations that develop building codes and standards of relevance to the issue of renewable energy in buildings. Obviously, getting any new requirement into the national model codes and standards, including renewable energy requirements, means that the processes and procedures of the targeted code and standard developing organization must be followed and that any concerns that voting members of these organizations may have need to be addressed.

- The American Society of Heating, Refrigerating and Air-Conditioning Engineers (ASHRAE) develops and maintains Standard 90.1, the national model standard for 
energy efficiency in the design of commercial and high-rise multi-family buildings. ASHRAE also develops Standard 189.1, a voluntary standard for high-performance green buildings. ASHRAE's membership includes representatives from building systems suppliers, building designers, advocates for energy efficiency, and users of the codes and standards developed by ASHRAE.

As the developer of Standards 90.1 and 189.1 with co-sponsor Illuminating Engineering Society (IES) (see Section 9.1.3 below), ASHRAE's main interest on renewable energy is how renewable energy requirements can be incorporated into Standards 90.1 and 189.1 and then adopted by states or local jurisdictions. ASHRAE has a work plan to increase the efficiency of Standard 90.1 by 2013 and ASHRAE is also attempting to keep Standard 189.1 "ahead" of Standard 90.1 as a high-performance option.

Standard 90.1 does not currently contain renewable energy requirements, but buildings with renewable energy sources may receive credit for this energy in the whole building performance approaches with Standard 90.1 - the Energy Cost Budget Method and the Performance Rating Method. Standard 189.1 does currently contain renewable energy requirements in the form of an On-Site Renewable Energy Systems requirement for 6.0 $\mathrm{KBtu} / \mathrm{ft}^{2}$ (annual production) of conditioned space. Purchase of Green-e compliant renewable electricity products is also allowed for meeting this requirement.

- The International Code Council (ICC) develops and maintains the International Energy Conservation Code (IECC), the national model code for energy efficiency in the design of low-rise residential buildings and also the national model for energy efficiency in the design of commercial and high-rise multi-family buildings (with a reference to ASHRAE Standard 90.1). The ICC also develops the International Green Construction Code (IGCC), a voluntary code for high-performance green commercial and high-rise multifamily buildings (with reference to ASHRAE Standard 189.1). The ICC also develops a complete family of codes (the international codes or I-codes) that cover all aspects of building design, including structural, fire, ventilation, and many other aspects. The ICC also develops ICC/NAHB 700, a voluntary code for high-performance green low-rise residential buildings. ICC's membership is primarily building officials charged with enforcing the building codes.

As developer of the IECC, IGCC, and ICC/NAHB-700, ICC is interested not only in how renewable energy requirements could be incorporated into codes, but also in how these requirements might be enforced by building officials and the impacts of these requirements on health and life safety. Items of interest include (but are not limited to) how renewable energy requirements impact structures on roofs (which may be subject to wind or seismic loads), how renewable energy systems are interlocked with existing building energy systems and how those renewable systems may be turned off by building officials if required, and how the presence of power generating equipment on buildings or on-site impacts the ability of building officials to isolate the building. Many of these concerns are shared by National Fire Protection Association (NFPA) (see below). 
The latest version of the IECC (the 2012 IECC - currently awaiting publication) contains renewable energy requirements in the form of one part of a three-part option. Buildings may be designed with either lower lighting power density, higher equipment efficiency, or renewable energy in the quantity of $1.75 \mathrm{Btu} / \mathrm{ft}^{2}$ (not less than 0.5 watts) (peak load) of conditioned floor space.

- The NFPA develops fire and life safety codes. NFPA develops a suite of codes that are primarily associated with fire and life safety called the National Codes. NFPA's membership is primarily members of the fire protection services. There is some overlap between NFPA and ICC because ICC utilizes NFPA's "National Electrical Code” as the basis of the International Electrical Code. There is also some overlap between NFPA and ASHRAE because NFPA offers a code called NFPA 900 that includes copies of ASHRAE Standard 90.1 and Standard 90.2 (for low-rise residential buildings).

As the developer of fire, electrical and life safety codes, NFPA has an interest in how renewable energy systems impact the fire and life safety of buildings. Items of interest include (but are not limited to) how renewable energy requirements impact structures on roofs (which may be subject to wind or seismic loads), how renewable energy systems are interlocked with existing building energy systems and how those renewable systems may be turned off by building officials, and how the presence of power generating equipment on buildings or on-site impacts the ability of building officials to isolate the building. Issues of access to buildings through roofs covered with solar PV panels and live electrical wires are of great interest to fire fighters.

Currently, the energy codes developed by NFPA in conjunction with ASHRAE (NFPA 900) do not address renewable energy because ASHRAE Standards 90.1 and 90.2 do not address renewables. NFPA 70, the National Electrical Code (NEC $®$ ), is the most widely adopted code in the world. Article 690 of the NEC ${ }^{\circledR}$, Solar Photovoltaic Systems, specifically addresses the design and installation of photovoltaic systems and equipment, and includes requirements for sizing and protection of circuits, disconnect means, wiring methods, grounding, marking and connections to other sources (www.nfpa.org).

- The International Association of Plumbing and Mechanical Officials (IAPMO) develops and maintains the Uniform Plumbing Code (UPC) and Uniform Mechanical Code (UMC).IAPMO’s 2009 Uniform Solar Energy Code includes the plumbing requirements from the UPC and the electrical requirements from the National Electric Code (NEC) for PV systems. IAPMO also maintains a Green Plumbing and Mechanical Code

Supplement. To the extent that any renewable energy requirements apply to plumbing or mechanical systems (such as solar hot water systems), IAPMO will also be an important target organization.

All of these code development organizations (or at least committees that meet under their umbrella) will be important stakeholders in the process of adding renewable energy requirements to the energy codes. In fact, it is likely that these organizations will be the primary target of DOE's efforts because it will be within their committees that consensus on the content of the national model codes will be achieved. 


\subsubsection{High-Performance Green Building Rating Organizations}

The high-performance green building rating organizations develop rating systems for buildings that are being built "above" or "beyond" energy codes. Whereas energy codes and standards only deal with energy, high-performance green building rating systems typically include not only higher levels of energy efficiency, but also green or sustainable design requirements. The distinction between codes and standards and rating systems is becoming blurred as ASHRAE and ICC develop high performance green standards. The National Residential Green Code, ICC/NAHB-700, looks very much like a rating system.

One key feature of the rating organizations and their rating programs is that users of the rating systems typically pick which items to rate their building on; whereas in codes and standards, there is relatively little choice. Another key feature of these rating programs is that they typically focus on buildings that are being designed or built to be "better than code minimum". High-performance green building rating systems have in the past offered points for renewable energy systems with specific capacities. As codes and standards begin to require renewable systems, there will need to be some modification of the high-performance green building rating systems to require "more renewable energy" or renewable energy with "certain characteristics".

- US Green Building Council (USGBC) develops and maintains the Leadership in Energy and Environmental Design (LEED) rating system.

- Green Building Initiative (GBI) develops and maintains the Green Globes rating system.

While these organizations do not develop energy codes, the requirements they put into their high-performance green building rating systems are often pre-cursors to energy code requirements. These organizations should be invited to participate in any DOE process to develop code change proposals related to renewable energy.

\subsubsection{Professional Design Organizations}

The professional design organizations represent the designers of buildings and building systems. Architects, engineers, and lighting designers are all represented. ASHRAE has a dual role as a developer of codes and standards and a representative of the mechanical design profession. The Illuminating Engineering Society (IES), as co-sponsor of Standard 90.1, also has this dual role. The American Institute of Architects (AIA) is an active participant in the development of the IECC and IGCC and represents the architectural design profession. Designers play an important role in renewable energy because it is the designers who specify what systems and equipment go into building design. Without a designer saying "we need a renewable energy system" or "we can use a renewable energy system" in a particular building, there may be no incorporation of renewable energy systems into the design of a building.

However, renewable energy systems are not necessarily the obvious solution for these design professionals. Renewable energy systems are not necessarily a mechanical system, although the power generated by renewable energy systems may be used by mechanical systems. (Solar hot water systems that are both renewable and mechanical systems are an exception). Renewable 
energy systems are not lighting systems, although the electricity generated by solar photovoltaic (PV) systems may be used in lighting (and the more ardent supporters of solar PV systems on the committee that develops Standard 90.1 tend to be lighting designers). And, renewable energy systems are not part of the building envelope and thus may not get attention from architects. Education of all these disciplines will be needed so that they can do their part in making sure renewable energy systems are included and the energy from those systems is used properly in buildings.

- ASHRAE as a professional design organization tends to focus on mechanical designers who may use renewable energy for cooling and heating of buildings.

- American Institute of Architects (AIA), as a professional design association, focuses on architects who are responsible for the design of the building envelope and who may be responsible for the overall design of the building. Building integrated renewable energy systems can impact the design of the building envelope.

- IES as a professional design organization focuses on lighting designers who may use renewable energy for lighting of buildings. The committee that develops lighting requirements for Standard 90.1 is also responsible for plug loads and power systems in buildings, and renewable energy may be used there as well. Although a lighting design organization by itself may not be a primary target of DOE's stakeholder activities for renewable energy, IES is also a co-sponsor of Standard 90.1 and is therefore a primary target along, with ASHRAE.

- Construction Specifications Institute (CSI) is the organization of designers who write specifications for buildings. Construction specifiers are a secondary target of DOE in this stakeholder effort because DOE ultimately wants renewable energy systems to be as easy to specify, select, and install as any other building systems. CSI plays an important role in the specification and selection steps.

It is the professional design community that will be responsible for implementing the renewable energy requirements in new codes and standards in their building designs. It is imperative that the building design community be actively involved in the development of new renewable energy requirements.

\subsubsection{Code enforcement community}

The code enforcement community consists of organizations whose members are responsible for enforcing building codes. Some organizations focus on only certain codes, while other organizations focus on the whole suite of building codes. The concerns of code officials of all types generally fall under two categories - safety and enforceability. Do the proposed requirements impact the health or safety of the occupants of the building or anyone who might respond to an emergency in the building? Are the proposed requirements enforceable by a code official? Note that all of these organizations listed under "code enforcement" are also listed under "code and standard developers". Organizations that develop codes (with the exception of ASHRAE) tend to also be involved in enforcement, and were described above. They include:

- ICC represents building officials of all types

- NFPA represents fire services officials, including fire chiefs and fire inspectors 
- IAPMO represents plumbing and mechanical officials.

Because it is ultimately the code enforcement community that ensures that energy code requirements are followed, it is imperative that code officials are familiar with and involved in the development of renewable energy requirements. Given the dual roles of these organizations as code developing organizations and organizations of the code enforcement community, there will be some overlap in outreach activities to these organizations. For example, ICC is the developing organization for the IECC, one of DOE's target codes, but it also represents building officials who need to know how to enforce new renewable energy requirements. NFPA is important not only for its National Electrical Code, but also for the fact that it represents fire service organizations that have legitimate concerns about energy producing systems on buildings and the impact of those systems on fire fighting.

\subsubsection{Local, State, and Federal officials}

In the United States, building codes are adopted and enforced at the state or local level. That makes organizations associated with local and state officials an important link in the chain to get new requirements implemented in local and state codes. States and local officials may also be an important factor in getting net metering requirements implemented in their state or locality. (See discussion under Utility Organizations).

- National Association of State Energy Offices (NASEO) represents the state energy offices that are often (but not always) responsible for adoption of building energy codes in their states.

- National League of Cities (NLC) represents the interests of cities. Building energy codes may be adopted at both the state and local level and if state adoption is not an option, city adoption may be an option.

- National Conference of State Legislatures (NCSL) represents the legislatures of states and territories in the U.S. In states where codes are adopted by legislative action, the state legislatures are the driver for adoption of new codes.

- National Governors Association (NGA) represents the governors of states and territories in the U.S. In states where codes are adopted by executive action, governors and their state executive branch are important drivers for adoption of new codes.

- National Conference of States on Building Codes and Standards (NCSBCS) provides a forum for states to exchange information on a variety of building code and standard issues. NCSBCS does have a specific focus on energy efficiency of buildings.

- Individual state or local code agencies are also candidate stakeholders, In particular, California, Oregon, Washington, and Massachusetts have been leaders in energy codes at the state level. Seattle, Boulder, and Austin are examples of local governments that have adopted progressive energy codes.

The above group of organizations may have a role in adopting various requirements, especially for public buildings. They should be informed and used as a deployment mechanism, but probably won't have much of a role in helping to resolve the issues and develop proposals. 
The Federal government also takes an active role in the design and construction of Federal buildings and often plays a prominent role as an "example" for the private sector in terms of adoption of new technologies, including renewable energy. DOE, General Services Administration (GSA), and Environmental Protection Agency (EPA) all play specific roles in this process and all may be considered stakeholders in any renewable energy topic.

- Department of Energy helps develops energy codes and standards for state adoption, writes the Federal building energy efficiency standards, develops new energy efficiency technologies, and provides support to other Federal agencies.

- GSA operates the Office of High-Performance Green Buildings, designs and maintains buildings for many other agencies, and provides support to other Federal agencies. GSA is also specifically tasked with showcasing new technologies for buildings.

- EPA is involved in benchmarking of building energy usage, operates the Energy Star rating system, and provides support to other Federal agencies.

DOE is obviously the sponsor of this work, and staff from DOE will be deeply involved in the development of any proposals on renewable energy that DOE will develop. DOE should also reach out to GSA and EPA on development of renewable energy requirements. DOE has collaborated with EPA previously on code change proposals for the IGCC, so there is some precedence for this type of collaboration.

\subsubsection{Utility Organizations}

One major issue with renewable energy is that it may be available when it is not needed, and therefore, many buildings with renewable energy systems need to feed excess power generated back into the electrical grid. The electrical grid is heavily regulated at the local, state, and regional level, and the issue of "net metering" or the ability to feed power back into the grid is very important for many renewable energy technologies. This means that the local electrical utility becomes a stakeholder of sorts in renewable energy requirements. In the codes world, the Building Energy Code Program (BECP) has also found that whenever electrical utilities are involved, natural gas utilities need to be involved as well, for political reasons if nothing else. The following organizations are likely to have some involvement as utility stakeholders:

- Edison Electric Institute (EEI) represents share-holder-owned electric companies.

- American Gas Association (AGA) represents the interests of natural gas utilities and their customers.

- National Association of Regulatory Utility Commissioners (NARUC) represents state public service commissioners who regulate essential utility services, including net metering.

- Large Public Power Council (LLPC) represents the nation's largest locally-owned, notfor-profit power systems.

The role of utilities is secondary. Utilities need to know that these requirements are being developed, and they need to be informed of progress, but they do not need to be critical players in the development of these requirements. However, utilities do need to be supportive of renewable energy and the associated grid access issues that may arise. 


\subsubsection{Renewable Energy Industry}

The US also has a number of organizations that represent various aspects of the renewable energy industry itself. These are separate from the building industry in that renewable energy does not need to be tied to buildings, but in the case of renewable energy requirements in building energy codes, these organizations should be very supportive stakeholders. Organizations may be national or regional, and focused on one specific renewable energy technology or all technologies. Organizations include:

- American Solar Energy Society (ASES), both thermal and electric divisions

- Solar Energy Industry Association (SEIA)

- Geothermal Energy Association (GEA)

- Interstate Renewable Energy Council (IREC)

- National Electrical Manufacturers Association (NEMA)

- Renewable Energy Marketing Association (REMA).

These organizations can be and should be highly enthusiastic supporters of renewable energy in codes, and will, therefore, be valuable stakeholders in this process. All of these industry organizations can be expected to have their own biases and objectives based on their membership composition, but they can still supply some support for development of requirements. The two organizations listed first, ASES and SEIA, are probably the two most important given the recommended approaches being developed as part of this task.

\subsubsection{Energy Efficiency/Renewable Energy Advocacy Organizations} As a Federal agency, it is not necessarily appropriate for DOE (or its National Laboratories) to lobby states to adopt new codes. Other organizations need to be out there pushing for inclusion of new requirements in codes and standards, and some organization(s) need to be pushing states to adopt those new codes. These organizations are collectively referred to as Energy Efficiency/Renewable Energy Advocacy Organizations. Organizations may be national or regional in scope.

All of these organizations have been involved in advocacy efforts for better codes and adoption of new codes in states. As a general rule, all of these groups are likely to be strong supporters of renewable energy requirements in codes and standards. What they can use from DOE is documentation of the impact of the renewable energy requirements that they can use in their advocacy efforts.

\section{National Groups}

- Alliance to Save Energy (ASE)

- American Council for an Energy Efficient Economy (ACEEE)

- Building Code Assistance Project (BCAP)

- National Resources Defense Council (NRDC)

- Energy Foundation

\section{$\underline{\text { Regional Groups }}$}


- Midwest Energy Efficiency Alliance (MEEA) serves the Midwest states.

- Northeast Energy Efficiency Partnership (NEEP) serves the Northeast and Mid-Atlantic states.

- Northwest Energy Efficiency Alliance (NEEA) serves the Northwest states.

- Southeast Energy Efficiency Alliance (SEEA) serves the Southeast states.

- Southwest Energy Efficiency Partnership (SWEEP) serves the Southwest states.

These organizations are also likely to be very enthusiastic supporters of renewable energy requirements in energy codes. DOE has routinely worked with these groups for many years in developing new code requirements and generating support for those code proposals. NEEA and NEEP in particular have long supported the development of progressive building energy codes in the Pacific Northwest and the Northeast, respectively. SWEEP may have a strong interest in incorporating renewable energy requirements into codes.

\subsubsection{Builders and Contractors}

These organizations include organizations that actually build buildings and building systems. Renewable energy systems are new enough and different enough to potentially require additional training or outreach to organizations of builders and contractors.

- National Association of Home Builders (NAHB) represents many of the homebuilders in the U.S. They are a critical stakeholder that must be included in any discussions on residential renewable energy requirements.

- National Electrical Contractors Association (NECA) represents electrical contractors in the U.S. Any PV requirements will affect them, and they can provide valuable input.

- National Roofing Contractors Association (NRCA) represents roofing contractors. Roofs are ideal places for many solar PV applications, and there is likely to be an impact on roofing contractors because of this.

- Association of General Contractors

These organizations are key stakeholders in the development of renewable energy requirements. The NAHB is sensitive to any requirements that raise the cost of construction of new homes or small commercial buildings, and renewable energy requirements may indeed raise the cost of construction. This is a perspective that must be brought to the table. NECA and NRCA may be less sensitive to cost issues than NAHB, but they will be mindful of how renewable energy requirements can impact their membership. For both organizations, the impacts may be positive.

\subsubsection{Building Owners and Managers}

Last, but not least, are the associations of building owners and building managers. Building owners can exert a large influence on the systems that are included in new construction, and building managers essentially control how buildings are operated. Both of these stakeholder groups can be very important in the success or failure of any building energy code requirement.

- Building Owners and Managers Association (BOMA) represents building owners and building managers. 
- National Multi-Housing Council represents owners, managers, and developers of multifamily apartment buildings.

The building owners and manager are the folks responsible for the cost of building the building and the cost of operating and maintaining the building. With their focus on costs, renewable energy requirements will likely be a tough sell in the short term. DOE should keep them informed of progress and invite their comments on proposals, but DOE should also assume that many of their comments will be negative.

\subsection{Recommended approach interaction with stakeholder involvement}

In Section 7.0, Strategy Discussion, and Section 8.0, Recommendations by Sector, BECP provides recommendations for adding renewable energy requirements to codes. These recommendations are briefly listed in the Table 9.1 below. 
Table 9.1: Impacts of Recommendations on Stakeholder Involvement

\begin{tabular}{|c|c|}
\hline Recommendation & Impact on Stakeholder Involvement \\
\hline 1. Continue to pursue energy efficiency & $\begin{array}{l}\text { Virtually all stakeholders will agree with this } \\
\text { recommendation. }\end{array}$ \\
\hline $\begin{array}{l}\text { 2. Align and coordinate national policies } \\
\text { a. Utility-scale policy versus distributed RE } \\
\text { through building energy codes } \\
\text { b. Financial incentives and other supporting } \\
\text { measures and programs }\end{array}$ & $\begin{array}{l}\text { Virtually all stakeholders will agree with this } \\
\text { recommendation. }\end{array}$ \\
\hline $\begin{array}{l}\text { 3. Foster or convene National Stakeholders } \\
\text { forum }\end{array}$ & This recommendation is discussed in Section 9.3.1. \\
\hline 4. Sequencing Renewable Energy Requirements & $\begin{array}{l}\text { There will be some stakeholders who like this and } \\
\text { others who want to move as fast as possible. } \\
\text { Balancing these two groups will be critical. }\end{array}$ \\
\hline $\begin{array}{l}\text { 5. Bring renewable energy requirements in } \\
\text { gradually as returns for energy efficiency } \\
\text { diminish }\end{array}$ & $\begin{array}{l}\text { This approach is already being taken in the codes } \\
\text { world. See discussions of Standard 189.1, IGCC, } \\
\text { and } 2012 \text { IECC elsewhere in this document. }\end{array}$ \\
\hline $\begin{array}{l}\text { 6. RE technologies - Require separate PV and } \\
\text { solar hot water requirements. Leave wind, } \\
\text { geothermal and CHP to performance paths. }\end{array}$ & $\begin{array}{l}\text { There will be stakeholders associated with wind, } \\
\text { geothermal, and CHP who want the same } \\
\text { "prominence" given to their technologies as to PV } \\
\text { and solar hot water. Explaining why DOE is } \\
\text { focusing on PV and solar hot water will be crucial. }\end{array}$ \\
\hline $\begin{array}{l}\text { 7. Commercial Buildings } \\
\text { a. RE electric requirement } \\
\text { b. Water heating requirement - combine with } \\
\text { other water heating measures } \\
\text { c. RECs - allow use in limited circumstances }\end{array}$ & $\begin{array}{l}\text { These are all specific topics that should be } \\
\text { discussed with the national stakeholder group. } \\
\text { a. There will likely be a diversity of opinion on } \\
\text { the RE electric requirement. } \\
\text { b. There will likely be a lot more consensus on } \\
\text { the water heating requirement. } \\
\text { c. There will be a large diversity of opinion on } \\
\text { the use of RECs. }\end{array}$ \\
\hline
\end{tabular}


Table 9.1: Impacts of Recommendations on Stakeholder Involvement continued

\begin{tabular}{|c|c|}
\hline Recommendation & Impact on Stakeholder Involvement \\
\hline $\begin{array}{l}\text { 8. Residential Buildings } \\
\text { a. RE electric requirement - define as } \\
\text { appropriate } \\
\text { b. Water heating requirement - combine with } \\
\text { other water heating measures } \\
\text { c. RECs - do not allow } \\
\text { d. Passive solar design - do not recommend } \\
\text { but ensure that codes allow }\end{array}$ & $\begin{array}{l}\text { These are all specific topics that should be } \\
\text { discussed with the national stakeholder group. } \\
\text { a. There will likely be a diversity of opinion on } \\
\text { the RE electric requirement. } \\
\text { b. There will likely be a lot more consensus on } \\
\text { the water heating requirement. } \\
\text { c. There will be a large diversity of opinion on } \\
\text { the use of RECs. } \\
\text { d. There will likely be consensus on this } \\
\text { recommendation. }\end{array}$ \\
\hline $\begin{array}{l}\text { 9. Public buildings - could serve a leadership } \\
\text { role. }\end{array}$ & \\
\hline $\begin{array}{l}\text { 10. Renewable Energy Mitigation Program - This } \\
\text { type of approach does not fit within existing } \\
\text { codes and standards, but a generic program } \\
\text { for interested jurisdictions could be developed. }\end{array}$ & $\begin{array}{l}\text { This is a topic that should be discussed with the } \\
\text { national stakeholder group. }\end{array}$ \\
\hline $\begin{array}{l}\text { 11. Renewable Ready Requirement - not } \\
\text { recommended }\end{array}$ & $\begin{array}{l}\text { This is a topic that should be discussed with the } \\
\text { national stakeholder group. There will be } \\
\text { stakeholder groups that like the idea of "renewable } \\
\text { ready" requirements as the first costs may be less. }\end{array}$ \\
\hline
\end{tabular}

Table 9.2 shows the recommended level of stakeholder involvement in DOE's renewable energy proposals for energy codes. Organizations are listed as needed for buy-in, awareness, dissemination, and deployment.

Table 9.2: Level of Involvement of Stakeholder Groups

\begin{tabular}{|l|l|}
\hline Level of Involvement & Example Organizations (by category) \\
\hline $\begin{array}{l}\text { Buy-in (active input on committee or into SDO } \\
\text { process) }\end{array}$ & $\begin{array}{l}\text { ASHRAE, ICC, AIA; USGBC, code advocacy } \\
\text { groups, key states (Calif., Mass.), ASES, SEIA, } \\
\text { FEMP, BOMA, NAHB. }\end{array}$ \\
\hline $\begin{array}{l}\text { Awareness (inform about the process, invite } \\
\text { written comments) }\end{array}$ & Many of the other groups listed \\
\hline $\begin{array}{l}\text { Dissemination (can help notify and disseminate } \\
\text { info to members) }\end{array}$ & All organizations listed \\
\hline $\begin{array}{l}\text { Deployment (responsible for or important to local } \\
\text { adoption) }\end{array}$ & $\begin{array}{l}\text { NASEO, NLOC, NCSL, and other state and local } \\
\text { official organizations }\end{array}$ \\
\hline
\end{tabular}




\subsection{Plan for getting input, buy-in}

BECP recommends a three-pronged approach to getting input and buy-in from these organizations. The three prongs are 1) establishment of a national renewable energy code group to help advise DOE on development of codes and standards, 2) outreach to nationally important groups, and 3) formal training for targeted groups.

\subsubsection{Establish national renewable energy code forum to help develop standards}

With renewable energy being a relatively new topic in energy codes, DOE needs to convene an advisory group of interested stakeholders to help guide the direction of DOE's proposals. This group need not have a formal existence, but DOE does need a group of stakeholders to bounce ideas off of, and that group is probably not the same groups that are involved in discussions of other energy code proposals that DOE may have.

Current code discussions primarily involve professionals with expertise in other aspects of energy efficiency. They may or may not have expertise or even strong interest in renewable energy, and they have many other important issues to consider, so renewable energy may not receive the attention it deserves. In addition, there are stakeholder groups affected by these codes and standards that should probably be included in the dialogue. BECP recommends a forum be established to discuss the key issues, brainstorm possible solutions, and develop proposals for the key code-development organizations. The key organizations for this forum are those listed as having a level of involvement of "buy-in" in Table 9.2.

One group of stakeholders that DOE has not considered before for inclusion in advisory groups like this is DOE's own Federal Energy Management Program (FEMP). FEMP has a number of staff directly engaged in promotion of renewable energy systems for Federal buildings that could provide very useful feedback to BECP. The General Services Administration (GSA) also has staff directly involved in dealing with renewable energy and Federal buildings, and these staff could serve as useful advisors as well.

\subsubsection{Outreach}

DOE needs to conduct outreach on their renewable energy proposals for codes and standards, just like they do on any other topic being proposed for inclusion in codes and standards. This outreach might include presentations on renewable energy requirements to selected forums and making information on renewable energy requirements available on the BECP website (www.energycodes.gov).

\subsubsection{Presentations}

BECP has a task entitled "National Organizations" that provides outreach to national organizations of interest to DOE and energy codes. Many of the organizations listed above as having a stake in renewable energy requirements are also organizations that have a stake in other energy code requirements, and BECP is already targeting them. Renewable energy should become one more topic of discussion with these organizations. 
It may be that some of the organizations listed above are not part of the current national organizations list and these organizations will need to be targeted separately. The same approach used in the National Organizations task (offering to deliver targeted information presentations to national gatherings of targeted organizations) can be utilized. Topics of interest to specific groups of stakeholders may be identified from Table 9.2.

\subsubsection{Information}

An approach BECP uses for all code requirements, but especially for new requirements such as renewable energy requirements, is to post relevant information on the BECP website (www.energycodes.gov). This information could take many different forms, such as CodeNotes or special webinars on renewable energy requirements and technologies. There may already be information on the DOE FEMP website related to renewable energy technologies that could be referenced as well. BECP should regularly send information items on renewable energy requirements to all the organizations discussed in Section 9.1 and ask that the information be disseminated to their membership. BECP may also consider developing organizational-specific information items that can be more easily disseminated to members of these organizations.

\subsubsection{Formal training}

Formal training on energy code requirements is usually only required for members of the design community (who actually design buildings) or the code enforcement community (who enforce building codes and standards). All other organizations may be recipients of informational presentations, but only the design and enforcement communities need to know the "nuts and bolts" of the new requirements. BECP has a long history of providing training and training materials for both these groups and BECP will seek out opportunities to specifically address renewable energy requirements once those requirements are in place in energy codes and standards. The first opportunity to do this will likely be in association with the 2012 IECC, which will be considered by many states and local jurisdictions for adoption.

\subsubsection{Schedules}

Schedules for outreach are dependent on when DOE wishes to start reaching out to stakeholders on renewable energy issues. Two of DOE's target codes and standards for renewable energy requirements are Standard 90.1-2013 and the 2015 IECC. The following dates related to those codes and standards are more or less set in stone, and DOE can plan its outreach activities for the next few years based on these dates:

June 20112012 IECC published

May 2011 DOE Draft Renewable Energy White Paper Available

June 2011 DOE performance-based continuous maintenance proposal (CMP) to Standard 90.1-2013

January 2013 Code change proposals for 2015 IECC due

October 2013 Standard 90.1-2013 published

April 20142015 IECC published

Many of the stakeholder organizations discussed above have annual conferences that could also be targeted for presentations. BECP's National Organizations task makes it a point to get on the agenda for these conferences, and renewable requirements could be part of the presentations 
made at these conferences. Topics of interest to specific groups of stakeholders may be identified from Table 9.2. 


\subsection{References}

Dirks, JA. 2010. “An Exploration of Impacts of Wide-Scale Implementation of Net Zero-Energy Homes on the Western Grid.” PNNL-19693. Pacific Northwest National Laboratory, Richland, WA.

Griffith, B, N. Long, P. Torcellini, and R. Judkoff. "Assessment of the Technical Potential for Achieving Net-Zero Energy Buildings in the Commercial Sector.” National Renewable Energy Laboratory. Technical Report NREL/TP-550-41957, December 2007. www.nrel.gov/docs/fy08osti/41957.pdf

Kreutzmann, A. (February 2008). “Solar modules in 2008.” Photon International, pp.126-135.

Margolis, R. and J. Zuboy. 2006. "Nontechnical Barriers to Solar Energy Use: Review of Recent Literature.” Technical Report NREL/TP-520-40116, National Renewable Energy Laboratory, Golden, Colorado. September. www.nrel.gov/docs/fy07osti/40116.pdf (Accessed May 2011) Renewable Energy Policy Network for the 21st Century (REN21). (2008). Renewables 2007 Global Status Report 2007. Paris: REN21 Secretariat. www.ren21.net/publications. Accessed May 2011.

U.S. Department of Energy. "Energy Efficiency Trends in Residential and Commercial Buildings.” Energy Efficiency and Renewable Energy Division. October, 2008. apps1.eere.energy.gov/buildings/publications/pdfs/corporate/bt_stateindustry.pdf (accessed May, 2011)

Solar Energy Industries Association (SEIA) 2010. "U.S. Solar Market Insight, 2010 Year in Review: Executive Summary.” Copyright 2010 SEIA/GTM Research. http://www.seia.org/galleries/pdf/SMI-YIR-2010-ES.pdf (accessed May, 2011)

Wilson, Alex 2009. “The Folly of Building-Integrated Wind.” Published in Volume 18 of Environmental Building News by BuildingGreen.com. May 2009. http://www.buildinggreen.com/auth/article.cfm/2009/4/29/The-Folly-of-Building-IntegratedWind/

Wiser, Ryan, Mark Bolinger. Peter Cappers, and Robert Margolis. 2006. "Letting the Sun Shine on Solar Costs: An Empirical Investigation of Photovoltaic Cost Trends in California.” LBNL59282. Lawrence Berkeley National Laboratory, Berkeley, California. 


\title{
11.0 Acronyms of Organizations Referenced in This Report
}

\author{
ACEEE American Council for an Energy Efficient Economy \\ AGA American Gas Association \\ AIA American Institute of Architects \\ ANSI American National Standards Institute \\ ASE Alliance to Save Energy \\ ASES American Solar Energy Society \\ ASHRAE American Society of Heating, Refrigerating and Air-Conditioning Engineers \\ AWEA American Wind Energy Association \\ BCAP Building Codes Assistance Project \\ BOMA Building Owner and Managers Association \\ CMP Continuous Maintenance Proposal \\ DOE U.S. Department of Energy \\ EEI Edison Electric Institute \\ EPA U.S. Environmental Protection Agency \\ FEMP Federal Energy Management Program \\ GEA Geothermal Energy Association \\ GBI Green Building Institute \\ GSA U.S. General Services Administration \\ IALD International Association of Lighting Designers \\ IAPMO International Association of Plumbing and Mechanical Officials \\ ICC International Code Council \\ IES Illuminating Engineering Society \\ IREC Interstate Renewable Energy Council \\ LPPC Large Public Power Council \\ MEEA Midwest Energy Efficiency Alliance \\ NARUC National Association of Regulatory Utility Commissioners \\ NASEO National Association of State Energy Offices \\ NCSBCS National Conference of States on Building Codes and Standards \\ NHA National Hydropower Association \\ NEEA Northwest Energy Efficiency Alliance \\ NECA National Electrical Contractors Association \\ NEMA National Electrical Manufacturers Association \\ NBI New Buildings Institute \\ NCSL National Conference of State Legislatures \\ NEEP Northwest Energy Efficiency Partnership \\ NFPA National Fire Protection Association \\ NGA National Governors Association \\ NHA National Hydropower Association \\ NLC National League of Cities \\ NMHC National Multi-Housing Council \\ NRCA National Roofing Contractors Association \\ NREL National Renewable Energy Laboratory \\ NRDC Natural Resources Defense Council
}


REMA Renewable Energy Marketing Association

SEEA Southeast Energy Efficiency Alliance

SEBANE Solar Energy Business Association of New England

SEIA Solar Energy Industries Association

SWEEP Southwest Energy Efficiency Partnership

USGBC US Green Building Council 


\section{APPENDIX A}

Annotated Bibliography of National/International Precedents 



\section{Appendix A: Annotated Bibliography of National/International Precedents}

\section{A1 National model codes and standards}

Text included below are excerpts from actual code documentation.

\section{A1.1 ASHRAE Standard 189.1}

American Society of Heating, Refrigerating and Air-Conditioning Engineers, Inc. (ASHRAE) Standard 189.1. Standard for the Design of High-Performance Green Buildings Except Low-Rise Residential Buildings. Atlanta, 2010.

In June, 2010, the ASHRAE 189.1 committee approved changes to the renewable energy requirements of Standard 189.1. ("Proposed Addendum f to Standard 189.1-2009 Standard for the Design of High-Performance Green Buildings," Public Review Draft, First Public Review (September, 2010). Changes to the current standard are indicated by underlining (for additions) and strikethrough (for deletions).

Users must meet the mandatory provision (7.3.2) and either the Performance Option (which is performance based and does not include a specific renewable energy requirement) or the Prescriptive Option (7.4.1.1, below).

\section{Mandatory}

"7.3.2 On-Site Renewable Energy Systems. Building project design shall show allocated space and pathways for future installation of on-site renewable energy systems and associated infrastructure Building projects shall provide for the future installation of en-site renewable energy systems with a minimum rating of $3.7 \mathrm{~W} / \mathrm{ft}^{2}$ or $13 \mathrm{Btu} / \mathrm{h} / \mathrm{ft}^{2}(40$ $\left.\mathrm{W} / \mathrm{m}^{2}\right)$ that provide the annual energy production equivalent of not less than $6.0 \mathrm{kBtu} / \mathrm{ft}^{2}$ $\left(20 \mathrm{kWh} / \mathrm{m}^{2}\right)$ for single story buildings and not less than $10.0 \mathrm{kBtu} / \mathrm{ft}^{2}\left(32 \mathrm{kWh} / \mathrm{m}^{2}\right) . "$ multiplied by the total roof area in $\mathrm{ft}^{2}\left(\mathrm{~m}^{2}\right)$ for all other buildings. multiplied by the total roof area in $\mathrm{ft}^{2}\left(\mathrm{~m}^{2}\right)$. Building projects design shall show allocated space and pathways for installation of on-site renewable energy systems and associated infrastructure.

"Exception: (1) Building projects that have an annual daily average incident solar radiation available to a flat plate collector oriented due south at an angle from horizontal equal to the latitude of the collector location less than $4.0 \mathrm{kWh} / \mathrm{m}^{2} /$ day, accounting for existing buildings, permanent infrastructure that is not part of the building project, topography or trees., are not required to provide for future on-site renewable energy systems."

\section{(2) Building projects that comply with Section 7.4.1.1.”}

Prescriptive option

“7.4.1.1 On-Site Renewable Energy Systems. Building projects shall contain on-site renewable energy systems that provide the annual energy production equivalent of 6.0 
$\mathrm{KBtu} / \mathrm{ft}^{2}\left(20 \mathrm{kWh} / \mathrm{m}^{2}\right)$ multiplied by the total roof area in $\mathrm{ft}^{2}\left(\mathrm{~m}^{2}\right)$ of conditioned space-for single story buildings and not less than $10.0 \mathrm{kBtu} / \mathrm{ft}^{2}\left(32 \mathrm{kWh} / \mathrm{m}^{2}\right)$ multiplies by the total roof area in $\mathrm{ft}^{2}\left(\mathrm{~m}^{2}\right)$ for all other buildings. The annual energy production shall be the combined sum of all on-site renewable energy systems."

"Exception: Buildings that demonstrate compliance with both of the following are not required to contain on-site renewable energy systems:

1. "An annual daily average incident solar radiation available to a flat plate collector oriented due south at an angle from horizontal equal to the latitude of the collector location less than $1.36 \mathrm{kBtu} / \mathrm{ft}^{2} /$ day $\left(4.0 \mathrm{kWh} / \mathrm{m}^{2} /\right.$ day $)$, accounting for existing buildings, permanent infrastructure that is not part of the building project, topography and trees, and

2. "A commitment to purchase of renewable electricity products complying with the Green-e Energy National Standard for Renewable Electricity Products of at least 7 $\mathrm{kWh} / \mathrm{ft}^{2}\left(75 \mathrm{kWh} / \mathrm{m}^{2}\right)$ of conditioned space each year until the cumulative purchase totals $70 \mathrm{kWh} / \mathrm{ft}^{2}\left(750 \mathrm{kWh} / \mathrm{m}^{2}\right)$ of conditioned space.”

Van Geem, Martha. "Options and Opportunities for Onsite Renewable Energy Integration Renewable Ready." Statement before the Committee on Science and Technology, U.S. House of Representatives. November 15, 2010. http://science.house.gov/hearing/energy-and-enviornmentsubcommittee-hearing-renewable-energy-integration (accessed May 2011). Van Geem is a member of the ASHRAE Standards Project Committee (SPC) responsible for development of ASHRAE Standard 189.1. This testimony provides background on development of the renewable energy requirement in ASHRAE Standard 189.1.

\section{A1.2 International Green Construction Code (IGCC)}

International Code Council (ICC). International Green Construction Code, Public Version 1.0. March, 2010. http://www.iccsafe.org/cs/IGCC/Pages/default.aspx (accessed May 2011)

Section 611, Building Renewable Energy Systems, requires that:

- A renewable energy system is defined as a system that derives its energy from "solar radiation, wind, waves, tides, landfill gas, biomass, or the internal heat of the earth."

- "Buildings and surrounding property or building sites when there are multiple buildings on the building site" ... "shall be equipped with one or more renewable energy systems that have the capacity to provide not less than two percent of the total calculated annual energy use of the building(s) or ... have a rating of at least $1.75 \mathrm{Btu} / \mathrm{hr}$ or $0.50 \mathrm{~W} / \mathrm{ft}^{2}$ or at least 0.50 watts per square foot of conditioned floor area... .” If the renewable energy system is a solar water heating system, it shall be capable of meeting at least 10 percent of the building's annual estimated hot water energy usage. Exceptions are permitted where:

o “... at least four percent of the total annual building energy consumption from renewable generation takes the form of a five-year commitment to renewable energy credit ownership, confirmed by the code official"; or

o Shading of a photovoltaic or solar water heating system is greater than 50 percent 
o Solar insolation is less than $4 \mathrm{kWh} / \mathrm{m}^{2} /$ day for a photovoltaic system, or 3.5 $\mathrm{kWh} / \mathrm{m}^{2} /$ day for a solar water heating system.

0 Average annual wind speed is less than $14.5 \mathrm{mph}(6.5 \mathrm{~m} / \mathrm{s})$ where measured at the 80-m (262 ft) height or in areas having a wind power classification of Class 3 or less where measured at the 50 -m (164 ft) height.

- Renewable energy systems shall be metered and monitored separately from the building's electrical meter.

- Some installation and other requirements are provided for solar photovoltaic systems, solar water heating systems, and wind energy systems.

- NOTE: Solar thermal and other renewable energy systems are allowed under Section 611.6, which is not included. It is unclear whether this includes daylighting, biomass, or geothermal heat pumps. It is also unclear what an applicant is to do if photovoltaic, wind, and solar water heating are not available because of the exceptions. Must the applicant install another system?

Section 603, Energy Use and Atmospheric Impacts, allows any "energy savings from renewable energy derived on site" to be deducted when calculating building total annual net energy use (TANEU). The intent is to encourage the use of on-site renewable energy systems.

Sec. 608, Building Service Water Heating Systems, requires that:

- Pools located in conditioned spaces meet at least 25\% of design annual energy use and $50 \%$ of peak design for HVAC in the conditioned space with either an on-site renewable energy system or a heat recovery system.

- $\quad$ Snowmelt systems supplement at least $25 \%$ of design annual energy use and $50 \%$ of design peak load with either an on-site renewable energy system or a heat recovery system.

- Plumbing and electrical systems provide be pre-wired and pre-plumbed for the future installation of a solar water heating system that will be capable of providing at least $50 \%$ of the energy needed for service water heating (kitchen, laundry, bath), and pool, spa and hot tub water heating.

- $\quad$ Space for a future storage tank, large enough for a solar thermal system sized to provide $50 \%$ solar fraction, shall be identified and reserved.

\section{A1.3 International Energy Conservation Code (IECC)}

The 2012 International Energy Conservation Code is being amended along the lines of the Oregon residential energy code, except that it applies only to commercial buildings and multifamily buildings four-stories or taller. In addition to the mandatory requirements of the IECC, applicants must choose one of three prescriptive options: high-efficiency equipment, highefficiency lighting, or the renewable energy requirements below. The amendment would require installation of an on-site renewable energy system that provides not less than 1.75 Btus or 0.50 watts per square foot of conditioned floor area, or not less than $3 \%$ of the energy used within the building for building mechanical and service water heating equipment and lighting. 
506.4 On-site renewable energy. Total minimum ratings of on-site renewable energy systems shall comply with one of the following:

1. Provide not less than 1.75 Btus, or not less than 0.50 watts, per square foot of conditioned floor area.

2. Provide not less than $3 \%$ of the energy used within the building for building mechanical and service water heating equipment and lighting regulated in Chapter 5.

\section{A1.4 National Green Building Standard}

National Association of Home Builders, International Code Council, American National Standards Institute. “National Green Building Standard"TM”: ICC 700-2008.” NAHB, 2009.

The "National Green Building Standard" applies to residential buildings only. It is a point system with four performance levels - Bronze, Silver, Gold, and Emerald - across seven categories. Points are provided for several renewable energy options, but there are no mandatory renewable energy provisions.

\section{A1.5 New Buildings Institute Core Performance Guide}

The New Buildings Institute has developed Advanced Buildings Core Performance Program establishing a prescriptive guideline for small and medium-sized commercial buildings. The USGBC has adopted the Core Performance Program into its LEED NC program in lieu of modeling to demonstrate compliance with Energy \& Atmosphere (EA) Credit 1, Optimize Energy Performance. Chapter 5 of the 2009 IECC code, which was the basis for the Massachusetts "Stretch Code," is also developed on NBI's Core Performance program. On-site renewable energy to supply 10 percent of more of building electric or thermal loads is included as an enhanced performance option.

New Buildings Institute. Advanced Buildings Core Performance Guide. July 2007. http://www.advancedbuildings.net/tools-guidance/core-performance (accessed May 2011)

\section{A1.6 National Renewable Energy Laboratory}

Lissell, L., T. Tetreault, and A. Watson. "Solar Ready Buildings Planning Guide.” National Renewable Energy Laboratory, December 2009. NREL/TP-7A2-46078, www.nrel.gov/docs/fy10osti/46078.pdf. This document identifies the important aspects of building design and construction to enable installation of photovoltaic, solar hot water, and solar ventilation preheat systems at some time after the building is constructed. Buildings that are solar ready will be in a position to take advantage of an environment more favorable to renewable energy. Installation efficiency can be maximized and costs minimized by understanding these systems' requirements and accounting for them during the design and construction of the building. Solar installation on buildings that are not solar ready may not be technically possible, or the added costs of making infrastructure changes may make solar applications economically prohibitive. The Guide discusses the issues that should be considered at the time of design and construction that will help ensure a building can accommodate solar energy technologies at a future date as the technologies become cost-effective. It deals with issues such as location to avoid shading, roofing materials, roof and wind loading, plumbing and/or wiring chases, and 
other considerations. It is not written in code language or format, so may not be directly useful for code purposes.

Margolis, R. and J. Zuboy. Nontechnical Barriers to Solar Energy Use: Review of Recent Literature. National Renewable Energy Laboratory, Technical Report NREL/TP-520-40116, September 2006. www.nrel.gov/docs/fy07osti/40116.pdf. NREL reviewed 19 documents published since 2000 to identify nontechnical barriers to solar energy use. From the summaries provided, only two of the documents mentioned codes and standards as possible barriers. The principle barriers were: lack of government policy supporting renewable energy (13); lack of information (12); high costs (10); difficulty overcoming established energy systems (10), financing (10); failure to monetize environmental and other social benefits (8); inadequate workforce skills and training (7); interconnection and net metering (5); and aesthetics and poor public perception (4).

\section{A1.7 International Association of Plumbing and Mechanical Officials, Uniform Solar Energy Code}

International Association of Plumbing and Mechanical Officials (IAPMO). 2009 Uniform Solar Energy Code. www.bookmarki.com/2009-Uniform-Solar-Energy-Code-p/14-091.htm. IAPMO adopted a Uniform Solar Energy Code in 1976, and updates it every three years. It is developed under the ANSI consensus standard process, and applies to the erection, installation, alteration, repair, replacement, addition to, use or maintenance of solar energy systems.

Dunlop, James. “Licensure and Qualifications for Solar Energy System Installations.” IAEI Magazine Online, September 2008. www.iaei.org/magazine/?p=471. "While both classes of solar energy systems are often associated, they are very different types of energy systems. Solarthermal system installations require plumbing skills and are dictated by plumbing codes; while PV system installations require electrical skills and are governed by electrical codes. General building construction skills are required for the structural installation of either PV arrays or solar thermal collectors, and when installed on buildings and rooftops, roofing and weather-sealing skills are also required. Most solar energy systems are not fully integrated, listed equipment like a plug-and-cord appliance that can be simply installed by the consumer. Rather they are a fieldassembly of electrical components and hardware subjected to building codes and construction standards and their installation is considered a skilled craft trade that should be performed by properly trained, qualified journeypersons and licensed contractors.”

"Presently there are a dozen or more states that have addressed solar installations from a regulatory perspective, including Arizona, California, Colorado, Connecticut, Florida, Hawaii, Maine, Michigan, Nevada, New Jersey, Oregon, and Utah. ... With a couple of exceptions, these states have independently addressed solar-thermal installations under the plumbing trade, and PV systems under the electrical trade.”

"The North American Board of Certified Energy Practitioners (NABCEP) offers an independent certification for PV system installers; however, it is not a governmental license or endorsement to engage in trade practice or contracting. Candidates for this certification qualify based on documented PV systems installation experience and training, must pass a 4-hour 60-question examination, sign a code of ethics, and maintain practice and continuing education for re- 
certification every three years. A job task analysis for PV installations has been developed by NABCEP, and is the basis for the certification program and examination content. While intended as a voluntary, value-added credential, NABCEP certification is becoming increasingly important to participate in this industry. For example, Maine and Ohio both require NABCEP certification to become eligible for state rebate funds, and Utah requires the certification to qualify for their solar contractor license. Numerous specifications are now requiring the bidder to retain or employ a NABCEP-certified individual on the project. However, not all NABCEP certificants are legally licensed and entitled to pull permits and engage in construction contracting. Many are architects, engineers, educators, salespersons, journeypersons or others who may be integrally involved with PV projects, and may work with or for contractors or integrators, but are not contractors themselves.” www.nabcep.org

\section{A1.8 National Fire Protection Association, NEC 690}

The National Fire Protection Association (NFPA) maintains 300 safety codes and standards. NFPA70, the National Electrical Code (NEC®), is the most widely adopted code in the world. Article 690 of the NEC®, Solar Photovoltaic Systems, specifically addresses the design and installation of photovoltaic systems and equipment, and includes requirements for sizing and protection of circuits, disconnect means, wiring methods, grounding, marking and connections to other sources. www.nfpa.org

\section{A2 State Requirements}

\section{A2.1 California Green Building Code (CALGREEN)}

California has a state building code, commonly referred to as Title 24. Local jurisdictions may adopt additional requirements. To ensure some level of consistency, and to make it more likely that jurisdictions will adopt "beyond code" requirements by saving them the effort of developing their own standards, the California Building Standards Commission developed the California Green Building Code as a model for local jurisdictions. Unlike Massachusetts, where jurisdictions must adopt the state model "stretch code" if they wish to adopt additional requirements, code jurisdictions in California may modify the recommended CalGreen standards or adopt something entirely different.

http://www.bsc.ca.gov/CALGreen/default.htm (accessed May 2011)

http://www.bsc.ca.gov/CALGreen/greencode.htm (accessed May 2011)

\section{RESIDENTIAL Voluntary MEASURES}

CalGreen provides two levels of compliance for energy efficiency. Tier 1 requires homes to be exceed the requirements of the California Energy Code by 15\%, and Tier requires exceeding it by 30\%. Applicants may demonstrate compliance using the Performance Approach, or meet the Prescriptive Approach. To qualify for Tier 1, applicants must meet 4 electives from the list provided, and 6 electives for Tier 2. Four of the electives on the list include renewable energy options. Applicants may (1) install a photovoltaic system in accordance with the California Energy Commission's New Solar Homes Partnership; (2) install a solar water heating system with a Solar Fraction of at least 0.5 in accordance with the Solar Rating and Certification Corporation (SRCC) OG 300 standard; or install one of two solar-ready options. 


\section{NONRESIDENTIAL VolunTARY MEASURES}

The nonresidential requirements in CalGreen are structured similarly to the residential requirements. There are two levels of compliance for energy efficiency. Tier 1 requires homes to be exceed the requirements of the California Energy Code by 15\%, and Tier requires exceeding it by 30\%. Applicants may demonstrate compliance using the Performance Approach. The model code does not specify any electives from the Energy Efficiency Division. Presumably Calgreen requires the measures listed to be installed if applicants choose to use the Prescriptive Approach. Included on the list of prescriptive measures are pre-wiring for future solar, or installation of an on-site renewable energy system for at least $1 \%$ of the electric power and the electrical demand required to meet $1 \%$ of natural gas and propane use.

\section{A2.2 Colorado}

HB 09-1149, enacted in May 2009, requires builders of single family homes to offer solar as a standard feature to all prospective homebuyers. Builders are required to give the buyer the option to either have a photovoltaic (PV) system or a solar water heating system installed on their new home, or to have all the necessary wiring and/or plumbing installed so that they can easily add a solar system at a later date. The builder must also provide the buyer with a list, maintained by the Governor's Energy Office, of every solar installer in the area, so the buyer can obtain expert help in determining if their home's location is suitable for solar and what the estimated cost savings would be. http://www.state.co.us/gov_dir/leg_dir/olls/sl2009a/sl_235.htm (accessed May 2011) http://www.leg.state.co.us/clics/clics2009a/csl.nsf/fsbillcont3/56DAD78B9D26BD51872575390 06E7FF9?open\&file=1149_enr.pdf (accessed May 2011)

Senate Bill 08-117, passed by the 2008 Colorado legislature, limits permit fees that counties and municipalities can charge for active solar energy devices to the lesser of the local government's actual cost to issue the permit or $\$ 500$ for a residential application or $\$ 1,000$ for a nonresidential application. http://www.state.co.us/gov_dir/leg_dir/olls/sl2008a/sl_238.htm (accessed May 2011)

\section{A2.3 Florida}

Florida House Bill 697 passed in 2008 establishes a schedule of improvements to the energy efficiency requirements of the state building code, ramping from at least $20 \%$ better than the 2007 code by 2010 in 10\% increments every 3 years to 50\% better by 2019. Florida does not specifically mandate use of renewable energy. http://bcap-energy.org/node/227 link to HB 697 (accessed May 2011).

\section{A2.4 Hawaii}

Hawaii passed legislation in 2008 requiring solar water heaters to be installed on the new singlefamily dwellings, starting in 2010. Exemptions are granted if:

(1) installation is impracticable due to poor solar resource;

(2) installation is cost-prohibitive based upon a life cycle cost-benefit analysis that incorporates the average residential utility bill and the cost of the new solar water heater system with a life cycle that does not exceed fifteen years; 
(3) a renewable energy technology [wind or photovoltaic] system ... is substituted as the primary source for water heating; or

(4) a demand water heater device approved by Underwriter Laboratories, Inc., is

installed, provided that at least one other gas appliance is installed in the dwelling."

Legislative intent is that "if the potential variance applicant is not the party who will ultimately pay for the energy cost consumption, then only paragraph (1), (2), or (3) of subsection (a) in section 196-6.5, Hawaii Revised Statutes, should apply.” The legislature intended for a consumer to have the option to use gas appliances with the full knowledge that such a system may be more costly and less efficient.”

\section{A2.5 Massachusetts "Stretch Code"}

In 2009 Massachusetts approved Appendix 120AA as an optional appendix to its mandatory statewide Massachusetts Building Code 780 CMR. The appendix is designed to be about 30 percent more stringent than the 2006 IECC and ASHRAE Standard 90.1-2004. Towns and cities may adopt the appendix as a uniform alternative to the base energy efficiency requirements of the state code. By October, 2010, 64 cities and towns adopted the appendix.

Residential buildings less than 3,000 square feet must be receive a rating of 70 or less using the Home Energy Rating System (HERS), created by the Residential Energy Services Network (RESNET), where a rating of 100 is a code compliant home built based on the IECC 2006 code and 0 is a zero net-energy home. Homes larger than 3,000 square feet must receive a rating of 65 or less. The Stretch Code does not mandate the use of renewables in residential buildings.

Commercial buildings larger than 100,000 square feet must meet a performance standard set at 20 percent below the energy usage of ASHRAE 90.1-2007, with no specific renewable energy requirement. Medium-sized commercial buildings, which include residential buildings of 4 stories or more, but that are less than 100,000 square feet, have the option of meeting the same 20\% better than ASHRAE 90.1-2007 performance standard, or using a simplified, prescriptive energy code. The prescriptive code is based on Chapter 5 of the IECC 2009 energy code with additional efficiency improvements. One of the improvements includes a choice of either high efficiency HVAC equipment, further lighting energy reductions, or on-site renewable energy. This prescriptive option for commercial buildings was developed from the Core Performance program of the New Buildings Institute.

http://bcap-energy.org/node/418 link to Massachusetts BBRS (accessed May 2011) http://www.mass.gov/?pageID=eopsmodulechunk\&L=3\&L0=Home\&L1=Public+Safety+Agenci es\&L2=Massachusetts+Department + of + Public + Safety\&sid=Eeops\&b=terminalcontent\&f $=$ dps bbrs_build_code_changes_public_hearing\&csid=Eeops (accessed May 2011)

\section{A2.6 Oregon}

The Oregon Residential Energy Code is one of the most energy-efficient in the U.S. Oregon has long followed a simple prescriptive path which has been popular with builders, with a performance alternative for innovative designs. Because of its stringency, however, it has become more difficult to simply adopt new prescriptive requirements. One of the next logical measures to require was a high efficiency (90 percent) natural gas furnace. However, this 
equipment is regulated by federal standards, and Oregon was not prepared to begin a lengthy (and questionable) exemption process. In lieu of moving toward a more complicated performance-based code, which could lead to builders to choose natural gas furnaces as a way to meet the standard, Oregon has taken the approach of prescriptive options. In addition to the basic requirements, builders are required to select one prescriptive option from a list of nine options. The options were established based on approximate equivalency with the high efficiency furnace, which was determined to be cost-effective. Two of the options include installation of a solar water heating system 40 square feet or larger, or a photovoltaic system of at least 1 watt per square foot times the conditioned floor area. Oregon has not evaluated the code, but anecdotal information suggests most builders are indeed choosing to install the high efficiency furnace. http://bcap-energy.org/node/90, follow link to 2008 Oregon Residential Specialty Code. www.oregon.gov/ENERGY/CONS/Codes/docs/ResPub_2.pdf for the list of options.

\section{A3 Local Requirements}

Text included below are excerpts from actual code documentation.

\section{A3.1 Southwest U.S. (SWEEP)}

Dunn, Steve (SWEEP), Michelle Britt and Eric Makela (Brit Makela Group), "Going Beyond Code: A Guide to Creating Energy Efficient and Sustainable Buildings in the Southwest.” Southwest Energy Efficiency Project (SWEEP), December 2008. http://swenergy.rlmartin.com/programs/buildings/codes/beyondcode/ (accessed May 2011)

p. 110. "Jurisdictions seeking to require higher efficiency heating and cooling equipment for their beyond code programs have several options available.

1. Require increased efficiencies only for voluntary beyond code programs. This allows the user to install minimum efficiency equipment through a code minimum program.

2. Provide a trade-off option by allowing minimum efficiency equipment to be installed if increased levels of insulation and more efficient windows are installed.

3. Implement an addition measure "path" which requires builders to select among multiple measures to achieve increased efficiency (for example, solar thermal hot water, enhanced envelope, or high efficiency mechanical systems).

4. Develop a fee and rebate program, in which homes that meet minimum code are required to pay an additional permit fee, and those that exceed minimum code requirements by a specified level receive a rebate. ...

\section{A3.2 Arizona}

\section{A3.2.1 Chandler, Arizona}

Incentives for meeting LEED.

- Plan review expedited from 20 days to 10 days.

- Award / recognition.

- Fee reimbursement: 50\% for LEED certified, 75\% for Silver, 100\% for Gold, and 200\% for Platinum.

- Technical assistance. 
New municipal buildings shall use renewable energy when feasible.

\section{A3.2.2 Scottsdale, Arizona}

Scottsdale Green Building Program, http://www.scottsdaleaz.gov/greenbuilding (accessed May 2011)

Residential - mandatory 15\% better than IECC or Energy Star for Homes.

- 1 point for photovoltaics meeting at least $50 \%$ of exterior site lighting.

- 2 points for each 10 percent of electrical load met by photovoltaic power system.

- 4 points for Solar water heating system meeting 60 percent of annual water heating load.

Commercial

- Points awarded for 10, 20 and 40 percent of peak power demand $(\mathrm{kW})$ provided by an on-site renewable energy system.

- Points awarded for $75 \%$ and $100 \%$ of electrical energy provided from renewable sources by engaging in at least a two-year renewable energy contract.

Scottsdale provides expedite plan review, construction job site signs, lecture series, recognition on city web site, homeowner's manual.

\section{A3.2.3 Tucson I Pima County Green Building Program, Arizona}

“Regional Residential Green Building Rating System,” August 2009. http://www.pimaxpress.com/Green/default.htm

Pima County assigns the appropriate Green Building Rating Level.

- Points are awarded for building size: 1 point for every $200 \mathrm{sq}$. ft. less than 2,300 sq. ft, and a penalty of 1 point for every $200 \mathrm{sq}$. ft. greater than 2,800 sq. ft.

- Point each for pre-wiring or pre-plumbing the home.

- Points for PV and SDHW like Scottsdale.

\section{A3.3 California}

\section{A3.3.1 California}

Numerous communities have already adopted "beyond code" provisions either as requirements, or as options eligible for local incentives such as expedited permitting. None require use of renewable energy, but include renewable energy as a qualifying option. A list is maintained by the California Department of Justice. http://ag.ca.gov/globalwarming/pdf/green_building.pdf (accessed May 2011)

\section{A3.3.2 West Hollywood, California}

West Hollywood adopted a Green Building Program in 2007. The program established minimum green building requirements for all building projects, including new construction, tenant improvements, remodeling and additions. One of the minimum requirements is "Future Photovoltaics." Projects shall maintain a 300 square foot or larger section of south or west roof area clear of vent pipes or other obstructions, increase the structural capacity of the roof by 4 
pounds per square foot, and install conduit 0.75 inch or larger, with pull boxes as needed, from the roof to the electrical room (or electrical panels if no electrical room is provided).

In addition, new commercial buildings and multi-family buildings or three units or more must comply with the Green Building Point system. A minimum of 60 points is required, and projects that reach 90 points are eligible for possible incentives such as expedited permitting and flexibility in parking, open space, setbacks, and FAR requirements. Included in the 160 total points eligible are 15 points for use of renewable energy - pre-plumb for solar water heating (1 point), install a solar water heating system (2 points), install a solar pool heating system (2 points), and install photovoltaics (1 point/kW, maximum 10 points).

http://www.weho.org/index.aspx?page=194, follow link to “Green Building Ordinance” and “Green Building Manual.” (accessed May 2011)

\section{A3.4 Colorado}

\section{A3.4.1 Aspen / Pitkin County, Colorado}

Through the energy policy in the building code, the City of Aspen and Pitkin County regulate the amount of exterior energy use for snowmelt, spas and swimming pools. The energy for these uses must come from the house energy budget or 50\% can be supplied from on-site renewable energy systems. The Renewable Energy Mitigation Program (REMP) allows the payment of a mitigation fee instead of installing on-site renewable energy systems. In addition, houses over 5,000 square feet are required to install a small renewable energy system on site or pay a fee of $\$ 5,000$. The fee for houses over 10,000 square feet is $\$ 10,000$. Total fee and energy use cannot exceed $\$ 100,000$ or $240,000,000$ BTU. Since its inception, the fund has accumulated approximately \$8 million. REMP fees are dedicated to energy efficiency and renewable energy projects. REMP will offset at least 2 pounds of $\mathrm{CO} 2$ for every pound permitted under REMP over 20 years. Currently, the projects are offsetting 6-8 lbs. of CO2 for every pound permitted. Note: Aspen has approved a new REMP program, but Pitkin County has not. REMP will expand to include new fee structures for commercial buildings, and the program is likely to take effect by August. http://www.aspenpitkin.com/Departments/Community-Development/Building/Building-EnergyCodes/Efficient-Building-Program (accessed May 2011)

New Rules Project and the Western Area Power Administration provide some more detail of how the Renewable Energy Mitigation Fund work. http://www.newrules.org/environment/rules/climate-change/renewable-energy-mitigationprogram-aspen-and-pitkin-county-co http://www.wapa.gov/es/pubs/esb/2003/03Feb/esb021.htm

\section{A3.4.2 Boulder, Colorado}

Boulder requires a HERS Rating Certificate for new residential construction. Green points for energy efficiency and solar options do not apply to new construction because they encompassed by the HERS Index. They apply only to remodels of existing homes, as verified by an energy audit or an optional HERS rating. Points are given for the following renewable energy options. 
1. Passive solar heating design, with modeling documentation and the designers signature verifying calculations of the solar heat gain fraction.

2. Solar Thermal Domestic Hot Water Systems.

3. Solar Thermal Space Heating or Pool/Spa Systems

4. Pre-plumb for solar thermal retrofits. Minimum 1/2” (5/8” OD) copper pipes, min. 1” wall thickness high temperature $250^{\circ} \mathrm{F}$ rated insulation, and THN shielded 4 conductor sensor wiring between the attic and the water heater location. To accommodate "active" systems, provisions should be made for a solar storage tank footprint (with pressure relief drain line) and an electrical outlet for a pump. An $8 \mathrm{ft}$. by $8 \mathrm{ft}$. section of southfacing roof suitable for future installation of solar panels must be provided.

5. Active solar electric system.

6. Pre-wire for future solar electric PV System Retrofits. Install conduit from the attic to a location near the electric service entrance/circuit breaker panel, allowing space for installation of PV modules on south-facing roofs, and ensuring that roof trusses are adequate to accommodate any added roof loads. Maintain a 200 sq. ft. or larger section of unshaded south roof area clear of vent pipes and other obstructions to allow for installation of modules. Install 3/4 inch or larger EMT (electrical metal tubing) or FMC (flexible metal conduit) to accommodate wires run from the attic to a junction box near the main panel and meter.

Boulder, City of. "City of Boulder Residential Building Guide: Green Building and Green Points Guideline Booklet,” www.BoulderGreenPoints.com, April 2008. (accessed May 2011) http://www.dsireusa.org/incentives/incentive.cfm?Incentive_Code=CO06R\&re=1\&ee=1 (accessed May 2011)

\section{A3.5 Illinois}

\section{A3.5.1 Chicago Green Permit Program:} http://www.cityofchicago.org/city/en/depts/bldgs/provdrs/green_permit.html (accessed May 2011) The City of Chicago provides expedited permitting and a partial permit fee waiver for buildings meeting green criteria, including use of renewable energy equipment.

\section{A3.6 New Mexico}

\section{A3.6.1 Albuquerque, New Mexico}

“Albuquerque Energy Conservation Code: Albuquerque Green. Vol. I: Commercial and MultiFamily Residential Buildings.” http://www.cabq.gov/albuquerquegreen/green-goals/greenbuilding (accessed May 2011). Albuquerque adopted the 2006 IECC with amendments that exceed the code.

- Section 504.7.1 requires that "The primary source of energy for heating swimming pools shall come from solar collectors. All pool heaters shall be equipped with a readily accessible on-off switch to allow shutting off the heater without adjusting the thermostat setting." 
“Albuquerque Energy Conservation Code: Albuquerque Green. Vol. II: One- and Two-Family Detached Dwellings and Townhouses.” http://www.cabq.gov/albuquerquegreen/greengoals/green-building (accessed May 2011).

- 402.8 Roof Reflectance. Roof coverings that meet one of the following standards shall be installed on new roofs and on existing roofs that are being re-roofed:

1. Reflective roof coverings that are Energy Star qualified.

2. Low slope (2 inches in 12, or less) roof coverings that have an initial solar reflectance of 0.65 or greater as determined by the Cool Roof Rating Council.

3. Steep slope (greater than 2 inches in 12) roof coverings that have an initial solar reflectance of 0.25 or greater as determined by the Cool Roof Rating Council.

- 403.8.2.1. [Swimming Pool] Energy source. The primary source of energy for heating swimming pools shall come from solar collectors.

\section{A3.6.2 Santa Fe, New Mexico}

Santa Fe Green Building Code, July 2009. http://www.santafenm.gov/index.aspx?NID=1297 (accessed May 2011)

Adopted residential green building code requirements that go beyond IECC. Santa Fe provides four levels of certification (Silver, Gold, Platinum, and Emerald), with the minimum level required by the code. The code requires all new single family residential units to be HERS certified (tested and certified according to the Enhancements to the National Home Energy Rating Standards as adopted by the Residential Energy Services Network (RESNET)).

There are two mandatory renewable energy requirements.

- If a heat pump is used for heating, it must have an HSPF $>9.0$ and at least half the load must be met by a photovoltaic or other renewable electric source.

- Home must provide solar-ready sleeved penetrations in accordance with Section 712.2.1 of the New Mexico Green Building Code IRC.

Points allowed for:

- $\quad$ Sun-tempered design: long side of home faces within $30^{\circ}$ of south; glazing area limited to less than $7 \%$ of south face, $4 \%$ of east and north faces, and $2 \%$ on west face; overhangs on south-facing glass.

- Passive design: masonry material >4” thick with surface are 6 times that of south glazing; provision for forced air flow to adjoining areas as needed.

- Solar water heating: between $35-50 \%$, and greater than $50 \%$.

- PV: points for 800-1999, 2000-3999, 4000-5999, and >6,000 kWh/yr;

\section{A3.7 New York}

\section{A3.7.1 Long Island, New York}

By November, 2009, 10 of 13 towns on Long Island, New York, have adopted the New York ENERGY STAR-Labeled Homes (NY ENERGY STAR) program as code. ENERGY STAR 
requires that homes be rated according to the Home Energy Rating System (HERS), created by the Residential Energy Services Network (RESNET), making HERS the default code compliance and enforcement system. The choice is left to the buyer whether to build to Tier 1, 2, 3, or Tier 4 . However, all new homes must obtain the rating, meaning energy efficient homes are not at a cost disadvantage of having to obtain one. Renewables are not required, but are an allowable option.

\section{A3.8 Texas}

\section{A3.8.1 Austin, Texas}

http://www.austinenergy.com/Energy\%20Efficiency/Programs/Green\%20Building/Participation/ participationFormsAndGuides.htm (accessed May 2011)

Austin Energy: Green Building. “Guide to the Single-Family Rating, Version 2008.”

- The Rating level is indicated by one- to-five stars. There are no mandatory renewable energy requirements. Points are given for solar thermal and photovoltaic systems.

Austin Energy: Green Building. “Commercial Guidebook: v 2009_01.”

- Points for PV or purchase of RECS.

- No points for solar thermal.

- Points for solar reflectance (cool roofs).

\section{A4 Requirements for Public Buildings}

Text included below are excerpts from actual code documentation.

\section{A4.1 State Laws Requiring Use of Solar Energy in Public Buildings}

Several states require use of solar energy in new public buildings if they are life-cycle costeffective. Two states go beyond this requirement, Hawaii and Oregon.

\section{A4.1.1 Hawaii}

State buildings, including new residential facilities receiving state funds, must meet minimum LEED* or other approved construction and energy efficiency standard. Solar water heating systems must be installed in all state facilities, if life-cycle cost-benefit analysis determines it to be cost-effective. (HB 2175, 2006.)

http://www.capitol.hawaii.gov/session2006/bills/HB2175_htm (accessed May 2011)

\section{A4.1.2 Oregon}

$1.5 \%$ of the total cost of a building project funded by the state must be dedicated to inclusion of solar systems in the building. (HB 2620, 2007.) http://oregon.gov/ENERGY/CONS/PublicSolar.shtml, (accessed May 2011) http://www.leg.state.or.us/07orlaws/sess0300.dir/0310.htm (accessed May 2011)

\section{A4.1.3 Minnesota}

Minn. Stat. 16B32 requires agencies preparing a predesign for a new building to consider meeting at least two percent of the building's anticipated energy needs from on-site renewable 
energy resources (wind and solar), or supply a full cost and carbon analysis explaining why renewables would not be cost-effective. Agencies cannot count passive solar design or daylighting toward meeting this requirement. Minnesota Statutes 2008, Chapter 179, Section 29 section 16B.32 https://www.revisor.mn.gov/statutes/?id=16B.32 (accessed May 2011) ; Minnesota Sustainable Buildings Guidelines http://www.msbg.umn.edu/e_2.html (accessed May 2011).

\section{A4.1.4 California}

Solar energy equipment should be installed by January 1, 2009 on any public building or facility, new or existing, where such an installation is determined to be cost-effective over the life of the system, and funding is available.

\section{A4.1.5 Delaware}

Governor Jack Markell, Executive Order Number Eighteen , "Leading by Example Towards a Clean Energy Economy and Sustainable Natural Environment," says that "For buildings owned and operated by State executive branch agencies, the State shall target at least $20 \%$ of its overall annual electric energy demand from clean, renewable sources by the end of fiscal year 2012, and $30 \%$ of its overall annual electric demand from clean, renewable sources by the end of fiscal year 2013.” http://governor/delaware.gov/orders/exec_order_18.shtml, (accessed May 2011)

\section{A4.1.6 Florida}

The Florida Energy Conservation and Sustainable Buildings Act (Florida Statues 255.251) mandates the use of solar technologies and energy efficiency measures when determined to be cost-effective over the life of the building. The Department of Management Services must build new buildings to LEED standards. Florida law requires that all new educational facilities include passive solar design. Florida Statutes (Section 1013.44) mandates that schools with hot water demands exceeding 1,000 gallons per day must include a solar water heating system that provides at least $65 \%$ of hot water needs whenever economically feasible. Swimming pools in educational facilities shall be heated either by a waste heat recovery system or a solar energy system whenever feasible (Florida Statutes 1013.44).

\section{A4.1.7 New York}

Gov. Pataki, Executive Order No. 111, December 2004, calls for agencies to purchase electricity produced from renewable sources in the amount of $10 \%$ of the electric energy requirements by 2005, increasing to $20 \%$ by 2010. http://www.nyserda.org/programs/exorder111orig.asp (accessed May 2011)

\section{A4.1.8 Arizona}

Arizona law requires that new state building projects, including state office buildings, school districts, community college districts and universities, over six thousand square feet follow prescribed solar design standards and that solar improvements be evaluated on the basis of life cycle costs. These projects must include evaluation of: (a) proper site orientation; (b) active and passive solar energy systems for space heating; (c) solar water heating; and (d) use of solar daylighting devices. The life cycle cost requirements state that solar energy and energy conservation design, equipment and materials shall be used if the simple payback in energy savings is eight years or less. ARS 34-452. 


\section{A4.1.9 Ohio}

S.B. 221 in 2008 directed the Ohio School Facilities Commission (OSFC) to adopt "solar-ready" requirements and guidelines for schools. The OSFC Resolution 08-164 provides requirements, which have been incorporated into the Ohio School Design Manual. The requirements deal with roof shading, orientation, structural integrity, and electrical system access. (Ohio School Design Manual, Chapter 7 - Sustainable Design, http://osfc.ohio.gov/Library/2009OhioSchoolDesignManual/tabid/165/Default.aspx) (accessed May 2011)

\section{A4.2 Federal Government}

\section{A4.2.1 Energy Policy Act of 2005 (EPACT)}

The Energy Policy Act of 2005 (P.L. 109-58, 42 U.S.C. 15851) requires Federal agencies, to the extent economically feasible and technically practicable, to ensure that the following amounts of the total electricity consumed by the Federal Government come from renewable energy:

- Not less than 3\% in fiscal years 2007-2009

- Not less than 5\% in fiscal years 2010-2012

- Not less than 7.5\% in fiscal year 2013 and thereafter

A bonus equivalent to doubling the amount of renewable energy is available if it is produced and used on-site at a Federal facility, or is produced on Federal lands (including Indian lands) and used at a Federal facility.

\section{A4.2.2 Energy Security and Independence Act of 2007 (EISA)}

EISA 2007 requires that 30\% of the hot water demand in new Federal buildings (and major renovations) be met with solar hot water equipment provided it is life-cycle cost-effective.

\section{A4.2.3 Executive Order 13423}

Executive Order 13423 requires that agencies "ensure that (i) at least half of the statutorily required renewable energy consumed by the agency in a fiscal year comes from new renewable sources, and (ii) to the extent feasible, the agency implements renewable energy generation projects on agency property for agency use.” It also requires that agencies use new renewable energy sources (placed in service after January 1, 1999) equal to half or more of the EPACT 2005 renewable energy requirement. While EPACT allows only electricity from renewable resources, EO13423 allows agencies to use non-electric renewable energy sources to meet the requirement. However, these non-electric renewable energy sources cannot be used to meet the EPACT 2005 requirement. The table below shows the differences between the two requirements. Executive Order 13423, "Strengthening Federal Environmental, Energy, and Transportation Management,” 24-January-2007. http://www.fedcenter.gov/programs/eo13423/ (accessed May 2011)

\begin{tabular}{|l|c|c|c|c|c|}
\hline & $\mathbf{2 0 0 7 - 2 0 0 9}$ & $\mathbf{2 0 0 9 - 2 0 1 2}$ & $\mathbf{2 0 1 3}$ onward & $\begin{array}{c}\text { Can include non- } \\
\text { electrical? }\end{array}$ & $\begin{array}{c}\text { New or old } \\
\text { source? }\end{array}$ \\
\hline $\begin{array}{l}\text { EO 13423 new renewable } \\
\text { energy sources minimum } \\
\text { requirements }\end{array}$ & $1.5 \%$ & $2.5 \%$ & $3.75 \%$ & Yes & $\begin{array}{c}\text { No, exclusively } \\
\text { new }\end{array}$ \\
\hline
\end{tabular}




\begin{tabular}{|l|c|c|c|c|c|}
\hline $\begin{array}{l}\text { EPACT } 2005 \text { total } \\
\text { minimum renewable } \\
\text { energy requirements }\end{array}$ & $3 \%$ & $5 \%$ & $7.5 \%$ & No & Yes \\
\hline
\end{tabular}

\section{A4.2.4 Federal Energy Management Program (FEMP)}

Further guidance by the Federal Energy Management Program (FEMP, under the U.S. Department of Energy's Office of Energy Efficiency and Renewable Energy (EERE), allows agencies to meet the requirements of EPACT 2005 and EO13423 by purchasing Renewable Energy Certificates (RECs), provided guidelines on verification and double counting to followed. U.S. Department of Energy, Office of Energy Efficiency and Renewable Energy (EERE), Federal Energy Management Program (FEMP). "Renewable Energy Requirement Guidance for EPACT 2005 and Executive Order 13423.” 28-January-2008.

http://www1.eere.energy.gov/femp/regulations/guidance.html (accessed May 2011)

Eighteen (18) agencies used renewable electric energy equivalent to at least 3\% of their total electricity use and half of it was from sources developed after January 1, 1999. The entire federal government purchased or produced renewable energy equivalent to $4.1 \%$ of its electricity use in FY 2009. It is unknown how much was provided from renewable energy sources on the facility, but it is presumed most of it was from the purchase of RECs. "2010 OMB Scorecard for Energy, Transportation and Environment.” January, 2010. http://www.fedcenter.gov/programs/eo13423/ (accessed May 2011)

The Department of Defense National Defense Reauthorization Act of 2007 requires 25 percent of the electricity produced and used by the DoD to comes from renewable energy sources. Anne Sprunt Crawley, "Integration of Renewable Energy into New Construction and Major Renovations,” www1.eere.energy.gov/crawley_re071310.pdf.13-July, 2010. (last accessed August 2010)

\section{A5 International}

Text included below are excerpts from actual code documentation.

\section{A5.1 Australia}

BCA 2007, http://www.abcb.gov.au/go/about bca p2 (accessed May 2011)

Australia revises its building code every three years. The last revision was 2010. The code does not require use of solar energy. Australia's code is performance-based. Heating for a conditioned space "must to the degree necessary, obtain energy from a source that has a greenhouse gas intensity that does not exceed $100 \mathrm{~g} \mathrm{CO} 2 \mathrm{e} / \mathrm{MJ}$ of thermal energy, or a source that is renewable on-site such as solar, geothermal and wind; or another process as reclaimed energy.” (JP-3) Solar water heating is an allowable alternative for swimming pools and spas. (J7.3 and J7.4, respectively)

For domestic water heating Australia requires low emissions systems, such as high efficiency natural gas, heat pumps, or solar water heating. (Vol. II DTS, Sec. 3.12.5.6). If used, the solar 
water heater must provide $40 \%$ of the hot water load for a small building ( 1 or 2 bedrooms), and $60 \%$ of the hot water demand for a large building (3 or more bedrooms). Renewable energy certificates are an acceptable alternative, depending on the number of bedrooms - 14 RECs for one or two bedrooms, 22 RECs for three or four bedrooms, and 28 RECs for five bedrooms or more

George Wilkenfeld \& Associates, for Australian Building Codes Board. "Specifying the Performance of Water Heaters for New Houses in the Building Code of Australia,” Sydney, December 2007.

\section{A5.2 Brazil / Sao Paulo}

Baerbel Epp. "Sao Paulo Feels the First Effects of Its Solar Building Code.” Solar Thermal World, 05/21/2009. http://www.solarthermalworld.org/node/600 (accessed May 2011). Interview with Carlos Arthur A. Alencar about the solar building code campaign "Cidades Solares" (Solar Cities)" in Brazil. Alencar is president of the solar thermal industry association DASOL/ABRAVA and managing director of the solar thermal manufacturer Enalter Engenharia Indústria e Comércio.

Cidades Solares already initiated and supported the approval of 30 laws. At present, there are also 94 draft laws going through the approving process. ... The São Paulo law from July 2007 highly increased the awareness among policy makers. The city has 19 million inhabitants and a GDP of US\$ 102 billion. Its authorities made solar water heaters a mandatory part of new buildings, for both residential and non-residential estates - applying the by-law to hotels, sport clubs, schools, swimming pools restaurants, etc. ... There are 26 states. None of them are allowed to implement solar building laws for residential or commercial buildings on their own. But they can devise obligations, so-called binding regulations, that require solar hot water systems for public buildings and publicly financed projects, such as schools, swimming pools, hospitals, asylums, rehabilitation centres etc. The state of Rio de Janeiro was the first to implement such a law in January 2008. The São Paulo State law is the next being processed. Several states have included solar thermal tenders for new social housing projects.

Baerbel Epp. “Solar Obligation By the Municipality in Sao Paulo.” 6-02-2009. http://www.solarthermalworld.org/node/631 (accessed May 2011).

São Paulo, requires a solar water heating system for both residential and non-residential buildings approved after July 2008. The buildings covered are those intended for commercial (in special cases), industrial (if hot water is needed for the industrial process or if showers are to be installed for the staff), and, in general, any other use that entails the presence of dining rooms, kitchens or collective laundries.

- Hotels, motels and similar buildings

- Health services

- Sport clubs

- Barracks

- Schools, nurseries

- Public swimming pools

- Private buildings with up to three bathrooms 
The solar thermal system must provide at least $40 \%$ of the entire annual demand for heating sanitary water and pools. Products have to be certified in compliance with the National Institute of Metrology, Standardization and Industrial Quality (INMETRO). The provisions shall not apply to buildings in which it is technically impossible to achieve the conditions to meet the above-mentioned share of annual energy demand.

www.cidadessolares.org.br

Prefeitura do Municipío de São Paulo: www.capital.sp.gov/br

Secretaria Municipal de Habitação, Elton Santa Fe Zacarias, sehab@prodam.pmsp.so.gov.br

\section{A5.3 Canada}

\section{A5.3.1 Fort St. John, British Columbia}

The City of Fort St. John offers a $\$ 500$ incentive for a limited number of homes to meet solarready requirements, including:

1. a roof location of suitable size, pitch and orientation

2. labeled conduits from the mechanical room to the attic

3. extra plumbing valves and fittings on the water heater

4. an electrical outlet at the planned solar tank location

5. construction plans that indicate the future component locations .

Generally, making a house solar ready will add approximately $\$ 300-\$ 500$ (including labour) to the cost of building a new home. This estimate considers pipes, accommodation and design requirements for future installation of a solar hot water system. www.fortstjohn.ca (accessed May 2011)

\section{A5.3.2 Vancouver, British Columbia}

Vancouver requires that every new house be equipped with a solar ready pipe run consisting of at least two $50 \mathrm{~mm}$ (2 inch) pipes and having at least a $20^{\circ}$ angle measured above the horizontal level that run from the home's service room (where the water tank is) to the attic. This will allow for the future installation of roof-mounted solar energy generating equipment without needing to tear open walls and ceilings. In addition, these pipes are suitable for use with either solar energy system, giving the future homeowner the greatest amount of flexibility. The law follows guidelines established by Natural Resources Canada http://www.solarbc.ca/sites/default/files/images/blog/Solar_Ready_Builders_Specs_NRCan.pdf (accessed May 2011)

\section{A5.4 China}

Pembina Institute states that China requires every new building to use solar water heaters. Pembina Institute for Sustainable Energy Solutions. http://www.pembina.org/re/global/support (accessed May 2011)

However, we were unable to find any other confirmation. Bin Shui, research scientist with the Pacific Northwest National Laboratory, confirmed that solar water heating is not required by national law or regulation, though some local provinces do have requirements. 
Mentaneau, Phillipe. World Energy Council. Policy Measures to Support Solar Water Heating. http://www.worldenergy.org/documents/solar_synthesis.pdf (accessed May 2011). May, 2007.

"In China, the diffusion of solar water heating systems is ... governed by market forces and free competition. The state's main role is to build consumer confidence by ensuring that quality is maintained and improved in this sector, which it does through the use of standards and quality labels. The situation is much the same in India, where ... the main constraint ... remains financing...."

Table: SWHs in operation (in MWth)

\begin{tabular}{|l|c|c|r|r|r|r|}
\multicolumn{2}{c}{2006} & \multicolumn{2}{c}{2005} & \multicolumn{2}{c}{2004} & \multicolumn{1}{c}{2003} \\
\hline China & $n d$ & $n d$ & 43400 & 33950 & 25970 & 19250 \\
\hline Japan & $n d$ & $n d$ & 5408 & 5232 & 5036 & 4801 \\
\hline Turkey & $n d$ & $n d$ & 5096 & 4256 & 3696 & 3346 \\
\hline Germany & 5428 & 4588 & 3923 & 3398 & 2894 & 2516 \\
\hline Israel & $n d$ & $n d$ & 3353 & 3304 & 3024 & 2744 \\
\hline Greece & 2298 & 2133 & 1979 & 1828 & 1715 & 1609 \\
\hline Brazil & $n d$ & $n d$ & 1586 & 1563 & 1540 & 1506 \\
\hline USA & $n d$ & $n d$ & 1502 & 1469 & 1432 & 1397 \\
\hline Austria & 1819 & 1623 & 1460 & 1332 & 1215 & 1108 \\
\hline Australia & $n d$ & $n d$ & 1117 & 1011 & 917 & 839 \\
\hline
\end{tabular}

Source : IEA, 2006 and ESTIF, 2006 for European countries

\section{A5.5 Cyprus}

“The History of Solar Water Heating.” http://www.sunbelt-solar.com/history.html. (accessed May 2011) “Cyprus, like Israel, has only one natural energy resource: the sun. Otherwise, like Israel, it totally depends on imported oil to run its power needs. The knowledge of solar water heating came to Cyprus from Israel in the 1960s. The Cypriots knew a good idea when they saw it. To set an example to its citizens of good energy husbandry, the national government committed to installing solar water heaters on all state buildings. Unexpectedly, the government's role in promoting solar became paramount when, in 1974, the Turks invaded the island, uprooting thousands of Greek Cypriots from their homes. The government had to house nearly one-third of the island's population and, since it built the homes, had to put up solar water heaters. When the remaining population saw how well the heaters worked, they too soon became users.

\section{A5.6 England}

\section{A5.6.1 National}

It is the policy of the U.K. government to generate $10 \%$ of its electricity from renewable energy sources by 2010, though most was expected from large-scale generation facilities. However, Britain's national building regulations, L1A: Conservation of Fuel and Power in New Dwellings, and L2A: Conservation of Fuel and Power in New Buildings Other Than Dwellings, do not require the use of renewable energy. The UK also passed legislation in 2007 requiring that Energy Performance Certificates be provided to prospective buyers or tenants for all buildings. The intent is that rating 
information provided by the EPC will help drive energy efficiency and renewable energy improvements.

“Building a Greener Future: Towards Zero Carbon Development.” Department for Communities and Local Government, December-2006.

http://www.communities.gov.uk/archived/publications/planningandbuilding/buildinggreener

(accessed May 2011)

UK Building Regulations Covering Energy Efficiency.

http://www.energysavingtrust.org.uk/business/Business/Housing-professionals/Building-

Regulations-covering-energy-efficiency (accessed May 2011)

“Code for Sustainable Homes” and “The Effect of Building Regulations Part L1 (2006) on

Existing Dwellings.” UK Energy Saving Trust.

http://www.energysavingtrust.org.uk/nottingham/Nottingham-Declaration/Local-

Services/Planning-and-Building-Control/Building-control (accessed May 2011)

UK Department of Communities and Local Government. "Policy Planning Statement 1: Climate Change.” December-2007.

http://www.communities.gov.uk/publications/planningandbuilding/ppsclimatechange (accessed May 2011)

Office of the Deputy Prime Minister. "Policy Planning Statement 22: Renewable Energy.” 10August-2004. http://www.communities.gov.uk/publications/planningandbuilding/pps22 (accessed May 2011)

UK Department of Communities and Local Government. "Recast of the Energy Performance of Buildings Directive.” July-2009.

www.communities.gov.uk/documents/planningandbuilding/pdf/1301240.pdf (accessed May 2011)

UK Department of Communities and Local Government. Explanatory Memorandum to the Energy Performance of Buildings Regulations, No. 1669, 2007.

www.legislation.gov.uk/uksi/2007/1669/pdfs/uksiem_20071669_en.pdf (accessed May 2011)

\section{A5.6.2 Merton Rule}

In 2004, the Borough of Merton adopted a local planning policy that requires new developments to generate at least $10 \%$ of their energy needs from on-site renewable energy sources. In 2008, the government's Planning Policy Statement - Planning and Climate Change - PPS1 required local planning authorities to consider renewable energy targets for new developments. Numerous local authorities have adopted similar requirements similar to the 'Merton Rule.' The Merton rule covers all buildings, not just homes. The most commonly accepted threshold is 10 homes or 1,000 m2 of non-residential development. See references in section 5.5.1.

\section{A5.7 European Union}

European Commission, Energy Directorate. “Directive 2010/31/EU of the European Parliament and of the Council of 19 May 2010 on the Energy performance of Buildings,” Official Journal of 
the European Union , L 153/13, 18 June 2010. http://eur-

lex.europa.eu/JOHtml.do?uri=OJ:L:2010:153:SOM:EN:HTML（accessed May 2011)

On 19 May 2010 a recast of The Directive on energy performance of buildings” (2002/91/EC) was adopted in order to strengthen the energy performance requirements and to clarify and streamline some of its provisions. The Directive on energy performance of buildings (2002/91/EC) is the main legislative instrument at EU level to achieve energy performance in buildings. Under this Directive, the Member States must apply minimum requirements as regards the energy performance of new and existing buildings, ensure the certification of their energy performance and require the regular inspection of boilers and air conditioning systems in buildings.

The recast calls for member states to ensure that all new buildings are nearly zero-energy buildings by 31 December 2020, and that new buildings occupied and owned by public authorities are nearly zero-energy buildings by 31 December 2018. They shall adopt national plans with intermediate targets for improving the performance of new buildings by 2015. 'Nearly zero-energy buildings' are defined as buildings requiring nearly zero or very low amount of energy that can be covered to a very significant extent by energy from renewable sources, including energy from renewable sources produced on-site or nearby.

The Commission should lay down a comparative methodology framework for calculating costoptimal levels of minimum energy performance requirements. It is the sole responsibility of Member States to set minimum requirements for the energy performance of buildings and building elements. Member States must justify any discrepancies greater than 15 percent between the calculated cost-optimal level and the minimum energy performance requirements in effect, or plan appropriate steps to reduce the discrepancy.

\section{A5.8 Germany "Renewable Energy in the Heat Sector Act of 2008"}

http://www.bmu.de/english/renewable_energy/downloads/doc/42351.php (accessed May 2011). Three documents:

- "Act on the Promotion of Renewable Energies in the Heat Sector (Erneuerbare-EnergienWärmegesetz-EEWärmeG) of 2008.” This translation is a legally non-binding version. Only the version published in the Federal Law Gazette (Bundesgesetzblatt) 2008 I No. 36, p. 1658, published on 18 August 2008, is legally binding.

- "Consolidated Justification."

- "The Renewable Energies Heat Act (EEWärmeG) in Brief.”

The Act requires the use of renewable energy to meet a percentage of a building's thermal energy demand. The requirements apply to both residential and non-residential buildings. The percentage varies by renewable energy source:

- Solar thermal - $15 \%$, or for residential only $0.04 \mathrm{~m}^{2}$ per $\mathrm{m}^{2}$ of heated floor area

- Alternative energy savings measures (i.e., insulation) $-15 \%$

- Gaseous biomass - 30\%

- Liquid or solid biomass $-50 \%$

- Geothermal (incl. air-to-air heat pump >3.5 Seasonal Performance Factor) - 50\%

- Waste heat or combined heat and power (CHP) - 50\% 
It is important to note that energy-savings measures and heat pumps, including both ground source and air-to-air heat pumps, may satisfy the requirements. Except for residential solar thermal systems, the requirements are performance-based; applicants must submit calculations of the building's thermal load and proof that the renewable energy system will provide the required percentage of that load.

At the time of this writing information on the split between renewable energy technologies used to meet the requirements of the law were unavailable. How many buildings are installing energy savings measures or air-to-air heat pumps to meet the law is unknown.

\section{A5.8.1 Marburg, Germany}

Marburg passed an ordinance requiring the use of solar-heating panels on new homes and homes undergoing renovations, including homes getting new heating systems or roof repairs. The law requires 1 square meter of solar panel for every 20 square meters of heated floor space, with a minimum size of 4 square meters. The City may impose a fine of $€ 1,000$ on those who do not comply. Exempt from the new law are buildings with an existing district heating system, a combined heat and power generator, or a wooden pellet oven.

The ordinance may have unintended consequences. The article cites one example, Götz Schönherr, who already has solar panels on his roof. He hoped to reinsulate his home, but to satisfy the regulation, he would have to install a larger solar panel than he currently has, leading him to not insulate the roof. The ordinance was counterproductive.

Links to articles about Marburger Solarsatzung: http://www.marburg.de/detail/95284 (accessed May 2011) http://www.marburg.de/detail/93470?vt=*Solarsatzung (accessed May 2011) Kulish, Nicholas. “German City Wonders How Green Is Too Green.” New York Times, August 6, 2008. http://www.nytimes.com/2008/08/07/world/europe/07solar.html (accessed May 2011)

\section{A5.9 Greece}

Volioti, Zoi. "Can the Sunshine Be Enough? An Evaluation of the Greek Photovoltaic Rooftop Programme.” Masters Thesis, Lunds Universitet, 2010. http://www.lumes.lu.se/database/alumni/08.10/Thesis/Volioti_Zoi_Thesis_2010.pdf (accessed May 2011)

Greece provides incentive for residential solar water heating and photovoltaics, but no building code requirements. In June 2009 the Greek Minister of Development announced the Joint Ministerial Decision for free PV installation projects of up to $10 \mathrm{KWp}$, for use on the roofs of houses and business buildings. This will mean easier and faster procedures for buildings' owners, who can then take the license to install PV panels on their roofs. This program will be valid until December of 2019. Under Greece's Feed-in Tariff, building owners, after covering their needs in energy consumption, will sell the rest of the energy which they produce to DEI SA (Public Power Corporation) at a higher price than they pay to DEI for each kW. http://www.pvtech.org/tariff_watch/greece (accessed May 2011) 
Baerbel Epp. “Greece Mandates Solar for New and Refurbished Buildings.”, Global Solar Thermal Energy Council 15-Dec-2010. http://www.solarthermalworld.org/node/1521 (accessed May 2011)

As of January 2011, all new buildings in Greece have to cover at least $60 \%$ of their domestic hot water demand by solar technology. This regulation is part of law L3851/2010 to implement Directive 2009/28/EC, “on the promotion of the use of energy from renewable sources”, in combination with L3661/2008, which is part of the implementation process of the European Energy Performance of Buildings Directive (EPBD).

Ministry of Environment, Energy, and Climate Change. "National Renewable Energy Action Plan in the Scope of Directive 2009/28/EC.” 2010. www.ypeka.gr/LinkClick.aspx?fileticket=CEYdUkQ719k\%3d\&tabid=37 (accessed May 2011)

"L3851/2010 on "Accelerating the development of Renewable Energy Sources to deal with climate change and other regulations in topics under the authority of MEECC".

The new law complements L3661/2008, by setting new requirements that stipulate the coverage of $60 \%$ of the need of new buildings for hot water by solar thermal systems after 1 January 2011. ... Furthermore, L3851/2010 stipulates that by 31.12.2019, all new buildings must cover the total of their primary energy consumption with RES, CHP, district heating on a large area scale/block scale as well as heat pumps. This requirement is extended to all new public buildings by 31.12.2014 at the latest.”

\section{A5.10 India}

"Building Sector Policies and Regulation for the Promotion of Solar Water Heating Systems." Prepared by CTRAN Consulting for India Ministry of New and Renewable Energy, March-2010. http://mnre.gov.in/pdf/Uniform\%20Policy\%20on\%20Solar\%20Water\%20Heating.pdf (accessed May 2011)

Several jurisdictions (Karnataka, Chandigarh Union Territory, others) require the use of solar water heaters for industries where hot water is required; hospitals and nursing homes; hotels, motels, banquet halls and guest houses; jails, barracks, and canteens; housing complexes; residential buildings greater than 600 square feet of floor area; government buildings, schools, and other educational and institutional buildings.

At the national level a draft Solar Water Heating Order is being considered. It would require solar water heating for:

- Housing;

- Residential, cantonment, barracks and prisons including sanatorium;

- Sporting complexes;

- Commercial establishments premises like hotels, restaurants, shopping complexes, multi-plexes,

- IT Complex; 
- Industrial, in general if hot water is needed for the process and, also, when the installation of showers for the staff is mandatory, any other which involves the existence of dining-rooms, kitchens or collective laundries.

- High-raise buildings as defined by respective local bodies

- Swimming pools.

The amount required would be based on the following table:

\begin{tabular}{|l|c|}
\hline \multicolumn{1}{|c|}{ Type of Use } & $\begin{array}{c}\mathbf{1 0 0} \text { litres per day shall be provided } \\
\text { for every unit below: }\end{array}$ \\
\hline Restaurants $>100 \mathrm{~m}^{2}$ & $40 \mathrm{~m}^{2}$ of seating area \\
\hline Lodging establishments and tourist homes & 3 rooms \\
\hline Hostel and guest houses & 6 beds/person capacity \\
\hline Industrial canteens & 50 workers \\
\hline Nursing homes and hospitals & 4 beds \\
\hline Community halls and convention halls & $30 \mathrm{~m}^{2}$ of floor area \\
\hline Recreation clubs & $100 \mathrm{~m}^{2}$ of floor area \\
\hline Single-family residential & Single unit $>200 \mathrm{~m}^{2}$ \\
\hline Multi-family residential & 500 lpd for every 5 units \\
\hline
\end{tabular}

A three year lead-time is recommended before the law takes effect. It is recommended to cover all types of residential and commercial buildings, but a compromise would be to require solar water heating in commercial buildings first while providing incentives for residential buildings. For maximum effect, the report recommends adoption of "flanking" measures such as bureaucratic streamlining and provision of loans and incentives.

\section{A5.11 Ireland}

S.I. No. 854 of 2007 (http://www.irishstatutebook.ie/2007/en/si/0854.html) (accessed May 2011) requires that new dwellings be designed and constructed so that a reasonable proportion of the energy consumption of the dwelling is provided by renewable energy sources. The Ministry for Environment, Heritage, and Local Government, has established defined this as " $10 \mathrm{kWh} / \mathrm{m}^{2} /$ year contributing to energy use for domestic hot water heating, space heating or cooling; 4 $\mathrm{kWh} / \mathrm{m}^{2} /$ year of electrical energy, or a combination of these which would have equivalent effect.” (Technical Guidance Documents, Part L: Conservation of Fuel and Energy Conservation-Dwellings, http://www.environ.ie/en/TGD/) (accessed May 2011) .

Buildings larger than $1,000 \mathrm{~m}^{2}$ shall consider the use of decentralized (on-site) renewable energy, but there is no mandatory requirement to use renewables. (S.I. No. 666 of 2006, http://www.irishstatutebook.ie/2006/en/si/0666.html) (accessed May 2011).

\section{A5.12 Israel}

Mentaneau, Phillipe. World Energy Council. Policy Measures to Support Solar Water Heating. http://www.worldenergy.org/documents/solar_synthesis.pdf (accessed May 2011). May, 2007. 
Historically, Israel was the first country in 1980 to introduce a regulation about the use of solar energy in new buildings for reasons of energy security. This legislation has had a great success and made SWHs a mainstream technology.

“The History of Solar Water Heating.” http://www.sunbelt-solar.com/history.html (accessed May 2011). "The new Jewish state had so little electricity that it prohibited its daytime use for household water heating - a rule enforced by energy police. Seeing in this a business opportunity, an engineer who had visited Florida adapted the design for Israel's special needs. With the capture of oil fields in Egypt's Sinai Peninsula during the Six-Day War, Israelis had sufficient fuel supplies to run electric water heaters cheaply, driving solar water heaters nearly out of business. Six years later, with the Arab oil embargo, the subsequent loss of Sinai and the rise of an unfriendly government in Iran turning off its oil spigot to Israel, the solar water heater business moved out of the shade. The government mandated the use of solar water heaters on all buildings less than 27 meters in height.

"Currently, Israel shares with Cyprus the highest per-capita use of solar water heaters in the world, and more than 90 percent of Israeli households heat their water with the sun. Interestingly, neither nation provides any monetary incentives for using solar water heaters.

“Solar Power in Israel.” http://en.wikipedia.org/wiki/Solar_power_in_Israel (accessed May 2011) Israel has required solar water heaters for new homes since 1980, and for all residential buildings since the early 1990s. Israel estimates that solar water heaters meet about $4 \%$ of Israel's total energy demand.

Sternman, David. “Israel's Solar Industry: Reclaiming the Legacy of Success.” Climate Institute. http://www.climate.org/topics/international-action/israel-solar.html (accessed May 2011), July, 2009.

\section{A5.13 Japan}

“Japan Energy Conservation Handbook, 2009.” http://www.asiaeeccol.eccj.or.jp/databook/2009e/index.html (accessed May 2011). Chapter 2: Energy Conservation Laws and Policies in Japan.

Evans, Meredydd, et. al. “Country Report on Building Energy Codes in Japan.” Pacific Northwest National Laboratory, April 2009.

Energy Conservation Law (Law Concerning the Rational Use of Energy), was adopted in 1979 and amended in 1983, 1993, 1998, 2002, 2005 and 2008. Under the Energy Conservation Law, Japan has issued a set of building energy standards for commercial and residential buildings. The Criteria for Clients on the Rationalization of Energy Use for Buildings (CCREUB) was first issued in 1979, and the newest version was released in 1999 by the Ministry of International Trade and Industry (MITI) and the Ministry of Construction (MoC). There are two building energy standards related to residential buildings: (1) Design and Construction Guidelines on the Rationalization of Energy Use for Houses (DCGREUH), issued by MoC in 1980, and later 
revised in 1992 and 1999; and (2) Criteria for Clients on the Rationalization of Energy Use for Houses (CCREUH), issued by MITI and MoC in 1980, and later revised in 1992 and 1999.

Owners of small and medium-sized buildings must submit plans before proceeding with construction or renovation. The code is primarily performance-based. Solar energy is allowed as one of several ways to meet water heating efficiency requirements in commercial buildings.

\section{A5.14 Portugal}

European Renewable Energy Council. "Portugal: Renewable Energy Policy Review.” http://www.erec.org/fileadmin/erec_docs/Projcet_Documents/RES2020/PORTUGAL_RES_Poli cy_Review_09_Final.pdf (accessed May 2011). The System of Energy Certification (SCE) for buildings complemented by a Regulation on energy conditioning in Buildings (RSECE) and a Regulation on the Thermal properties of buildings (RCCTE) are pieces of legislation passed in mid 2006. They develop a strategy to implement the directive 2002/91/CE on the Energy Certification of Buildings. The RSECE, in its article 14, determines the conditions under which a newly built building should be provided with a centralised energy conditioning system, obliging to make use of RES sources in all those cases where a study proves that it is financially viable. The National Energy Agency ADENE is the body in charge of the implementation of the Certification System. Heat from biomass boilers is one of the technologies benefiting from this new scheme.

European Commission. “Implementation of the EPBD in Portugal: Status and Planning.” P-08, 11-09-2006. Decree 80-2006, revisions to Thermal Regulations for Buildings (RCCTE, Articles 3-6). Mandatory solar water heating on all buildings, effective either 2008 or 2009 depending on the size of the building.

CEETNA. "REFUND+: Quantitative and Economic Assessment of Direct Fiscal Measures - A Portuguese Case Study.” November, 2007. http://ftpnrj.free.fr/refund+/Portuguese_economic_report.pdf (accessed May 2011) “In April 2006, Portugal adopted new building codes in order to comply with European directive 2002/91/CE: the code on energy supplying systems in buildings (RSECE) and the code on thermal performances of buildings (RCCTE). The last one requires the use of solar thermal collectors for hot water production in new or renovated buildings (in the case where exposure conditions are favorable) on the basis of one square meter per person.” Fn 5, page 8 (also on page 17)

European Solar Thermal Industry Federation. “Country Reports: Portugal.” http://www.estif.org/solarkeymark/skii/results/countryreports/final/PORTUGAL-FINAL.pdf (accessed May 2011) “Thermal Performance Building Code: (RCCTE) (Decreto-Lei n. ${ }^{\circ}$ 80/2006. DR 67 SÉRIE I-A de 2006-04-04): Improves the existing code, requiring $1 \mathrm{~m}^{2}$ per person of solar water heating if there is favourable conditions for exposure (if the roof or cover runs between SE and SW without significant obstructions). The total can be reduced to $50 \%$ if space is necessary for other important usages of the building. This performance calculation is done using a programme developed by INETI - Solterm programme. The installers of these systems must be certified, and the solar system must have a six year guarantee. “ 


\section{A5.15 Spain}

\section{A5.15.1 Solar Thermal}

European Solar Thermal Industry. "The Spanish Technical Building Code, Royal Decree 314:2006 of 17 March 2006: English Translation of the Solar Thermal Sections.” Accessed at: www.estif.org/policies/solar_ordinances (accessed May 2011) Spain requires the installation of a solar water heater on a newly constructed or renovated building in which there is a demand for domestic hot water and/or the conditioning of a covered swimming pool. System size varies by climate zone and the hot water load of the building, on a sliding scale ranging from $50 \%$ to $70 \%$ if the backup energy source is electricity, and $30 \%$ to $70 \%$ of the demand if the backup energy source is natural gas, propane, and other. The law specifies the minimum water heating load to be used for design purposes for about 20 categories of residential and nonresidential buildings. The effects of collector orientation and tilt shall be factored in to the sizing calculation, and if the losses exceed a specified amount based on whether the collector is architecturally integrated, parallel to the flat to the roof, or other, the solar water heating requirement is waived. The law also provides minimum system safety requirements, including but not limited to frost protection, overheating protection, resistance to pressure, backflow prevention, piping, electrical connections, structural mounting, etc.

\section{A5.15.2 Photovoltaic}

Spain's law can be accessed in the original language at http://ec.europa.eu/environment/etap/pdfs/sept06_construction_norm_spain.pdf (accessed May 2011)

Koot, Edwin, "Spanish Markets in Need of Permits.” Solar Plaza, 13-Sept-2007. (Solar Plaza BV, Rotterdam, Netherlands) http://www.solarplaza.com/article/spanish-market-in-need-ofpermits (accessed May 2011) The new 314/2006 Royal Decree provides a Technical Building Code (TBC) that enforces (as of 29 September) the installation of PV on new large buildings, such as offices, government buildings, hospitals, etc.). The government agency IDAE estimates that this Decree will result in some 68-93 MWp of PV installations as part of the planned 363 MW target until 2010. The aim of this Decree is to stimulate integrating PV into buildings. The PV system should be part of the building design like any other installation and has to be part of the building permit granted by the local administration. The amount of PV to be installed can be calculated by applying a specific formula."

Herrero, Jose (Jose.herrero@ciemat.es). "Spanish Initiatives and Update of National PV Program.” Ministerio de Educaciony Ciencia (CIEMAT-MEC Renewable Energy Division), presented to PV ERA NET $8{ }^{\text {th }}$ Consortium Meeting, 29/30-March-2007, www.eupvplatform.org/fileadmin/Documents/MG_070403_Spain.pdf (accessed May 2011) Spain requires the use of photovoltaics in several categories of large non-residential buildings (Technical Building Code - Código Técnico de la Edificación, Section HE-5). The minimum building size to which the law applies is listed in Table 1, below. System size varies by building type, building size, and climate zone. To determine the system size, multiply coefficient A for the appropriate building type times the building size, add (or subtract) coefficient $\mathrm{B}$, and multiply 
the sum by the climate zone coefficient. The country is divided into five solar climate zones, each with a different multiplier relating to an additional 10\% difference in the solar resource relative to zone 1 . The minimum photovoltaic system size is $5 \mathrm{~kW}$.”

Table: Spain Photovoltaic

\begin{tabular}{|l|c|c|c|}
\hline Building Use & Minimum Size $(5 \mathrm{~kW})$ & Coefficient A & Coefficient B \\
\hline Supermarkets & $5,000 \mathrm{~m}^{2}$ & 0.001875 & -3.125 \\
\hline Retail & $3,000 \mathrm{~m}^{2}$ & 0.004688 & -7.8125 \\
\hline Warehouses & $10,000 \mathrm{~m}^{2}$ & 0.001406 & -7.8125 \\
\hline Offices & $4,000 \mathrm{~m}^{2}$ & 0.001223 & 1.3587 \\
\hline Hotels & $100 \mathrm{rooms}$ & 0.003156 & -7.8125 \\
\hline Hospitals and clinics & $100 \mathrm{beds}^{2}$ & 0.000740 & 3.28947 \\
\hline Pavillions & $10,000 \mathrm{~m}^{2}$ & 0.001406 & -7.8125 \\
\hline
\end{tabular}

Table: Climate Zone Coefficient

\begin{tabular}{|c|c|}
\hline Climate Zone & Coefficient \\
\hline I & 1.0 \\
\hline II & 1.1 \\
\hline III & 1.2 \\
\hline IV & 1.3 \\
\hline V & 1.4 \\
\hline
\end{tabular}

See also:

Caamano-Martin, Estefania. "Solar Urban Planning: The National State of the Art in Spain.: Intelligent Energy Europe. November 2009. www.polissolar.eu/IMG/pdf/Spain_National_Assessment.pdf (accessed May 2011)

\section{A5.15.3 Barcelona}

Mentaneau, Phillipe. World Energy Council. Policy Measures to Support Solar Water Heating. http://www.worldenergy.org/documents/solar_synthesis.pdf (accessed May 2011). May, 2007. "In 1999 the Barcelona City Council drew up municipal regulations which were extended in to the rest of the country in March 2006 when the new Technical Building Code was introduced. The purpose of the Code is to promote the use of SWH systems in all new or renovated buildings. It stipulates that in such buildings $60 \%$ of hot water demand must be met by SWH.

"The introduction of this regulation gave rise to numerous debates and protests. In particular, it was necessary to win over the various actors in the construction sector (architects, builders, investors, etc.). The most difficult group were the investors, who were not entirely convinced of the wisdom of such a choice, nor of the reliability of the technology. They were also concerned about the possible impact of the extra cost of solar installations on the construction market, and especially any extra time that might be needed to obtain equipment that was not readily available. Finally a moratorium of several months was allowed before the regulation was enforced to give everyone time to adjust to the new requirements. This is an example of a regulatory decision applicable across the board and which was drawn up with the general agreement of all the stakeholders. 
"The results achieved by Barcelona demonstrate the effectiveness of this approach, since the average surface area of collectors installed each year increased from 1,650 m² (i.e. $1.1 \mathrm{~m}^{2} / \mathrm{inhab}$.) before the Ordinance to 19,600 $\mathrm{m}^{2}$ (i.e. $13 \mathrm{~m}^{2} / \mathrm{hab}$.) in 2004 (Pujol T., 2004). The additional investment cost was finally kept to within 0.5 and $1 \%$ of total construction costs and was covered by no-interest loans offered by the Instituto de Crédito Oficial (Stirzaker, 2004).

"Regulatory measures result in a much larger market for the technology and can thereby help improve performance (reliability/cost) and enhance the visibility of the technology, as well as setting in motion a virtuous spiral that will lead to greater diffusion. Nevertheless, minimum quality levels must be imposed to prevent the solar energy obligation from encouraging the use of inexpensive but inefficient equipment. Standards and quality labels can ensure that such minimum requirements are met.”

\section{Page 24-25: Barcelona Experience}

"The Barcelona Solar Ordinance went into force in August 2000 (ESTIF), after a one-year moratorium to allow builders time to adjust. According to this bylaw all new buildings and buildings undergoing major refurbishment are obligated to use solar energy to supply $60 \%$ of their running hot water requirements. Swimming pool heating must be $100 \%$ from solar. ... Exemptions are being considered in cases where it is technically impossible to cover $60 \%$ of hot water requirements with a solar system but a technical study should justify such an exemption. The projects that do not follow the Municipal Ordinance are liable to sanctions with fines that may reach 3 million euros (Stirzaker P., 2004).

"The extra investment incurred by the Ordinance is estimated to be $0.5 \%-1 \%$ in building work and materials (Stirzaker P., 2004). This extra-investment may be financed by interest-free credit arrangements available from IDEA and the public credit institute, Instituto de Crédito Oficial (ICO). The credit backs up to 70\% of total investment (Ibid.) Even with such financing arrangements, reaching a consensus with all the stakeholders involved in the construction sector was essential to the success of the ordinance.

"Property developers, construction companies, architecture colleges and installation contractors have all been closely associated to the construction and implementation of the regulation. Nevertheless, a 18-month moratorium has been introduced for all the sectors to prepare for the new regulation and for installers to gain statutory certification. In parallel, the standard certification of solar systems and installation has been developed in order to prevent the installation of low quality equipment as a result of the ordinance. The City of Barcelona has also implemented a broad communication program and organized periodic round tables in order to promote and facilitate the acceptance of the Ordinance.”

\section{Page 13: from Conclusions}

"The regulatory approach exemplified by the Solar Ordinance is the perfect example of a package of measures where the complementarity of the instruments is vital. For regulations to work, they must be accompanied by information and awareness programmes, measures to maintain or improve quality (standards / labels), training and certification of installation contractors, special supply-side support measures (R\&D programmes, opportunities to achieve 
economies of scale), urban planning regulations that take into account solar energy, etc., and more generally the motivation and involvement of all the stakeholders in the sector.

"In addition to complementary instruments, policies to support the SWH sector must be designed on the basis of the maturity of the target markets. Although subsidies are generally effective, they could become counterproductive if they are introduced too late. When the market reaches a certain size, new building regulations or technical standards can gradually take over from economic incentives, at least those in the form of direct subsidies.”

PV Upscale. "Strategies for the Development of PV in Barcelona," 2008. http://www.pvupscale.org/IMG/pdf/Case-Study_Barcelona.pdf (accessed May 2011)

In 1999 Barcelona was the first European city to develop a Solar Thermal Ordinance making it compulsory to use solar energy to supply at least $60 \%$ of hot water demand in all new buildings, renovated buildings or buildings changing their use.

In 2003-04 the Barcelona Energy Agency and Barcelona Regional carried out a study to promote PV in buildings, with the aim of complementing the requirements stated by the Spanish Technical Building Code. A Solar PV Ordinance for the Municipality of Barcelona has been developed, with the aim of increasing PV penetration in the urban scale. It has specific energy targets for the following building types:

- Commercial and tertiary (services) buildings (new or renovated) with a minimum roof surface of 3,500 m2: the objective is to produce $10 \%$ of electricity consumption with PV.

- Office buildings (new or renovated) with a minimum surface of 1,500 m2: the objective is to produce $12 \%$ of electricity consumption with PV.

In 2002 the Barcelona Energy Agency (AEB) was entrusted by the Barcelona City Council to integrate PV in highly visible public buildings. By the end of 200839 projects had been carried out in public buildings across all city districts, with a total installed PV power of $1.65 \mathrm{MWp}$ :

- Barcelona City Council and districts buildings: 5 projects, $99 \mathrm{kWp}$.

- Social and cultural centres: 10 projects, $106 \mathrm{kWp}$.

- Primary and Secondary schools: 12 projects, $90 \mathrm{kWp}$.

- Public libraries: 6 projects, $65 \mathrm{kWp}$.

- Pergolas in public areas: 3 projects, $1198 \mathrm{kWp}$.

- $\quad$ Others (parks, markets, urban waste disposal plant): 3 projects, $90 \mathrm{kWp}$

The Ordinance requires that all new buildings and major renovations with a daily average energy consumption for hot water supply exceeding 292 MJ (approx. 2000 litres) generate at least 60 percent of the required energy is sourced from solar water heaters. Furthermore, the Ordinance regulates that heating of swimming-pools must be realised with a 100 percent of solar energy. The installation obligation covers all residential buildings, hospitals, gymnasiums and commercial buildings, which exceed the limit mentioned above. In case of residential buildings this is usually the case for buildings with more than 16 to 17 units of 4 persons each. The Barcelona model has been adopted by other cities such as Madrid and Seville. 
As a result of the ordinance, about 40 percent of newly constructed buildings in Barcelona have a solar water heater.

(p. II-4) The success of Barcelona Model is due to a fairly long period participatory planning exercise involving key stakeholders, that helped in understanding the problem areas and addressing it. Most of these areas were technical and a few were policy related. Second important point was the amendment taking into account the views and having a cool off period before full enforcement. It also had an institutional mechanism to act as pressure point and conscience keeper as well technical back-stopper. Then finally sustained political commitment saw its steady implementation. 


\section{APPENDIX B}

Complete Results of Renewables Integration Survey 



\section{Appendix B: Complete Results of Renewables Integration Survey}

\section{Background}

Members of the energy code, renewable energy, and energy efficiency buildings community were surveyed to solicit feedback about integrating renewable energy requirements into building energy codes. The survey was open from August 19-September 20, 2010.

\section{Methodology}

Standard survey techniques.

- Sample size: 160

- Surveys started: 75

- Started and not completed: 19

- Completed responses: 56

- Response rate: $~ 35 \%$ 


\section{Findings}

\section{Please choose the description below that best represents the type of work you do:}

(Respondents could only choose a single response)

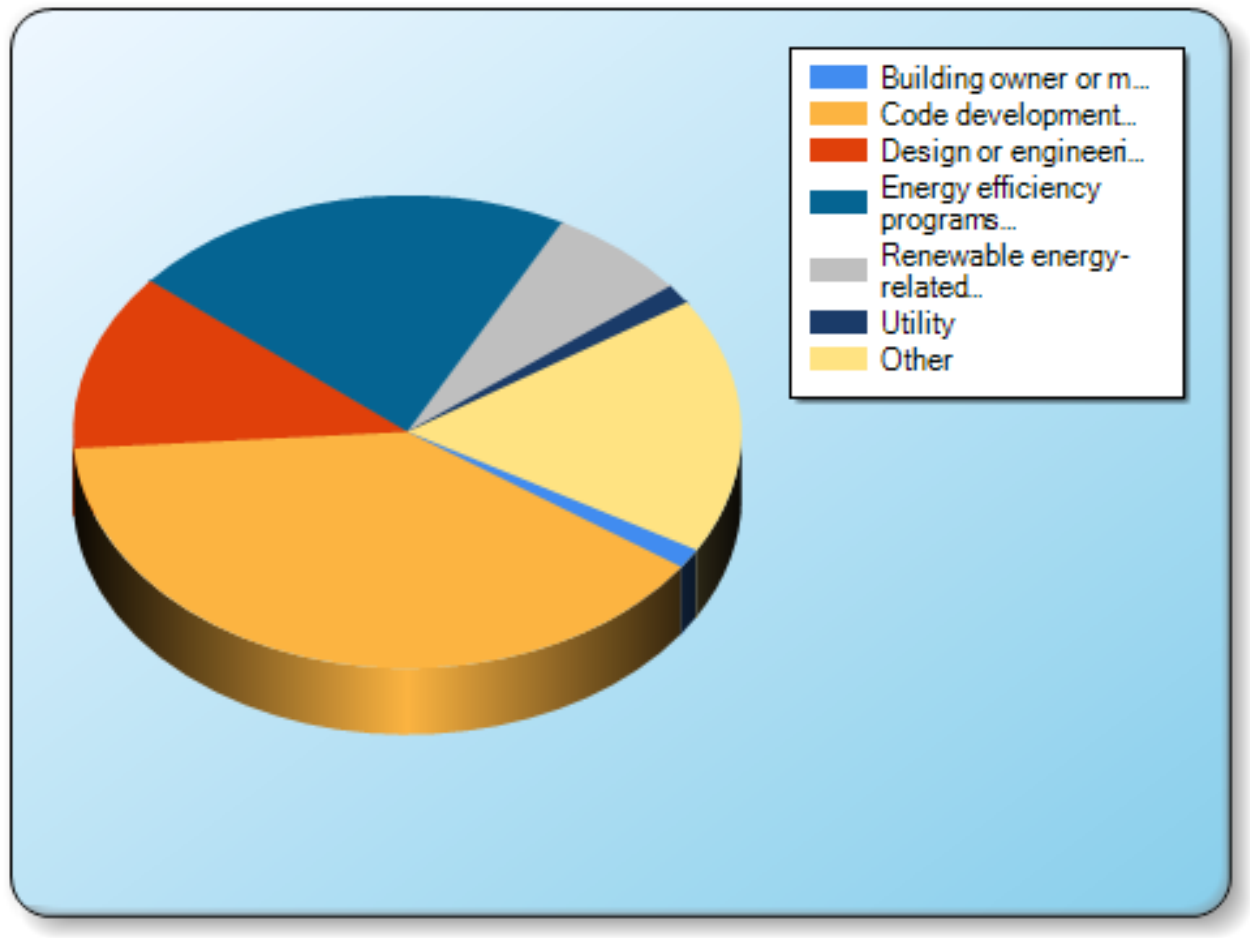

Please choose the description below that best represents the type of work you do: (Respondents could only choose a single response)

\begin{tabular}{|c|c|c|c|}
\hline Response & Chart & Frequency & Count \\
\hline Building owner or manager & & $1.4 \%$ & 1 \\
\hline $\begin{array}{l}\text { Code development or } \\
\text { enforcement }\end{array}$ & & $39.2 \%$ & 29 \\
\hline Design or engineering & & $12.2 \%$ & 9 \\
\hline $\begin{array}{l}\text { Energy efficiency programs or } \\
\text { advocacy }\end{array}$ & & $21.6 \%$ & 16 \\
\hline $\begin{array}{l}\text { Renewable energy-related } \\
\text { business or organization }\end{array}$ & & $6.8 \%$ & 5 \\
\hline Utility & & $1.4 \%$ & 1 \\
\hline Other & & $17.6 \%$ & 13 \\
\hline Not Answered & & & 1 \\
\hline \multicolumn{3}{|r|}{ Valid Responses } & 74 \\
\hline
\end{tabular}


Please choose the description below that best represents the type of work you do: (Other, please specify)

\begin{tabular}{l} 
Response \\
Code Regulator \\
\hline ZEB research \\
\hline Academic \\
\hline Utility trade association \\
\hline consultant \\
\hline PV R\&D and Codes \\
\hline Researcher \\
\hline R\&D \\
\hline Educator \\
\hline state energy office \\
\hline solar industry trade association \\
\hline Academic-Architectural Engineering
\end{tabular}




\section{Are you a member of an ASHRAE or ICC Committee that deals with energy codes?}

(Respondents could only choose a single response)

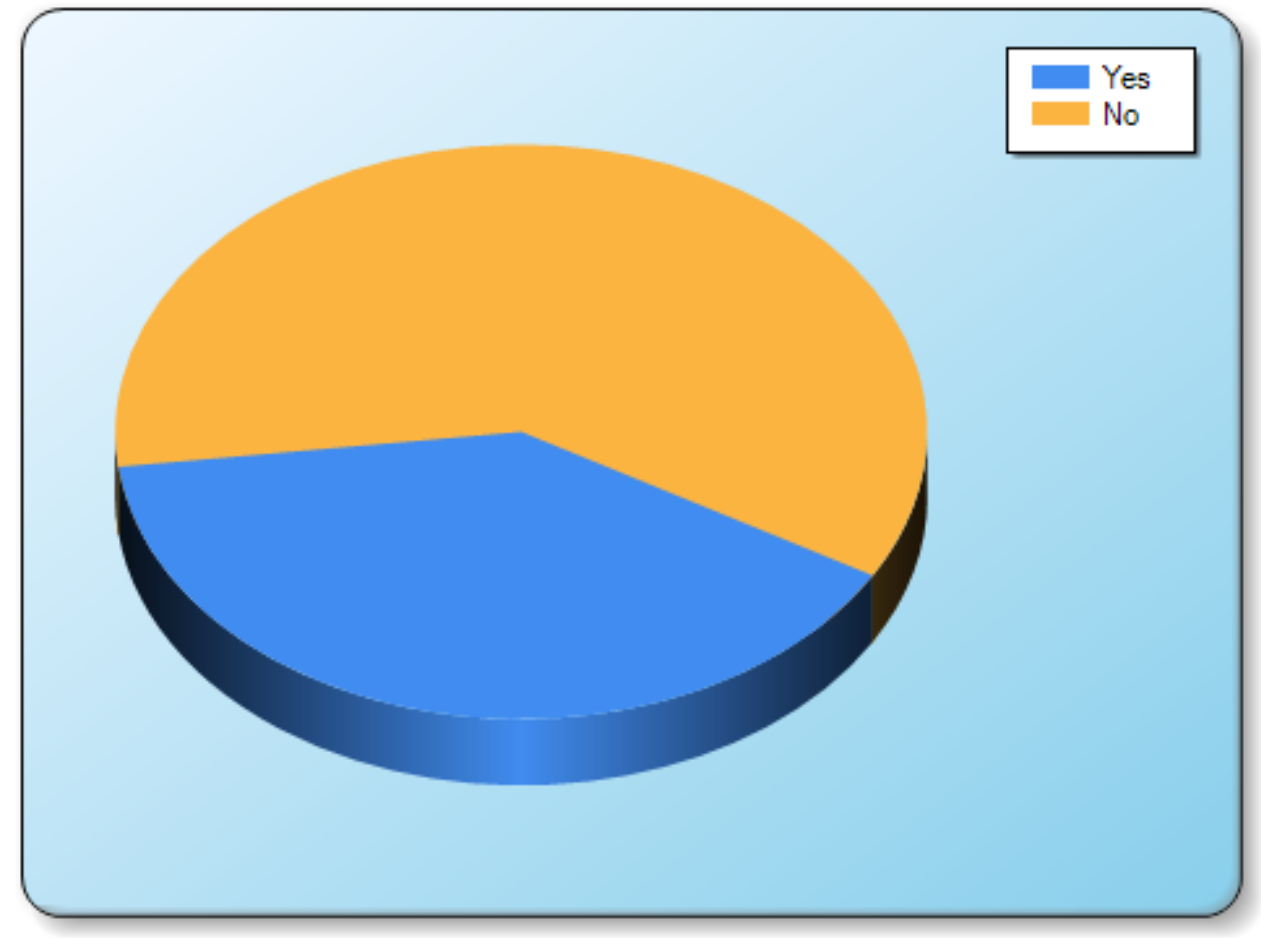

Are you a member of an ASHRAE or ICC Committee that deals with energy codes? (Respondents could only choose a single response)

\begin{tabular}{|l|l|l|l|}
\hline Response & Chart & Frequency & Count \\
\hline Yes & $39.7 \%$ & 29 \\
\hline No & $\mathbf{6 0 . 3 \%}$ & $\mathbf{4 4}$ \\
\hline Not Answered & & 2 \\
\hline & Mean & 1.603 \\
\hline & Standard Deviation & 0.493 \\
\hline & Valid Responses & $\mathbf{7 3}$ \\
\hline & Total Responses & $\mathbf{7 5}$ \\
\hline
\end{tabular}


1: Are there any electrical, plumbing, fire, building, mechanical or other code issues that you think are significant barriers to the use of renewable energy systems or have they mostly been addressed by IAPMO, ICC, IPC, IEC, IBC, ASME, ASTM, NFPA, and other standards?

(Respondents could only choose a single response)

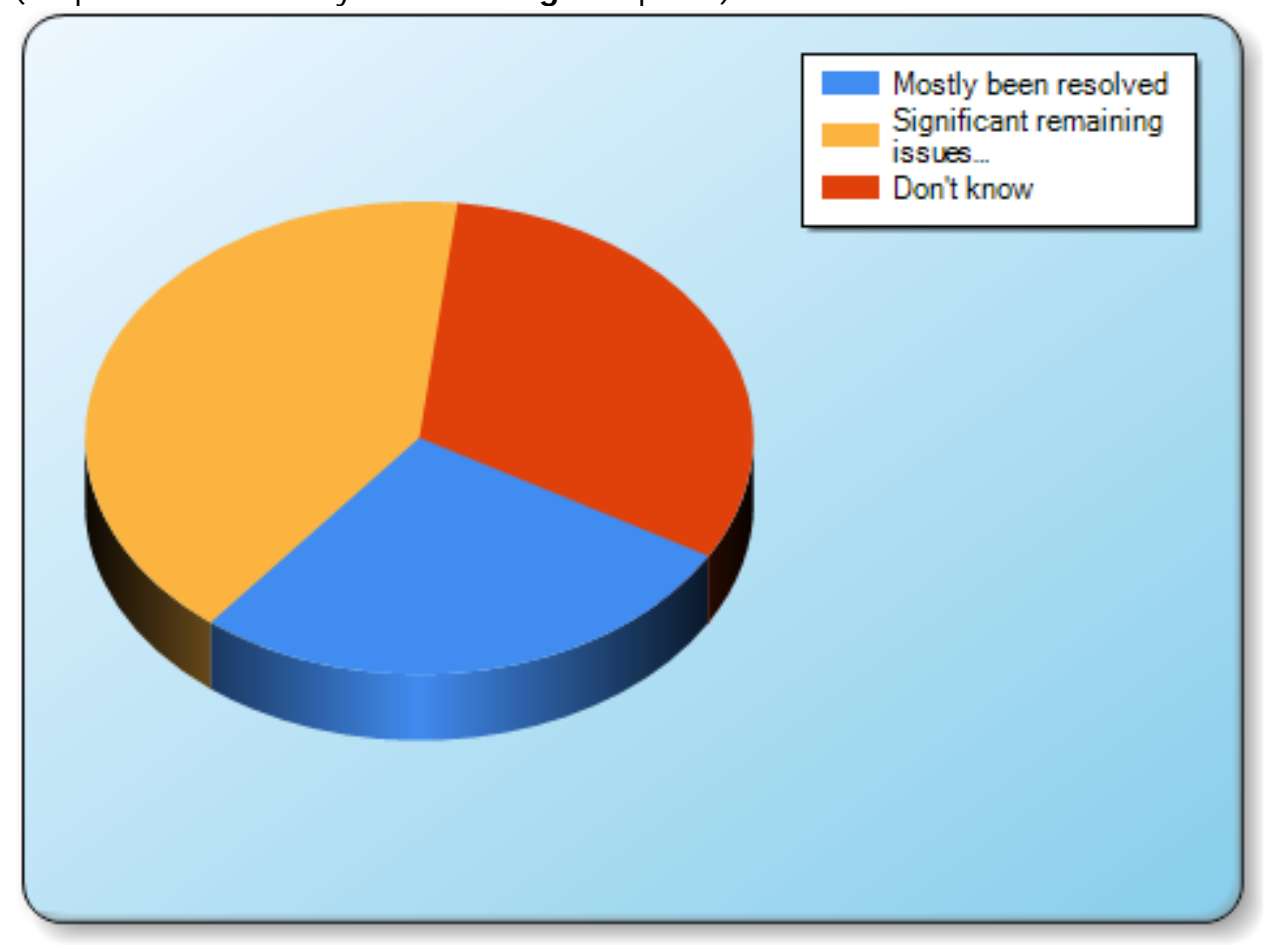

1: Are there any electrical, plumbing, fire, building, mechanical or other code issues that you think are significant barriers to the use of renewable energy systems or have they mostly been addressed by IAPMO, ICC, IPC, IEC, IBC, ASME, ASTM, NFPA, and other standards? (Respondents could only choose a single response)

\begin{tabular}{|c|c|c|c|c|}
\hline Response & \multicolumn{2}{|l|}{ Chart } & Frequency & Count \\
\hline Mostly been resolved & & & $27.4 \%$ & 20 \\
\hline $\begin{array}{l}\text { Significant remaining } \\
\text { issues (please describe) }\end{array}$ & & & $41.1 \%$ & 30 \\
\hline Don't know & & & $31.5 \%$ & 23 \\
\hline \multirow[t]{5}{*}{ Not Answered } & & & & 2 \\
\hline & & \multicolumn{2}{|c|}{ Mean } & 2.041 \\
\hline & & \multicolumn{2}{|c|}{ Standard Deviation } & 0.772 \\
\hline & & \multicolumn{2}{|c|}{ Valid Responses } & 73 \\
\hline & & \multicolumn{2}{|c|}{ Total Responses } & 75 \\
\hline
\end{tabular}


1: Are there any electrical, plumbing, fire, building, mechanical or other code issues that you think are significant barriers to the use of renewable energy systems or have they mostly been addressed by IAPMO, ICC, IPC, IEC, IBC, ASME, ASTM, NFPA, and other standards?

\section{Significant remaining issues (please describe)}

Response significant remaining issues

Wind towers are not covered and structural references to solar systems does is not specifically mentioned.

Related to wind and fire ratings of PV attached to buildings. Also codes limiting the electrical services (such as voltage support) able to be provided by inverters. I know groups are working on these code changes.

Code Coordination with other codes is still a issue

Fire code issues with being able to chop through a roof if it is covered in PV

Safety issues are a major impediment to energy code enforcement.

Just pulling permits from one jurisdiction to the next can be a real problem. They reinvent the wheel.

disconnect switches (safety/fire code),

Example: residential energy codes for windows that specify a shading coefficient without considering that in different climates and orientations, higher shading coefficients may be more energy efficient, and in others lower shading coefficient may perform

extensive code barriers for water collection and re-use; not an energy issue, but related

IPC - Water Re-use

rooftop PV and fire officials

issues relating to fire safety, and structural alterations that may impact safety of residents and firefighters required for some renewables are NOT resolved

Equipment oversizing issues not being adequately addressed except in Energy Star and RESNet

Air sealing performance only sufficiently covered in Energy Star \& RESNet

Indoor hydrogen fueling (forklifts) needs to be better addressed in the IFC, Clear language

addressing the installation of electrolyzers for hydrogen production, Large battery

manufacturing/repair/storage/charging needs to be more clearly addressed.

Envelope air sealing performance affecting the use of renewables

life/safety is often an exaggerated barrier to innovation

fire hazards associated with PV on structures

Growing issues with respect to PV and emerging fire codes.

Coordination with fire codes for rooftop installed solar collectors; local jurisdictional codes/bylaws, etc. limiting rooftop solar collectors. integration of solar as an element of building codes; solarorientation impacts need to be integrated into bldg

Need for walkways around roof mounted systems. Fire rating on water-filled polymer collectors:

should be no issue

Code Uniformity/ Lack of Knowledge Base

B.6 


\section{Response significant remaining issues}

Lots of little stuff that amount that increase results in more site specific engineering than is really needed. Standards that streamline permitting would be helpful. One major issue is fire code on commercial and residential buildings.

clear role of electricians in system installation

Potentially with the fire regulations for residential rooftop PV and the interconnection of larger PV systems to residential power systems. On-site electrical storage and backup power supplies.

The weight of systems on older homes is a concern that we haven't come up with a good answer too, Especially for solar thermal systems that are quite heavy.

fire safety requirements, venting requirements, structural requirements

utility interconnection/distribution

Construction stds for rack, mounting systems etc. 
2: Please rank, in order of importance, the actions you think best lead to widespread use of on-site renewable energy resources. Rank at least five, with 1 representing the most important action.

Address code (plumbing, electrical, fire, building, mechanical) issues (Respondents were limited to brief text responses)

\begin{tabular}{|c|c|c|c|}
\hline Response & Chart & Frequency & Count \\
\hline No Response Recorded & & $41.3 \%$ & 31 \\
\hline 1 & & $8.0 \%$ & 6 \\
\hline 10 & & $5.3 \%$ & 4 \\
\hline 2 & & $5.3 \%$ & 4 \\
\hline 3 & & $8.0 \%$ & 6 \\
\hline 4 & & $8.0 \%$ & 6 \\
\hline 5 & & $13.3 \%$ & 10 \\
\hline 6 & & $2.7 \%$ & 2 \\
\hline 7 & & $2.7 \%$ & 2 \\
\hline 8 & & $2.7 \%$ & 2 \\
\hline 9 & & $2.7 \%$ & 2 \\
\hline & & Valid Responses & 75 \\
\hline & & Total Responses & 75 \\
\hline
\end{tabular}


Address siting issues (solar access protection, homeowner association restrictions, etc.)

(Respondents were limited to brief text responses)

\begin{tabular}{|c|c|c|c|}
\hline Response & Chart & Frequency & Count \\
\hline No Response Recorded & & $33.3 \%$ & 25 \\
\hline 1 & & $9.3 \%$ & 7 \\
\hline 10 & & $2.7 \%$ & 2 \\
\hline 2 & & $12.0 \%$ & 9 \\
\hline 3 & & $12.0 \%$ & 9 \\
\hline 4 & & $12.0 \%$ & 9 \\
\hline 5 & & $5.3 \%$ & 4 \\
\hline 6 & & $2.7 \%$ & 2 \\
\hline 7 & & $4.0 \%$ & 3 \\
\hline 8 & & $2.7 \%$ & 2 \\
\hline 9 & & $2.7 \%$ & 2 \\
\hline 11 & & 1.3 & 1 \\
\hline \multicolumn{3}{|c|}{ Valid Responses } & 75 \\
\hline \multicolumn{3}{|c|}{ Total Responses } & 75 \\
\hline
\end{tabular}

B.9 
Address utility interconnection and/or net-metering issues

(Respondents were limited to brief text responses)

\begin{tabular}{|c|c|c|c|}
\hline Response & Chart & Frequency & Count \\
\hline No Response Recorded & & $29.3 \%$ & 22 \\
\hline 1 & & $12.0 \%$ & 9 \\
\hline 2 & & $13.3 \%$ & 10 \\
\hline 3 & & $12.0 \%$ & 9 \\
\hline 4 & & $6.7 \%$ & 5 \\
\hline 5 & & $12.0 \%$ & 9 \\
\hline 6 & & $4.0 \%$ & 3 \\
\hline 7 & & $2.7 \%$ & 2 \\
\hline 8 & & $1.3 \%$ & 1 \\
\hline 9 & & $4.0 \%$ & 3 \\
\hline 10 & & $1.3 \%$ & 1 \\
\hline Other Responses & & $1.3 \%$ & 1 \\
\hline \multicolumn{3}{|c|}{ Valid Responses } & 75 \\
\hline \multicolumn{3}{|c|}{ Total Responses } & 75 \\
\hline
\end{tabular}


Other Responses: The problem is more profound than this.

\section{Commission systems}

(Respondents were limited to brief text responses)

\begin{tabular}{|c|c|c|c|}
\hline Response & Chart & Frequency & Count \\
\hline No Response Recorded & & $48.0 \%$ & 36 \\
\hline 10 & & $4.0 \%$ & 3 \\
\hline 11 & & $4.0 \%$ & 3 \\
\hline 2 & & $9.3 \%$ & 7 \\
\hline 3 & & $5.3 \%$ & 4 \\
\hline 4 & & $8.0 \%$ & 6 \\
\hline 5 & & $6.7 \%$ & 5 \\
\hline 7 & & $4.0 \%$ & 3 \\
\hline 8 & & $6.7 \%$ & 5 \\
\hline 9 & & $2.7 \%$ & 2 \\
\hline 1 & & $1.3 \%$ & 1 \\
\hline \multicolumn{3}{|c|}{ Valid Responses } & 75 \\
\hline \multicolumn{3}{|c|}{ Total Responses } & 75 \\
\hline
\end{tabular}

B.11 
Ensure quality installations (training/certification of contractors, builders, installers)

(Respondents were limited to brief text responses)

\begin{tabular}{|c|c|c|c|}
\hline Response & Chart & Frequency & Count \\
\hline & & $22.7 \%$ & 17 \\
\hline 1 & & $2.7 \%$ & 2 \\
\hline 2 & & $24.0 \%$ & 18 \\
\hline 3 & & $9.3 \%$ & 7 \\
\hline 4 & & $17.3 \%$ & 13 \\
\hline 5 & & $8.0 \%$ & 6 \\
\hline 6 & & $6.7 \%$ & 5 \\
\hline 8 & & $2.7 \%$ & 2 \\
\hline Other Responses & & $6.7 \%$ & 5 \\
\hline \multicolumn{3}{|c|}{ Valid Responses } & 75 \\
\hline \multicolumn{3}{|c|}{ Total Responses } & 75 \\
\hline
\end{tabular}


Improve code inspections, enforcement

(Respondents were limited to brief text responses)

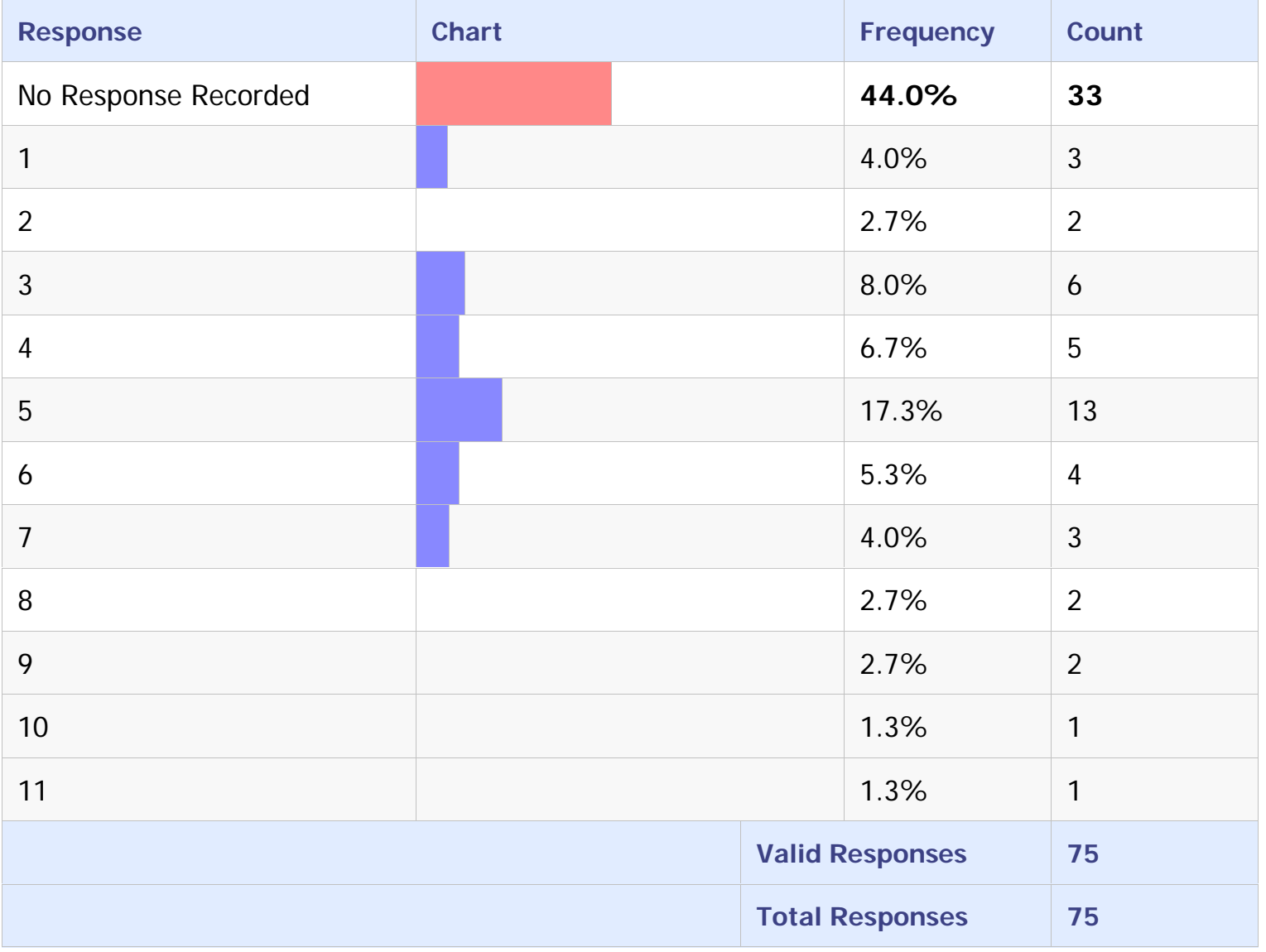

B.13 
Improve consumer awareness, marketing, \& image of renewables

(Respondents were limited to brief text responses)

\begin{tabular}{|c|c|c|c|}
\hline Response & Chart & Frequency & Count \\
\hline No Response Recorded & & $38.7 \%$ & 29 \\
\hline 1 & & $5.3 \%$ & 4 \\
\hline 10 & & $2.7 \%$ & 2 \\
\hline 11 & & $4.0 \%$ & 3 \\
\hline 2 & & $10.7 \%$ & 8 \\
\hline 3 & & $12.0 \%$ & 9 \\
\hline 4 & & $6.7 \%$ & 5 \\
\hline 5 & & $9.3 \%$ & 7 \\
\hline 6 & & $2.7 \%$ & 2 \\
\hline 7 & & $1.3 \%$ & 1 \\
\hline 8 & & $4.0 \%$ & 3 \\
\hline 9 & & $2.7 \%$ & 2 \\
\hline \multicolumn{3}{|c|}{ Valid Responses } & 75 \\
\hline \multicolumn{3}{|c|}{ Total Responses } & 75 \\
\hline
\end{tabular}




\section{Improve information to design professionals}

(Respondents were limited to brief text responses)

\begin{tabular}{|c|c|c|c|}
\hline Response & Chart & Frequency & Count \\
\hline No Response Recorded & & $33.3 \%$ & 25 \\
\hline 10 & & $2.7 \%$ & 2 \\
\hline 1 & & $1.3 \%$ & 1 \\
\hline 2 & & $9.3 \%$ & 7 \\
\hline 3 & & $18.6 \%$ & 14 \\
\hline 4 & & $13.3 \%$ & 10 \\
\hline 5 & & $5.3 \%$ & 4 \\
\hline 6 & & $4.0 \%$ & 3 \\
\hline 7 & & $4.0 \%$ & 3 \\
\hline 8 & & $1.3 \%$ & 1 \\
\hline 9 & & $5.3 \%$ & 4 \\
\hline 11 & & $1.3 \%$ & 1 \\
\hline \multicolumn{3}{|c|}{ Valid Responses } & 75 \\
\hline \multicolumn{3}{|c|}{ Total Responses } & 75 \\
\hline
\end{tabular}

B.15 
Reduce costs, improve financing, etc.

(Respondents were limited to brief text responses)

\begin{tabular}{|c|c|c|c|}
\hline Response & Chart & Frequency & Count \\
\hline No Response Recorded & & $18.7 \%$ & 14 \\
\hline 1 & & $49.3 \%$ & 37 \\
\hline 2 & & $14.7 \%$ & 11 \\
\hline 3 & & $4.0 \%$ & 3 \\
\hline 4 & & $5.3 \%$ & 4 \\
\hline 5 & & $2.7 \%$ & 2 \\
\hline 9 & & $2.7 \%$ & 2 \\
\hline \multirow[t]{3}{*}{ Other Responses } & & $2.7 \%$ & 2 \\
\hline & \multicolumn{2}{|c|}{ Valid Responses } & 75 \\
\hline & & Total Responses & 75 \\
\hline
\end{tabular}

\section{Require use of renewables through building codes}

(Respondents were limited to brief text responses)

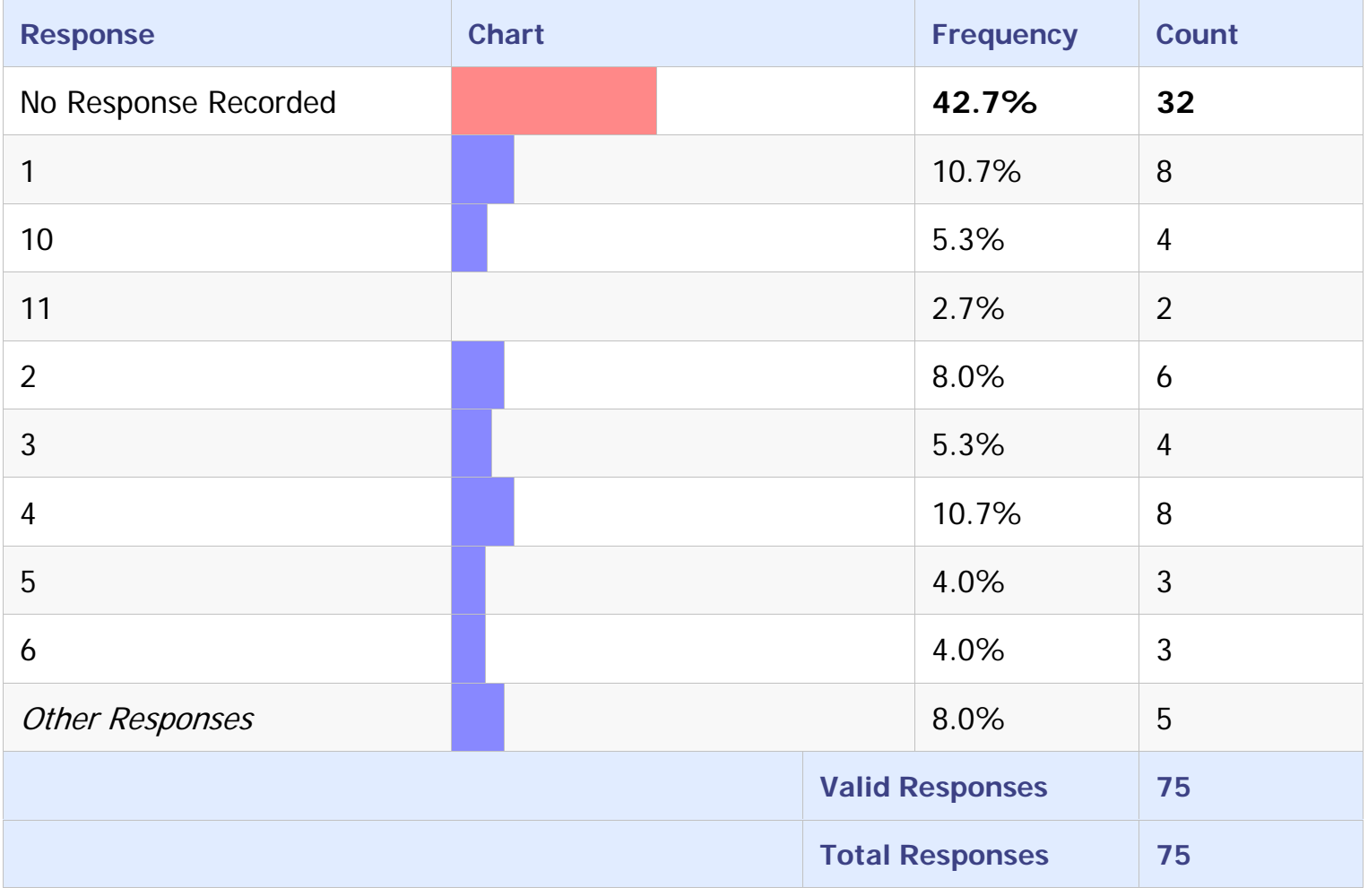

B.16 
Other Responses:

99

1055

Don't do this. Provide a goal (i.e. Btu/sf) and incentivize building envelope efficiency first, electric and HVAC system efficiency second and renewables last

\section{Resolve grid integration issues}

(Respondents were limited to brief text responses)

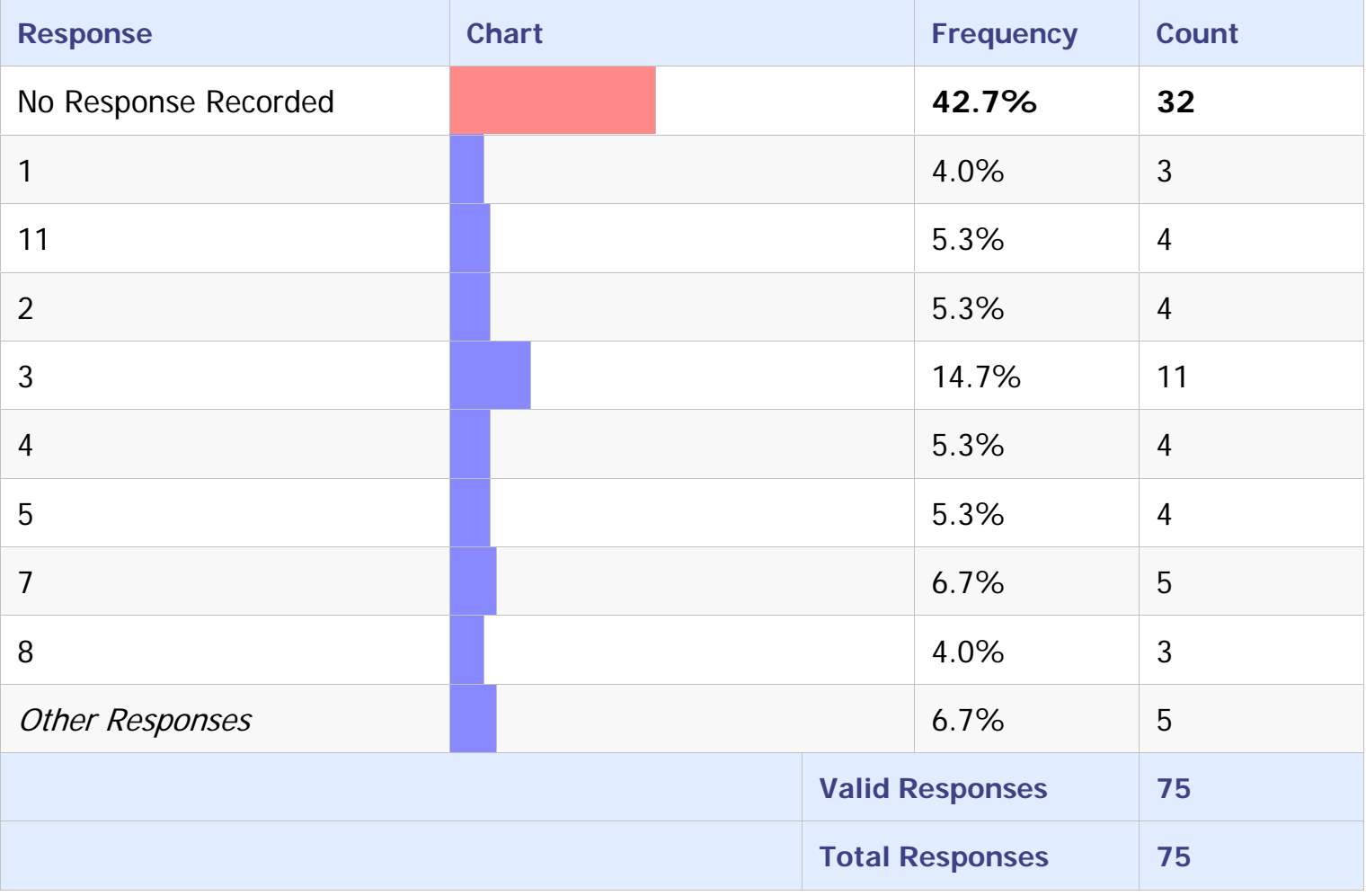

Other Responses: Not sure what issues you're referring to here. Are you referring to smart grids?

\section{Other (please specify and rank}

(Respondents were limited to brief text responses)

\begin{tabular}{|c|c|c|c|}
\hline Response & Chart & Frequency & Count \\
\hline No Response Recorded & & $86.7 \%$ & 65 \\
\hline \multirow[t]{3}{*}{ Other Responses } & & $13.3 \%$ & 10 \\
\hline & & Valid Responses & 75 \\
\hline & & Total Responses & 75 \\
\hline
\end{tabular}




\section{Response}

4 - Issue of utilities' business is to sell kWhs, but there involvement in grid T\&D, interconnection, and smart grid issues are needed for major renewable integration.

4-create economic incentives

1. Concentration on superior envelope performance that maximizes impact of renewables usage

1.

1. Concentrate on superior performance of envelope in order to maximize effectiveness of renewables

5

3 - Integration of renewables into the planning \& entitlement phase

1

1 Investor-owned utility lack of incentives

Reliability/maintainability 2

Responses

\section{Please explain the reasons behind your rankings in question 2.}

\section{Response to question 2}

Biggest issue today is cost. Renewables are just not coast effective without significant subsidy. Second issue I have seen is space for the equipment. Need utility interconnection to get the utilities involved in marketing renewables; also need alternative energy portfolio standard to FORCE the utilities to promote it Real and perceived costs are substantial impediments Lack of training for code officials, designers and contractors is another huge impediment

We need the major utilities to promote renewable energy if we intend to make the inroads we need. In addition to interconnection/net-metering issues, we need alternative energy portfolio standards requiring the utilities to invest in alternative energy sources. The real and perceived costs of deploying alternative energy must be addressed through extensive public education, consumer awareness AND financial incentives.

If it is not in the code (Required) its not going to be done unless you provide a lot of training and information and incentives to designers, builders, building owners and homeowners. Return on Investments(ROI) Cost, is a factor for owners

Solar access protection and wind turbine siting issues are critical to ensure a resource can be guaranteed over the life of the system. Standardizing utility and grid interconnection issues is important to ensure these systems are valued similarly across the us

This question demands far too lengthy an answer. What's more, I may change my mind about what it asks in an hour.

We already have a mandatory solar water heating law. The biggest barriers are landlords not seeing any advantage to themselves, and opposition by homeowner associations, despite law overriding covenants.

Economics are the strongest drivers; therefore, decreasing costs and increasing benefits ought to yield the best result. 
Response to question 2

$\mathrm{RE}=$ renewable energy cost \& quality (installers \& siting) are most important. In a quality install commissioning is assumed. Gird integration issues for on-site are not the same as centralized RE farms (wind or solar) far from loads. Requiring RE seems like overreach and paving the way for a backlash.

Experience through research and analysis on renewables.

Reduce costs is not just on equipment but also on time to pull permits, cost of permits, all the BS, then move to the Utilities and their attitude.

High initial costs remain the biggest implantation issue with the exception of wood-based renewables.

All building owners do economic analysis, and on-site systems are most popular in areas with the most subsidies (CA, NJ).

Basically few people will consider using renewables until it is a mandatory requirement in the building code.

If required by law (code) it will happen

The initial cost and the ability to sell electricity back to the grid at a reasonable rate are of paramount importance. I can't afford renewables.

Financing is a key barrier, but utility intertie and larger grid issues remain the most significant. To a lesser degree, installers that promote renewables before efficiency are a problem. Codes seem like a low priority on renewables.

Solar access and aesthetic issues have been most important Boulder. Solar was not widely installed in our city before utility rebates became available.

Renewables are expensive and somewhat of an unknown, so requiring them through codes will achieve the greatest saturation. However, there are a number of people who are ready to take the steps. To make sure that they can do that without too much trouble, designers need to be better educated so that they can specify the systems and utilities need to be better educated so that they are not concerned about interconnection issues.

Without the support of the Public, Design Professionals, Builders, and the Financial Community, progress will never be made; they will all look for loopholes around the code. Banks, etc., will not provide proper additional value to a project thus making it less financially feasible.

Most of these issues are local, and can be a major impediment in some areas, but are only a minor impediment in others. It doesn't make sense to me to focus national attention on resolving local issues. The fundamental impediment to the use of renewables is still the questionable finances.

The key to implementing a new product is education on various levels.

I don't think there should be widespread use of on-site renewable energy resources. I believe it is bad public policy until the industry can offer a much, much cheaper technology.

costs are the main barrier to voluntary uptake. Other than breaking through the cost barrier, mandating renewables is the next best way to gain uptake.

Ultimately the investment must be made by the owner in sustainable and energy conscious buildings. That investment must be represented as justified and beneficial. Now the second point, education and understanding, not just bottom line. Now the codes and regulations can be acceptable as minimum expectations followed by consulting and guidance by the design community. The regulators role is next in promotion as well as ensuring compliance. The quality of installation is directly related to satisfactory inspection based on an understanding of design solution. This process resolves in continued stewardship to the codes and update. Macro scale attention can run on a parallel track with attention to the utility delivery model. Finally the commissioning piece remains the third party owner representative process of performance. 
Response to question 2

The codes will reach $30 \%$ improvement as directed by DOE. Now we need to take a breath and teach how to administer it. Commissioning also means measurement to me - enough modeling. Let's see how it's really working. Quality installations will create a confident market and education will create market momentum.

I'm assuming you are talking about large commercial residential and retail projects not individual homes. Cost is the number one issue, if developers/owners can't afford the system, and you want $\mathrm{RE}$, then you only option is to force through the code.

I'm speaking primarily from a residential focus. Motivating homebuyers to want renewable systems (and pay for them) is the biggest hurdle.

Cost is far and away the biggest barrier for on-site renewables.

1. Renewables are the "sizzle;" but thermal and air sealing performance are the real meat in the sandwich; without first spending to achieve a maximally efficient envelope, money and resources are wasted on the amount of renewables required to achieve ZNEB. 2.

Designers need to be knowledgeable to provide for increased use in new construction; consumer awareness is needed for buy-in; costs need to be lowered; the installers need to know how to correctly install the systems; and uniform rules are needed in dealing with utilities and grid integration.

Without funding and utility access, even interested people won't get involved.

1. Renewables investments waste money and resources if not preceded by maximizing the envelope effectiveness; thereby making it less costly to achieve ZNEB. 2. Education of trades/contractors is left to the local building officials and is NOT THEIR JOB. Current neglect of the parties who actually are responsible for DOING THE WORK makes it extremely difficult to gain ground in \% compliance. 3. Design professionals still designing solutions to problem symptoms and not causes. (e.g. ventilated attics are still being used with low emissivity roofing materials to create ovens above habitable spaces that can only function with the use of mechanical ventilation to minimize the loads) 4 . Codes still need revisions to eliminate/minimize the use of design practices that fail to consider energy impacts. They also need more guidance for design and selection of HVAC and renewables; NAECA needs to be removed from the HVAC equipment market as the market has outstripped its regulatory agency and is negatively impacted by its presence. 5. Pre-Commissioning of systems before $\mathrm{C}$ of $\mathrm{O}$ must be done and reported back to the code process as accomplished.

Our County Building Divisions are ill-equipped and under-educated regarding renewables. Complex applications become horror stories, and even simple solar WH applications are held up for months when there's a glitch. The utilities are claiming they're on the verge of renewables overload. Some AOAO's continue to reject solar H and PV's despite a law to the contrary. Solar WH is mandatory for new construction.

First cost concern is still the rule.

Safety first, social issues, quality assurance,

Cost will always be the main driver but I believe what we pay now for energy should be addressed since we do not pay the full cost for it. Renewables are competitive if that's considered. The rest of it is just my ranking of a combination of the support and incentive necessary.

Codes should dictate PV-ready requirements for new construction including appropriate electrical systems and raceways from the roof. 


\section{Response to question 2}

In our area, Austin, TX, the financing, marketing and image are not relevant though they may be in other areas. Our concern is more with the performance of systems i.e. commissioning, quality installs, quality inspections. Siting issues are still an issue because many subdivisions in Austin and TX require that PVs and solar thermal systems not be visible from the street. Finally when I identify code issues I am not referring to code barriers to installation but to codes that are needed to facilitate proper installation. I understand that these are being developed but are not yet in place.

Requiring renewables through building codes will lead to widespread use on-site renewables. Making renewables affordable will reduce the resistance of the HBA to including renewables for residential occupancies. Ensuring that buildings have access to solar access is critical to acceptance. Net metering issues will also need to be addressed in order to be able to be installed in buildings. The other issues that are listed are less important to getting widespread use of renewables.

First costs can be significant barriers for renewables. Zoning and other restrictions are also a concern. The overriding importance of reducing reliance on fossil fuels informs the need to make renewables a mandatory aspect of building design.

Maintstreaming renewables demands Certified Installers and Designers and the consuming public must be aware that it works and is affordable

Cost is obvious. Incorporating renewables into building energy codes can allow for tradeoffs between other measures and pave the path for ZNE homes in the code. Significant barriers to be overcome here. Finally, critical that we get renewables into the planning \& entitlement phase, including solar-oriented street/lot/building orientation issues. Many developers/projects are making solar or GHG commitments at entitlement, but no good way to integrate/follow up CEQA and/or T24 codes.

By addressing the utility interconnection issues that should cover the grid integration part. Siting is an issue that will become more of an issue as we move forward. Right now many H. Assoc. are a problem for solar. Quality installations are what will make or break the industry and consumer education is an ongoing process, as much as I would like to hope that it wasn't. Even in my small will informed community more education needs to be done. Too many anti "solar myths" are surfacing to undermine the industry.

I have found that interconnection issues stop the adoption of renewable energy (in whatever form). Until utilities are on board and the interconnection issues resolved, this will never get passed the idea stage.

Continuous solar access is not a right and the onus is on the property owner to get easements for "ancient lights" strategies to develop relationships/ infrastructure for distributed power to be able to address the scale of gov facilities do not exist renewables should be the LAST thing installed after all of the efficiency is squeezed out of the building and operations- we do not want "green bling"

Some of the biggest barriers I see are financial ones--homeowners and businesses can't get financing for renewable energy installations. Following behind are NI MBY and code barriers.

Cost is by far the most important factor in water heating.

I think that the biggest road block to more widespread use of renewable energy systems is the first cost (parts + installation). After that, I think the more important issues are proper installation and appropriate application in the area.

This country needs to change the paradigm of how we measure "cost". "Cradle to grave" should be the starting point of any analysis. Extraction of the raw materials- to the remediation of the waste or by product of production.

A code requirement would ensure widespread installations, but you can't put a code in place that would require installing a system that is not cost effective 
Response to question 2

A lot of the challenges to RE are really only solved through time and experience gained at all levels. There is no one barrier and all barriers can be overcome with money. Challenge is that money is generally the 1st constraint.

National leadership and validation of the importance and priority of renewable energy systems being integrated into buildings needs to be stable, sustained, consistent, financially reasonable, and aggressive. National policies that will address interconnection and the value of this energy will significantly raise the bar.

First, simplify the regulatory application of renewables and expand the market demand; second, ensure the technical and installer credibility and reliability; third, address specific issues that may arise in some locations and installations; fourth, develop a means to assure quality and good design, and fifth, address remaining jurisdictional review.

The biggest obstacle is that investor-owned utilities have a primary responsibility to provide a return on investment to the investors and not to reduce greenhouse gas emissions nor to address the needs of their customers. They are in the business of selling energy and anything that reduces the amount of energy they sell is contrary to that goal. The level of technical expertise needs to be raised industrywide. These technologies are also changing and improving rapidly and it's difficult for people to keep up so ongoing training should be required for licensing. Also, your option of "require use of renewables through building codes" points to a concern of people putting on renewables before doing everything possible for energy efficiency. Our priorities are 1. Building envelope efficiency, 2. Equipment or system efficiency, 3 renewables. Codes should incentivize this prioritization. Also, solar access protection can be inconsistent with increased density which is a component of new urbanism goals that reduce energy use by having more shared walls/floors and by facilitating alternative transportation. I have not yet found the perfect solar access protection example.

These are all critically important issues. In addition, reducing inconsistencies in application of codes between jurisdictions, standardize code fees (not necessarily reduce them but make them sensible and reasonable), Reducing paperwork so that the safety and quality issues become more important than paperwork.

Most of these are important so it is difficult to rank. However, I think that since there has been successful use of renewable, driving mass use through codes is appropriate but will need to be coupled with a growing demand from consumers for better-than-code installations to continue to pull the market and help code requirements for renewables become more stringent over time. Education and correct information sharing is the key to understanding and the application of any new energy resource.

At least in the US, I think cost, reliability, quality assurance, and knowledgeable design and construction teams are the key, not regulations. Make something reliable and economical and it will be adopted.

My rankings are based on the policy barriers to introducing renewables. Until those are addressed, all that codes will do is cause problems. People won't be able to meet the code requirements. It will cost too much. All of this would breed resentment towards renewables and overall retard their progress.

I think the actual issues of installation and design are easily addressed, the cost nature and most often long payback period makes system installation prohibitive. Bring down costs and the other rankings will naturally start to fall in line. 
3: Should the use of on-site renewable energy be considered as a code requirement even if it doesn't meet standard tests of cost-effectiveness?

(Respondents could only choose a single response)

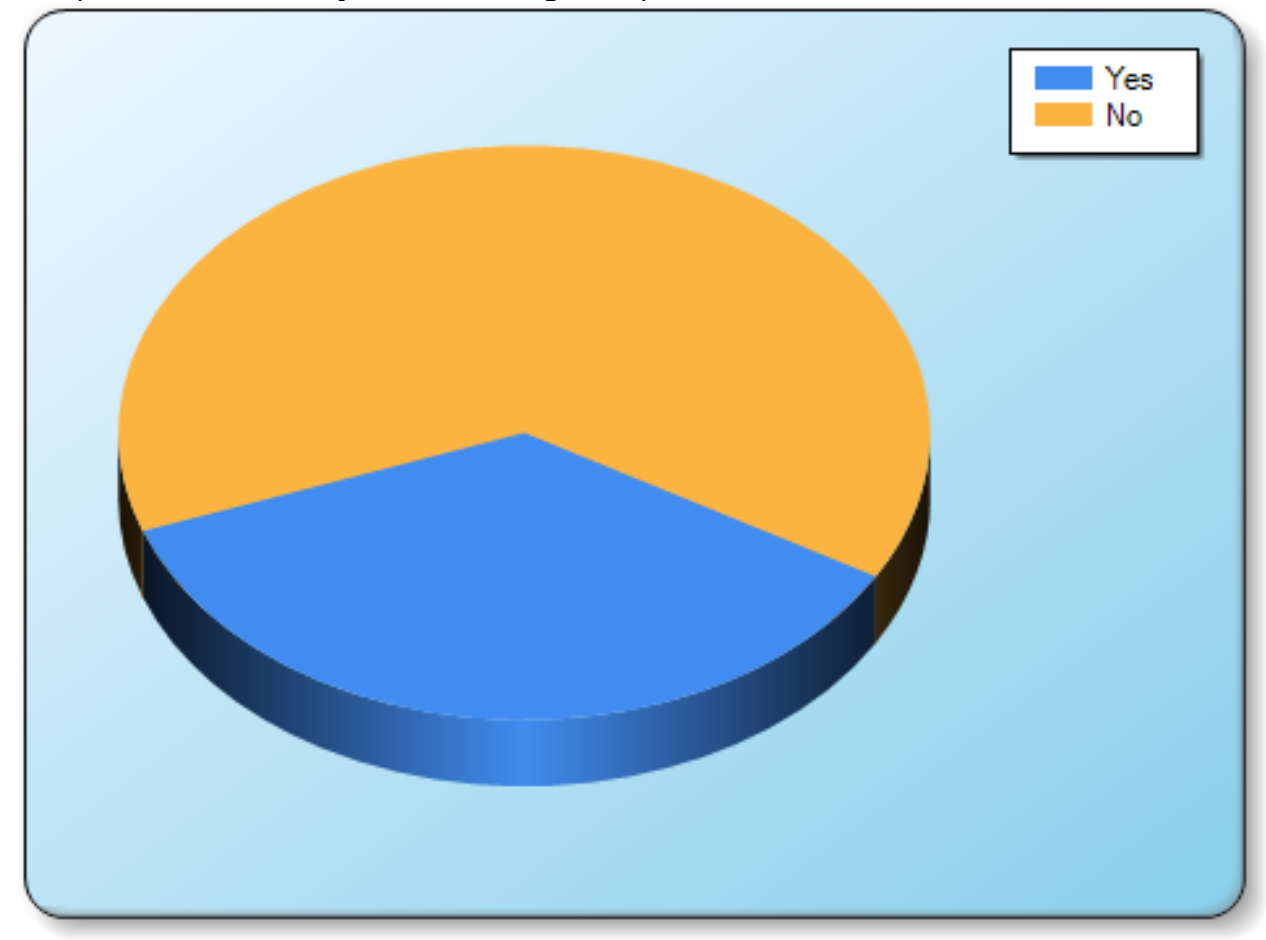

3: Should the use of on-site renewable energy be considered as a code requirement even if it doesn't meet standard tests of cost-effectiveness?

(Respondents could only choose a single response)

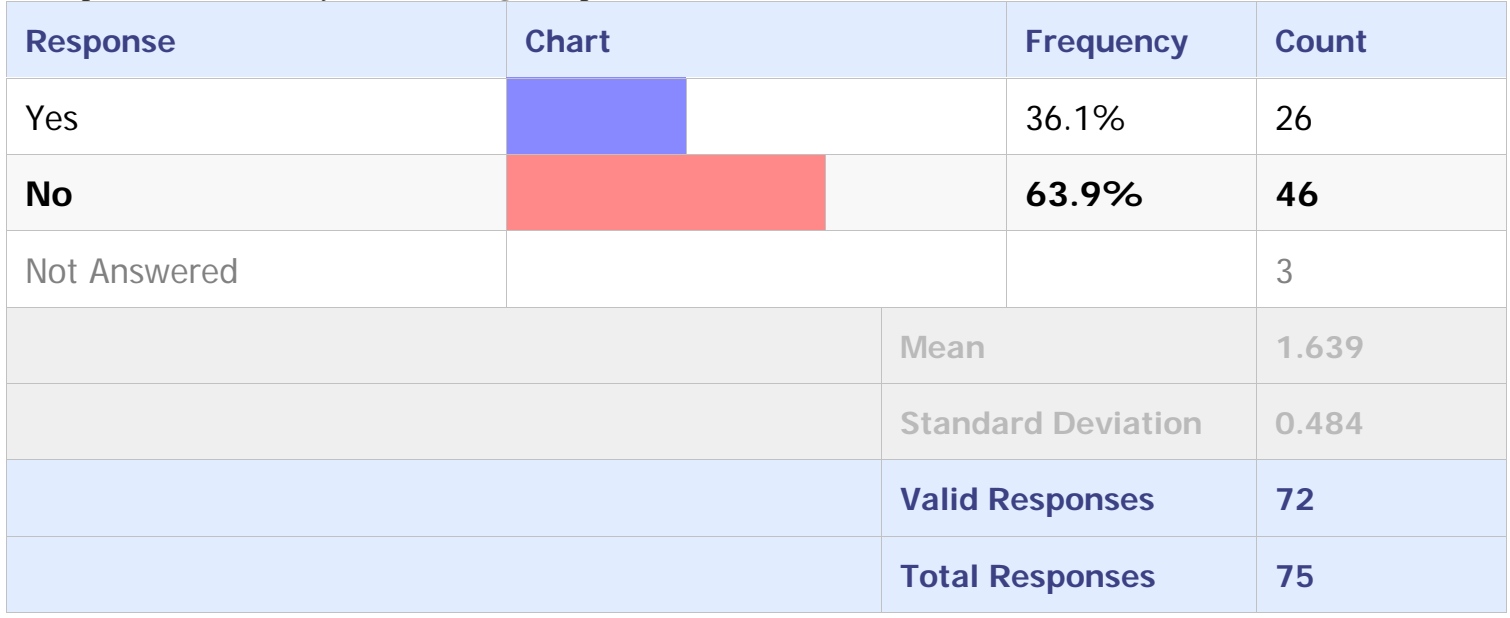




\section{Explain your answer and how the cost-effectiveness barrier might be addressed.}

Response to question 3

As scarce as funds for development are right now and as fragile as our economy is, we need to think hard about forcing unproductive and non-cost effective expenditures on an already strained economy.

Mandatory deployment of onsite renewables needs to be a public policy issue addressed via other means than building codes. However, building codes must incorporate standards for safe and effective installations when renewables are used.

Larger national issues exist like subsidies to the fossil industry. If a free market rules, then the price will discover the proper approach and owners will decide accordingly in this free country. Building codes are NOT the appropriate vehicle for pushing renewable energy. Codes should regulate how and where, but not mandate the use of any type of energy or fuel.

Because all the work that will be done to get it into the code, will be for nothing, as states amend that section out of the code because it is not feasible and has too long of a ROI Actual costs and cost effectiveness in real projects is different than a national cost-effectiveness assessment. Renewables are competitive to code efficiency in specific markets with incentives and good renewable energy resources. Solar hot water is starting to become cost effective for federal projects that require (ESA 2007) SHW to be used for $30 \%$ of a hot water load (when cost effective)

Seems to me cost effectiveness comes about when the cheap energy problem gets properly addressed. We do not pay the true costs for what we use and instead defer that to our children. Hawaii's residential kWh rates range from 25 to 40 cents. There's no reason to require any measure with a payback of over 5 years.

The only reason for requiring implementation without regard to a cost-effectiveness test is to improve market penetration, which is laudable. Cost-effectiveness should be considered, but in a very broad sense that considers externalized environmental and social costs and other factors that do not readily or easily reduce to dollars and cents.

Requiring RE seems like overreach and paving the way for a backlash. Energy efficiency is the biggest RE source, and there are a lot more cost-effective of ways of harvesting it.

Renewables should only be considered as an optional way to meet energy codes, there are real physical barriers that have to be considered. Third party financing and very aggressive tax incentives change the typical cost-effectiveness analysis.

ABSOLUTELY NOT!

Define cost effective? Who's cost effective, retail to the consumer or wholesale at the utility?

Requiring un-economic measures because of guesses as to future events is criminal. The predictions of the experts regarding energy costs have been very exaggerated. We should not use codes to push political beliefs. Renewable technology can be retrofitted at little incremental cost over original equipment. The technology is still rapidly evolving so a code requirement dooms structures to yesterday's technology.

On-site systems do not reduce the energy use of the building, unless it acts as a "cool roof" in southern climates. Building energy codes address energy efficiency of building components and systems, not the production of energy on-site.

When it is part of the building code, it will eventually and probably sooner than later, become cost effective.

No one questions the cost effectiveness of their car or its airbags. If we can include renewable energy systems as part of the overall mortgage structure of the house, first costs are less of an issue. And what is the ROI of a Kitchen counter top? 
Response to question 3

A small amount should be required to bring down costs.

Renewables should not be considered until all more cost effective conservation strategies have been implemented. This represents about a $60 \%$ reduction in energy use before any renewables are purchased. How could you justify spending more for less, when the cost-effectiveness argument has been used to torpedo efficiency improvements for decades? And what is the point of installing renewables to serve inefficient buildings? This doubles the cost; first the expense of costly renewable systems, then the expense of buying more capacity to serve excess loads. High performance energy codes often result in larger homes being required to install solar to meet code.

Renewables should be an option - The cost-effectiveness cannot just be defined in terms of fuel costs, must also include distributed generation benefits, environmental costs, etc.

Prices come down when measures are required in codes since there is a larger market so manufacturers are willing to invest in production improvements which bring down prices. The reason to do this now is to start to build the design and installation expertise, as all net-zero buildings are going to need renewables either on-site or within the neighborhood.

Financial institutions to add value for renewable systems. Utilities to offer financial incentives for renewables.

Yes. Building codes require many things that are not cost effective. There is a larger societal good that needs to be considered.

If it was slightly non-cost-effective it would be fine. When something costs $\$ .25 / \mathrm{kwh}$ it is irresponsible to make it mandatory.

Societal cost is not addressed through standard cost effectiveness calculations.

Currently my answer is no because every structure and building affected by code has an owner. At the present time the education and long term benefit challenge has not been met. I believe that over time, in the near future, cost-effectiveness will coincide with educated stewardship. A minimum energy code should be cost effective. Otherwise limited capital is transferred from cost effective conservation (reduction of energy needed) to non-cost-effective renewable. In addition, the renewable lifetime might be 15-years, while a cost effective insulation requirement would have a 40 year life.

It's a waste of money and resources. Put it where it does the most good.

Depends upon what is important to you. May be more effective to spend money in other ways to reduce carbon than to force use via building codes. But you could argue that increasing the market via code requirement would lower cost or meet some other goal (i.e. energy security) As the energy codes get more stringent in general, renewable options will become more attractive. It could be counter-productive to outright mandate renewables. Reducing a home's energy requirements needs to always come first.

Building codes are intended as minimum requirements, and including costly and non costeffective requirements will simply result in fewer adoptions of such codes, or local amendments that remove the offensive provisions.

We're still working on $30 \%$ improvement to the codes. $50 \%$ will be a much larger "fight" than the $30 \%$. And renewables should be an option for utilities and consumers. California is moving forward with their requirements. Let's see how they do.

Make it cost effective and you will get acceptance; mandate it without effectiveness and you grow resentment.

You can't require someone to do something that isn't cost effective. 
Response to question 3

Cost effectiveness of renewables needs to be addressed through incentives based upon performance and durability of the on-site systems. Otherwise the market can be polluted through systems that don't stand up to the rigors of weather and erratic grid performance, failing to deliver when critical On this island, the latest kWh cost was 26.7 cents; on Kauai it's over 40 cents. At those prices, virtually any technology should have a below-7 year payback time.

But the key is knowing how much to mandate, and in what areas to allow exceptions

Cost effectiveness is very different for renewable energy. It is more a policy and social issue.

Actually, my answer would be "maybe." If society seeks to promote renewables then society should bear most of the costs but in many cases unless a project "must" look to renewables experience shows they won't.

Let the market get the cost down.

Requiring renewable energy systems as a code requirement when not cost-effective essentially subsidizes renewable energy systems over other measures that are more cost effective and that could have the same overall energy impact on the project (i.e. energy efficiency upgrades). As you suggest in question 4, the use of outcome-based requirements that set an aggressive energy target will still allow the use of renewable energy systems, but will drive them to be used only when they make financial sense.

Yes, but our first priority should always be energy efficiency. Installing on-site generation should never be allowed to be a trade off for that energy efficiency in codes.

It should be considered an option given the current costs associated with renewables. As the price per $\mathrm{kW}$ is reduced the requirement can go from an option to a requirement.

Financing, grants and incentives.

Cost effective is an artificial term given the quiet and hidden subsidies given to fossil and nuclear based generation systems. For example how is removing a mountain top and polluting the valley and water ways below cost effective?

"Solar ready" measures enable future solar installation when it does become cost effective. Assuming building base-case orientation with optimal solar orientation is another way to passive renewables in. Having the capability to use solar as a trade-off or option is also important and groundwork needs to be built into codes.

Requiring on-site renewables will cause a back lash we cannot afford to have at this time.

Need to deal with the interconnection issues. How net-metered energy is priced will markedly affect the cost-effectiveness. Homeowners, businesses should be able to sell net-metered energy at retail rates. If they are forced to sell at wholesale rates as utilities want, cost-effectiveness becomes difficult to achieve.

Cost of externalities reflected in ROI cost for building and site resiliency in building/site valuation building must be efficient and operated efficient first then apply renewables - reduce the load then apply renewables!

The cost of carbon and the real cost of fossil fuels needs to be built into the cost of fossil fuels, thus making renewables competitive. It is not an issue of incentivizing renewables or forcing nonprice competitive renewables (people will only be more resistant!), but rather having a market price for fossil fuels which reflects its actual cost to society. 


\section{Response to question 3}

It should definitely be considered. This question needs more clarification. Are you talking about a minimum energy code? Or are you talking about voluntary code programs that go above the minimum (a voluntary green construction code)? If it is the former, I would lean towards no - I think that requirements in the minimum energy code ought to be some test of cost-effectiveness. Also, just because I think consideration should be given, that does not mean I think requirements should be incorporated. I would need to investigate further to determine that. If it is the latter, a voluntary code, then I think that renewables can definitely be considered without cost justification.

\section{See above for how we currently are measuring cost.}

This is an area where the codes should be a vehicle to drive the market instead of following it; this regulatory push is needed in the short term so that we can build capacity and begin to drive pricing down to the level that will be necessary to continue to achieve more aggressive energy reduction targets.

The standard tests are designed for EE measures. There needs to be a separate costeffectiveness standard for RE. The standards should require EE before RE. Why install PV if you have T12s and no insulation.

\section{But have a performance test to deal with exceptions}

Making RE a code requirement can start very small. It forces jurisdictions to address it. It forces builders to think about how to do it for the least cost. It is a very effective tool for pushing improvements. As long the only tool to move the market is incentives, it creates a warped market that does not focus making it easier. They typical comment is "You're getting so much money, what's a little more cost gonna hurt" The trick is to make code requirements tied to kWh not installed kW.

These systems should be bundled with the balance of building component requirements and expectations. The value of these systems will become quickly apparent in more ways than "just" the bottom line. A diet of all potatoes might be quite cost effective from a short-term financial analysis, but we all know that we need more diversity than the cheapest solution. A diet rich in colorful fruits and vegetables may be more expensive, but it also means fewer costs in other budget areas.

Grid integration issues are so large that a code requirement would likely be unworkable. Safety issues on the reliability of power supplies to homes are extensive and must be addressed on a large scale, house design and layouts would need to be significantly regulated including height, vegetation, use of reflective materials, and a host of other details.

Make it a performance requirement like Btu/sf or better yet, annual tons of greenhouse gas emissions per sf and incentivize building envelope first, electrical and HVAC system efficiency second and renewables last.

While it may be true that right now some technologies may not be cost-effective it is important to look at the long term - long term, renewables will help hold down fossil fuel costs and reduce environmental and public health consequences of business as usual.

This is one of the best methods to generate demand for market transformation.

I'll qualify my answer by stating the test of cost-effectiveness should be set appropriately and consider lifecycle costs. I believe that since code is mandatory, requirements should be costeffective and building practices that are not should be part of voluntary programs until the cost barriers can be reduced.

No info to offer at this time.

There are other ways to get renewables into the utility system that may be considerably more economical than on-site or feasible when it is not. Code requirements mandating on-site renewables could be counterproductive. 
Response to question 3

Most code requirements have to be cost effective. Even when they are cost effective, the actual cost of a code provision hinders adoption and compliance. Introducing renewable energy as an option or as a trade off is a better approach.

These are options and choices, and not all renewables will work with any degree of effectiveness on any one site. These are issues of rights of ownership. This isn't an issue if they become cost effective via payback periods being reasonable.

Responses

4: In your opinion, should renewable energy requirement be prescriptive, performance- or outcome-based? Rank your choices in order of preference from 1-3 with 1 being most preferred.

\section{Prescriptive requirements}

(Respondents were limited to brief text responses)

\begin{tabular}{|l|l|l|l|}
\hline Response & Chart & Frequency & Count \\
\hline No Response Recorded & & $14.7 \%$ & 11 \\
\hline 1 & $16.0 \%$ & 12 \\
\hline 2 & $16.0 \%$ & 12 \\
\hline $\mathbf{3}$ & $\mathbf{5 0 . 7 \%}$ & $\mathbf{3 8}$ \\
\hline Other Responses & $2.7 \%$ & 2 \\
\hline & Valid Responses & 75 \\
\hline & Total Responses & $\mathbf{7 5}$ \\
\hline
\end{tabular}

Other Responses:

1. Outcome

Performance 


\section{Performance based (based on percent of overall-building load)}

(Respondents were limited to brief text responses)

\begin{tabular}{|l|l|l|l|}
\hline Response & Chart & Frequency & Count \\
\hline No Response Recorded & $14.7 \%$ & 11 \\
\hline 1 & $24.0 \%$ & 18 \\
\hline $\mathbf{2}$ & $\mathbf{4 9 . 3 \%}$ & $\mathbf{3 7}$ \\
\hline 3 & $9.3 \%$ & 7 \\
\hline Other Responses & $2.7 \%$ & 2 \\
\hline & Valid Responses & 75 \\
\hline & Total Responses & 75 \\
\hline
\end{tabular}

Other Responses:

2. Performance

Outcome

Outcome-based requirement - set overall building energy use target and let builder/designer/owner determine how to meet it

(Respondents were limited to brief text responses)

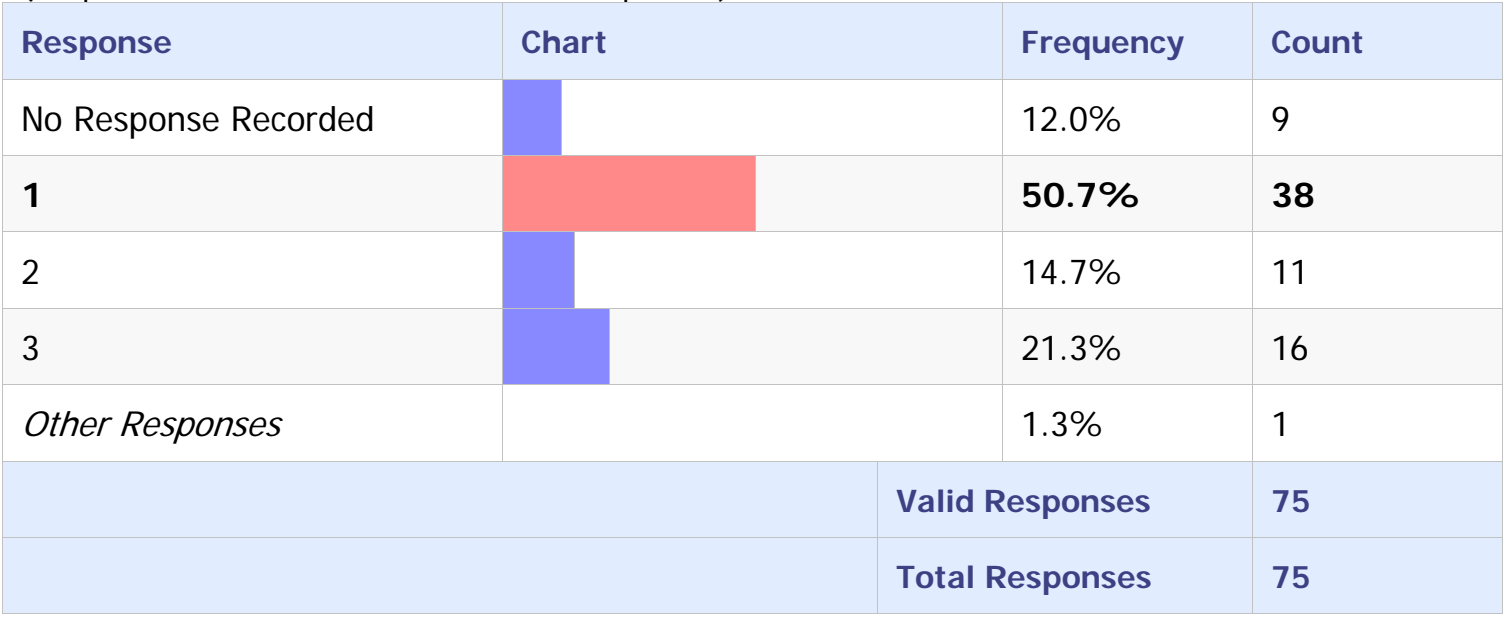

Other Responses

3. Prescriptive (if we have to) 


\section{Explain or comment on your answer to question 4.}

Response to question 4

Make it performance based. Allow tradeoffs to get best fit of renewables in a particular installation.

The only valuable means to achieving energy independence is through methods that actually produce verifiable results. An outcome-based OR performance-based system is preferable to a prescriptive path, but both require a much more sophisticated and educated design industry than currently exists.

see no. 3

The consumption of energy in a building must be regulated, but there are multiple means by which those goals can be achieved. The smart deployment of renewable energy is not aided by non-discriminatory requirements for on-site renewables in a building code.

Builders, architects and homeowners are always saying " just tell me how to build it and I will build it that way"

Actual effectiveness of renewables is very site dependent and local costs will drive decisions. Allowing a design team/owner to evaluate these local conditions using outcome based performance requirements ensures the best value for a local problem with a local solution The outcome is the point so it makes sense that it be \#1. Prescriptive requirements do not account for that "point" at all and so should be last. Performance based requirements fall somewhere in between.

We're seeing some poorly-performing LEED homes and buildings. There are many ways to "game" prescriptive requirements. Outcome is as close to the truth as possible.

Setting outcomes and letting intelligent people determine how to meet them is always the best approach, in my opinion.

$\mathrm{RE}$ is one component of the energy consumption-production problem; outcome-based solutions allow for all answers when arriving at the solution.

Should not be required, but should be part of an option pathway.

This question is unclear. What is meant by "renewable energy requirement?"

No easy answer on this one

Should not be a part of building codes until cost-effective criteria met

See above

Should be based on the geographic and regional supply of renewable resources, as well as access to resources by the specific building. Building energy use targets should only be based on enduse energy consumption, not on whether there is on-site fossil fuel, electric, or thermal energy production.

Energy use target should be kwh/sq ft, increasing though with sq footage. For example a 5,000 sq ft single family home should have an energy use per sq foot much less than a $1500 \mathrm{sq} f \mathrm{ft}$ single family home.

Should be most effective

It's hard to determine the building load. Outcome based only works if the tools are in place and gaming is curtailed.

This question makes very little sense without more context. It is hard to see how you could draw conclusions from the results of this survey question. It is not well explained. Is the outcome a total building outcome, or just a renewable capacity outcome? Won't any renewable requirement be a percentage of building load? If there is an outcome requirement, then renewables may not be required, but that is not clear from this wording. 


\section{Same as \#3}

This is climate -specific. But over time increasing percentages will have to come from renewables, whether it is on-site or from the grid. Make it easy to incorporate - do not require performance modeling.

Performance, BUT based on a Btu per square foot of gross floor area per year. - Basing a renewable requirement on a percent of overall building load would necessitate that an annual energy analysis be performed for every building. This is a waste of money that could be spent on the renewable energy system itself (or other energy efficiency measures). - It's much better to have a policy of meeting a certain percent of the energy consumption through renewables. Perhaps start small at $1-2 \%$ of the total consumption. Then, again at the policy level, do the math for an average building and use that to set criteria for code requirements for all buildings. For example, if an average new nonresidential building consumes 32,000 Btu/ft2-yr and you want renewables to meet $1-1 / 2 \%$ of the energy consumption, then require that all buildings have renewable energy systems capable of producing $500 \mathrm{Btu}(\sim=32,000 \times 1.5 \%)$ per square foot of gross floor area per year.

Prescriptive virtually eliminates innovative design solutions for a project. Performance allows for trade-offs and a measurable overall building load. Outcome based would invariably lead to energy use decided by the political process

Cities are America's green future. Performance-based and outcome-based requirements are usually difficult to meet in dense urban areas. Since dense urban areas are much more energy efficient that suburban or rural areas (especially when transportation energy is considered), building codes should be encouraging construction there, not discouraging it. I would like to see simple prescriptive requirements for renewables based on roof area, parking lot area, and climate. Turkey's requirement that all new homes incorporate solar hot water systems is a very good example of this.

I am somewhat supportive of "solar ready" requirements in the code. Nothing for the actual equipment.

\section{Ease of enforcement}

Let's start with the throw away; renewable energy performance is based on too many variables to prescribe requirements. Region, use and available resources are only the beginning to a complex set of variables. This isn't like prescribing a 100' exit travel distance. Now the Outcome vs. Performance; though similar in objective the outcome-based model engages more detail and conscious decision regarding use. Performance based code may just generalize use, size, location, etc and provide that target. Taking it one step further, the owner is faced with an energy use target that allows for the strategic formulation of any number of solutions, ultimately realizing the energy use target.

The renewable piece is too complex for prescriptive. Even though I'm a code official and support elegant, simple solutions like prescriptive requirements design has so much more to do with it than a simple offset.

Outcome base or performance based are theoretically better than prescriptive, but if a simple answer works for a large number of applications, making a prescriptive rule would dramatically reduce admin costs.

While it is a good thing when homebuilders use performance calculations in design, the state of the industry is that most will not, or will not take it seriously if they do. Prescriptive options have a much better chance of becoming standard practice. Your description of outcome-based requirements doesn't match the way others are using the term. Generally, it means that regulation of the code extends to the post-occupancy period, where metered consumption is used to evaluate compliance. I view that as an expensive prescription that will mostly generate cheating or lawsuits or both. 
Response to question 4

Prescriptive requirements are still useful and a good first step, especially in building codes, where code officials and design professionals need the precision that such requirements entail

Performance based does a better job of addressing the overall building impact.

Requiring people to do something is a bad idea.

Prescriptive is too loose; cannot possibly include all of the diverse parameters possible within differing renewables systems; Performance measures initial capability; enforcement can only demand this yardstick during the duration of construction. Outcome goes beyond construction and measures longer term performance and durability.

The builders tell me over and over, "Don't tell me how to build a house. Tell me what you want, give me incentives, and let me figure it out."

Prescriptive probably would be easiest to enforce.

Do it right first: prescriptive Performance based for the experts Outcome-based in the long term

The outcome is the whole point so making requirements based on that just makes sense.

Prescriptive requirements can be simple but they may lead to inequities which can create bad experiences with renewables.

Currently, every RE system is unique and cannot be prescriptive due to constant changes in the available equipment and specifications.

Logically, setting an outcome based requirement will drive designers/owners to pursue the most cost effective energy efficiency technologies first, ideally with renewable energy making up any gap that remains.

Again, any on-site renewables requirement should be separated from the energy efficiency requirements for the building. So, using your definitions performance is really the only option I would support at all.

Renewables can be integrated for both outcome and performance based codes since is either a percent of the energy use of the building of to meet an EUI. Prescriptive codes are mandatory and therefore do not allow for an option.

Outcome based is more flexible and reliable.

Nothing beats actual results.

Establishing residential building energy code baseline to include passive solar/optimal solar orientation (e.g., base-case prescriptive requirement includes minimal W-facing area) can drive significant low-cost passive solar utilization, and a cost effective way to tighten code. Prescriptive solar-ready measures can facilitate both future PV installs when cost decreases, and lower cost to current PV installations as PV/solar measures are already included in the building design.

I like outcome based, but if it is self reporting it will not be done well.

There are too many variables (climate zone, specific lot conditions) to prescriptively set requirements. Outcome based codes work best. There is too much uncertainty in when and how much the renewable energy system will provide energy to predict with a performance approach. prescriptive can end up giving what is not needed - performance based can be used by a savvy owner or outcome based allows the design team to innovate and optimize

If it were required, perf is best, vs. prescriptive.

I think that an outcome based requirement does not provide widespread use of renewable energy. At this point in time, if there is an outcome based requirement, I think that people will probably first go to other options (better envelope, HVAC, lighting, etc) to try to reach the target before considering renewable systems. 


\section{Response to question 4}

Policy, policy policy........and then enforce, enforce, enforce.

Let building owners determine the most cost effective way to hit targets; that way innovation is supported in development of both energy efficiency measures and renewables.

If you set a stringent outcome, ZNE for example, people will be incentivized to invest in the most cost effective measures first (load reduction), then invest in the more expensive option (renewables). Performance allows flexibility in design, which is crucial when looking at PV because not all sites are well-suited. For example, sometimes it'll be better to have tall trees to reduce HVAC load than have a PV system.

These can all be rolled into one requirement

The goal is performance, but code has to be prescriptive for 2 reasons. 1 it is easier to enforce. 2 it makes it clear to the applicant how far they have to go and doesn't increase risk for them that they would have to cover with an increased cost. A good prescriptive requirement should have performance based metrics.

I don't know. At this point, we still need to spur the market to action and develop the capacity of the market. Each building is unique, has different uses and expectations, cookie-cutter policy is not going to be successful.

This question would seem to be premature.....

By setting a goal and letting people decide how to get there you inspire innovation. This also allows people to take advantage of emerging technologies which the prescriptive requirements cannot address before they are introduced and so will always be behind. If someone can meet an outcome requirement without equipment that has embedded greenhouse gas emissions in its manufacture and will require maintenance and ultimate replacement, so much the better.

The site use will help to guide the best renewable technology choice

I believe that allowing design professionals the latitude to creatively meet aggressive goals is generally the best approach.

Right now, I'm not convinced that outcome-based requirements deliver on comfort and IAQ ... "jury is still out".

I think the rationale for this ranking is already explained in comments on earlier questions.

There are too many energy efficiency provisions that are more cost effective to make RE prescriptive. Because of the fact, that RE will function sporadically and that it will be more of an add on, I think making it part of an outcome based requirement makes more sense.

Again, don't agree with mandated requirements. But to provide an answer the Outcome based system is best solution to get bang for your buck. 
5: If prescriptive or performance-based on-site renewable energy requirements were implemented, on what should siting requirements be based?

(Respondents could only choose a single response)

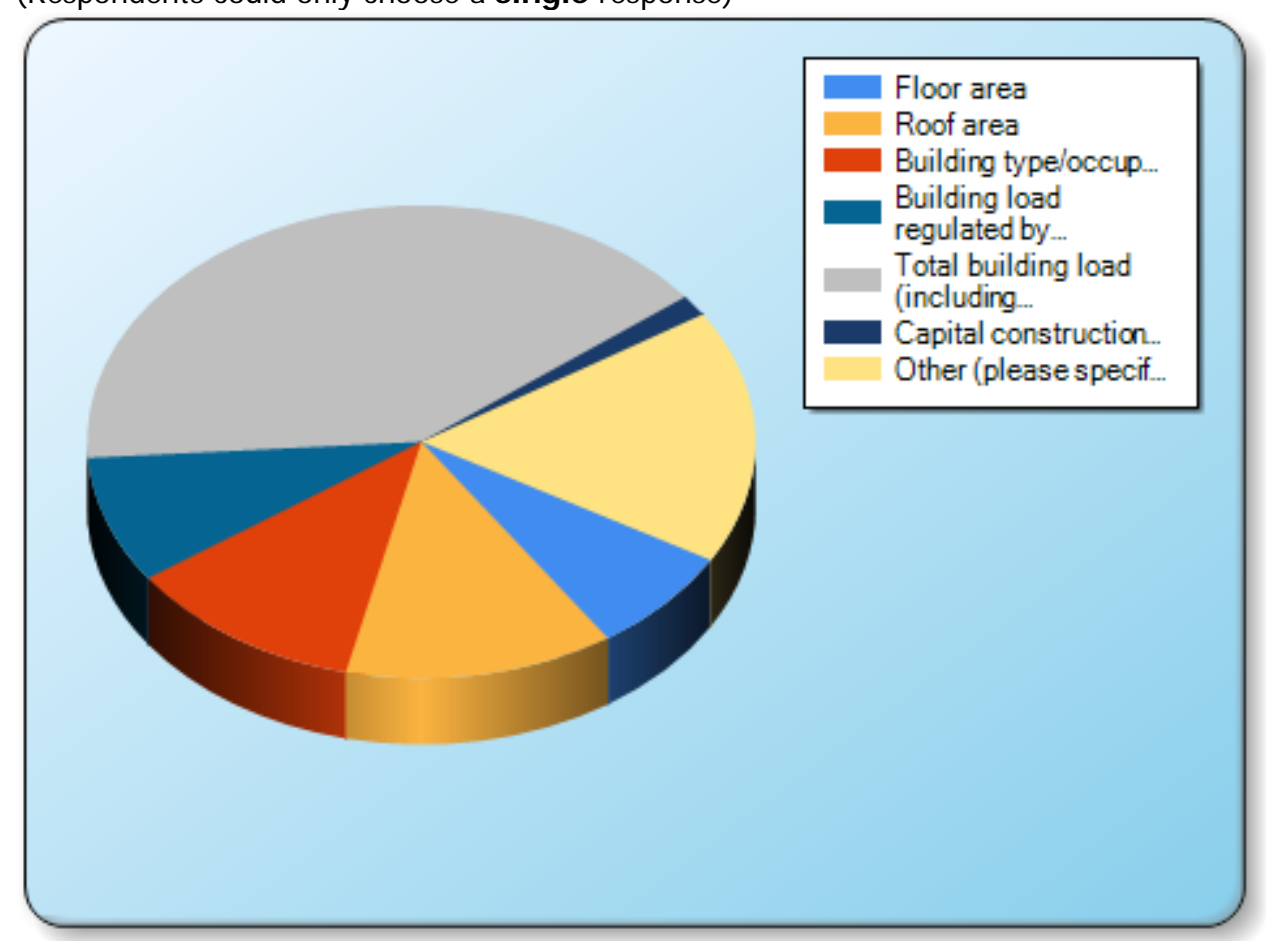


5: If prescriptive or performance-based on-site renewable energy requirements were implemented, on what should siting requirements be based?

(Respondents could only choose a single response)

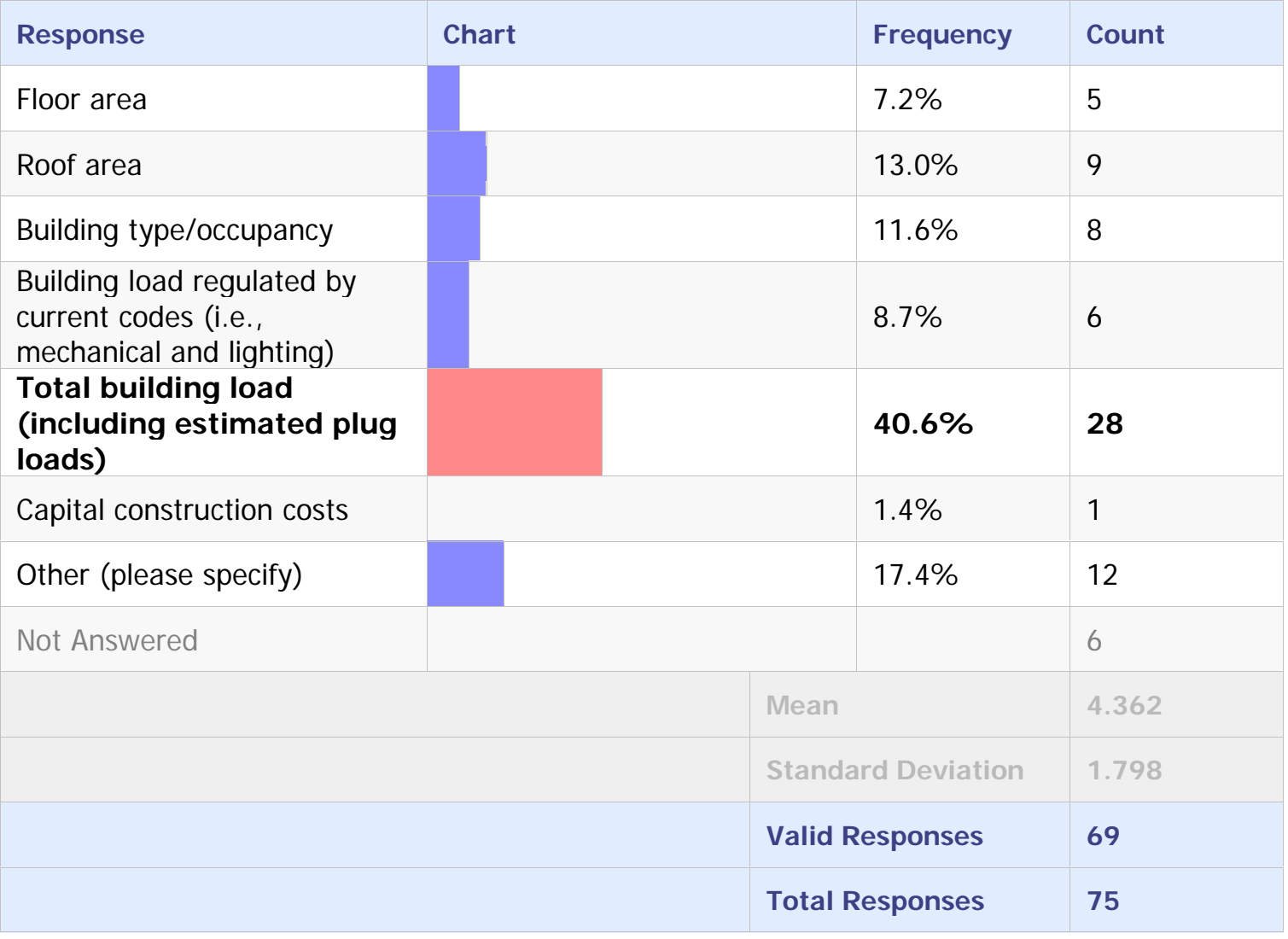

\section{Explain your answer choice for question 5.}

Response to question 5

Depends. Large single story buildings could use roof area. Large multistory buildings with small footprint should use another method. Allow purchase of green energy as alternate compliance. This meaning of this question is not totally clear to me. However, the only criterion for system selection that makes sense is the amount of energy expected to be used by the building. If renewables are to be mandated, such requirements should be based on the total energy load anticipated for the building....especially by how much those loads may exceed the allowable energy budget for the building.

This is a constant, as opposed to the plug load which can vary greatly. No sense to totally recreate the wheel Use the existing codes to our advantage.

Allows for design teams to evaluate optimal siting and technology.

Building load incorporates floor and roof area but total load is what needs to be addressed. It's also useful for the owner to know what these figures are.

Total building load would encourage designers to minimize energy requirements. Also, we have many MacMansions with very, very high energy requirements.

Total building load is the best reflection of HOW MUCH ENERGY WILL BE CONSUMED.

No easy answer here 
Response to question 5

Buildings need access to the sun/wind (unless using geothermal energy), and especially in urban areas, the roof may be the only area of the building to get such access.

It becomes more challenging to use solar the higher the building.

Floor area is a good compromise between roof area (which affects realistic capacity) and use type, which affects total load characteristics of the building. Building load has no relationship to roof area, while roof area alone puts higher burden on warehouse projects.

Same as \#3

We should be working toward certain overall percentages coming from renewables, just as in RPS.

Keep it simple and equitable. - Basing a requirement on roof area is patently unfair as it allows a 40-story building to only provide $1 / 40$ of the renewable energy as a 1-story building. - Basing it on occupancy types gets too complicated. - Basing it on any of the other factors is too loose and subject to gaming.

A 100,000 sf Factory with little glass but heavy loads can be sited one way, while the same size Office Building or Retail space will require entirely different design criteria.

Roof area and parking lot area. There are practical reasons for this, but more important it creates an incentive to not provide parking, and to building multistory buildings (which have less thermal envelope area per unit of volume than single-story buildings).

No response. See above comments.

If I understand the question then my answer reflects the regulatory model that is available to use. Siting generally addresses all components from use to materials to mass to transportation, the list goes on. Each of those components is directly related to a set of rules; code or zoning. Ultimately, just like accessibility became mainstreamed with various rules and codes the principals of siting must be mainstreamed into those same rule sets. So not only on what, but where should siting be most effectively based.

Roof area is not always available (e.g. if rooftop equipment is installed) Floor area doesn't make sense since multi-story building floor area does not mean renewables can be installed. High and low-rise buildings in different environments have different possibilities.

The only thing that matters is the total building load.

Assume "siting' means mandatory on-site renewable. Also assume that the energy use of the proposed building is the best metric to base renewable requirements on.

Possibly several of the options need to be considered, but the size of the home is probably the best primary determinant. Smaller homes tend to use less energy than larger ones and, for affordability reasons, have greater need to avoid high capital costs, so it makes sense to for requirements to be more "avoidable" in those homes.

thresholds should be based on the availability of the resource being tapped - wind, solar, hydro, etc.

If you intend to make an impact it has to be based upon total building load.

Florida's code is based on conditioned floor area. We give credit against the baseline budget for renewable features.

Siting/orientation should be considered only in conjunction with passive design features (southfacing glazing; SHGC; PF; mass storage, etc.) and after all cost-effective improvements are made to the envelope and then the selections of HVAC/SHW systems that meet the loads.

We're a densely populated city. Roof space and yard space is often at a premium. The other categories are moot if there's no room for the technology.

For now with current mainstream renewable technology, roof area makes the most sense. In the future, might change this. 
Response to question 5

Most neutral approach

Total building load, again, is what's trying to be addressed. Additionally it can include such quantities as floor and roof area, occupancy, etc.

Your menu only allows one choice so I had to pick type/occupancy. Any performance based requirement would also have to include provisions for solar accessible space (roof and walls) and total building load.

For PV systems space to place systems is important. For buildings located in an urban area roof area is critical.

Actual building energy use is the issue.

Make as much as you use

Multiple parameters above needed (I could only select one).

Basing it on loads is the only way to get to a true reduction in $\mathrm{CO} 2$.

I would also include total building load (which is related to building type/occupancy).

total load is total load ... awareness needs to be raised of how much we consume not matter what it comes from OTHER- the total load may need to be in a metric with occupancy type as well...

I think that an effective way to mandate renewable energy may be to say, "OK, you know how much energy your lighting/HVAC system is using, now figure out how to reduce that load by $10 \%$ using renewable systems." This will be very difficult, if not impossible to enforce, however easily enforceable requirements (basing it on floor area/roof area) are not very practical.

If a determined "fixed" amount of electricity were allocated to a building facility and when the building exceeded that allocation it meter/switch to the utility opened, the net result would be two-fold....efficiency and then self production would be the common practice.

You need to take load into consideration, but you also have to consider how much space is on the roof. You may decide the RE system should provide different \%s of the load for different building types. Why not include process load in the RE requirement? Require a small \% of process load to be met by on-site RE. Most large processes occur in buildings with huge roofs that could accommodate much bigger systems than what's required for lighting and HVAC. Processes are also often on TOU rates - helps with cost effectiveness, though RE still probably doesn't pencil out.

Roof area is easy to measure and is most likely the limiting factor for how much RE can be achieved.

Buildings are unique, both in their use and their siting. What works well in one place may fail elsewhere. Cookie-cutter policy will create many problems.

This issue could end up having the renewable system driving the building design rather than appropriate function

If the goal is to reduce greenhouse gas emissions then that should be the test. A per square foot requirement would address the differences between larger and smaller buildings. For singlefamily residential, the GHG/sf should be lower for larger homes (less exterior area per SF and more embedded GHG in the building materials that should be compensated for). For commercial buildings there should be differences for occupancy type in broad categories (i.e. health care should have a higher number as the comfort levels are more critical where people are sick). Also, GHG of equipment for things like manufacturing should also be considered but probably separately from the HVAC and basic electrical systems.

It's really important to look at the local micro-climate in context with the building usage so that the right type and design of renewable energy system is specified. 


\section{Response to question 5}

Total building load is the only factor that deals directly with the problem at hand. The other factors have only an incidental connection to how much energy the building will use.

I was tempted to say roof area because that gets to the issue of opportunity for renewables. But I believe it's more of a responsibility issue - if you are going to build a high energy consuming building, you should "compensate" for that use by incorporating renewables.

The use of a building governs what are the operating needs which also affects the energy requirements.

I don't like this approach and if it was implemented I'd prefer total load, but if it isn't all regulated, it is going to be difficult to enforce.

RE should, for now, be considered an add-on and not a vital part of the energy of a building. As such, the size should be measured on the total building load so as to make sure that it won't be oversized.

This keeps a degree of flexibility and option for the owner to potentially progress into have systems. 
6: If codes move toward being less prescriptive and more outcome-based, should they include a separate renewable energy requirement to ensure people become familiar and experience renewable energy systems, or should the builder/owner be able to decide how best to meet the target?

(Respondents could only choose a single response)

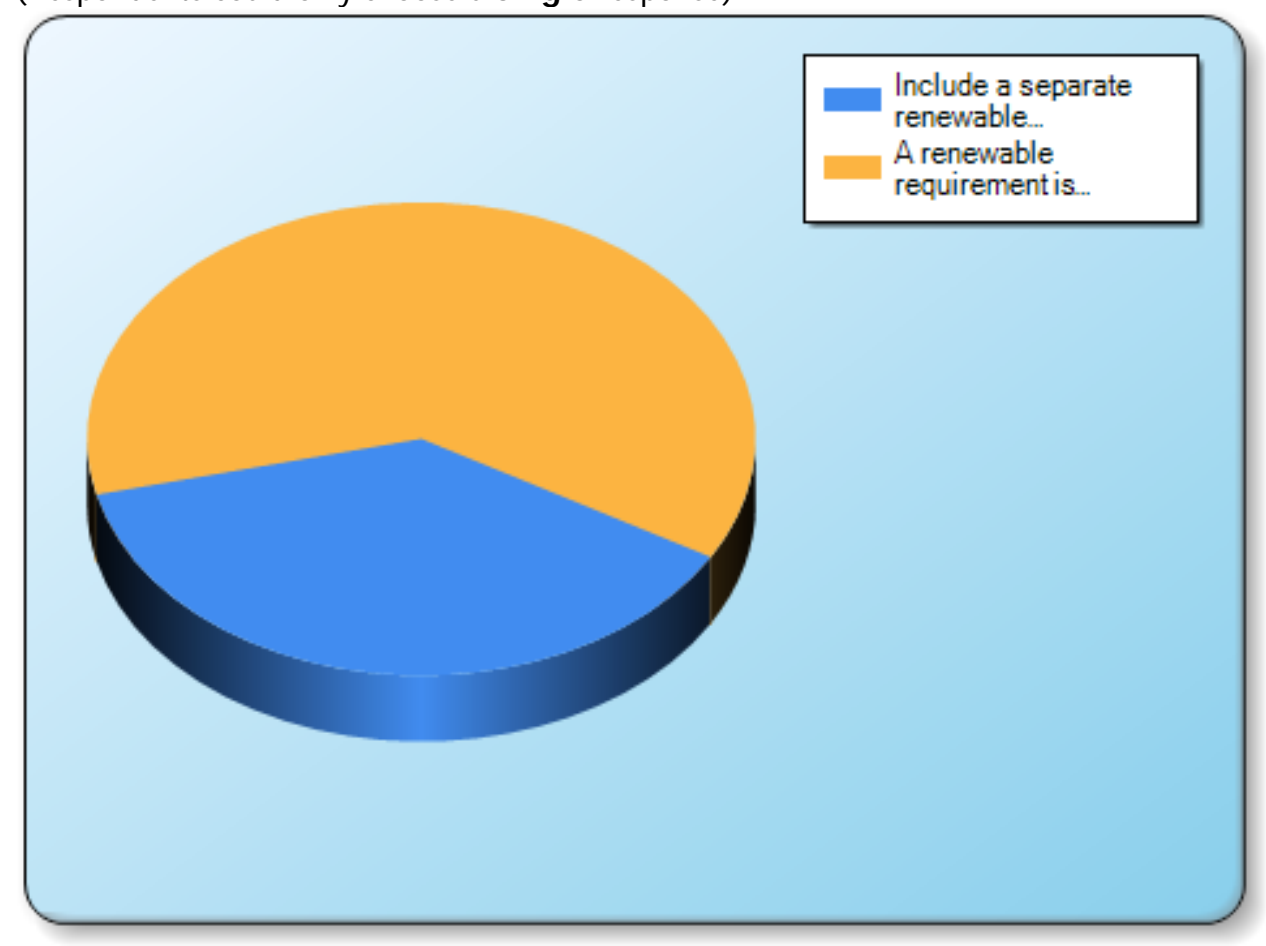


6: If codes move toward being less prescriptive and more outcome-based, should they include a separate renewable energy requirement to ensure people become familiar and experience renewable energy systems, or should the builder/owner be able to decide how best to meet the target?

(Respondents could only choose a single response)

\begin{tabular}{|l|l|l|}
\hline $\begin{array}{l}\text { Response } \\
\text { Chart }\end{array}$ & Frequency & Count \\
\hline $\begin{array}{l}\text { Include a separate renewable } \\
\text { energy requirement; it will } \\
\text { help develop experience with } \\
\text { renewables and spur the } \\
\text { market }\end{array}$ & $37.9 \%$ & 25 \\
\hline $\begin{array}{l}\text { A renewable requirement } \\
\text { is unnecessary and } \\
\text { conflicts with the intent of } \\
\text { an outcome-based code; } \\
\text { leave it to the } \\
\text { builder/ owner to decide } \\
\text { how to meet the target }\end{array}$ & $\mathbf{6 2 . 1 \%}$ & $\mathbf{4 1}$ \\
\hline Not Answered & & \\
\hline & Mean & \\
\hline & Standard Deviation & 0.489 \\
\hline & Valid Responses & $\mathbf{6 6}$ \\
\hline
\end{tabular}

\section{Please comment on your response to question 6.}

Response to question 6

Sources of energy should not be dictated by the building codes.

see no. 3

Energy improvements designs should be cost driven. With a large enough energy improvement requirement not only will low cost energy efficiency be used but renewable energy will also be needed.

Energy policies must be debated and enacted in a consensus-based process, or at least via a legislative process. Renewable energy mandates do not belong in the building code until such processes are complete. To include such mandates in the codes prior to community consensus on the goals of the energy policy will prove to be detrimental to the adoptability and enforceability of the codes.

They will not know what to do without the guidance or a requirement to be met

Also consider certified renewable energy credits - from a societal point of view, off-site owner installed/financed renewables are the equivalent as on-site renewables

This option is most politically acceptable and it directly gets to the goal of the building using less energy. It's also easier to administer.

In Hawaii, people are very familiar with solar water heating systems and PV installations are tripling every year. 
Response to question 6

Mixing energy production with energy efficiency does not make sense and can lead to perverse outcomes (building uses 200,000 kWh and 15,000 therms but has an on-site system producing $100,000 \mathrm{kWh}$ and 5,000 therms being labeled as more "energy efficient" than the same building that only uses $105,000 \mathrm{kWh}$ and 2,000 therms to begin with).

No renewables should be required until cost of additional efficiency (on each project) exceeds cost of renewables.

This will be very jurisdiction-specific, but to build on-site renewable infrastructure will need specific requirements.

Ultimately, all buildings/neighborhoods will need on-site renewables to reach net-zero energy. We need to start to develop the design and installation knowledge now.

Renewable energy is too site, state, and occupancy specific to be feasibly included as a code requirement. It also stifles innovation.

An outcome-based code does not replace a prescriptive code so this is not an answerable question. Ask Eric Makela, he'll explain.

Need to jumpstart the industry infrastructure leading to market transformation.

Sometimes the regulatory model must be courageous even if taking small steps to shift the current paradigm. The outcome-based code must include renewable energy...start slow but don't avoid.

A separate renewable requirement incorrectly skews the market.

The only enforceable code is an adoptable one.

You could always include a building label or signage to summarize energy conservation/renewable energy measures

Requirements have to be enforced, which requires infrastructure and personnel. Better for the $\$ \$$ to go to legitimate design professionals than to enforcement staff. Hence, if the code can be a relatively simple limit, for example, on equipment capacities and such, builders can spend their money on design assistance rather than code permits.

But not mandatory. Such as an appendix.

I think this sets up a false dichotomy. These two things aren't mutually exclusive. The compromise here seems to be renewable "ready" buildings - buildings that are set up to be able to incorporate the addition of renewable energy systems sometime in the future.

There needs to be a slight push (guidance) towards renewable energy.

Again, forcing people to do renewables is a bad idea.

The codes need to concentrate on what can be effective for ALL design solutions. Renewables are the way toward zNEB but are different for every location within the country due to climate, grid, population density and other factors and, as such, should be left to the capabilities of the designer.

Solar WH is already mandatory for new construction. The next step is requiring stub-ins and large electrical panels for PV.

The freedom to innovate is what's needed today.

I disagree with your definition of outcome based and performance based. Outcome based in my opinion and that of many of the people I work with would be a code based on actual performance of the building after it is constructed and occupied. An outcome based path would have to include a performance based intermediate compliance path that would simulate the design to ensure that the design at least had the potential to meet code. 


\section{Response to question 6}

Outcome based codes provide the ability of the designer to meet the EUI any way that is appropriate for the building. Including mandatory requirements in on outcome based codes is inconsistent.

It is necessary to mandate the use of renewables.

We need to change our energy paradigms as part of the desired outcome

I like the idea of a renewable energy requirement as the prescriptive baseline, but allow this to be traded off through performance approaches. Some solar measures (e.g., "solar ready" should still be required.

Looking at current building that honestly made an effort at outcome based result. They all most always ended up using renewables because otherwise they could not meet they stated target goals.

There are too many issues with installation, cost-effectiveness to make it a specific requirement. Outcome based codes (especially as requirements continue to tighten) will lead in this direction. there needs to be a feedback loop for a savvy owner to ask for optimized systems and be able to review the success of the meeting the outcomes

The selected answer matches my opinion on this.

Renewables are regional.... builders and private business have made incorrect and poor choices for long enough. Legislate and Mandate.

...BUT make sure that renewables do count toward hitting the outcome based targets.

Set the target low enough that it'll be difficult or impossible to reach the target without RE.

This is exactly why I am in favor of RE code requirements - make people learn, their motivation for reducing cost will help evolve RE.

Both, although the builders/owners don't have the capacity to make these decisions yet. Start with achievable goals to build the market and ramp up to stricter expectations; builders/owners and the professionals that support them need to have very positive experiences with this effort, or there will be too much push-back and the concept will be squashed for another generation. Introduction of energy supply requirements at the level of each building would seem to cause severe ripple effects on community, state and regional power systems Development of industry experience and spurring the market should not be done through codes but through government programs. Training could be required for licensed professionals and rebates or tax credit incentives should be used to spur the markets.

Code affects the bottom of the market so it is important to have requirements that keep this sector in line with more progressive buildings. Also, codes affect the mass market (as opposed to voluntary programs) so are necessary to leverage to drive up demand and drive down cost of important technologies.

Have no comment to offer to this question.

As I'm not sure how outcome based codes will work, I'm not sure. The problem with not having the requirement is that there will be no way to know how the RE system will fit with the total energy load. The outcome, after all, will be dependent on what is included in the building. However, RE is too expensive to make it a specific requirement, particularly if you don't know whether it will actually be needed.

Freedom of choice is the owner's right. 
7: Assuming the goal is to reach zero net-energy by some future date, and that electricity will still be needed for lights and miscellaneous end-use (plug) loads, does it make sense to require installation of renewable energy systems that generate electricity as opposed to systems that meet thermal loads?

(Respondents could only choose a single response)

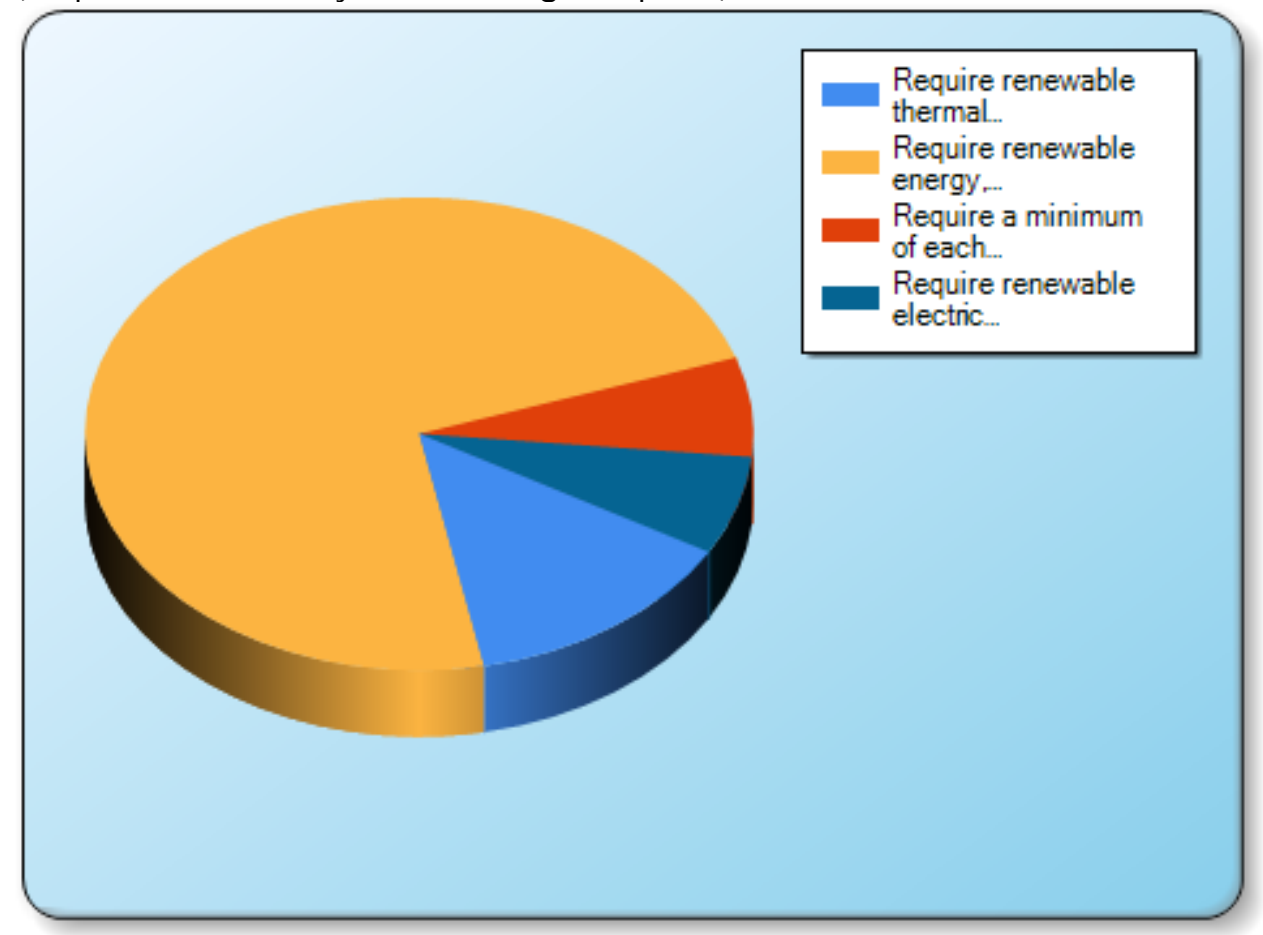


7: Assuming the goal is to reach zero net-energy by some future date, and that electricity will still be needed for lights and miscellaneous end-use (plug) loads, does it make sense to require installation of renewable energy systems that generate electricity as opposed to systems that meet thermal loads?

(Respondents could only choose a single response)

\begin{tabular}{|l|l|l|}
\hline \multicolumn{1}{|c|}{ Response } & Frequency & Count \\
\hline $\begin{array}{l}\text { Require renewable thermal as } \\
\text { a pre-cursor to a renewable } \\
\text { electric requirement }\end{array}$ & $13.6 \%$ & 8 \\
\hline $\begin{array}{l}\text { Require renewable } \\
\text { energy, let owner decide } \\
\text { whether thermal or } \\
\text { electric }\end{array}$ & $\mathbf{7 2 . 9 \%}$ & $\mathbf{4 3}$ \\
\hline $\begin{array}{l}\text { Require a minimum of each } \\
\text { (renewable thermal and } \\
\text { renewable electric) }\end{array}$ & $6.8 \%$ & 4 \\
\hline $\begin{array}{l}\text { Require renewable electric } \\
\text { only }\end{array}$ & $6.8 \%$ & 4 \\
\hline Not Answered & Vean & 6 \\
\hline & Standard Deviation & 0.691 \\
\hline & Total Responses & 65 \\
\hline
\end{tabular}

\section{Comment on your response to question 7.}

\section{Response to question 7}

How are you going to have net zero gas energy usage? We need to get real about the prospect of net zero energy usage. Let's do the best we can but not build unrealistic expectations that cause politicians and others to make foolish proclamations and requirements.

See comment \#6.

In some locations, access to thermal energy may be more realistic than access to electric, or viceversa.

Let's start slower with systems that are currently being used and installed

The Net in net-zero assumes exports of excess renewables to offset times of use from the grid. Electricity is the most common form of renewables available for export. Many of the demand side renewables are for reducing demand only- they cannot be exported. The renewable demand side efficiency measures include solar hot water, solar OA preheat, passive solar, solar thermally driven liquid desiccants, etc...

I do not believe any requirement should be considered. I believe that energy should be sold on an extremely progressive scale. $\$ 0.07 / \mathrm{kWh}$ for the first $2000 \mathrm{kWh}, \$ 0.15 / \mathrm{kWh}$ for the next 1500 $\mathrm{kWh}, \$ 0.25 / \mathrm{kWh}$ for the next $1000 \mathrm{kWh}$ and so on. 


\section{Response to question 7}

Solar water heating is extremely cost effective in Hawaii and it cuts our peak load (5-9 PM.)

Different regions have different climates and different resources, different resources within a city.

Again, there may be physical constraints that mean that requirements are unrealistic.

The most cost-effective building related renewable energy technology is solar heating systems (particularly for residential). Let economics drive the market. Mandating the installation of renewables does not permit this to happen. Also, having a goal of net-zero for buildings is not desirable.

None

Most buildings use electricity and fossil fuels, and to ignore fossil fuel use, especially in Northern climates where the fossil fuel use may be $50-60 \%$ of the total building energy usage, does not make sense.

Thermal loads may be able to be met through efficiency and design, but not plug loads I do not favor requiring renewables in either form. Require installation of all more cost-effective efficiency measures first.

Want to provide options, especially for different regions of US.

Allow the choice. - As the minimum percentage requirement rises over time, it will not be possible to achieve the percentage with solar thermal alone. However, you should still allow people to choose the mix that they want.

Flexibility will lead to greater innovation

I question whether net zero buildings are a worthwhile goal because of the increase in transportation energy that is usually associated with net zero buildings, and because availability of renewables usually does not coincide with desirable locations for new construction.

Whatever they choose needs to provide some minimum of Btu/kWh/therm equivalent.

Start with a choice and maybe add more stringent requirements.

Variety of circumstances will support the use of renewable energy regardless of application.

Plug and play; no moving parts; easy to maintain; realized benefit with direct metering

At least for us, it looks like thermal (Ground Source Heat Pumps) is going to be the first step we have to take, and then we will have to figure out how to meet the remaining requirements. But I can't confirm that is workable for everyone.

Can't pick one. Depends on too many other things, not least of which is location.

Early buy-in needs choices.

Would not require renewables.

Presently renewable electric energy should be FAVORED, since the investment return in decreased demand and distribution costs makes it a clear choice (not to abandon thermal energy and concentrate exclusively on electric) and most worthy of the majority of investment decisions. Already required. In Hawaii, "thermal" is water heating, which can account for as much as $40 \%$ of a home's load. With utility rebates and a 35\% state credit on top of the $30 \%$ federal credit, solar WH pays back in 3-4 years.

This will vary depending on the building type and occupancy 
Response to question 7

I'm not sure it's a good idea to require renewables. I believe if the true cost of today's energy is borne by today's people the economics will take care of themselves.

If renewable thermal is more cost effective to meet the thermal loads of the building than renewable electric, the size of the renewable electric system would just be reduced accordingly. As you state, renewable electric will always be needed.

Very few buildings will ever be able to meet ZEB, even with cost effective BI PV so there will always be a need for grid based electricity and gas. Because of this the renewable energy requirements should be in units of energy and buildings with high heating or hot water loads should be free to use solar thermal.

The designer should have the choice to either offset electrical power or thermal loads based on the building use.

The issue is energy, regardless of how it is used.

A mix of thermal and electric technology is the best overall solution because of the high efficiency of ST. If PV came even close it would be fine to have electric only.

Especially for optimal cost ZNE attainment, need to maintain flexibility in which fuel type/quantity is being offset by onsite solar. In some cases, solar thermal will be an ideal match and it can be very costly to offset larger thermal loads with PV electric... and vice-versa.

Depends on what works best in what location.

We still don't have a good handle on much of the electrical load in a home. Requiring PV renewable would only cause problems and lead to disillusionment with PV.

solar thermal systems can readily meet hot water demand and in some small scale buildings the heating demand as well - the price point is more accessible to promulgate this type of renewable first... also it does not need to "grid connect"...

Situations may exist where no thermal load is required. Water may be more precious in the future than the need for electricity. Renewable power at its smallest calorie of production.

Energy is fungible; though there are differences in efficiency of production and use, we shouldn't differentiate btwn electric or thermal

The load will vary and owner should weigh whether thermal or electric makes more sense.

The early goal of an RE code is to develop experience in the system. As such the size of the array or technology is not as important. Ultimately PV will beat ST because heat pumps will displace electric resistance and gas fired water heaters.

Require a minimum of each, recognizing regional differences and performance variation and needs, and allow for trade-offs in some situations

This question appears to disregard significant climatic differences/potential that would challenge the application of the national code

Wouldn't the ultimate goal be to reduce greenhouse gas generation to safe levels? Do we care if the reduction happens at the building or at the utility? Wouldn't the answer to this also depend on location and availability of renewable energy (either electric or thermal?) as well as the need (mild climates versus very cold or hot)?

Again, project teams should be allowed to use their own ingenuity in meeting a goal. ALL policies should be structured to encourage improvement of efficiency PRIOR to looking at renewable generation.

This is a good first step as we work on improving the ability to estimate plug loads.

I do not have an answer to offer to this question.

Thermal will probably make more sense economically long before electric does. We should aim for RE at some point, but to start, we should get thermal. 


\section{Response to question 7}

Performance and freedom of deciding what is best for each specific project.

Valid Responses

51

Total Responses 


\section{8: When should renewable energy requirements begin to be integrated into code?}

(Respondents could only choose a single response)

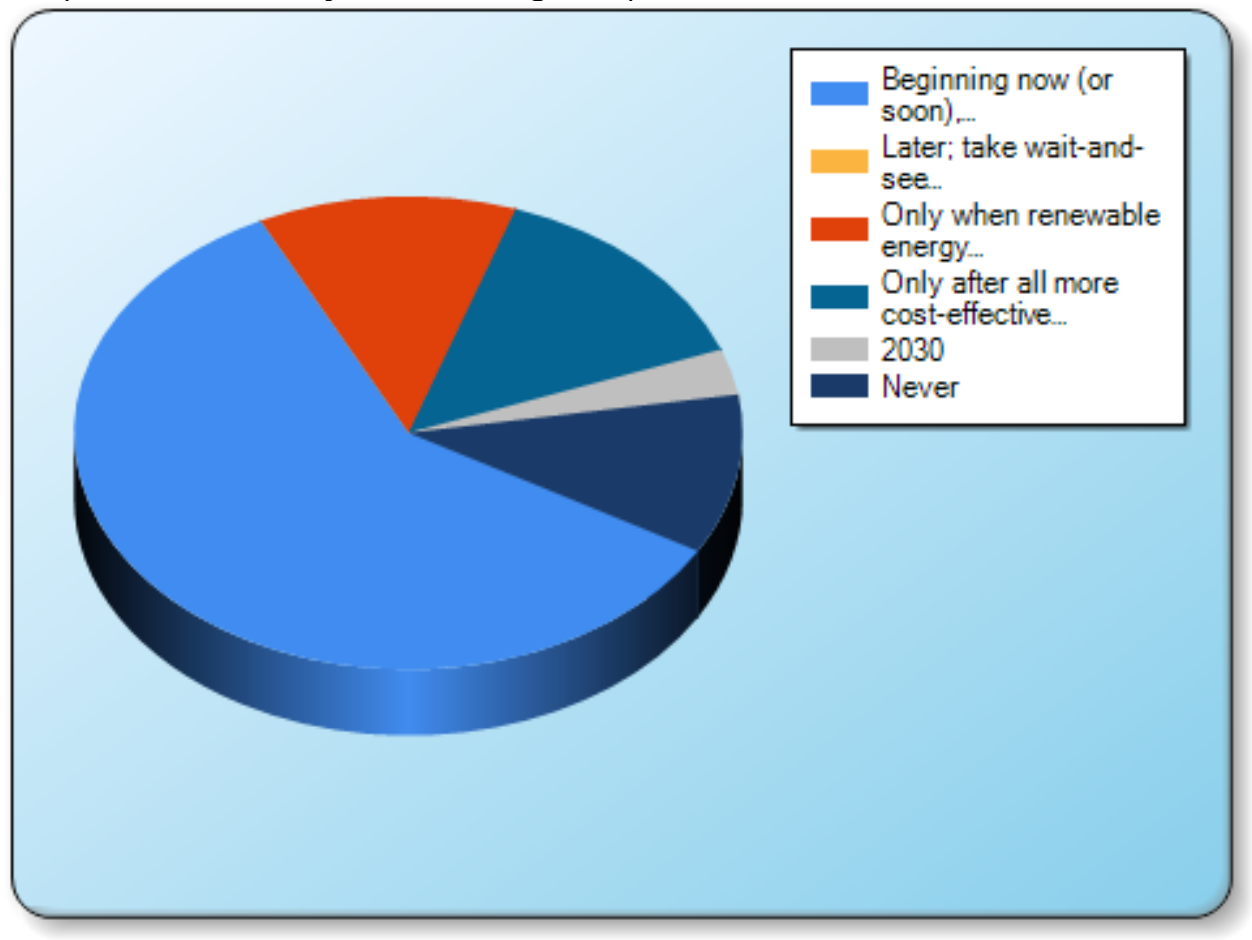

8: When should renewable energy requirements begin to be integrated into code? (Respondents could only choose a single response)

\begin{tabular}{|l|l|l|}
\hline $\begin{array}{l}\text { Response } \\
\text { Beginning now (or soon), } \\
\text { in tandem with } \\
\text { improvements to energy } \\
\text { efficiency requirements }\end{array}$ & Frequency & Count \\
\hline $\begin{array}{l}\text { Later; take wait-and-see } \\
\text { approach; wait until costs } \\
\text { drop }\end{array}$ & $\mathbf{5 9 . 4 \%}$ & $\mathbf{3 8}$ \\
\hline $\begin{array}{l}\text { Only when renewable energy } \\
\text { has become cost-effective }\end{array}$ & $0.0 \%$ & 0 \\
\hline $\begin{array}{l}\text { Only after all more cost- } \\
\text { effective energy efficiency } \\
\text { has been adopted }\end{array}$ & $12.5 \%$ & 8 \\
\hline 2030 & $14.1 \%$ & 9 \\
\hline Never & $3.1 \%$ & 2 \\
\hline Not Answered & $10.9 \%$ & 7 \\
\hline & Valid Responses & 64 \\
\hline & Total Responses & 65 \\
\hline
\end{tabular}

B.48 


\title{
Comment on your answer to question 8.
}

\author{
Response to question 8
}

Needs no explanation.

See comment \#6.

As state above, mandates for the inclusion of renewables should NOT be incorporated into the codes until comprehensive energy policies are legislated. However, clear and usable requirements on how renewables should be installed must be included in the codes now to ensure effectiveness and safety of all installations.

Only as a performance option- not as a minimum requirement

See \#7. Poor people should not be forced into something they cannot afford. Gluttonous energy consumption is the problem.

We already have mandatory solar hot water heating and we're upgrading IECC 2009.

It has become cost effective in some places already.

Proposed IECC 2012 (EC147) has a renewable option pathway for that last 3\% energy savings. Time is now.

Renewable energy does not make the building more energy efficient.

but a very small amount

This is the key theme of my responses. See comments above.

Prefer energy efficient buildings first, solar second/last.

start with option packages

Need to develop the design and installation expertise.

Baby steps at first, then increasing as costs come down and innovations increase. Similar to Energy Conservation. We've already waited too long with both

Start slow but start. Countless opportunities exist; even with utility providers. Wisconsin Electric provides customers the opportunity to purchase a percentage or even $100 \%$ electric power from renewable sources...that could satisfy the code requirement.

Really 2 answers here - the other is when renewables are cost effective.

Depends on who is paying!

In some sense they're already part of the codes, via performance compliance paths. Providing prescriptive options could be the next step.

Such technologies can be integrated into a performance-based code right now on a cost, BTU or percentage of a load basis.

Requirements for renewables will be marketable and timely when all efficiency/conservation measures have been brought to market acceptance

Solar WH is already on the books statewide. With prices dropping to around $\$ 5 /$ watt, $P V$ is rapidly becoming cost-effective, given our high $\mathrm{kWh}$ prices.

Phase 1 could be renewable ready Phase 2 gradual requirements for renewable Phase 3

mandatory requirements for renewable or energy target 
Response to question 8

Assuming we never bear the true costs of energy then it's important to get started now rather than later.

Again, I think that an outcome-based approach will push the technologies when they are mature enough to stand on their own.

Note already being proposed for the 2012 IECC.

$50 \%$ reduction by 2010 to stay in step w/2030 initiative.

If not now, when? Why wait when it is practical and reasonable to begin now?

Important/critical to RE requirements into the code now, even if "baby" steps to set the groundwork for future enhancement. Given the time frame of code development, waiting is not a good option.

To me the "cost" issue is a red herring and will always be a "reason" for trying to get out of doing something.

We should always include pathways in the code for adding renewable. Make it a trade off option for example. However, requiring it now before all of the other cost-effectiveness measures would only raise cost excessively without providing much of a benefit. Remember, most people would mistakenly opt for renewable based on popular perceptions.

codes should optimized energy efficiency first( reduce loads) then apply renewables when the cost of adding more insulation is the same as placing renewables... similar to PassivHaus approach but allowing for right sized renewables ...

This answer depends on which code you are talking about. If it's a mandatory minimum code, I could see a prescriptive tradeoff option - if you have $10 \%$ renewable, you can have $5 \%$ worse lighting. I don't think it should be a mandatory requirement for the minimum code. If it's a voluntary code (green code) I think that mandatory/prescriptive/performance options are appropriate for inclusion in the immediate to near future.

Put a stick in the sand now, and then work on improving the standards over time.

The time to gain local experience for solar is now.

The sooner the better. The technology is available and will continue to improve and costs will continue to drop. Integrating RE into buildings as policy will kickstart the market better than any other effort.

Why ignore community level application of renewables, utility renewable portfolios and regional differences of renewable potential?

Greenhouse gas emission limits should be implemented now but specifically requirementing renewable energy should never happen.

There are cost effective opportunities available today that can be integrated more broadly

Renewable energy requirements should first be offered as an available option to the builder before it becomes a mandated requirement.

There may be a time when we could start to incorporate RE prior to getting all the other ee measures in place. This is particularly true if we start switching to outcome based codes.

However, RE should not go into effect until it is cost effective.

This is not an issue of fire or life safety - codes are minimum documents and cost effective and efficient systems will be incorporated because they are a good business decision. They won't have to be mandated. 
9: Should renewable energy requirements be introduced into voluntary 'green" or "stretch" codes and programs first (i.e., LEED, GBI, ASHRAE 189.1, IGCC, etc.)?

(Respondents could only choose a single response)

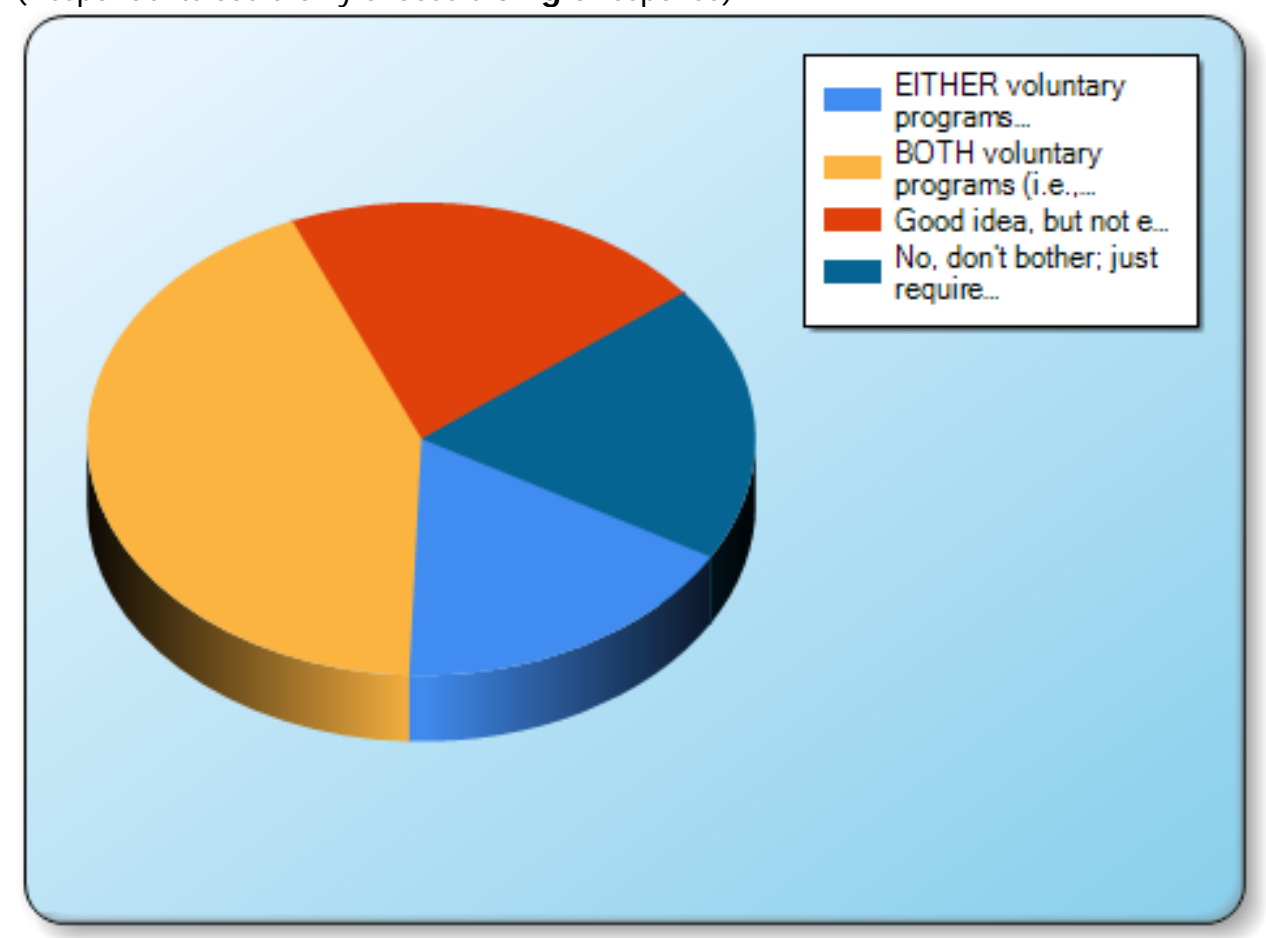


9: Should renewable energy requirements be introduced into voluntary 'green" or "stretch" codes and programs first (i.e., LEED, GBI, ASHRAE 189.1, IGCC, etc.)?

(Respondents could only choose a single response)

\begin{tabular}{|c|c|c|c|c|}
\hline Response & \multicolumn{2}{|l|}{ Chart } & Frequency & Count \\
\hline $\begin{array}{l}\text { EITHER voluntary programs } \\
\text { (i.e., LEED, GBI) OR } \\
\text { voluntary standards (i.e., } \\
\text { ASHRAE 189.1, IGCC, stretch } \\
\text { codes) for at least three years }\end{array}$ & & & $17.2 \%$ & 10 \\
\hline $\begin{array}{l}\text { BOTH voluntary programs } \\
\text { (i.e., LEED, GBI ) AND } \\
\text { voluntary standards (i.e., } \\
\text { ASHRAE 189.1, I GCC, } \\
\text { stretch codes) for at least } \\
\text { three years each }\end{array}$ & & & $43.1 \%$ & 25 \\
\hline Good idea, but not essential & & & $20.7 \%$ & 12 \\
\hline $\begin{array}{l}\text { No, don't bother; just require } \\
\text { it }\end{array}$ & & & $19.0 \%$ & 11 \\
\hline Not Answered & & & & 7 \\
\hline & & Mean & & 2.414 \\
\hline & & Stand & rd Deviation & 0.992 \\
\hline & & Valid & esponses & 58 \\
\hline & & Total & esponses & 65 \\
\hline
\end{tabular}

\section{Explain your answer to question 9.}

\section{Response to question 9}

Until it is cost effective - yes.

See comment \#6.

a lot of state energy codes are already better than these programs

I do not believe renewable energy should be a requirement yet.

The more flexibility the better. A lead-in time will help shift the culture to renewables.

Get everyone thinking about it.

None. See above

No, as some of the stretch codes may be the "base code" within 1-3 years.

Poor survey design assumes I agree with one of these answers. 


\section{Response to question 9}

Want to provide options.

Wanted to see more answers to choose from: - Should be in both voluntary programs, AND voluntary standards, AND adopted as a requirement by progressive local jurisdictions and states. - Obviously the solar resource varies around the country, so the implementation of renewable energy requirements should also be expected to vary.

The various standards need to be "codified" and need to become more consistent with each other (e.g. IECC and ASHRAE 90.1)

Nothing that expensive should be a requirement for a code or standard (voluntary or not).

Voluntary programs can do what they want as long as the subsidies aren't insanely high.

Introduce limited requirements in mandatory codes, and more aggressive requirements in voluntary programs immediately.

With the adoption of standards and codes currently around the country it is essential to have renewables part of all potential regulatory tools.

Is this a trick question? Thought it's already in there.

Need to push everywhere

It never hurts to introduce things through those kinds of programs. I'm dubious whether three years is the right number.

If funds are available through utility or government programs, people will go there.

Use the standards to circumvent the NAECA equipment issues and leverage the more efficient appliances with renewables.

LEED especially has been criticized for not giving enough weight to energy. This would push the issue forward.

There is a great need for awareness and understanding of renewable energy

These codes always advance the mandatory codes.

None of the above options is "no."

Voluntary programs don't have much impact in most of the country. LEED has already had ten years to introduce the concept nationally and has not had a significant impact so I don't see any reason to delay in hopes that future impacts on renewables will be higher.

This question will be answered in October when a renewable requirement maybe incorporated into Chapter 5 of the IECC.

Market transformation is the operative paradigm.

Simple and straight forward

RE requirements are fine in the voluntary standards/programs (both are being adopted by cities/states/others). However, we still need to get these into the state building energy codes. I like CA and OR's approach. CA's "Cal Green" tier $1 \&$ tier 2 provides cities a way to require increased energy efficiency. Incorporating RE into T24 is also important. OR's energy code also has incorporated solar well--as a starting point.

broad and aligned coverage is best ...

I will comment that neither the IGCC nor "stretch codes" are voluntary standards. They are voluntary codes. As a representative from a standards developing organization, I am very cognizant of the use of "standard", and appreciate its proper use and application.

Aim for a mandatory requirement. If you can't get the mandatory requirement in the code now, put it in the voluntary code now and move it to mandatory later. 
Response to question 9

It is already in some of these documents

Start with a small target - for example a system that will produce $1000 \mathrm{kWh} / \mathrm{yr}$ per 1000 square feet of roof area (exclude unheated warehouses, farm buildings)

The base should be code which should require some level of RE in all new construction, phased in over a number of years. Stretch codes should exceed those requirements.

The stretch would be to give credit for net-zero

Don't bother with voluntary programs/standards. A high participation rate is about $5 \%$ which is not enough. Mandatory requirements which start out reasonably and increase fairly quickly over time are what are needed.

But per Q.8, there are some requirements that can go right in. For strategies not yet cost effective or easy to implement, those should spend some time in voluntary programs and standards.

A voluntary option is good, but not mandating which standards or program one has to comply with since there are currently many available options.

Again - I see this as an economics and business choice. Good systems that are cost effective and efficient will move the market.

\section{0: Prior to requiring the use of renewable energy, should renewable energy systems be included as an eligible alternative compliance option (i.e., under a point-based system or as an alternative prescriptive measure)?}

(Respondents could only choose a single response)

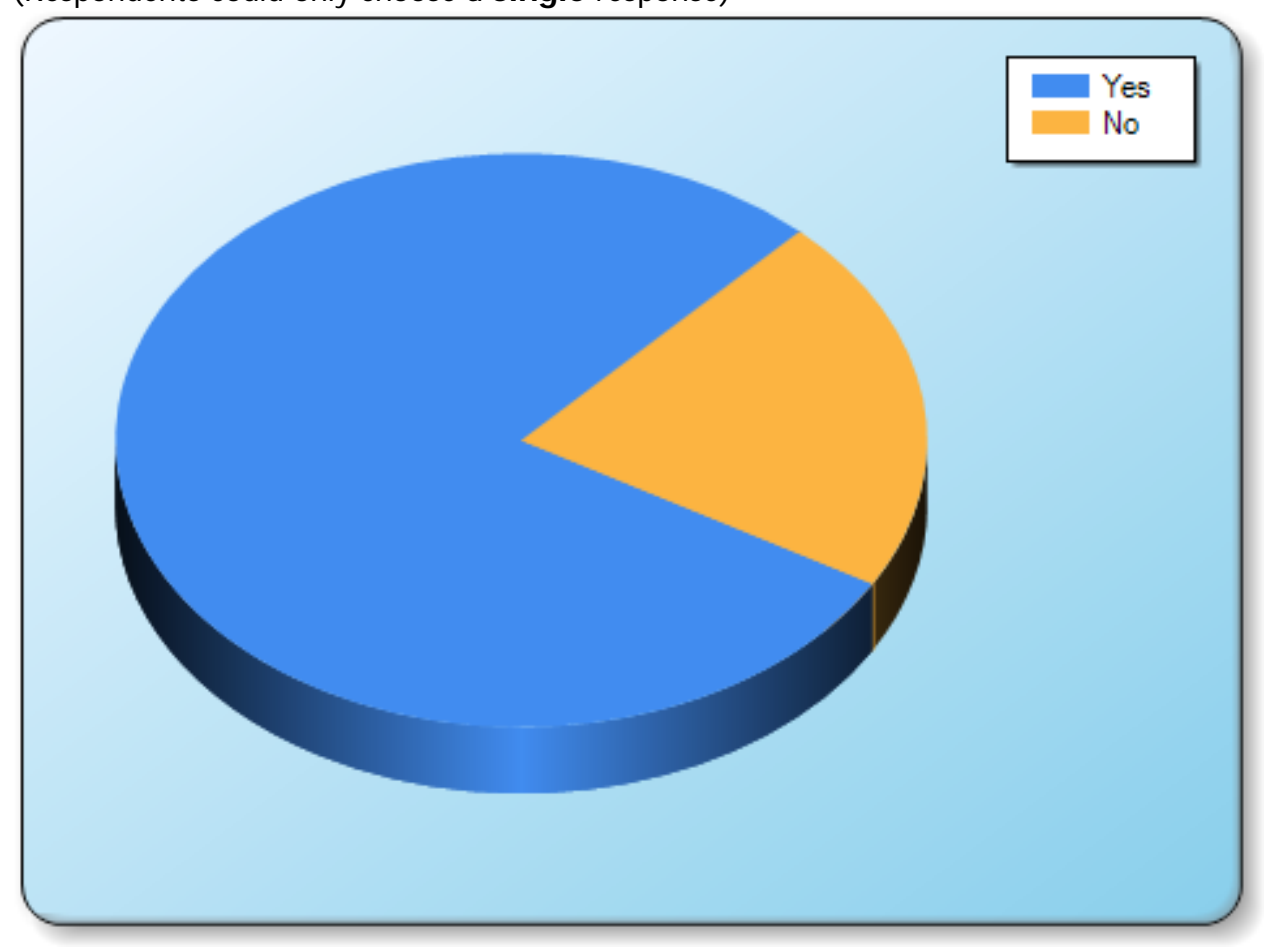


10: Prior to requiring the use of renewable energy, should renewable energy systems be included as an eligible alternative compliance option (i.e., under a point-based system or as an alternative prescriptive measure)?

(Respondents could only choose a single response)

\begin{tabular}{|l|l|l|l|}
\hline Response & Chart & Frequency & Count \\
\hline Yes & $\mathbf{7 8 . 7 \%}$ & $\mathbf{4 8}$ \\
\hline No & $21.3 \%$ & 13 \\
\hline Not Answered & & 4 \\
\hline & Mean & 1.213 \\
\hline & Standlard Deviation & 0.413 \\
\hline & Valid Responses & $\mathbf{6 1}$ \\
\hline & Total Responses & 65 \\
\hline
\end{tabular}

\section{Explain your answer to question 10 above.}

\section{Response to question 10}

This allows them to make the decision on the building they are building

In the future, when renewable energy needs to be considered as a requirement, it should be introduced gradually.

Gives the designer flexibility and increases usage.

Sure

Always as an alternative requirement.

See above

Renewable energy systems produce energy, but do not reduce the energy usage of the building where it is located (unless it is providing cool roof type savings).

Adding renewables to poorly designed buildings is just lipstick on a pig.

Want to provide options.

Don't make it so complicated.

Innovation and cost effectiveness

Better a mandatory requirement in a voluntary code than a voluntary requirement in a mandatory code. This is the only way that the problems will be worked out.

If people want to throw their money away that's fine as long as it's not heavily subsidized with taxpayer dollars.

Ultimately any adopting agency can make that decision, but the direction should be a minimum standard. 


\section{Response to question 10}

no. can't beat a great building enclosure and controls.

don't understand the question

Still don't like requiring new technologies, especially if they aren't cost effective.

Has to be crafted carefully so that efficiency/conservation cost-effective measures are prioritized over renewables.

If a builder didn't like a prescriptive efficiency measure, he could install PV or wind instead. He'd have to show how it would produce more energy than was lost by eliminating the prescriptive measure.

See comment question 8

If you are going to require it at some point, it would be good to familiarize at least part of the market with the technologies ahead of time.

The technology is proven and systems are in place to verify designs and to certify installers so there is nothing to be gained by making it optional.

This is listed as an option in the commercial code change proposal.

Same as \#10.

don't know

This is very important. I think it will be much easier/efficacious to start by including RE as an alternative compliance option. Given the contention of including RE into codes, this seems like a natural, perhaps requisite first step.

This would be a good way to get information on cost, implementation and outcomes. If things go wrong, they can be fixed and would not cause anger among the populace.

Projects MUST show how they reduce loads first ... operating a big consumer off of renewables does not make it ok... i.e. renewable HUMMER!!!

Yes and no. It could also be an alternative performance trade-off (think 90.1 performance path approach, not a performance target trade-off)

You should be able to use RE as an alternative compliance, but perhaps make it a requirement at the same time.

I wouldn't say "prior" but I do like the idea of equivalent alternatives for measure with a 20+ year life (shell, roofing, some HVAC)

RE should be required as soon as possible, with a ramp-up over a dozen or so years, otherwise it will always be bumped off the priority list and net zero will remain elusive.

would risk minimizing benefits of efficiency choices

Also a good strategy to "prove" the technology before requiring it for the "masses"

Renewable energy systems could be included as an option.

Already been done in the Massachusetts Stretch Code. Allowing it to be as part of an alternative compliance mode is a good way to start getting it incorporated into codes. 
11: Would it be meaningful to require pre-wiring for solar electric (PV) and/or pre-plumbing for solar water heating as a first step, or would that provide too marginal of a benefit to mandate?

(Respondents could only choose a single response)

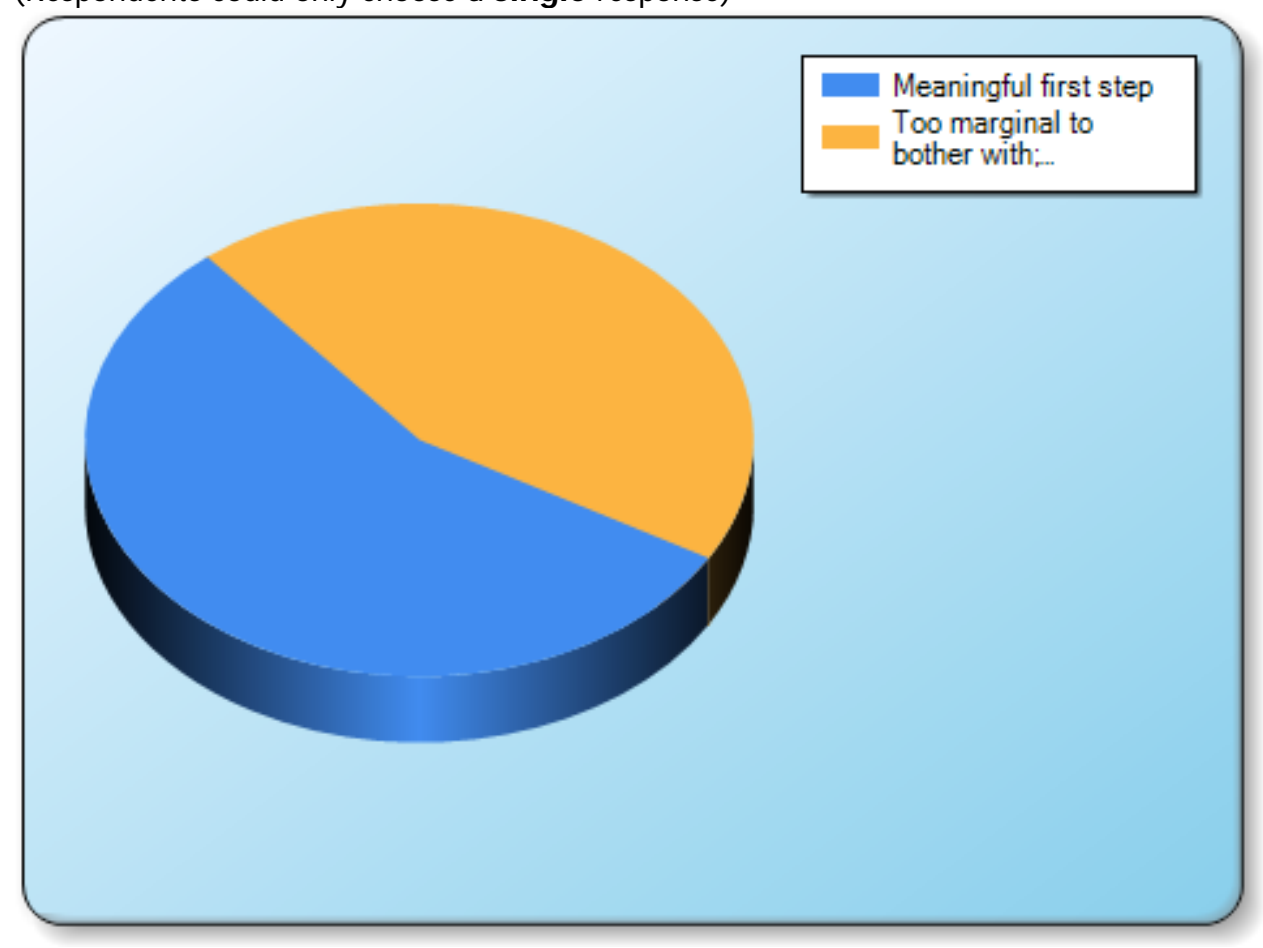

11: Would it be meaningful to require pre-wiring for solar electric (PV) and/or pre-plumbing for solar water heating as a first step, or would that provide too marginal of a benefit to mandate? (Respondents could only choose a single response)

\begin{tabular}{|l|l|l|l|}
\hline \multicolumn{1}{|c|}{ Response } & Frequency & Count \\
\hline Meaningful first step & & $\mathbf{5 5 . 7 \%}$ & $\mathbf{3 4}$ \\
\hline $\begin{array}{l}\text { Too marginal to bother with; } \\
\text { too few will use it, and it's } \\
\text { easy enough to plumb or wire } \\
\text { it later }\end{array}$ & $44.3 \%$ & 27 \\
\hline Not Answered & & & 4 \\
\hline & Mean & 1.443 \\
\hline & Standard Deviation & 0.501 \\
\hline & Valid Responses & $\mathbf{6 1}$ \\
\hline & Total Responses & $\mathbf{6 5}$ \\
\hline
\end{tabular}




\section{Comment on your answer for question 11.}

Response to question 11

However, would only put this requirement into a voluntary code or standard.

It would depend on the direction of the comprehensive energy policy under consideration.

This will go beyond the scoping provisions of the codes and will not get enforced around the country with any consistency

Cheap and easy to do for new construction but not to retro.

We already require SWH and a bill to pre-wire for PV almost made it through the last legislature.

Interesting concept, but I cannot comment on cost-benefit calculations.

It depends on the requirement - pre wiring or pre-plumbing for a system to meet $1 \%$ of end-use needs, $5 \%$ of end-use needs, or $20-50 \%$ of specific needs (like service hot water)? Also, this question should ask about the use of on-site methane production from anaerobic digesters or onsite composting, in terms of "pre piping".

How do you know what you are pre-wiring or pre-plumbing for?

Not challenging to install later.

No. - What size do you plan for? - What if a later choice is building-integrated photovoltaics and the building is wired for roof-mounted? Don't waste people's money.

Only valuable if you also require installation of dunnage. The infrastructure cost associated with these systems is not in the piping or wiring, it is in the steel and waterproofing.

Much easier and cheaper to do it up front.

Caution when requiring added cost to systems that may not be installed. This would be coupled with added approval and permitting activity involving variances or waivers.

Not sure

Good idea to avoid the expensive retrofit excuse.

This has been tried in the IECC and was roundly defeated.

Reword to ask "to require the ability for future wiring or plumbing for." We don't want to prewire, and then ten years later find that the wiring from ten years earlier is insufficient. Make it solar ready with chase ways and facilities to support solar in the future.

Only if such wiring and/or plumbing was not cost prohibitive.

Take it in pieces: require location of conduit to simplify and reduce costs. Reason is that a prewire may be inadequate or over-designed for the technology eventually chosen.

Our studies show it'd add only a few hundred dollars and is an excellent inducement to adopt renewables.

This is the approach we took with Standard 189.1 and I think it is a reasonable first step.

See comment question 8

We are already moving in that direction. The cost to pre wire/plumb is very low when the building is under construction.

Will substantially reduce cost and complexity of the RE installation in many cases. 


\section{Response to question 11}

This is just another delaying action.

Reduces first cost of future installation of solar and could encourage installation.

The life-cycle costs of PV are likely to reduce significantly and as energy prices rise installation will become more attractive.

Very important aspect of preparing to have RE become widely accepted is building readiness. A RE ready building would spur many "fence sitters" to action.

We are examining this now. It's a good question. Pre-wiring, pre-plumbing are not desired by stakeholders--installers would face high risk of relying on someone else's work, and high likelihood that pre-wired wire would not be sized correctly, or code wiring sizes change... Stakeholder feedback recommends chases for easy future wiring, provisions of adequate roof space free of penetrations, etc.

That way a lot of retrofit will not need to happen and add cost to the building owner.

Homebuilders and trades need to figure out how incorporate this as a home is being built.

Reduces the resistance for later and already incorporated into the infrastructure of the project... AND solar thermal lines need insulation -this is hard to do after the fact in existing structures! 189.1 has a mandatory requirement that provides infrastructure for future renewable systems. Given a potential 70 year life of a building, it ought to be easily modified to allow for renewable. I don't think it's really easy to plumb of wire for it in high rise commercial buildings later on. If it is, I'd like to see documentation.

But must be followed up with an actual system installed with a specific time frame.

Marginal benefit, but it's a good stepping stone for more meaningful code requirements in the future.

Can require conduit to be put in place, but not wired.

Most builders would not want to spend the time/effort to determine if the preexisting wiring and certainly not plumbing was good enough that they would want to assume liability of using it. Too bad really, but that's the truth.

RE should first be required on commercial and industrial buildings with "solar-ready" infrastructure built into residential new construction. This is a very cost effective way to introduce the concept to the market and prepare them psychologically for next steps.

Without solar siting and roof area questions resolved, this is not helpful for a majority of homes New Mexico requires this now but I question it. Additional penetrations, especially to the roof, which may never be used (or need to be used) may not be a good idea. Maybe a chase that can be insulated but ready to be opened up for use when needed would be better.

I am somewhat ambivalent about this but believe it may not be prudent given the changing nature of systems.

Low-cost and by requiring this thinking in construction, it will not close out existing buildings from using solar

I have no comment to offer, more info and study on this issue needs to be done to determine its benefit and application for each climate and specific State needs.

It adds complexity and cost to the code without an obvious benefit. Such moves should be avoided. 
12: Would it be meaningful to require the use of renewables on outdoor or "Iuxury uses" as a first step, such as swimming pools, spas, snowmelt systems?

(Respondents could only choose a single response)

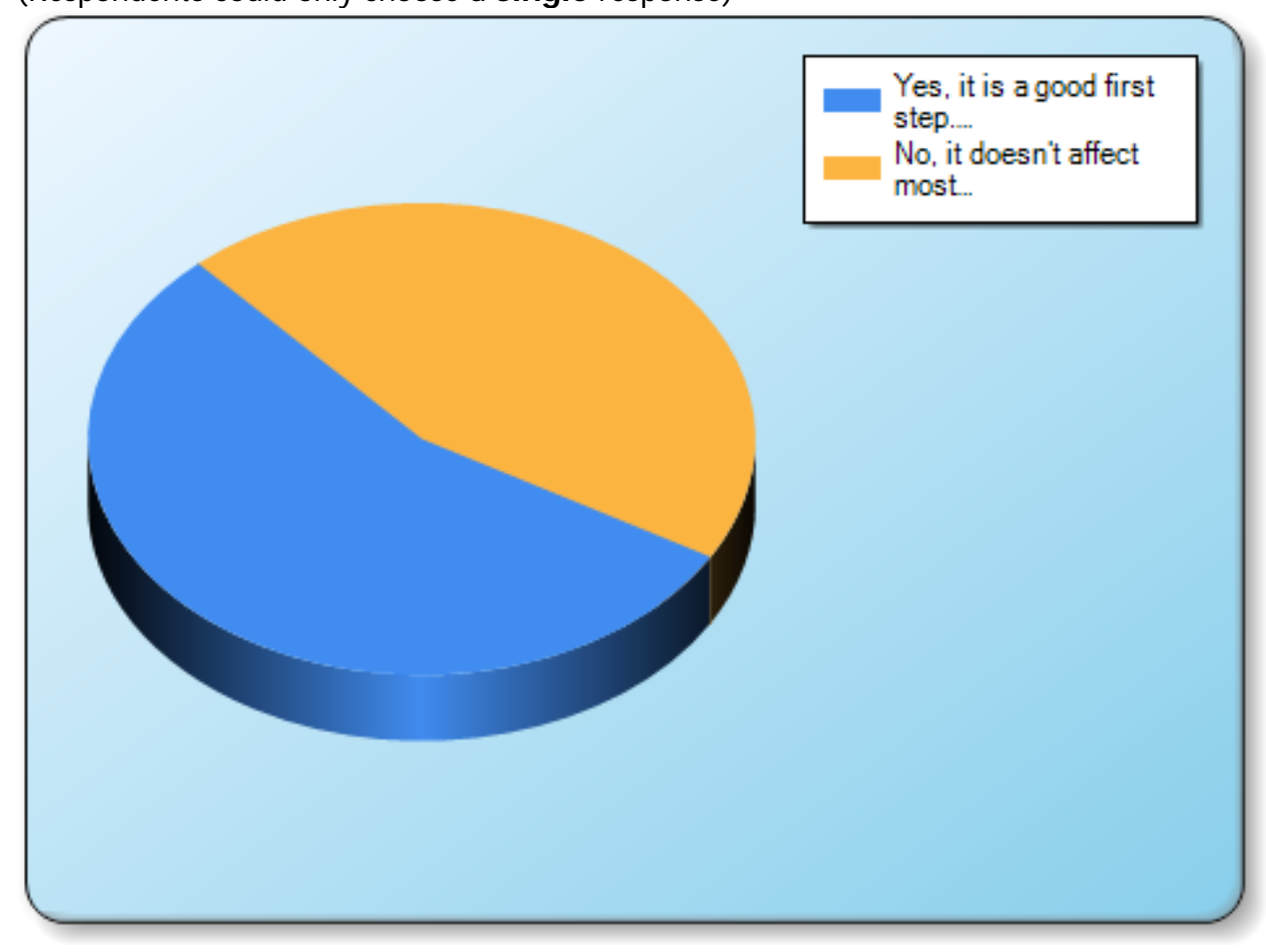

12: Would it be meaningful to require the use of renewables on outdoor or "luxury uses" as a first step, such as swimming pools, spas, snowmelt systems?

(Respondents could only choose a single response)

Response

Yes, it is a good first step. It should also include

No, it doesn't affect most

buildings and sends a

message that renewables are for the wealthy

Not Answered

\begin{tabular}{|l|l|l|}
\hline Chart & Frequency & Count \\
\hline & $\mathbf{5 5 . 0 \%}$ & $\mathbf{3 3}$ \\
\hline & $\mathbf{4 5 . 0 \%}$ & 27 \\
\hline Mean & 5 \\
\hline Standard Deviation & 0.502 \\
\hline Valid Responses & 60 \\
\hline Total Responses & 65 \\
\hline
\end{tabular}




\section{Provide comments about your response to question 12.}

Response to question 12

What a waste of fossil fuel these are

We included the IECC 2009 swimming pool requirement in our IECC 2006, and plan on moving to the IECC 1012 requirement.

Although I see the argument against as well.

Possibly. Renewables for these types of system installations can displace significant consumption of fossil fuels.

Solar pool heating is the \#1 cost effective use of solar in the entire USA

None see above

Also, there could be a statement of the percentage of outdoor use being met by the renewable systems.

I don't feel strongly about yes or no to this question.

This sounds like a good approach to a luxury tax on consumptive behavior. This is more about social engineering than renewables, but it is still a good idea.

Again, was looking for more choices in the answers: - Renewable requirements are most likely to first become mandatory for end uses where the energy need matches the solar resource.

Swimming pools are obviously at the top of that list. Conversely, snowmelt systems would likely be a poor fit.

People that can afford the luxury options can certainly afford the additional equipment to power them (for free, no less)

This is also very difficult to write as a prescriptive requirement.

The only concern with this would be the associated code or rules and the relevance to "building" performance vs. total site or metered use.

Depending on the location and use, snow/ice melt may not be a luxury.

We have been doing this since 2000 .

It's also a highly intrusive and value laden approach. We're Americans and it raises fears of the "nanny state" or over reaching of feds - currently at this time.

Except for pools, the options are probably limited and less cost effective than if systems apply to the whole house load.

Yes for snow melt.

Why are the choices here worded so specifically? My answer is no but not for the reason you provide. Carbon emissions are carbon emissions - reductions in all uses that lead to reductions in emissions should be required.

Still don't like the idea of requiring renewables.

The use of energy for advertising has been a 'sacred cow' that deserves to be lassoed and brought under control; requiring renewable power percentages for this activity would be a first step in getting local zoning to rein in abuses.

We already adopted the IECC 2009 provision requiring $60 \%$ renewables for pools without covers. Heat recovery counts as a renewable. IECC 2012 will require $100 \%$ renewables and include spas.

Luxury users are better able to pay the costs of RE 


\section{Response to question 12}

Disagree with everything but the "no" part of this answer. Again, outcome-based codes would take care of this. If outcome-based codes are not pursued, then I think that my answer would change to "yes."

This is a meaningful message as long as it doesn't get altered to say that renewables should only be used on "luxury" systems.

Being wealthy is no excuse for wanton consumption and waste, of course they should be caused to lead the less well off will gladly follow.

I'm not sure this is really the biggest issue I would focus on. I hear good arguments for either case. I think generally that the more RE in the code the better, and that this certainly makes future extensions of RE into other aspects of the code easier.

These are a great intro to what renewables can do! And then folks can switch to supplying other needs...

Not a bad idea. It's kind of like a luxury tax (see Monopoly).

Like in California, no fossil fuel can be used for pool heaters.

"Luxury uses" should require energy-neutralizing systems to offset their impacts.

If the greenhouse gas emissions per square foot of building have to be met then the GHG emissions for the operation of the luxury uses would have to be met within the same budget.

Provide this as an option to the builder, not as a requirement.

Doing this for niche uses has problems. See answer to question 11. 
13: Should government "lead by example" by requiring the use of renewable energy in public buildings before it is required in other buildings through codes?

(Respondents could only choose a single response)

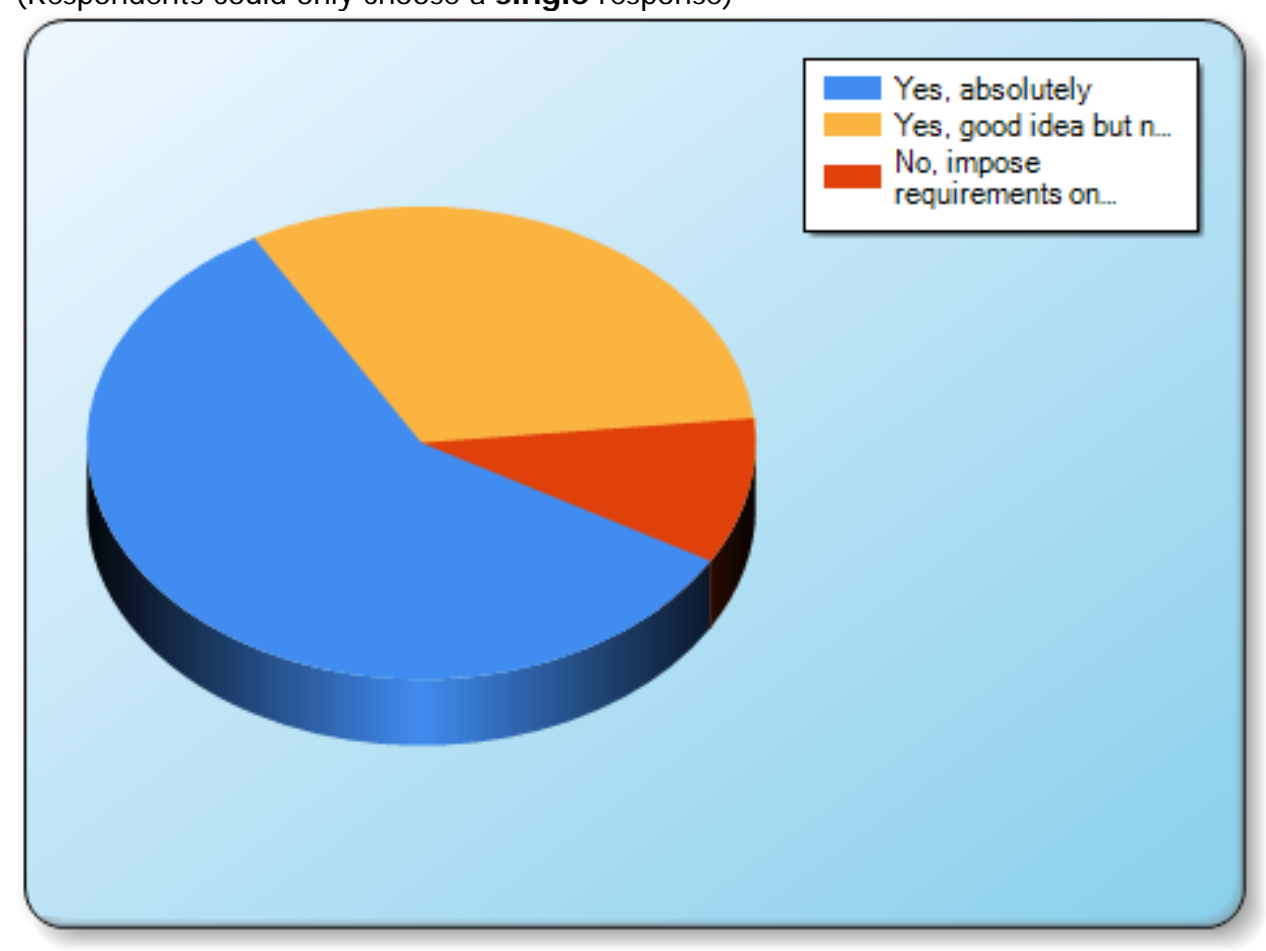

13: Should government "lead by example” by requiring the use of renewable energy in public buildings before it is required in other buildings through codes?

(Respondents could only choose a single response)

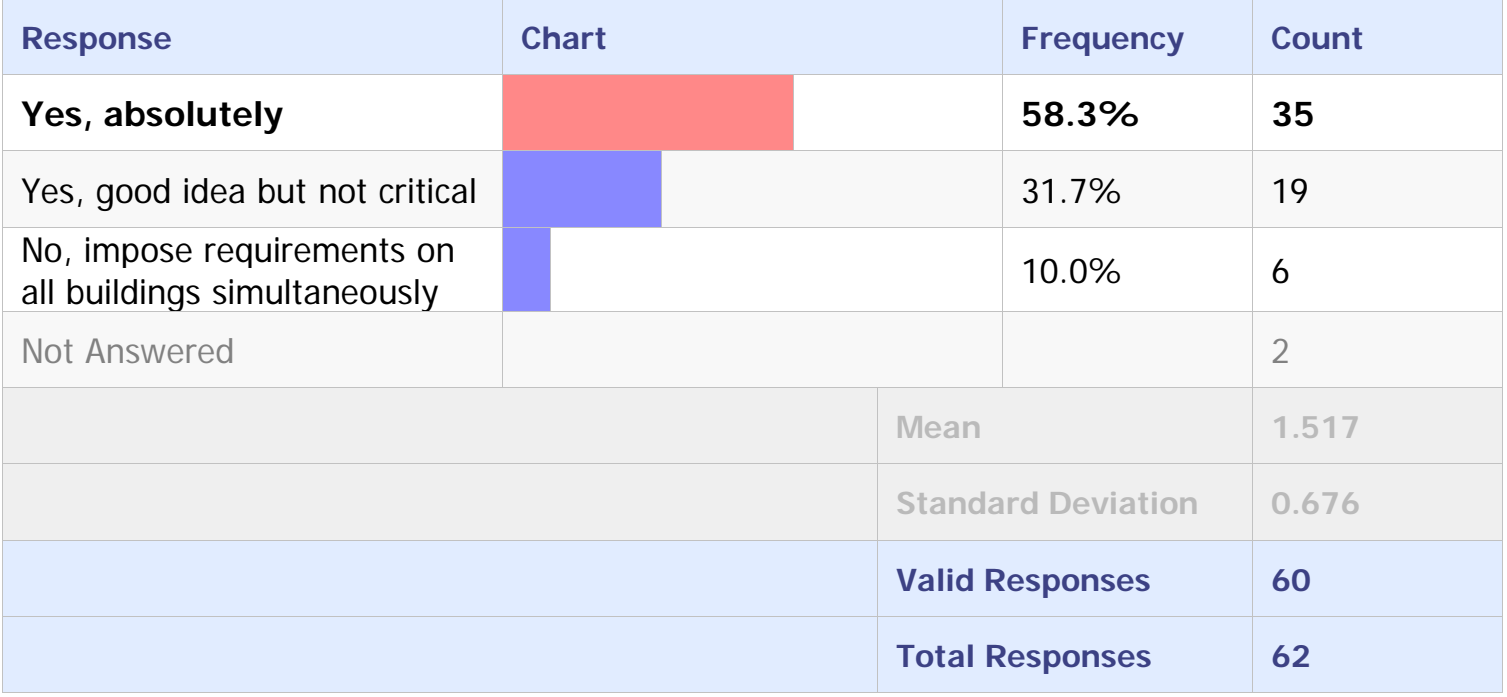




\section{What comments do you have about government "lead by example" use of renewable energy in public buildings?}

\section{Response to question 14}

Actually no- not at all. Requiring Govt to do what is not cost effective only unnecessarily increases the tax burden for us with no benefit to show.

This is a difficult step, as government nearly always makes procurement decisions based on firstcost instead of life-cycle cost.

"Lead by example" is an excellent first step for the deployment of renewables. However, the challenge is that government entities base their procurement decisions on first cost rather than on life-cycle cost analyses.

Right now there is a lot of do as I say not as I do in government We need to be careful on this one

Aready in ESA and Executive orders

We (State) and the City already require LEED, and renewables are easy points here.

Government buildings provide case studies of what to do and not do.

No requirements - let the market pull the technology.

None

Actually No, the concentration should be on energy efficiency first. Why isn't there a "No, not a good idea" box to check?

But not a lot if it is expensive.

The example needs to include all cost effective efficiency measures FIRST! But since gov't building assets are owned for very long time period, renewables should already be cost-effective in this context.

The more examples, the better.

Do not require it anywhere.

I thought this was already happening.

In my own opinion this is a great idea that never (or rarely) bears fruit. Owners are rarely swayed by the argument that all the gov't buildings did it first...Simultaneous implementation seems more practical to the goal.

Only after air sealing and retrofit measures. Then if it makes good business sense. don't want to be too big a target for "wasteful spending"

Yep. Always better to do as I do, not do as I say.

It's an okay idea (for commercial buildings anyway), but can give the flavor of "yet another government waste," which is counter-productive. In residential it's completely meaningless.

It is a useful idea, but government buildings should also be cost effective.

Needed to overcome the belief govt doesn't follow its own demands.

Government has a way of finding less expensive ways to do things later...i.e. value engineering. 


\section{Response to question 14}

Without visible commitment by those who make the rules, the uptake by the public will not have the example to learn by. Public education, acceptance and 'buy-in' is essential to good rules; once they see that the government is being careful and conservative about their tax dollars, then commitment follows.

Because governments' accounting systems rarely include accountability, they have traditionally lagged behind the private sector. Shifting to lead by example (in place in $\mathrm{HI}$ ), a sense of pride is installed in employees.

How can you preach or expect other to do it if you are not doing it.

This is a way by which a market for renewables is supported by society.

All government buildings should have renewables but that should not delay implementation of requirements for all buildings that have solar or wind access to have on-site renewables.

Renewables can be options in codes that impact private sector buildings before being required.

Gov't installations are good as examples will be less impactful.

The removal of the solar panels from the roof of the White House sent a message to America that we still need to address. The issue is not cowboys and Indians but the health of the planet.

A no brainer, of course they should - starting with schools!

Drives the market, builds demand, works out many issues, and helps establish installer/vendor bases... But DO NOT use this to preclude other energy codes from requiring RE just because we don't have it required at the Gov't level yet.

Walk the talk. Very important. But has to be a real commitment and not subject to the whims of political will. Too many see saws hurts the industry.

Keep in mind that this requirement becomes subject to the whim of the party in power.

Nonetheless, again it provides information without negatively affecting populace.

efficiency first - then assess if the site is viable for renewables OR distributed energy strategies in making agreements with other local sites for energy production

Make sure government does EE as well. Provide information on EE as well as PV

Perhaps start RE incorporation into $\mathrm{C}+\mathrm{I}$ buildings and wiring/plumbing for $\mathrm{RE}$ in all other buildings first, then phase in other sectors. Provide a ramp-up schedule so that all stakeholders understand long-term goals.

provided the applications are thoughtful and are shown to produce expected results

Always important to set a good example and, for the U.S., represents a significant portion of the market.

Interestingly the incentives available to citizens for homes or business aren't available for local government making it an even greater hurdle to consider making the investment. For the length of payback. 
14: Solar water heaters are generally more cost-effective than photovoltaics today. Should solar water heaters be required as a precursor to requiring PV so people begin to accept renewable energy requirements, even though it wouldn't help meet miscellaneous end-use (electrical) loads necessary eventually to achieve zero net-energy?

(Respondents could only choose a single response)

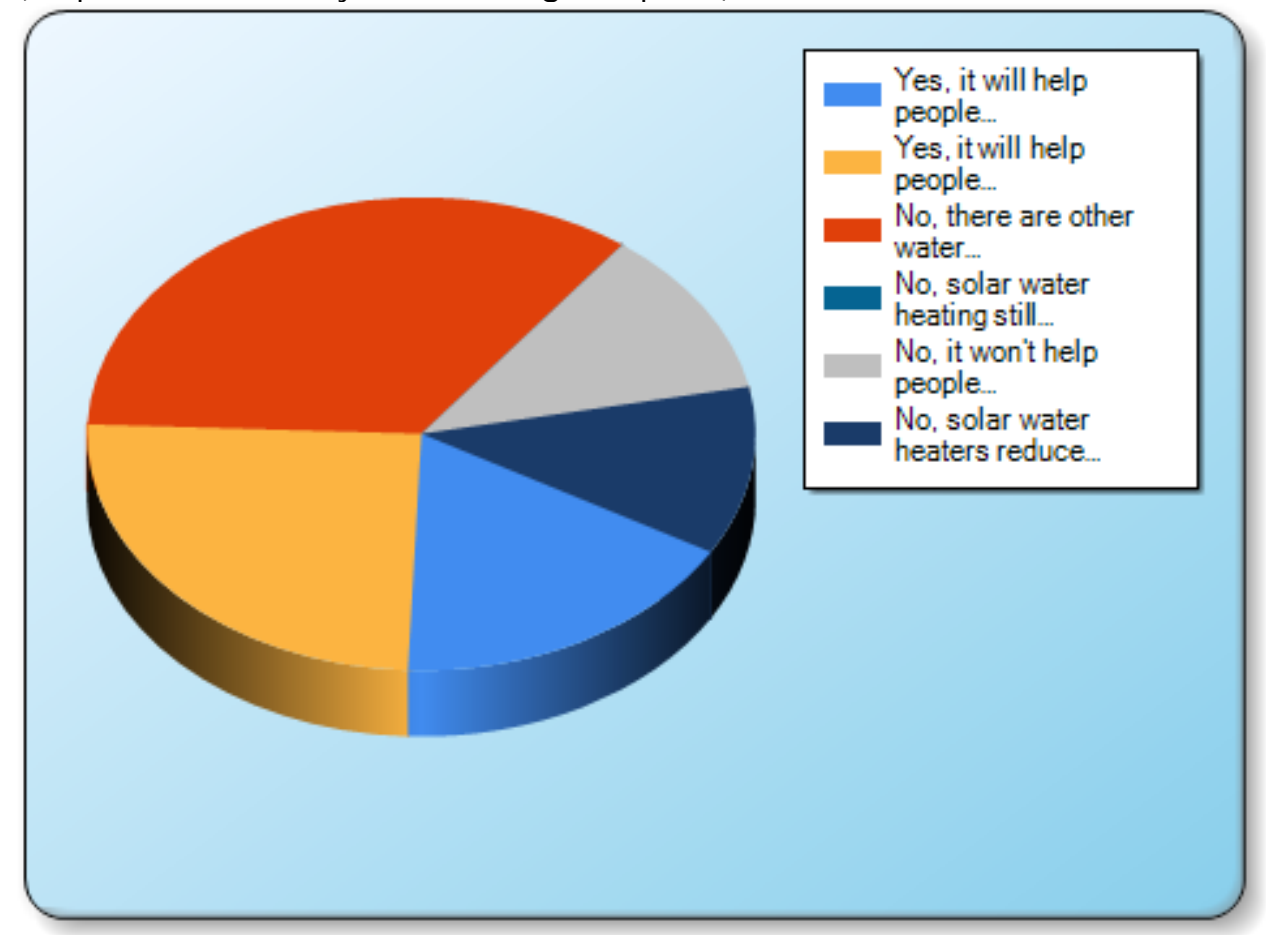


14: Solar water heaters are generally more cost-effective than photovoltaics today. Should solar water heaters be required as a precursor to requiring PV so people begin to accept renewable energy requirements, even though it wouldn't help meet miscellaneous end-use (electrical) loads necessary eventually to achieve zero net-energy?

(Respondents could only choose a single response)

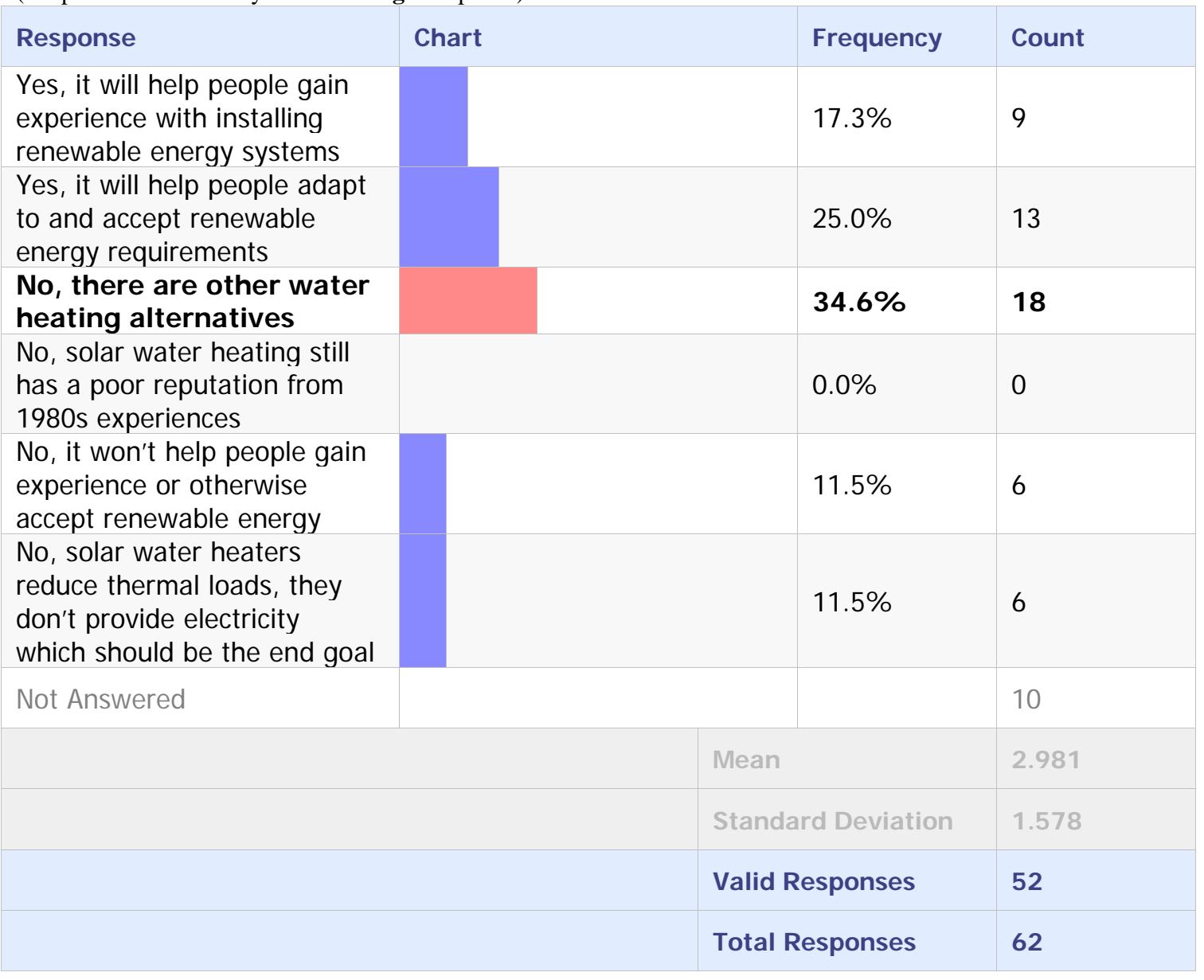

\section{Explain your answer response to question 14.}

\section{Response to question 14}

Solar WH should only be required or recommended where it makes sense to do so and is cost effective. And again, why do we assume that net zero energy is only ELECTRICAL energy? What about net zero gas?

See comment \#6.

I don't agree that providing more electricity should be the end goal. The end goal should be to reduce consumption of ALL energy types used in buildings. Requiring the use of solar thermal would be way too prescriptive and probably not widely appropriate.

We already require it, and PV use is tripling every year.

in some places electricity is used to heat water

Grid connected PV is pretty simple to install, meter and maintain. Solar water heating is more complex with significant maintenance issues. 
Response to question 14

No requirements - let the market pull the technology.

No

Actually no. The answers are pretty biased. If systems are required to reduce electric usage, they should be required to reduce fossil fuel usage. Reducing thermal loads is part of a "net zero" building - it should not just be about electricity, but ALL energy used at buildings. To achieve "net zero" you have to be net zero for ALL fuels, not just electricity. To be "net zero" for electricity while being a total energy waster with fossil fuels is a ridiculous outcome and a total distortion of what a net zero energy building should be.

The answer options don't align with my preferred response, but I believe a case could be made for solar DHW requirements in specific climates (i.e. where freeze protection is not an issue).

Don't like any of the answers. Solar technology should be a choice.

Both options should be offered

Again, looking for more choices in the answers: - People should be able to choose. Maybe some people like the notion of PV over solar water heating. What does it matter, as long as it provides the same amount of energy?

After people see that solar water heaters can be safe and dependable (and cost effective) they will be more open to renewable electrical options

We need to create an expectation that renewables will be included in building projects, rather than an expectation that they will not.

Solar systems in China cost $\$ 300$ and here they cost $\$ 5000+$. Heat pump water heaters are likely to make solar thermal irrelevant in the near future as they are already cheaper.

Don't want to limit requirements to one technology.

Hate to bank the success of PV on the success of water heating.

...if the systems work...

Yes and no - only sized for minimum load and installed in an engineer's or plumber's house.

Hey - let the economics decide what the cheapest way to reduce/get energy. Not quite sure why electricity would be more important than thermal except it's easier to move.

I think this depends a lot on location.

Requiring specific technologies in a building code, unless it is specifically intended as a green or stretch code, will be counterproductive. It will lead to slower or no adoption, and/or the removal of the language in adopting jurisdictions.

Climate zone specific. Don't install in northern Montana, but yes in Tucson.

Again, help people afford them and they will buy renewables.

Solar hot water heating and PV should be coupled with the incentives that will heighten awareness and bring both technologies deeper into the marketplace.

Solar WH is at least $3 \mathrm{X}$ as cost-effective in $\mathrm{HI}$ as are PV's. Might not make sense in some northern climates.

I believe requiring specifics like this can be counter-productive.

Lowering cost of PV are challenging solar hot water in the benefit/cost area. 


\section{Response to question 14}

Code should not favor one kind of renewable energy over another.

Solar thermal is renewable energy just as a PV system provides renewable energy. Whatever application is most appropriate for a building is the application that should be chosen.

This answer depends on if this is for residential or commercial buildings. Requiring solar for commercial only addresses a very small load in most commercial buildings. It does have an impact for residential buildings but this is also climate and site dependent.

This approach does not address the issue.

Both are good, but one might not lead to the other

I think that it's important that the most appropriate RE source be chosen. In some building classes (e.g., multi-family, lodging), it would make perfect sense to require solar thermal). However, requiring solar thermal on all res, or all commercial buildings would result in another 1980 's black eye. My recent experience that while solar thermal *may* be more cost effective, it has a much higher potential for problems in the installation, higher $O \& M$, etc. In many of the buildings we are involved in, a simple bullet-proof system, or making sure the system is right for the building/client, outweighs mandatory solar thermal requirements.

I don't like any of the answers. My answer would be no because it depends on the location of the site. All the other "no" answers I disagree with.

Solar thermal is a great intro - it is effective and accessible .... and is not grid connected... Have it on my house supplying domestic hot water and heat to a 1949 radiant floor system

SHW should take a parallel path to PV. SHW is gaining traction faster than PV due to cost effectiveness, but it shouldn't be considered a precursor to PV. SHW and PV will compete for roof space.

Case-by-case scenarios. In many cases biomass as combined heat and power would make far more sense.

The question is too narrow - some areas work for solar thermal much better than others -

While solar water heaters are more cost effective than PV, in some locals there may be other resources that are better. Also, while PV can be lain flat and still be quite efficient, this is not so with solar thermal. This can be a conflict in historic districts and other areas where aesthetic values are critical to a community or to the nation. Again, by letting people get to the GHG budget and allowing flexibility regarding how they get there and maybe, income areas, letting folks buy into a community PV project so the equipment is not on their property where a visual impact conflicts with other community values may be the better solution. One size does not fit all. Again, as long as it is structured to make sense with respect to project loads and to encourage EFFICIENCY first.

Again, the products and ways to achieve renewable energy resources should be optional and not mandatory.

It still helps with thermal loads and it will be cost-effective much sooner.

These systems are effective in most areas of the country and will build acceptance as well as reducing costs. 
15: Should the purchase of Renewable Energy Certificates (RECs) be allowed as an option to meet a renewable energy requirement?

(Respondents could only choose a single response)

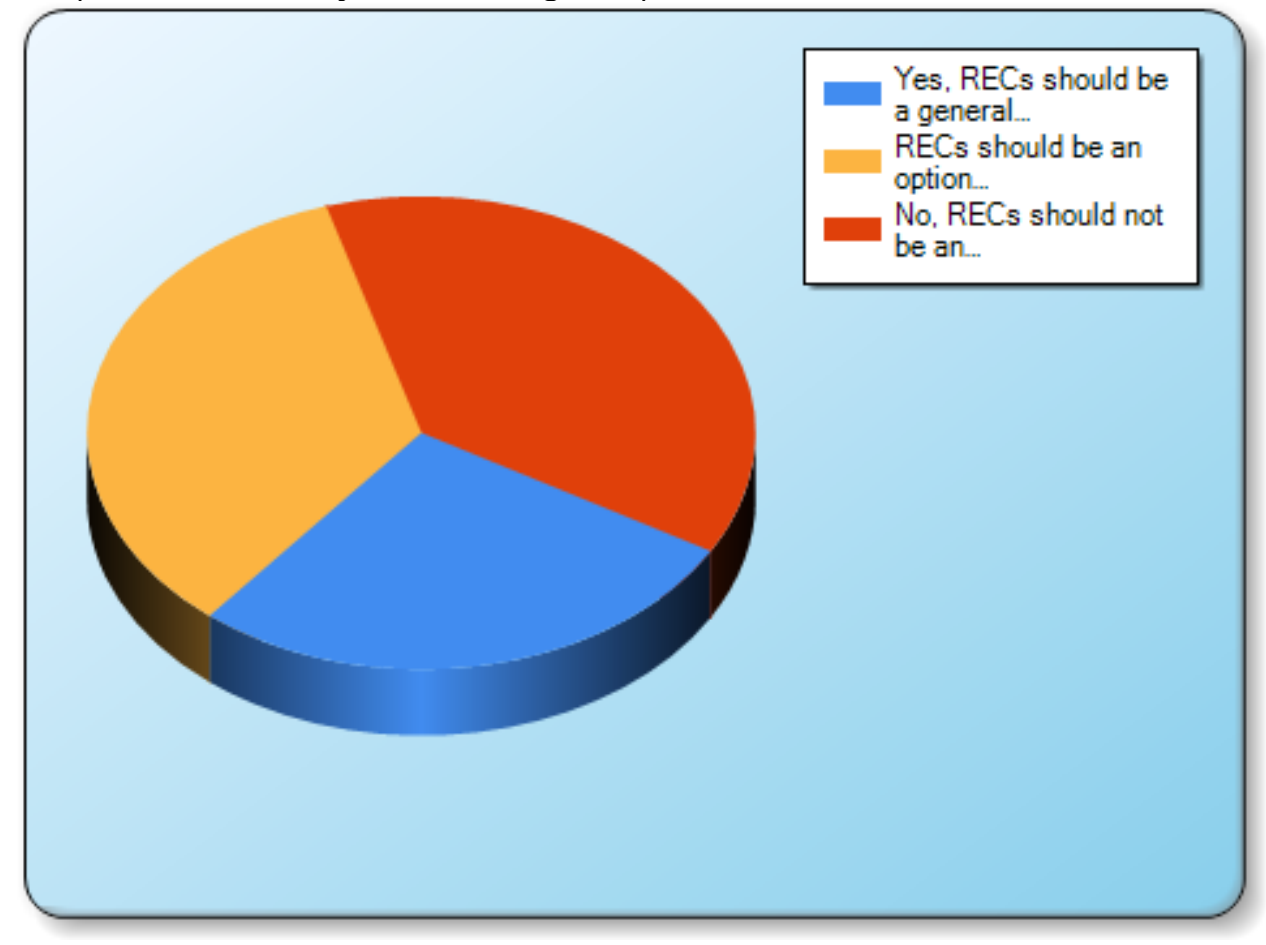

15: Should the purchase of Renewable Energy Certificates (RECs) be allowed as an option to meet a renewable energy requirement? (Respondents could only choose a single response)

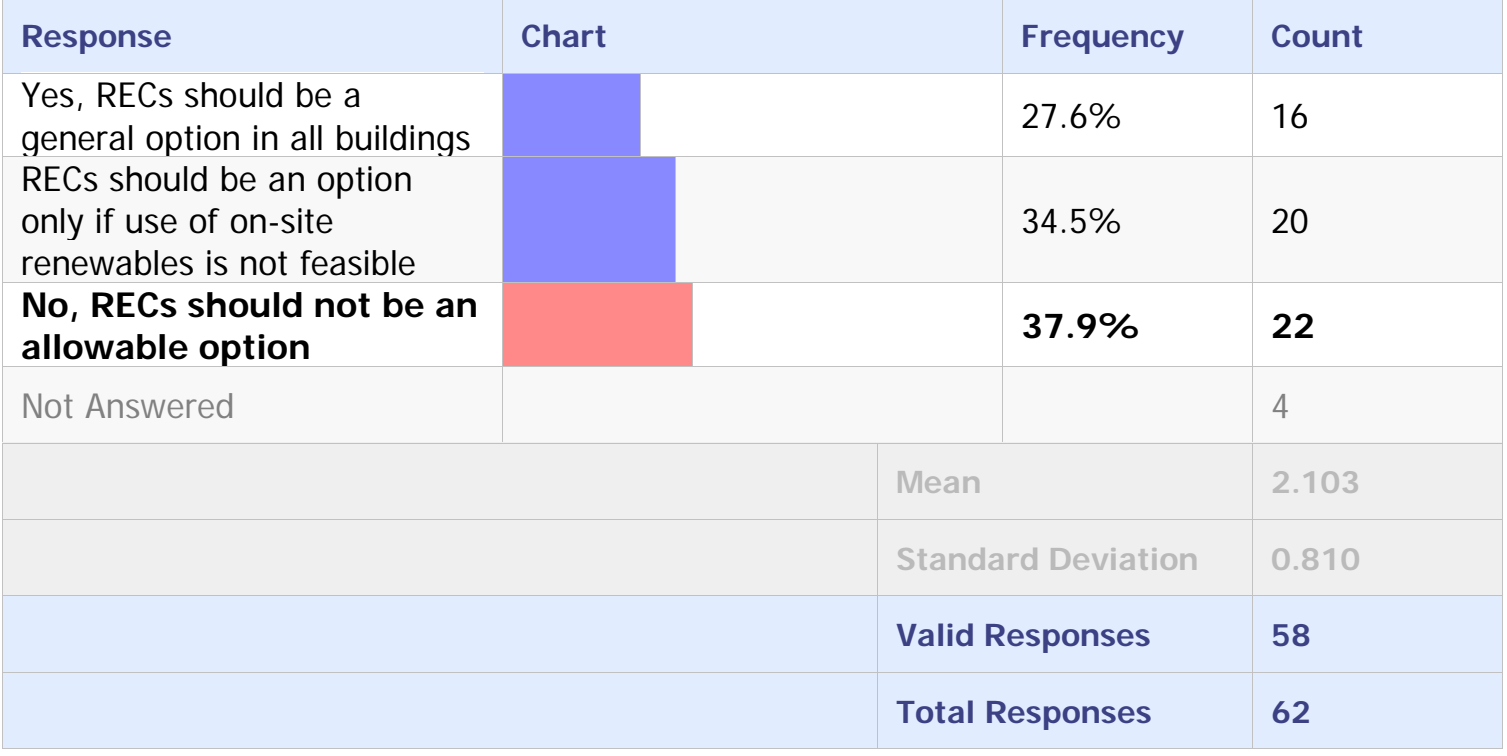




\section{Explain your answer and how the purchase of RECS can be ensured and/or enforced.}

Response to question 15

Yes, but we also need a national alternative energy portfolio standard in order to really spur the deployment of renewables.

On-site renewables are better because of reduced T+D losses, but may not get economies of scale.

Not familiar with RECS

Talk to a REC sales person.

Slippery slope. What is the time requirement? How is it enforced? Not really equivalent.

No

This will provide more flexibility to building owners, especially in urban areas with limited or no access to renewable resources.

Renewables are expensive and challenging. RECS are easy and inexpensive. They are not comparable.

RECs are rife with abuse. These should absolutely not be written into a code option (IGCC take note!). The only way to achieve equivalence is to require 20-30 years worth of RECs, and the code enforcement structure is totally unable to deliver this...

Only if solar gardens/community solar is not an option.

Code officials can't enforce RECS

NO, shouldn't allow people to buy their way out.

This is just not enforceable as a code requirement.

Building officials have no way of enforcing this. Someone could cancel their contract the day after the certificate of occupancy is granted.

No building integrated is necessary goal.

Too much bureaucracy. Why? Managing, controlling and administration of the REC shell game. It's better to require minimum performance standards.

Where the renewable energy is captured does not matter from a global standpoint. Accounting for transmission losses may be wise.

We have a third party to evaluate spending the REMP funds and require 2 elected official boards to agree on the spending.

Off site green power is going to have to be part of the equation. But I think a long term purchase contract would be more productive in the long run that RECS

Funny money and funny magic. Anybody else tries to do this and they would go to jail. Either put the renewables on or don't, but don't get into the funny money junk.

We need real reduction, not paper certificates. The general public already sees carbon credits as a sham.

Imagine all the old folks in Florida having to drain down a solar system during a freeze or putting up/down shutters before a hurricane.

RECs could be enforced through rate approvals by Public Utility controls that reward customers that cannot reasonably participate in on-site incentive programs.

Not familiar with REC's. 


\section{Response to question 15}

A national standard certification program is needed, perhaps directed by DOE.

If it is not possible to install renewable energy systems

Economies of scale dictate that larger producers of power are more efficient. RECs would allow smaller customers to participate in those benefits.

Both nationally and internationally RECS have too often led to gaming the system. If there are valid reasons that a building cannot meet on-site requirements then the building should be excluded.

Renewables should be a permanent part of the building since this is enforceable. Contracts are difficult to enforce.

While not ideal, REC's will promote investment and market transformation.

RECs are an easy way out of real action and the goal is widespread distributed energy not more of the same mega scale and vulnerable mega scale generation paradigms

The use of RECs would inhibit the use of renewables. There are always too many loopholes within these policies.

we need to look at strategies for distributed power arrangements

RECS should be verified by a third party.

Discount RECs over actual site built. Make people who buy RECs. buy $200 \%$ of what the code requires onsite. - I create an option, for those who do not want the architectural impact. Some parameters around the use of RECs could be used for substitution needs, i.e.: RECs from in-state projects.

This should be limited to areas where there are larger community or national values that are being balanced.

I don't know about the purchase of RECS but do believe that this is a good option since many buildings don't have the ability to cover all their energy use through renewables due to siting.

I do not know enough about REC's to offer an opinion at this time.

J ust "get out of jail cards" that substitute money for real action.

How would this be enforced within the context of codes? As a general policy option, it's problematic but possible. But code inspectors, builders etc shouldn't have to go through this. If something is going to be required, then make it required. If a site simply can't use these systems then deal with it on a site by site basis. 
16: What is the best way to phase in a renewable energy requirement?

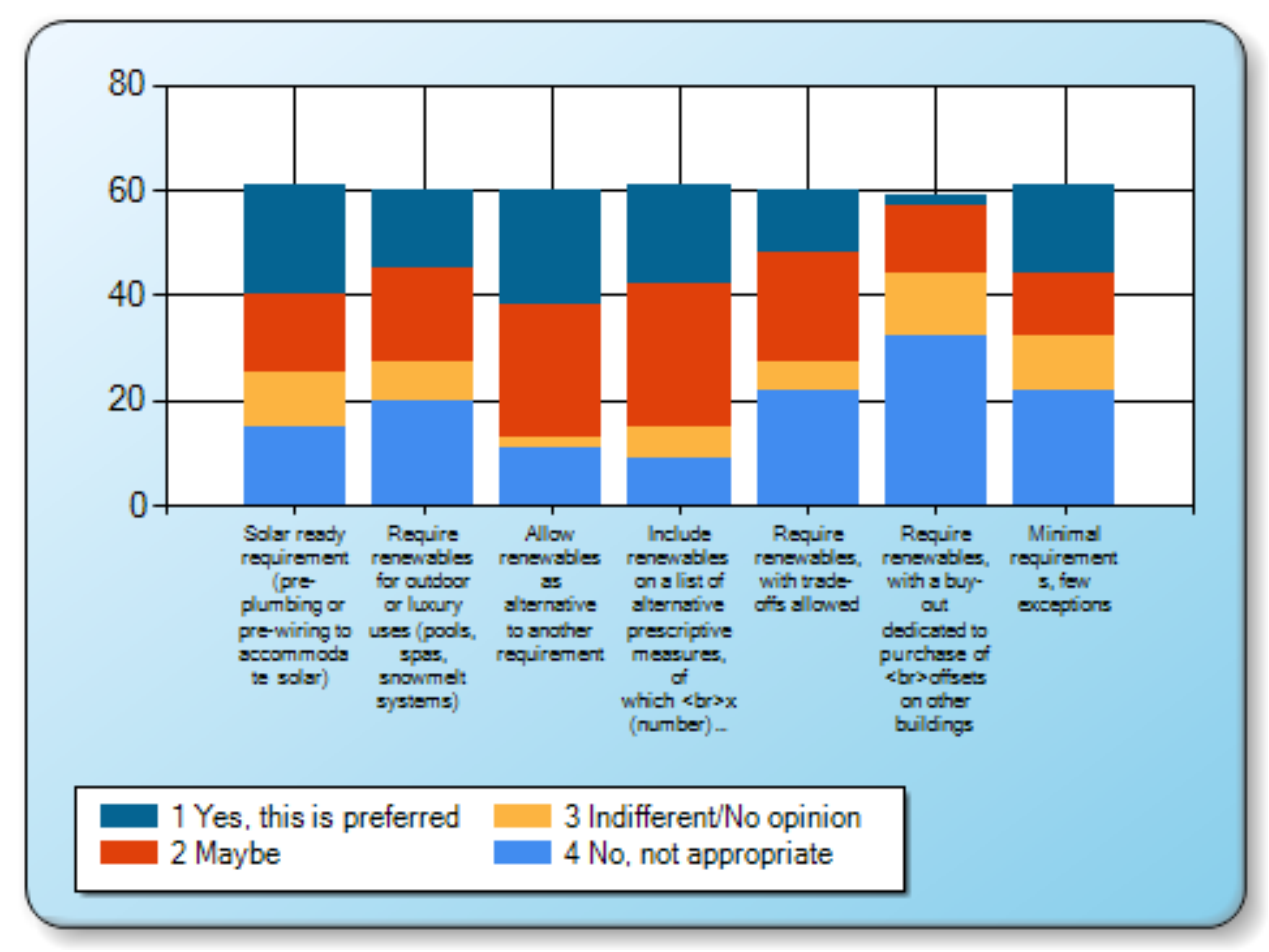

16: What is the best way to phase in a renewable energy requirement?

\begin{tabular}{|c|c|c|c|c|c|c|c|c|}
\hline & & $\begin{array}{l}1 \text { Yes, this } \\
\text { is } \\
\text { preferred }\end{array}$ & 2 Maybe & $\begin{array}{l}3 \\
\text { Indifferent/No } \\
\text { opinion }\end{array}$ & $\begin{array}{l}4 \mathrm{No} \text {, not } \\
\text { appropriate }\end{array}$ & Total & Mean & $\begin{array}{l}\text { Std } \\
\text { Dev }\end{array}$ \\
\hline \multirow{2}{*}{$\begin{array}{l}\text { Solar ready } \\
\text { requirement } \\
\text { (pre-plumbing } \\
\text { or pre-wiring } \\
\text { to } \\
\text { accommodate } \\
\text { solar) }\end{array}$} & Count & 21 & 15 & 10 & 15 & 61 & 2.311 & 1.191 \\
\hline & $\begin{array}{l}\% \text { by } \\
\text { Row }\end{array}$ & $34.4 \%$ & $24.6 \%$ & $16.4 \%$ & $24.6 \%$ & $100.0 \%$ & & \\
\hline \multirow{2}{*}{$\begin{array}{l}\text { Require } \\
\text { renewables for } \\
\text { outdoor or } \\
\text { luxury uses } \\
\text { (pools, spas, } \\
\text { snowmelt } \\
\text { systems) }\end{array}$} & Count & 15 & 18 & 7 & 20 & 60 & 2.533 & 1.200 \\
\hline & $\begin{array}{l}\% \text { by } \\
\text { Row }\end{array}$ & $25.0 \%$ & $30.0 \%$ & $11.7 \%$ & $33.3 \%$ & $100.0 \%$ & & \\
\hline
\end{tabular}




\begin{tabular}{|c|c|c|c|c|c|c|c|c|}
\hline & & $\begin{array}{l}1 \text { Yes, this } \\
\text { is } \\
\text { preferred }\end{array}$ & 2 Maybe & $\begin{array}{l}3 \\
\text { Indifferent/No } \\
\text { opinion }\end{array}$ & $\begin{array}{l}4 \text { No, not } \\
\text { appropriate }\end{array}$ & Total & Mean & $\begin{array}{l}\text { Std } \\
\text { Dev }\end{array}$ \\
\hline \multirow{2}{*}{$\begin{array}{l}\text { Allow } \\
\text { renewables as } \\
\text { alternative to } \\
\text { another } \\
\text { requirement }\end{array}$} & Count & 22 & 25 & 2 & 11 & 60 & 2.033 & 1.073 \\
\hline & $\begin{array}{l}\% \text { by } \\
\text { Row }\end{array}$ & $36.7 \%$ & $41.7 \%$ & $3.3 \%$ & $18.3 \%$ & $100.0 \%$ & & \\
\hline \multirow[t]{2}{*}{$\begin{array}{l}\text { Include } \\
\text { renewables on } \\
\text { a list of } \\
\text { alternative } \\
\text { prescriptive } \\
\text { measures, of } \\
\text { which } x \\
\text { (number) } \\
\text { must be } \\
\text { required }\end{array}$} & Count & 19 & 27 & 6 & 9 & 61 & 2.082 & 1.005 \\
\hline & $\begin{array}{l}\% \text { by } \\
\text { Row }\end{array}$ & $31.1 \%$ & $44.3 \%$ & $9.8 \%$ & $14.8 \%$ & $100.0 \%$ & & \\
\hline \multirow{2}{*}{$\begin{array}{l}\text { Require } \\
\text { renewables, } \\
\text { with trade-offs } \\
\text { allowed }\end{array}$} & Count & 12 & 21 & 5 & 22 & 60 & 2.617 & 1.180 \\
\hline & $\begin{array}{l}\% \text { by } \\
\text { Row }\end{array}$ & $20.0 \%$ & $35.0 \%$ & $8.3 \%$ & $36.7 \%$ & $100.0 \%$ & & \\
\hline \multirow{2}{*}{$\begin{array}{l}\text { Require } \\
\text { renewables, } \\
\text { with a buy-out } \\
\text { dedicated to } \\
\text { purchase of } \\
\text { offsets on } \\
\text { other buildings }\end{array}$} & Count & 2 & 13 & 12 & 32 & 59 & 3.254 & 0.921 \\
\hline & $\begin{array}{l}\text { \% by } \\
\text { Row }\end{array}$ & $3.4 \%$ & $22.0 \%$ & $20.3 \%$ & $54.2 \%$ & $100.0 \%$ & & \\
\hline \multirow{2}{*}{$\begin{array}{l}\text { Minimal } \\
\text { requirements, } \\
\text { few } \\
\text { exceptions }\end{array}$} & Count & 17 & 12 & 10 & 22 & 61 & 2.607 & 1.242 \\
\hline & $\begin{array}{l}\text { \% by } \\
\text { Row }\end{array}$ & $27.9 \%$ & $19.7 \%$ & $16.4 \%$ & $36.1 \%$ & $100.0 \%$ & & \\
\hline \multirow[t]{2}{*}{ Total } & Count & 108 & 131 & 52 & 131 & 422 & N/A & N/A \\
\hline & $\begin{array}{l}\% \text { by } \\
\text { Row }\end{array}$ & $25.6 \%$ & $31.0 \%$ & $12.3 \%$ & $31.0 \%$ & $100.0 \%$ & & \\
\hline
\end{tabular}


17: Should systems whose contribution is more difficult to measure (daylighting, passive solar design, possibly renewable thermal systems) be allowed to meet a renewable energy requirement? Or should the requirement apply only to renewable electric systems whose output can more easily be measured?

(Respondents could only choose a single response)

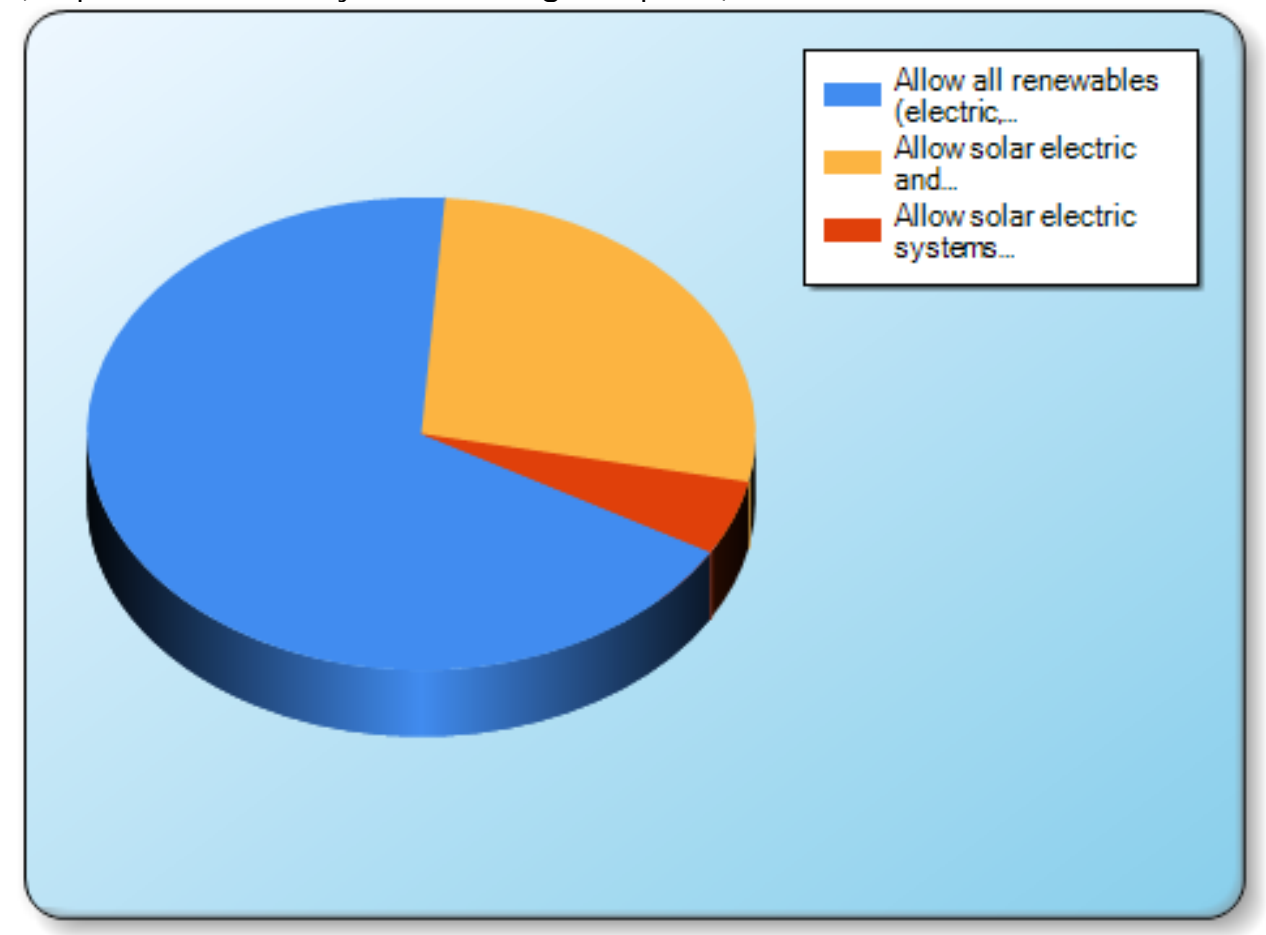


17: Should systems whose contribution is more difficult to measure (daylighting, passive solar design, possibly renewable thermal systems) be allowed to meet a renewable energy

requirement? Or should the requirement apply only to renewable electric systems whose output can more easily be measured?

(Respondents could only choose a single response)

\begin{tabular}{|c|c|c|c|c|}
\hline Response & \multicolumn{2}{|l|}{ Chart } & Frequency & Count \\
\hline $\begin{array}{l}\text { Allow all renewables } \\
\text { (electric, daylighting, } \\
\text { passive solar, and solar } \\
\text { water heating) }\end{array}$ & & & $67.8 \%$ & 40 \\
\hline $\begin{array}{l}\text { Allow solar electric and solar } \\
\text { water heating; do not allow } \\
\text { daylighting or passive solar }\end{array}$ & & & $27.1 \%$ & 16 \\
\hline $\begin{array}{l}\text { Allow solar electric systems } \\
\text { only; do not allow } \\
\text { daylighting, passive solar, or } \\
\text { solar water heating }\end{array}$ & & & $5.1 \%$ & 3 \\
\hline Not Answered & & & & 3 \\
\hline & & Mear & & 1.373 \\
\hline & & Stan & rd Deviation & 0.584 \\
\hline & & Valid & esponses & 59 \\
\hline & & Total & esponses & 62 \\
\hline
\end{tabular}

\section{Provide comments about your response to question 17.}

\section{Response to question 17}

Give owners as many options as possible IF we choose to do what is clearly not cost effective. Preferred option is to have minimal requirements until then.

The end goal is to reduce energy consumption, including electric energy even if renewable.

The impacts of passive and daylighting have an effect more like an efficiency measure. For logistical reasons of measurement and verification these technologies should be methods available (and encouraged) to meet energy use requirements not renewable generation requirements.

If you accept my premise that the goal is to reduce ALL energy use in buildings, then all verifiable means of getting to that goal should be encouraged.

How do you measure this to use it

Also allow small and medium wind, biofuels such as wood chip boilers, CHP fired with biofuels, etc. DO NOT allow energy extracted/delivered to the ground with ground source heat pumps or Evaporative cooling.

Daylighting and passive solar need more encouragement; we require high performance windows which are daylighting-friendly.

The goal of moving to net-zero-energy requires many actions. 


\section{Response to question 17}

Daylighting and passive directly offset loads so should be allowable and countable.

No

Provide maximum flexibility to the designer and building owner.

otherwise it disincentivizes good design

I wouldn't include daylighting in this list but I think that passive solar is being overlooked.

Question pre-supposes desirability of renewables requirements in the absence of efficiency.

Prefer performance based and flexibility

The requirement should be for on-site renewable energy power production: - Allow solar thermal (solar water heating) or solar electric (PV).

Contributions from any of the "passive" renewable sources is, in fact, relatively easy to calculate based on utility costs, and historical weather data, etc

We should draw a line between daylight and other ways of using solar energy.

No reason to trade these off. Daylighting and passive solar requirements should be separate.

All these should be allowed, but passive systems should be counted separately from active systems, and there should be requirements for active systems.

Education and demonstration of decisions regarding energy conscious design should not exclude at this time. Standards for measured performance will catch up.

Passive solar and daylighting are load reduction strategies, not load satisfaction strategies.

smart design options are certainly effective

You can easy measure elect and hot water. Require modeling is someone wants credit for passive solar design.

The last thing the code should do is discourage good options.

SS

Include the performance of as many renewables as possible in your performance-based code; make the code more stringent and make the options affordable.

Passive measures are an entirely separate category, as they are supposed to be designed and specified for service lives that approximate the service life of the building.

We already allow solar ceiling fans, passive attic cooling, radiant barriers and cool roofs as code options--and they work well and are cost-effective.

Never really thought of daylighting as a renewable until now, but that is what it really is.

Follow an integrated design process

Difficult but not impossible to measure but if the point is to promote renewables, why limit their application?

The difficulty here comes in setting the baseline for things like orientation/passive solar design. Why wouldn't designers just say they would have picked the worst orientation otherwise to obtain maximum credit?

Daylighting and passive solar are energy efficiency strategies and can and should be calculated to meet the efficiency requirements. They are not renewable energy strategies. 


\section{Response to question 17}

Note that daylighting should be required at a minimum. Passive solar can be allowed using an outcome or performance based code.

The most stringent approach is required.

\section{Reducing load is better than generating power}

I'm not sure I agree with how the question is framed. Depending on your view, these are not mutually exclusive options, CA T24 for example. You may have some daylighting components in the lighting section of the code. Perhaps passive solar and/or solar orientation components included in the base-case prescriptive energy budget, and then a discreet PV or SDHW generation requirement.

Having done several daylighting and passive solar buildings I can tell you that by using these techniques the building loads where reduced significantly (usually $40-60 \%$ ) before the use on any other renewable hardware.

Difficult to measure provisions will show up in reduced loads to the home. Allowing these options would only add loopholes and make the introduction of renewable technologies difficult to implement and enforce as it will add to the complexity of the code unnecessarily. People won't really know what will count.

Yes include all renewables and push the ancient lights concepts! The objective is to reduce loads...

Passive solar and daylighting should be encouraged before PV and SHW. They're more cost effective. Also need to look a trade-offs b/w cool roofs and window insulation for buildingintegrated PV glazings.

Modeling of these systems is not that difficult

Always allow a "Whole Building Analysis Approach." As an alternative - set criteria for these approaches that closes loopholes.

Buildings are systems and need to be recognized as such. Component additions can be made to existing buildings, but for new construction, all appropriate EE and RE systems should be considered. However, some of these systems need to be defined as either EE or RE.

As stated before _ THE GOAL SHOULD BE TO INCREASE EFFICIENCY FIRST. This could be accomplished by legislating overall energy use such that on-site renewables, passive strategies, and many other tactics become tools for meeting the goal. Efficiency is currently much more cost-effective and will therefore self-select as the preferred option among these.

We MUST allow passive design solutions and not create problems we have to solve (let's avoid them if possible)

I do not know enough about these systems to offer an opinion at this time.

The other requirements would be built into the energy efficiency requirements which would be measured as part of the energy outcome. To do RE, you need to directly measure it and this would fit in with the outcome approach.

All systems help. 
18: Which technologies should be considered as eligible (complying) renewable energy systems?

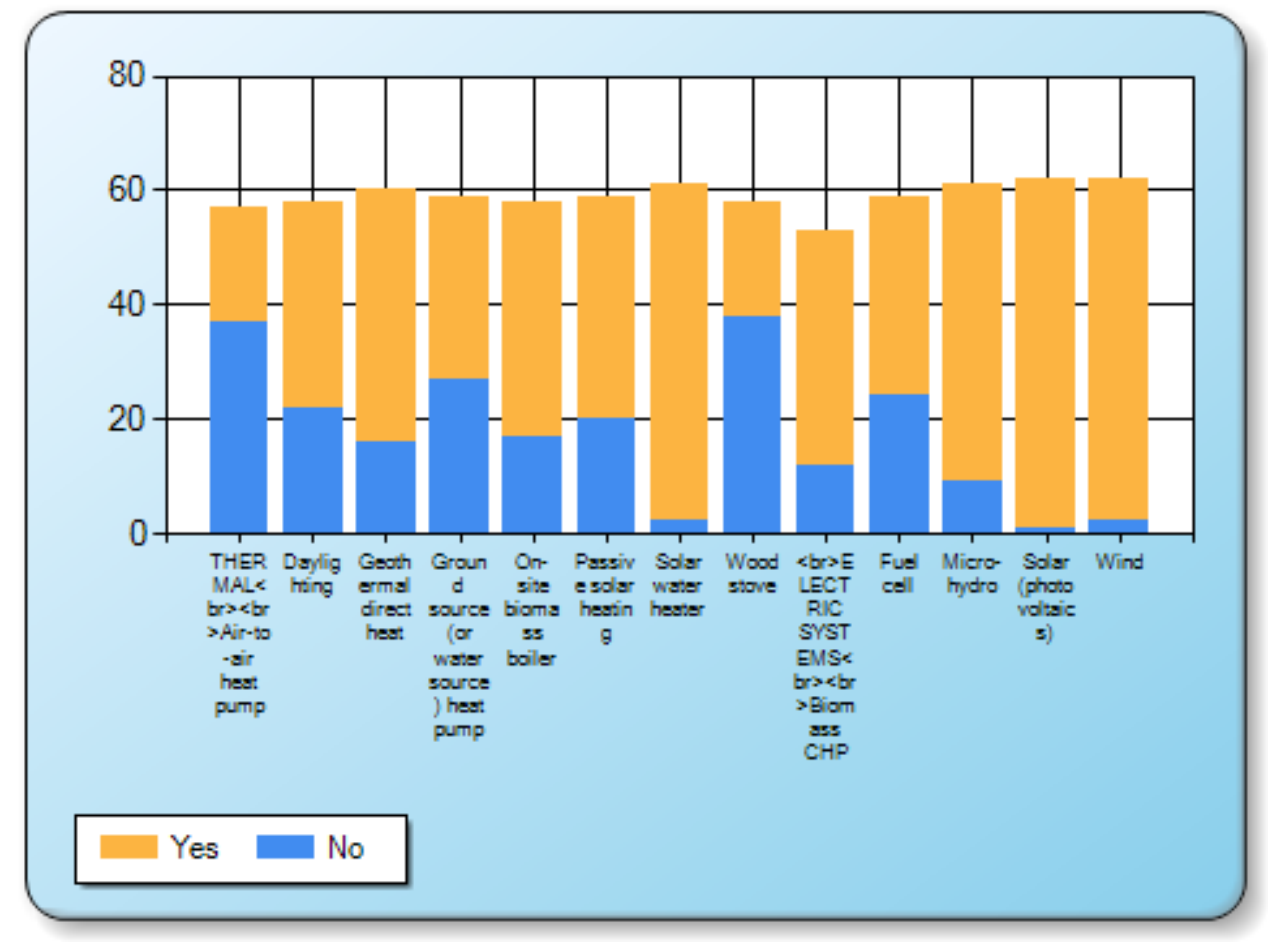

18: Which technologies should be considered as eligible (complying) renewable energy systems?

\begin{tabular}{|c|c|c|c|c|c|c|}
\hline & \multirow{3}{*}{$\begin{array}{l}\text { Yes } \\
20\end{array}$} & \multirow{3}{*}{$\begin{array}{l}\text { No } \\
\mathbf{3 7}\end{array}$} & \multirow{3}{*}{$\begin{array}{l}\text { Total } \\
57\end{array}$} & \multirow{3}{*}{$\begin{array}{l}\text { Mean } \\
1.649\end{array}$} & \multirow{3}{*}{$\begin{array}{l}\begin{array}{l}\text { Std } \\
\text { Dev }\end{array} \\
0.481\end{array}$} \\
\hline & & & & & & \\
\hline $\begin{array}{l}\text { THERMAL } \\
\text { Air-to-air heat }\end{array}$ & Count & & & & & \\
\hline & $\begin{array}{l}\% \text { by } \\
\text { Row }\end{array}$ & $35.1 \%$ & $64.9 \%$ & $100.0 \%$ & & \\
\hline \multirow[t]{2}{*}{ Daylighting } & Count & 36 & 22 & 58 & 1.379 & 0.489 \\
\hline & $\begin{array}{l}\text { \% by } \\
\text { Row }\end{array}$ & $62.1 \%$ & $37.9 \%$ & $100.0 \%$ & & \\
\hline \multirow[t]{2}{*}{$\begin{array}{l}\text { Geothermal } \\
\text { direct heat }\end{array}$} & Count & 44 & 16 & 60 & 1.267 & 0.446 \\
\hline & $\begin{array}{l}\% \text { by } \\
\text { Row }\end{array}$ & $73.3 \%$ & $26.7 \%$ & $100.0 \%$ & & \\
\hline \multirow{2}{*}{$\begin{array}{l}\text { Ground source } \\
\text { (or water source) } \\
\text { heat pump }\end{array}$} & Count & 32 & 27 & 59 & 1.458 & 0.502 \\
\hline & $\begin{array}{l}\% \text { by } \\
\text { Row }\end{array}$ & $54.2 \%$ & $45.8 \%$ & $100.0 \%$ & & \\
\hline \multirow[t]{2}{*}{$\begin{array}{l}\text { On-site biomass } \\
\text { boiler }\end{array}$} & Count & 41 & 17 & 58 & 1.293 & 0.459 \\
\hline & $\begin{array}{l}\text { \% by } \\
\text { Row }\end{array}$ & $70.7 \%$ & $29.3 \%$ & $100.0 \%$ & & \\
\hline
\end{tabular}




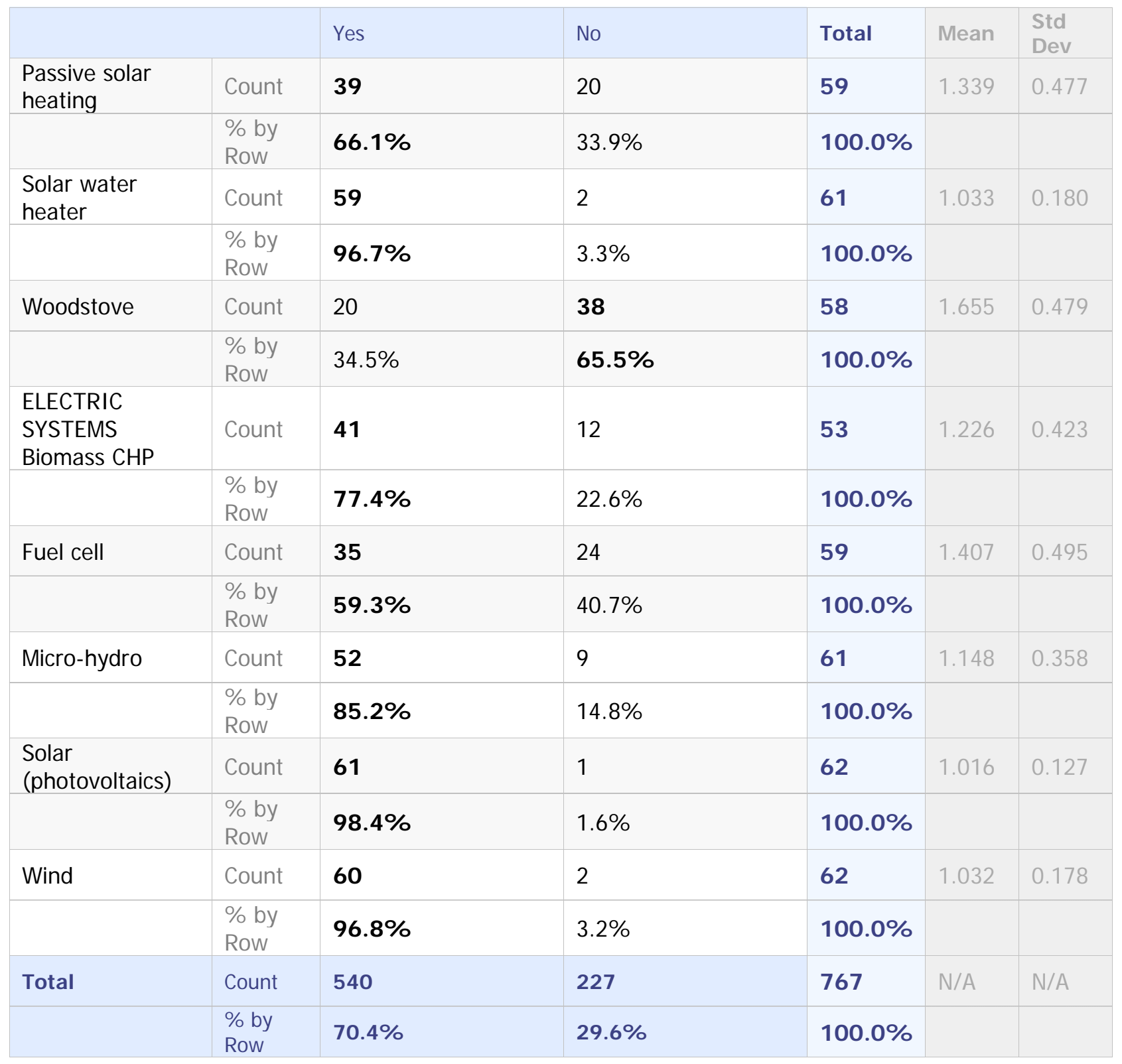


19: What would constitute grounds for a waiver from a renewable (solar) energy requirement? (Choose all that apply)

(Respondents were allowed to choose multiple responses)

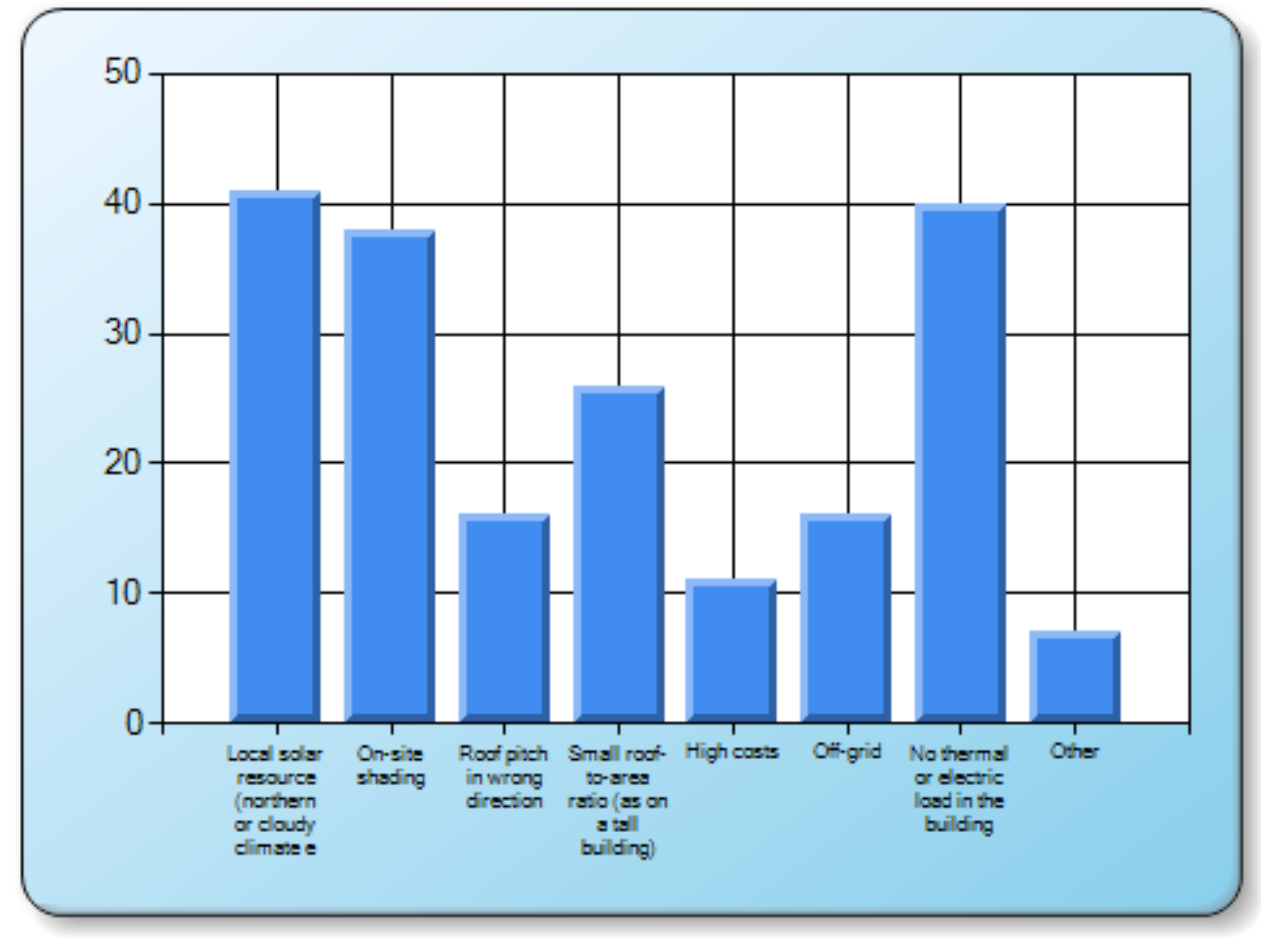

19: What would constitute grounds for a waiver from a renewable (solar) energy requirement? (Choose all that apply) (Respondents were allowed to choose multiple responses)

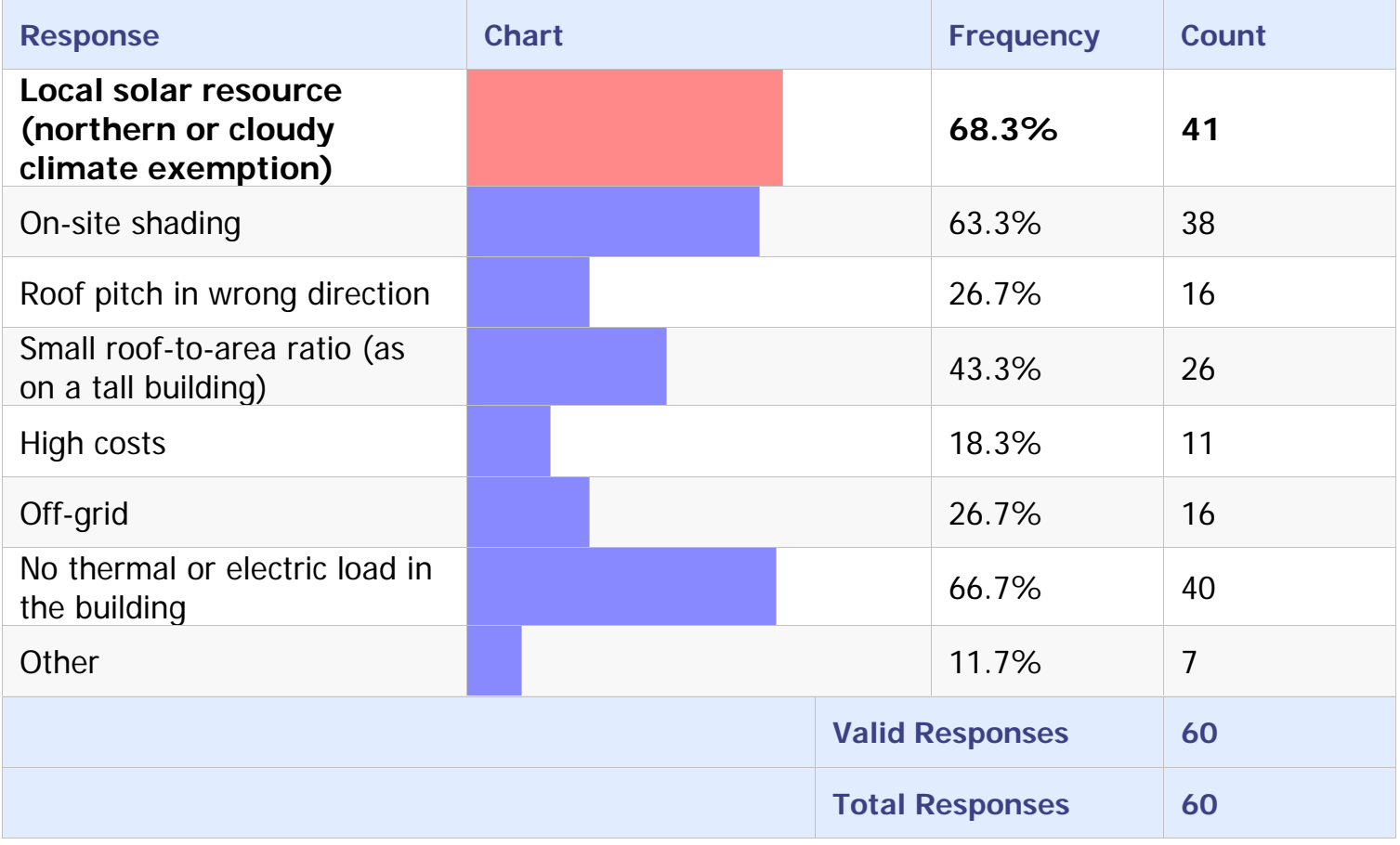




\title{
Please comment on your choices for renewable (solar) energy requirements waivers.
}

\author{
Response to question 19
}

Some consideration could be given for very poor local solar resource, but not sure this is needed. Some impoverished people opt for instant-on gas heaters. Otherwise, SWH is very cost effective and doesn't need waivers.

No

Putting a renewable system at a building that will produce little or no energy does not make sense from a resource point of view.

Clearly this should be based on the building impact (loads) and the regional renewable resource.

Question assumes desirability of a renewable requirement

If there was a shaded site, RECs could be offered as an option. However, NO sites should be totally exempt. Every building should provide on-site renewables or equivalent. (Otherwise, you send the wrong message by making sites with poor solar access more desirable to developers since they can be exempt from putting in the on-site renewables.)

Except for lack of local solar resource, all of the rest are design issues which can be met by any creative Architect/Engineer

Geographic region or no energy use by the structure. All other concerns are design problems to be addressed.

\section{Reasonableness}

Except for suburban green field development (and even in these projects) all of these issues are going to come up frequently.

There are so many it's hard to list them. That's why it would be better to simply limit loads and let the designers do their jobs.

High costs are subjective, just ask NAHB. $\$ 1.00$ more is high cost to them. Too broad of a term.

I object to renewable solar requirements.

Off-grid is a definite reason FOR renewables, except as modified by the location/geometry issues above; high costs are relative and can only be considered in context

Our mandatory solar HW law includes an alternative to be obtained via a waiver--allowing instant-on gas heater. About 200 people have applied for the waiver this year.

Anything that could not be made up for by the purchase of offsets or credits might be considered.

On site shading only if it could not be controlled/abated.

The requirement needs to be straight forward, either a building must comply or it is exempt and the only exemptions would be a lack of availability of the resource.

Cost should not be an issue for requiring solar. No solar access to the buildings should be a consideration as this is something that may be out of the control of the designer.

Waivers will really depend on how the requirements are written... Reasonable accommodations are necessary.

Need to be clear is it a waiver or exemption?

If it's' a new building that is constructed with wrong roof orientation for PV, owner should purchase offsets or reduce demand some other way.

None of these options - allow builders to offset with $200 \%$ ?? RECs or equivalent energy efficiency instead. 
Response to question 19

Especially during ramp-up, site-by-site considerations need to be acknowledged.

Nothing should constitute grounds for a waiver. Targets should be structured to accommodate conditions such as small roof-area.

The other choices seem an excuse - this is new construction so buildings should be designed for renewable energy use.

Renewable energy should not be a code requirement at this time, voluntary application should be encouraged.

Again I'm opposed to mandatory minimums. And believe if the economics are there for their use they will be design to the greatest degree possible as it is goo business.

\section{0: If solar access is not available, what is the best alternative?}

(Respondents could only choose a single response)

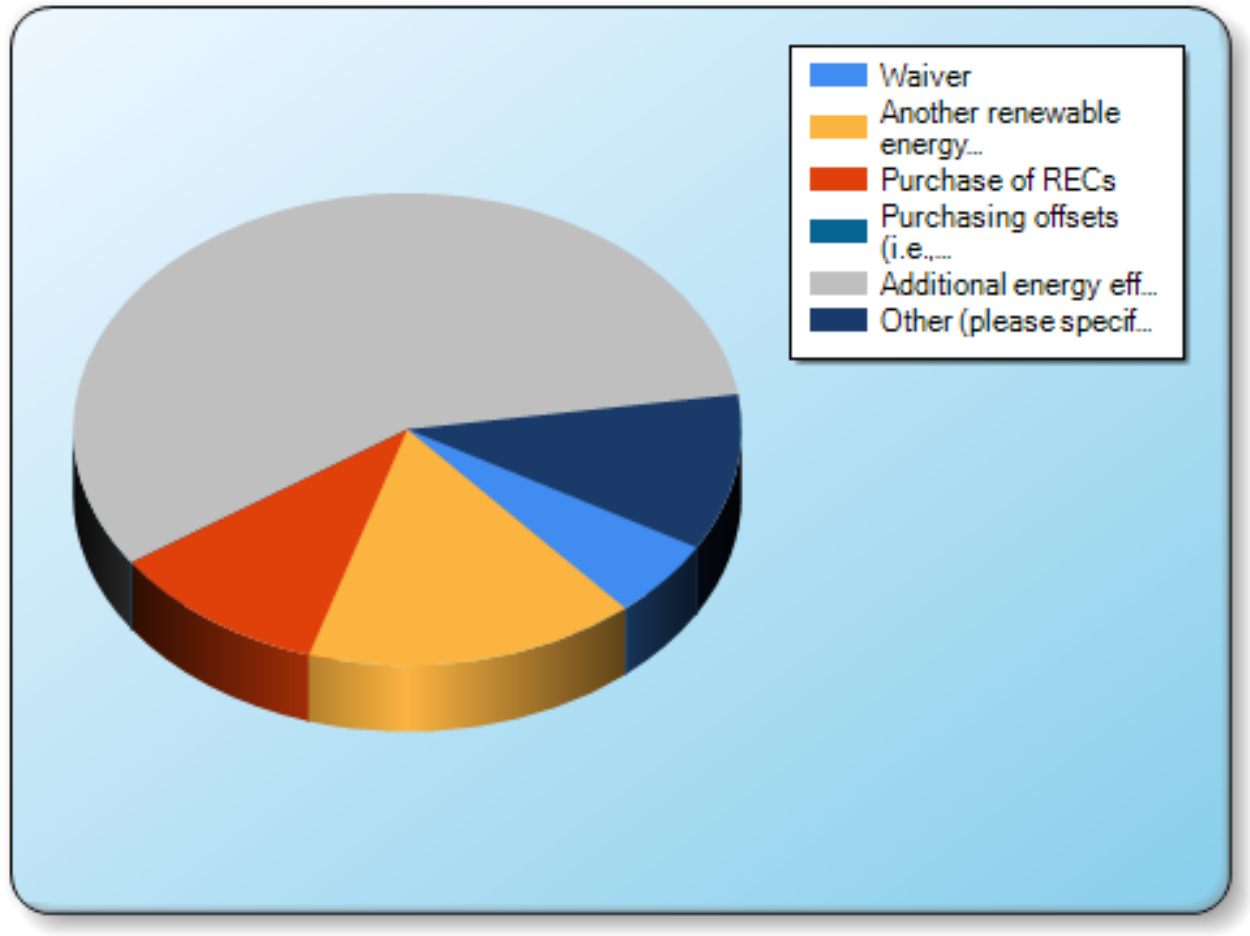


20: If solar access is not available, what is the best alternative?

(Respondents could only choose a single response)

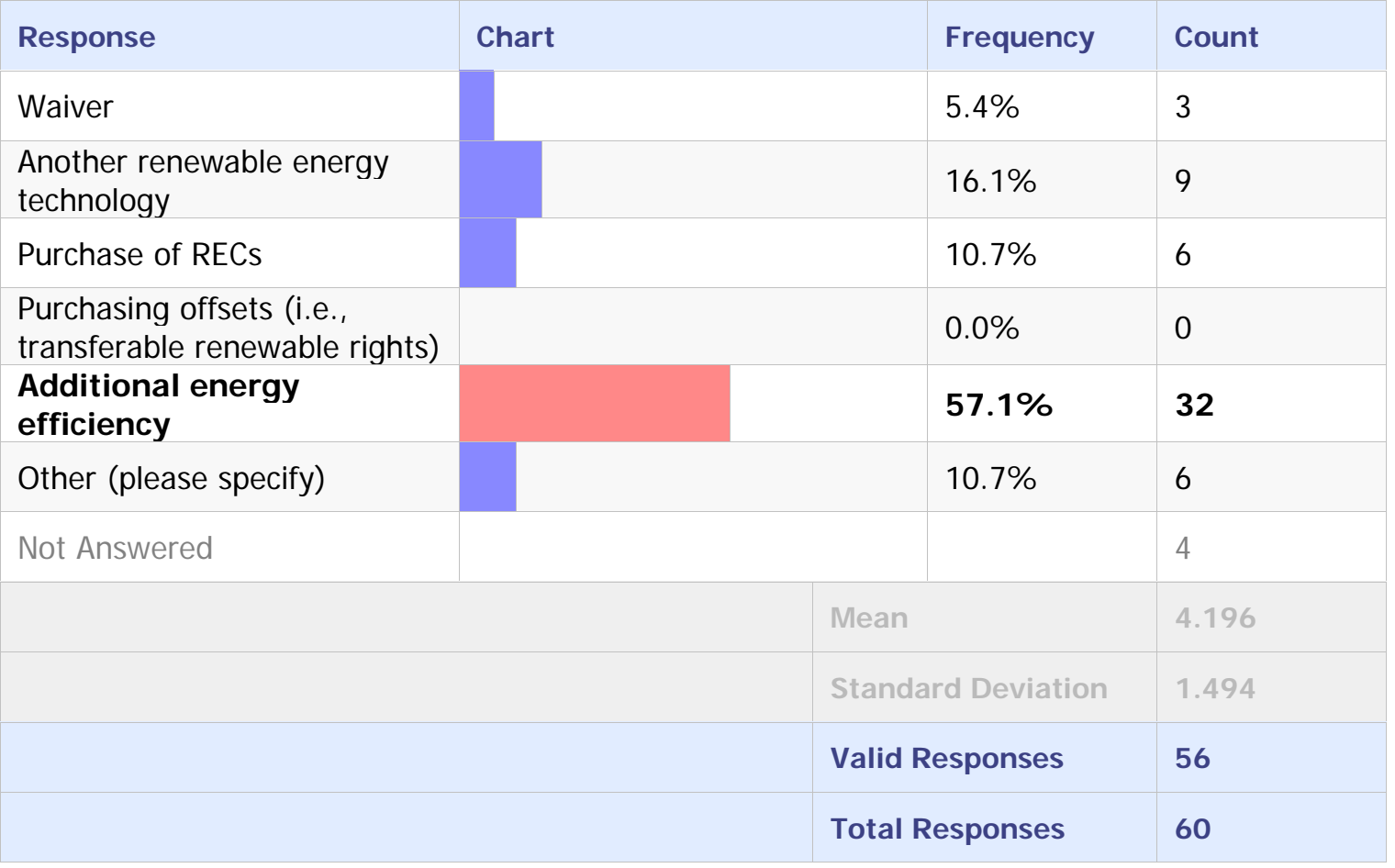

\section{Provide comments on alternatives to solar energy if access is not available.}

Response to question 20

Least expensive alternative

or additional energy efficiency

RECS and offsets also a good alternative

Instant-on gas takes the load off the electrical grid, and is very efficient.

no

More efficiency, then RECs

Question assumes renewables more important than efficiency

Solar gardens/community solar should become a more widely available alternative.

see above

Purchase of RECS as a last resort only.

Focus on a different renewable solution. Buy-out or additional energy efficiency does not address the renewable goal.

As much as can be squeezed out of design and controls; 
Response to question 20

See previous comment.

So, let them make other choices to get the building performance down. Would not require solar.

Additional energy efficiency technology may be available: ERV or more effective ERV (enthalpy); wind; geothermal; hydro could be possible; better equipment efficiencies/systems redesign

This technology has worked well here, and eliminates the water heating load from the grid.

Since I only get to choose one I will say waiver but substituting on site wind would also be an option if that resource is available.

If this is a mandatory requirement increasing the efficiency of the building to offset renewables is a reasonable alternative that can be enforced.

Action on site is best

How about a $200 \%$ EE offset, or a $150 \%$ REC offset?

The option to use technologies that reduce $\mathrm{CO} 2$ production can be encouraged rather than strictly focusing on solar systems

Efficiency is the best option and should be prioritized in ALL codes.

There are several good choices - I think that efficiency, other renewables, or RECs are all good options.

I do not have an answer to this question.

It should be a trade off. I suspect that energy efficiency will always be an attractive cost trade off with RE. 


\section{1: If it is impracticable to install renewable energy on a particular}

building, and in lieu of purchasing RECs, would it be reasonable to require the owner to cause to have installed an equivalent-sized renewable energy system on another (new or existing) building within the same code jurisdiction?

(Respondents could only choose a single response)

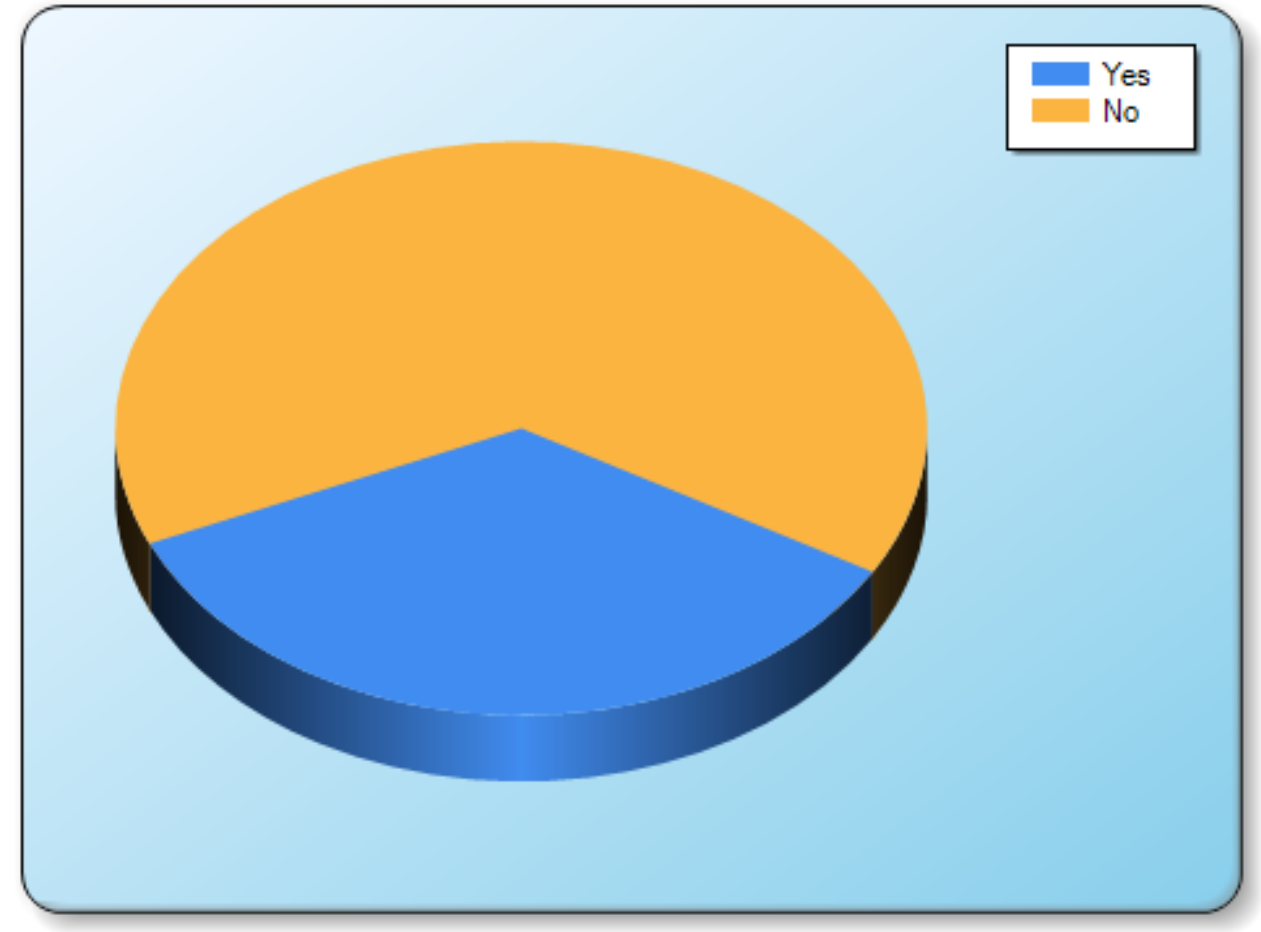

21: If it is impracticable to install renewable energy on a particular building, and in lieu of purchasing RECs, would it be reasonable to require the owner to cause to have installed an equivalent-sized renewable energy system on another (new or existing) building within the same code jurisdiction? (Respondents could only choose a single response)

\begin{tabular}{|l|l|l|l|}
\hline Response & Chart & Frequency & Count \\
\hline Yes & $35.1 \%$ & 20 \\
\hline No & $\mathbf{6 4 . 9 \%}$ & $\mathbf{3 7}$ \\
\hline Not Answered & & 3 \\
\hline & Mean & 1.649 \\
\hline & Standlard Deviation & 0.481 \\
\hline & Valid Responses & $\mathbf{5 7}$ \\
\hline & Total Responses & $\mathbf{6 0}$ \\
\hline
\end{tabular}




\section{Please explain your answer to question 21.}

Response to question 21

What would the benefit be for the purchaser other than meeting the code? No payback.

Pursue deeper energy efficiency.

These scenarios seem to be moving the authority of a building code into the realm of constitutional property rights. Moreover, if requiring an owner to install renewables on a building he does not own is considered acceptable, how is that substantively different from purchasing RECS?

The code permit for one building is not allowed to affect a totally different building Would be yes, except for the "code jurisdiction" item. Renewables should be installed where they have access to the best resource and can be matched to a load. Code jurisdiction is irrelevant. Instead, have him adhere to alternate efficiency practices such as instant-on gas and Energy Star appliances.

Is the other building exempt, and therefore need a sponsor?

no

Existing buildings may not be able to handle the systems on a retrofit basis. Also, very hard to enforce.

We need to consider total environmental impact - not necessarily individual buildings, but the sum

RECs not equivalent to directly installed solar capacity. Unless you define RECs to be system CAPACITY, not annual energy delivered by the system.

but tracking this over time could be a problem

Forcing an owner to install a renewable energy system on somebody else's building would be almost impossible to defend. Owner would have no control over operation, maintenance, or future disposal

This is just not practical.

Is there any precedent for this? Why not do this for efficiency, water, IAQ, etc. etc.?

Better option than buying RECS

Every property or site is comparable to an island. The codes and regulations are specific to that site from property line to property line. The challenge both regulator and owner must face is the minimum compliance of that site and project. Expanding the sphere of influence or regulation beyond that concern is not practical.

How can you require owner B to accept Owner A's renewable system. How would owner B satisfy the requirement at his/her space. This could be a mass Ponzi scheme.

administrative nightmare

Some Regions are just bad for certain types of renewables (i.e. wind in the south

Unreasonably complex record keeping. Causes money to be spent on the wrong things (enforcement rather than design/construction).

Fuzzy math again.

this should be dealt with by utility rps 


\section{Response to question 21}

Would not require renewables. Make them attractive options instead.

This answer would be YES only if the owner also owns the other site and has control over its use.

It's not the owner's fault--he shouldn't be penalized.

If this jurisdiction is located in a poor solar area, this would not help.

I even believe this should not be limited by code jurisdiction but that would prove an administrative problem.

What if they don't own another building?

In my code the only impractability would be the lack of the resource.

Codes are not typically applied to other projects since they are not within the scope of the permit.

The building owner or developer should install the building appropriate quantity of RE on a school other public building, low income home or house or worship in lieu of installing at their own site I believe that California Senate Bill 1 (or 2?) has this requirement, but at a developer level. There are many other precedents for this type of in-lieu trade.

This step toward distributed energy arrangements which for the scale of gov buildings would be needed...

But it should be additional capacity that isn't already required by code, and the system on the other roof needs to be sold at a reasonable price (w/o unreasonable mark-up).

cumbersome tracking

This is complicated enough (albeit very important!) and the logistics for such a plan will create loopholes and code compliance nightmares.

This approach would significantly complicate the legal and regulatory process

But only when there are extenuating circumstances.

Again, I am ambivalent about offsets of any kind, but this may be necessary.

All gets to the same end goal

Extremely difficult, if not, impossible to enforce. Who would enforce this? How? 


\section{2: Should use of off-building renewable energy resources be allowed?}

(Respondents could only choose a single response)

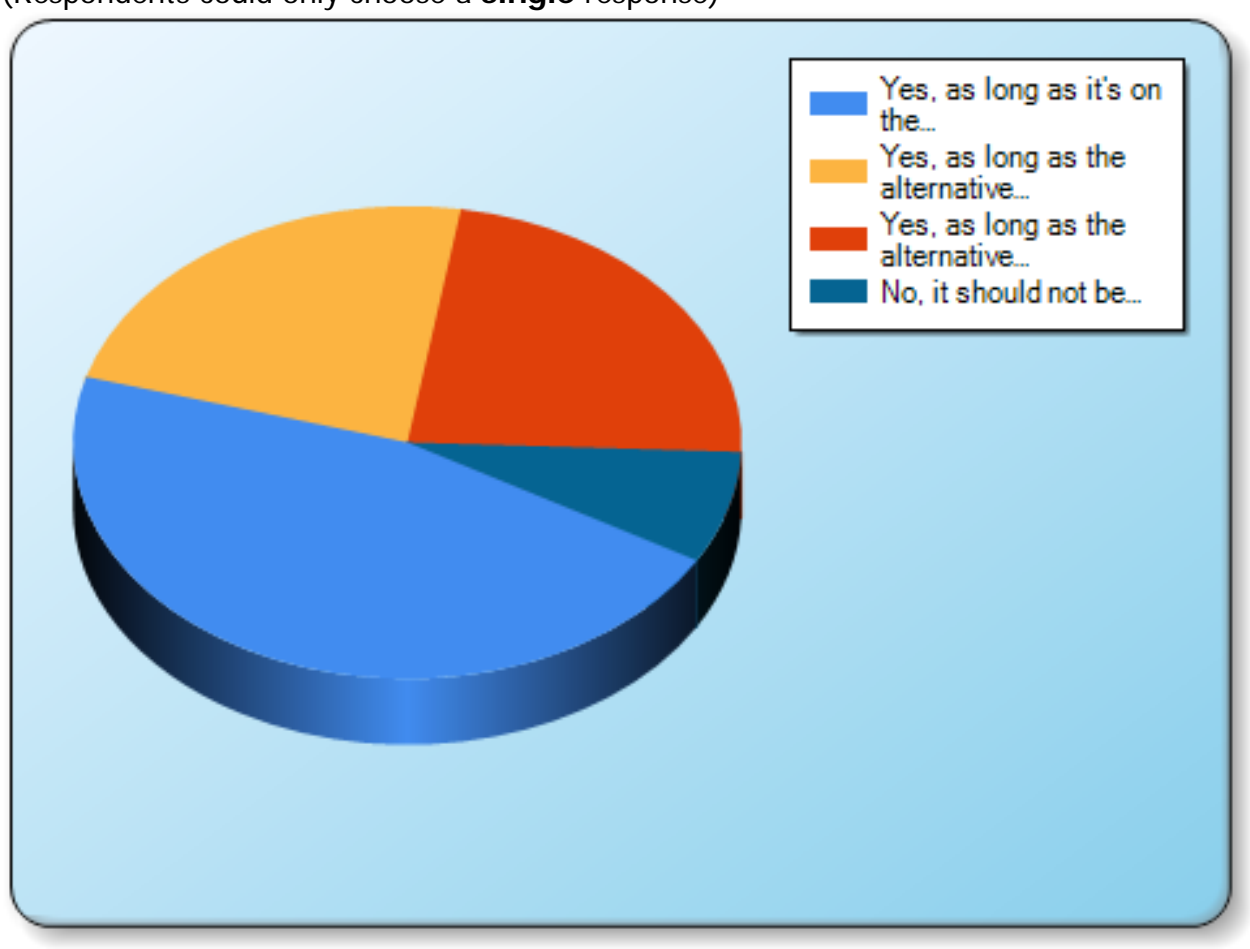

22: Should use of off-building renewable energy resources be allowed? (Respondents could only choose a single response)

\begin{tabular}{|c|c|c|c|c|}
\hline Response & \multicolumn{2}{|l|}{ Chart } & Frequency & Count \\
\hline $\begin{array}{l}\text { Yes, as long as it's on the } \\
\text { building site }\end{array}$ & & & $46.2 \%$ & 24 \\
\hline $\begin{array}{l}\text { Yes, as long as the alternative } \\
\text { site is under the same } \\
\text { ownership as the building }\end{array}$ & & & $23.1 \%$ & 12 \\
\hline $\begin{array}{l}\text { Yes, as long as the alternative } \\
\text { site is under the same } \\
\text { ownership as the building, } \\
\text { and within the same code } \\
\text { jurisdiction }\end{array}$ & & & $23.1 \%$ & 12 \\
\hline No, it should not be allowed & & & $7.7 \%$ & 4 \\
\hline Not Answered & & & & 8 \\
\hline & & Mear & & 1.923 \\
\hline & & Stan & rd Deviation & 1.007 \\
\hline & & Valid & esponses & 52 \\
\hline & & Total & esponses & 60 \\
\hline
\end{tabular}




\section{Please comment on allowing the use of off-building renewable energy resources.}

\section{Response to question 22}

Yes it should be allowed regardless of where it is located.

Keep it on the same site so in the future someone else does not own the site my renewable sauce is located on bad Idea

Renewable is renewable regardless of site.

How will "same ownership" options work if the owner sells?

Direct development of renewables should be allowed no matter the location.

No

Yes, as long as it provided by a regulated entity, like a utility.

Just "yes"

Who cares where they are located? As long as they are required to install new capacity, not buy energy from an existing renewable system.

Yes, but don't like any of the choices. Offsite and different owner should be allowed.

However, "site" could be defined as the block or neighborhood.

Yes because using renewables on individual buildings to make them net zero is bad public policy and horrible economics. I have never heard a rational explanation for why a single building should be net zero. Sorry, but scales of economy are not a myth.

Always allowed, but does it satisfy on-site renewable energy requirement? Only as a last resort.

Weaving a network of complying buildings in support of non-complying buildings does not address the simple challenge of meeting the minimum performance standards.

How about just Yes. It doesn't matter where the renewables are produced.

Does require cooperation

Don't believe you are going to get the most economical solutions/maximize carbon reductions if you restrict the geographic area too much.

Ownership is irrelevant; it will change.

Allow all use of off-building resource as long as it is part of the building's energy load/resource.

The other possibility is a contribution towards local utility development of distributed generation in the immediate neighborhood.

PV's as parking lot shelters are becoming popular, and serve to keep cars cooler.

Why does it need to be on site?

Too many questions about ownership, sizing of the system etc.

Many instances occur where off building is preferable e.g. parking structures, pole mounts etc. 


\section{Response to question 22}

I don't agree with any of the options. I think off-building RE is fine, and in many cases will result in positive, more cost effective outcomes. I see no need for ownership restrictions. In many projects, ownership gets very complex and this would simply unnecessarily limit. For example, consider the case of a master-developer who decides a PV farm is most cost effective/highest performance/ best chance of maximizing PV, and installs this on land owned by the HOA (or perhaps other ownership) and then sells the lots to different builders without PV encumbrances?

yes - this needs to be developed - contractual relationships and infrastructure

This should not eliminate or shield the owner from proper pollution controls. Also a more holistic approach in the evaluation of the amount of production required to offset the site demand. Must be interconnected with utility on the same distribution line. (forces proximity, without being too restrictive of large complex sites)

I defer to others for this and would love to be on a conversation about this.

The problem with separating them is that ownership changes and maintenance is important and agreements made get forgotten, often quickly.

Perhaps this is necessary and may help set precedent for new shared

ownership/governance/jurisdiction models. It should be regulated to ensure apples-apples energy quantities, however.

Why isn't "yes" one of the answers?

It would be better to simply trade off with additional energy efficiency. This approach is an enforcement nightmare. 
23: What can be done for remodels or tenant improvements of existing buildings to ensure they begin to use renewables and ensure some level of equity?

(Respondents could only choose a single response)

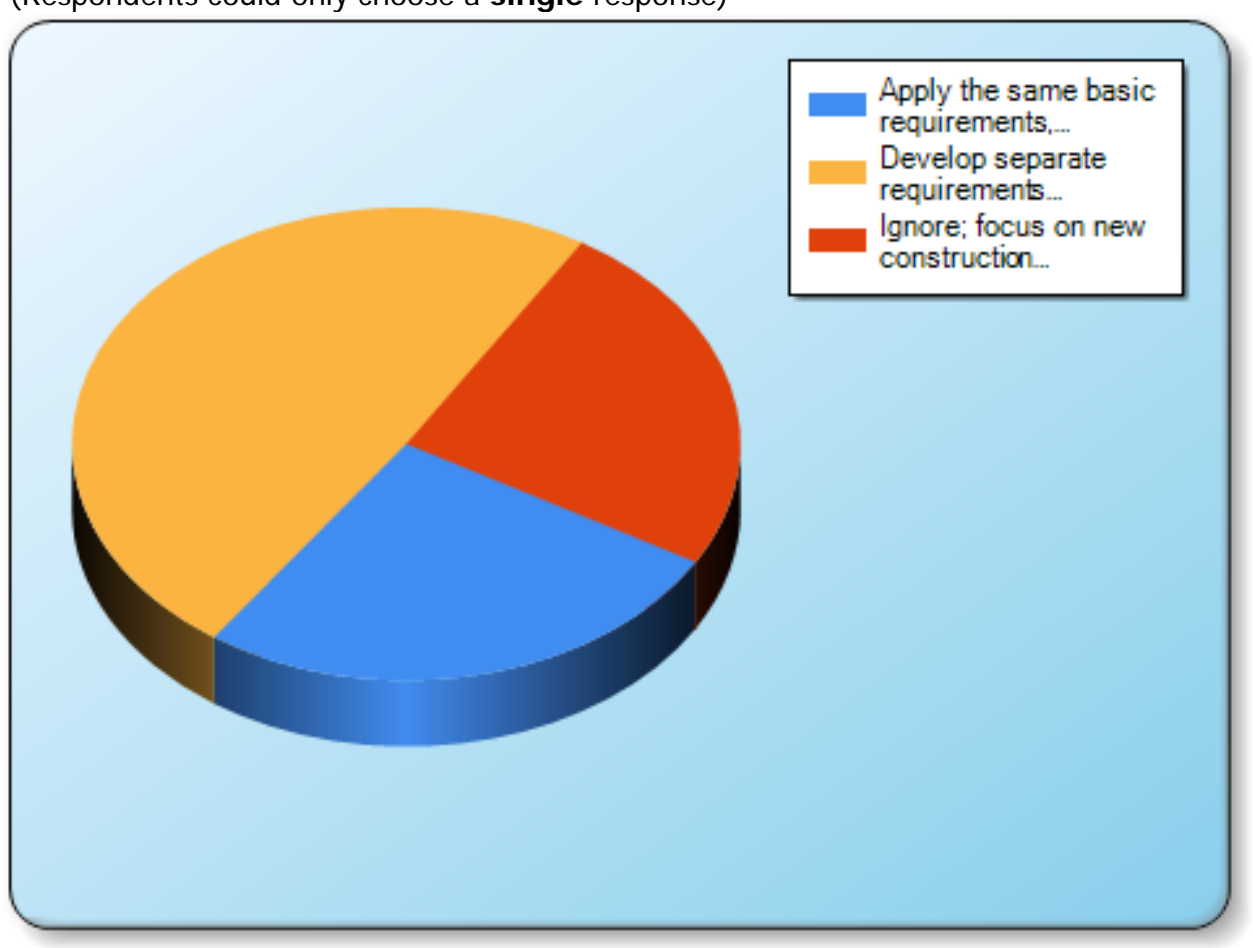

23: What can be done for remodels or tenant improvements of existing buildings to ensure they begin to use renewables and ensure some level of equity? (Respondents could only choose a single response)

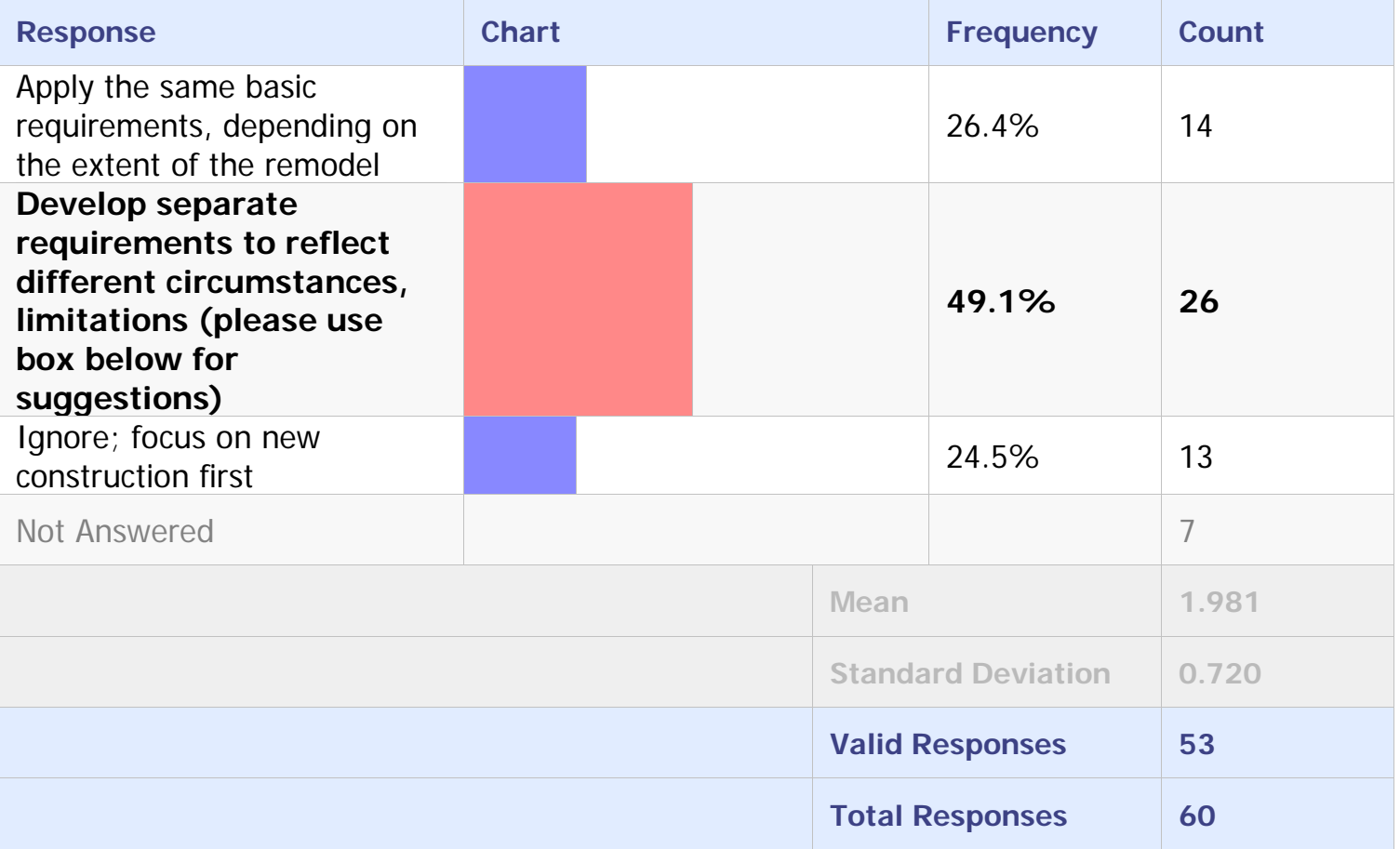




\title{
Provide comments or explain your answer choice for question 23.
}

\author{
Response to question 23
}

Too many retrofit issues for now.

See comment \#6.

Some things are not feasible to be applied as new construction Allow the Building Official to determine what is and is not feasible

New construction is handled. Must be mindful of some people's cost constraints. Offer a list of high-efficiency options instead, inc. real-time use/cost meters.

Potential use to offset required energy efficiency when building circumstances make the ee difficult, e.g. asbestos in the ceiling restricting lighting changes.

No

Due to high wiring and plumbing costs, it is usually way too expensive.

Require renewables in proportion to relative consumption of building. Energy hogs must upgrade or install solar. But first step must be efficiency.

Only require for additions over a certain size, 5,000 ft2?

Too difficult to implement in existing buildings right now. This also creates an incentive for the reuse of existing buildings.

Quite frankly what you touch shall comply. "Updates" for lack of better words will come based on the components being renovated or replaced.

Dependent on extent of retrofit. If none of the "renewable-possible" areas are being retrofit, none should be required.

Codes require only that which is remodeled be compliant.

This is extremely hard. It will take a lot of minds a long time to figure it out.

Address issues where there are potential conflicts with Fire Code or Building Code, to allow retrofits.

The International Existing Building Code needs a major rewrite. They need to include energy in the code and could also include renewable energy.

Provide funding. They will come.

Can't ignore the $90 \%+$ of existing buildings that offer substantial opportunities for energy conservation/efficiency. Requirements must recognize age and condition of the structure, plus the real opportunities for re-use rather than demolition.

Landlords traditionally don't install renewables on rented properties. Incentives superficially for landlords need to be put into place.

\section{See comment question 8}

The whole problem of how to get TFOs to simply comply with the energy code needs to be addressed first here. Unfortunately, I have to say this appears to be getting ahead of ourselves a bit.

For question 24 (below, there is no comment box), a system should not need to be commissioned if the installers know their trade. You wouldn't pay for a new car if you new you'd have to take it to a mechanic to get it running properly as soon as you drove it off the lot.....

This is a very difficult question and I don't have real answers, just a feeling that the requirements should be basically the same. 


\section{Response to question 23}

New construction should be focused on first because the loads can be reduced to make the best use of renewables.

Establish goals and review on case by case basis

Complex. In some cases, applying the same basic requirements to an extensive remodel may make sense; however, costs and impacts need careful analysis and code crafting. I think it is easier/better to start with writing a good new-construction code, which can be later extended to remodels after experience. Risk is that the code will be too cumbersome in remodels and cause backlash/unintended consequences.

remodels must address

This could be challenging $\mathrm{b} / \mathrm{c}$ not all existing buildings have suitable roof space or space on site to accommodate a RE system.

Case-by-case scenarios

A percentage of improvement up to the current requirement for new buildings, depending upon the extent of remodel.

As stated previously, ALL projects should be incentivized/required to meet aggressive targets first through efficiency and then through renewables and other means.

We can't even do remodels or tenant improvements with the codes we have now. 


\section{4: Should a renewable energy requirement also require systems to be commissioned?}

(Respondents could only choose a single response)

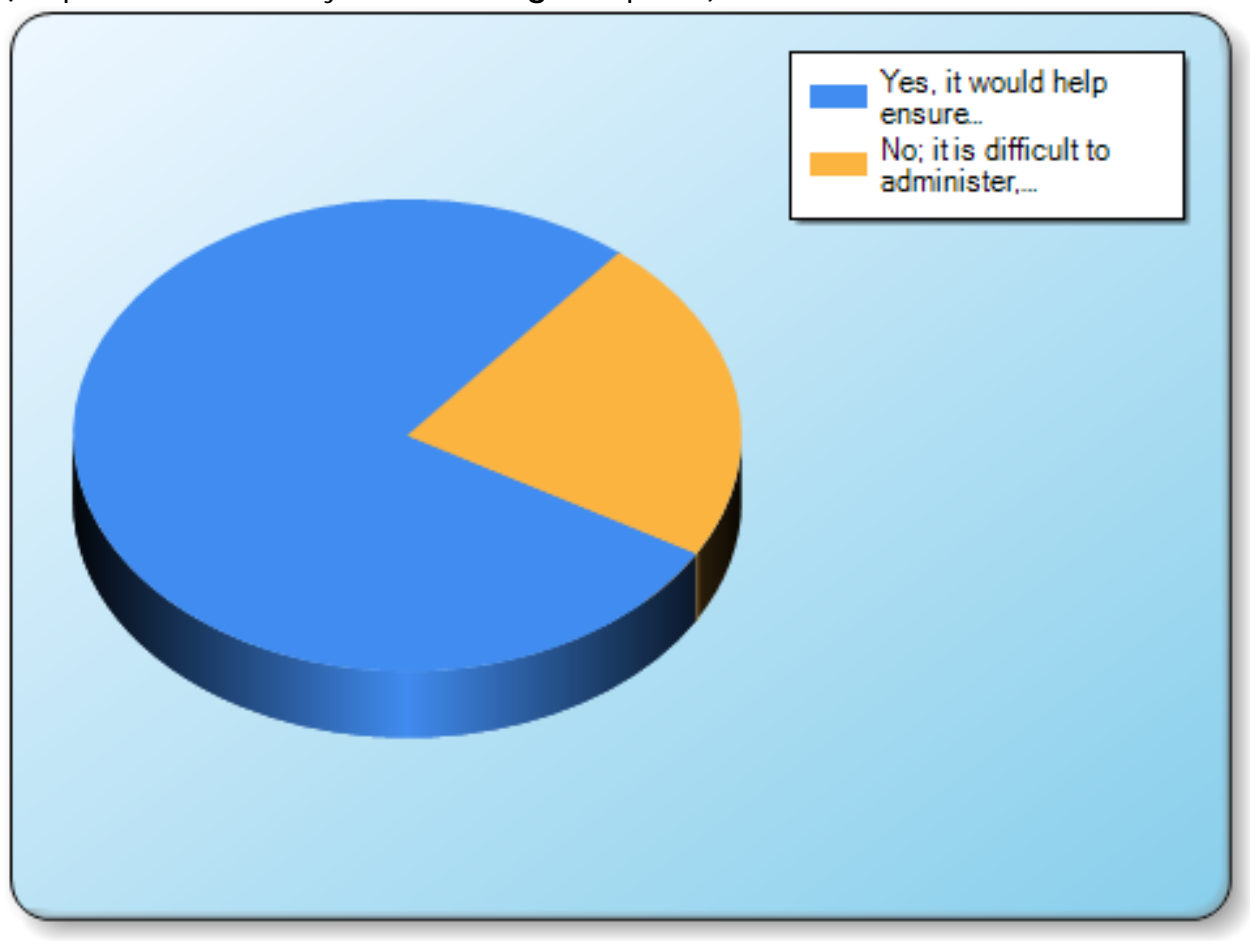

24: Should a renewable energy requirement also require systems to be commissioned? (Respondents could only choose a single response)

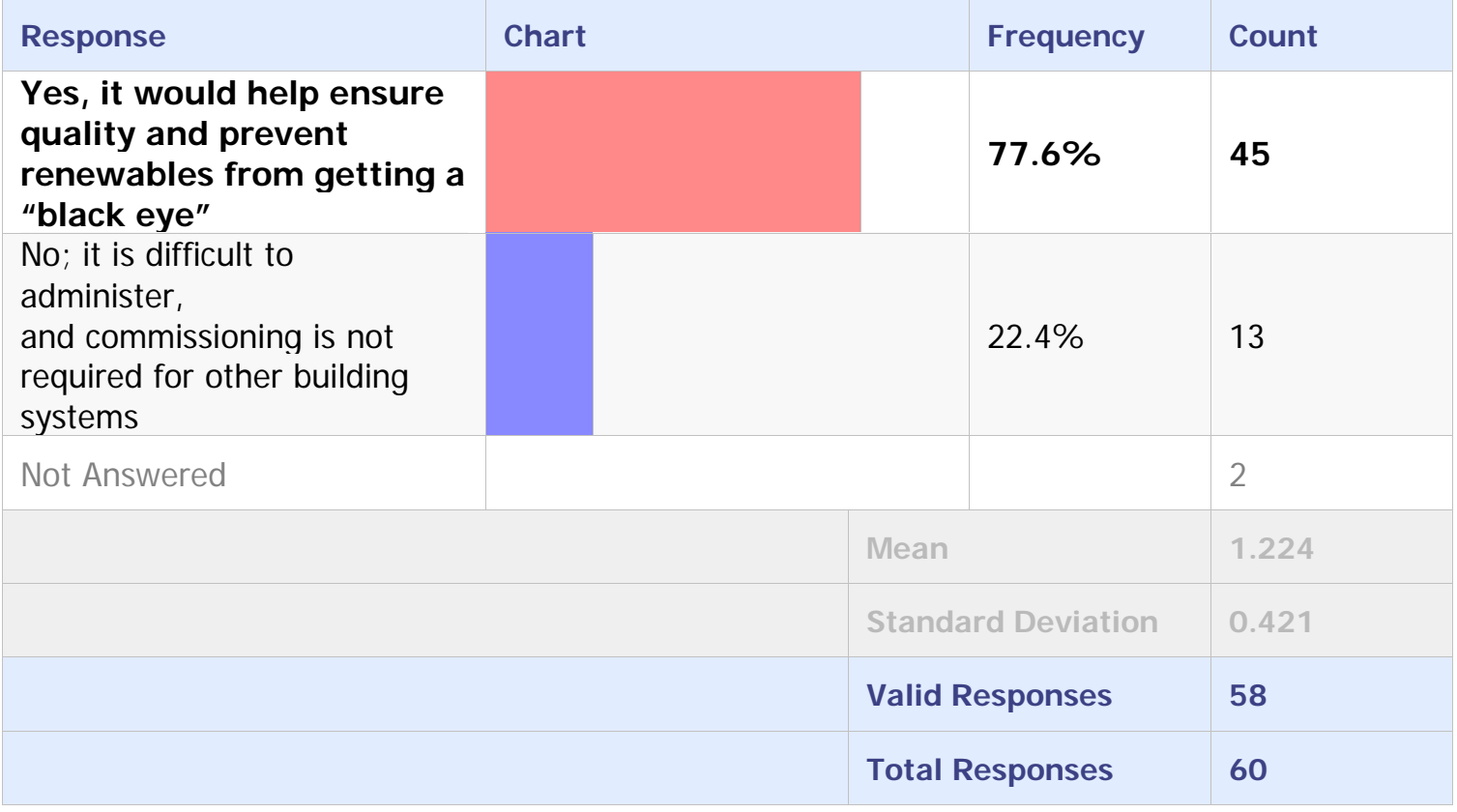




\section{How do you think renewable energy systems might be commissioned?}

Response to question 24

Hire a third party to inspect and commission.

Performance based analysis of design goals

Different requirements for different systems, perhaps a waiver if the energy will be metered and monitored.

Compare actual performance to design expectations.

Reporting of actual performance to ensure code compliance

A checklist is best. Hawaiian Electric Co. has a 100-point checklist for SWH and it's worked very well. We're developing a checklist for PV.

By a qualified installer. Perhaps a 3rd party, but that adds cost.

Based on trade association or 3rd party certification programs.

Make sure that they work as intended. This would include making sure that they generate energy and the energy is used as intended.

Require warranty on metered output.

Not any different from any other mechanical or electrical system.

I do not know.

No idea.

Third party independent agent.

The same manner as other system. Calibrate sensors, measure energy in and energy out (integrate over a day)

Certified third party

Have someone independent inspect the work/check system function.

Test output after 6 months/ 1 year of installation

Walk across the street, put your two hands up and look through the two thumbs. Just kidding, but that's how the HVAC industry has sized and commissioned equipment for residential for years. Need some new standard. Get ashrae one it. Pre-commissioning BEFORE $\mathrm{C}$ of $\mathrm{O}$; formal commissioning after building occupancy has been in place for enough time to get the both sides of HVAC wrung out.

As for the other systems, insure that they are install and delivering as per their design.

How is anything commissioned? At this point the CX process is so new that it is truly up to the owner to do his research. Renewable systems can be complex and they must function so having an expert as the owner's rep is a sensible thing. Not sure what the requirements would be.

Third party inspections and commissioning/tests with appropriate equipment. A new RE industry Output testing.

Protocols will need to be developed to allow for system commissioning. 
Response to question 24

Unclear question - the obvious answer is by the installing contractor

Not so worried about PV, but CX for solar thermal systems are particularly important for commissioning. Simple, sensible commissioning requirements are important. Better to have a few key commissioning/acceptance testing checks than to have an overly zealous/intensive CX requirement. Enforcement \& costs will be an issue. If you can get $80 \%$ of the commissioning bang with $\sim 20 \%$ of full CX costs via a few simple acceptance tests, this would be preferable. systems performance testing and metering over several seasons - the system may need to be "tuned" also refer to DOE guidance on this from the solar group commissioning varies for renewable used

Performance criteria established and verified.

Ensure system is installed correctly and that it is metering electricity generation properly?

Most renewable systems will be PPA's so commissioning is built in.

A third-party industry is born!

QC checklist and measurement protocols

Performance should be required to be monitored by the installer for at least one year and performance reports provided to the approving entity

These procedures are fairly well-established in the industry, I believe.

I don't know enough about the systems themselves but assume it's reasonable to set standards for inspection and testing - and standardize information that is provided to the code inspector. Not sure what you are asking for. Proper functioning of all components, proper function of controls in all operating modes. Output (to the extent that extreme conditions can be obtained during testing). Etc.

I don't have enough experience with commissioning to give a good response.

Responses

\section{5: Please summarize your recommended pathway for integrating renewable energy into building energy codes? (Which programs or codes, which system types, lead times, etc.?)}

Response (recommendations summary)

Voluntary first. Need to consider nuclear as renewable for now. Idea is to minimize coal and gas use. Nuclear is clean and comparatively abundant. Should be favored energy source. Need more focus EE first, but now? Once that is in place (hopefully ASAP) start in slowing requiring some renewables, perhaps just solar thermal on certain building types will lots of roof space and thermal loads. I believe there are other drivers that should be used first to reduce the cost of both PV and solar thermal before integrated into building codes, namely a carbon tax or carbon cap and trade and a RPS.

I disagree with the idea that the use of renewable energy should be mandated by the building codes. The use of renewable energy should be REGULATED by the building codes, as is currently the case. And the use of renewables should be promoted by means of being accepted as a tradeoff to other certain requirements in the code. 
Response (recommendations summary)

Develop good and simple prescriptive codes and start to get it out there and used through education and information before enforcement. Slowly as it is more widely accepted change over to enforcement

Develop EUI outcome based codes for on-site (efficiency and renewables) to hit. If EUI code is exceeded, require purchase of RECs for exceeded amount. This requires working with the utilities to set the EUI cap, and developing a rate that reflects this. This is done on a residential code basis in Italy (so I'm told) Mandatory SWH for new construction is already in place. Next, survey reasons for resistance to SWH in existing buildings and address those issues with additional incentives.

Allow for all means of reducing energy, especially conservation emphasis practical solutions Use $\mathrm{RE}$ where there are the resource $\&$ incentives.

Alternatives in IECC, IGCC for PV. Daylighting needs to be piloted in utility or other voluntary programs because it resists easy description.

cost-effective first... same test to move code as energy efficiency

None should ever be included in codes

There is no specific pathway. Energy production does not equal energy efficiency. They are apples and oranges and should be kept separate, to avoid "gaming" of energy numbers at the building site.

Require a small amount.

I am clearly on the wrong list! You are asking this question for people that agree with your premise that adding renewable requirements to code is a good idea!

Performance requirements are preferred. Owner/builder has flexibility to choose technology after energy efficiency options are exhausted.

Put in Energy Code, require a minimum energy production of $x x x$ Btu per square foot of gross floor area per year, allow RECs where there is a solar access problem.

Performance based codes in conjunction with requirements for Financial Institutions and Utilities to assign appropriate values to the renewable energy

Simple, mandatory prescriptive requirements that apply to all buildings based on the combined size of the roof + the parking lot. Should be based on climate so that we are not requiring installation of systems which do not work.

Don't do it now or in the near future. Invest in R\&D for the solar manufacturing industry until their non-subsidized price is

...This will result in a long thoughtful answer and approach based on the basic principles of mainstream integration from energy codes to building codes to zoning codes. Site, envelope, use, equipment, transportation, etc.

Outcome based requirement, doesn't matter where the renewable comes from. Reduce loads first - then do it efficiently, including renewables where it makes sense.

I like the IgCC followed by the IECC

1) Reduce demand, 2) develop economical renewables on site first (for us that would be Ground Source Heat Pump), 3) alternative compliance for the remainder (long term delivered green power or RECS).

You gave no comment box on Q24, so I'm commenting here: Commissioning is only needed because buildings still work even when their systems aren't working right. If the code limited capacities, for example, the systems would HAVE to work in order for the building to work. As it is now, over sizing replaces good design and implementation.

Use green or stretch code as path, allow options to designers and builders to increase buy-in, and avoid specifying or requiring any specific technology or system. 
Response (recommendations summary)

Appendix in IRC, IBC Referenced by plumbing, mechanical, and electric codes. Required solar ready chaseways in all residential buildings.

189.1 has a good start at it.

The appropriate place to integrate the renewable energy requirements is through the IECC and the IgCC.

The Energy Gauge USA (residential) and Energy Gauge Summit (commercial and high rise residential) already do this.

Renewables should be integrated: 1 ) into 'stretch' codes and voluntary efficiency standards (with or without 'green'); 2) into governmental projects; 3) into adoptable model codes. Commercial should proceed residential; existing dwellings should be co-terminus with new residential construction.

See comments question 8

The local jurisdiction's energy code must address this. Technical questions such as system types, lead times, etc will be particular to that jurisdiction.

PV and solar hot water read-buildings in National and Local Codes.

A pure outcome-based approach would alleviate a lot of the problems of requiring renewables.

Renewables should be integrated into codes as an option not as a mandatory requirement. This can be done for both residential and commercial codes. This will be done in the 2012 IECC in 2010 if the EC 147 passes.

California \& Oregon energy codes \& ongoing efforts seem to be a very good start. Start with some RE in the code, and build upon this. A multi-pronged approach will make the most sense. For example, baseline building energy use budgets should start including some passive solar/daylighting and related effects, which can be traded off. Vice-versa, PV or SDHW should be included as option for different compliance paths... You are not going to get to ZNE in one step, or fully desired RE level embedded in codes on first try. Therefore, embedding RE in the code in multiple ways is important and will allow for future tightening.

Distributed power arrangements and cost of externalities to inform ROI need to be addressed

Boot on neck...(kidding) Policy.

1. PV-ready requirement in base code if possible, but at least in reach code) 2 . Compliance option in performance (integrate PV into compliance software) 3. Prescriptive 4. Mandatory The marketplace is moving faster than the codes, thus the codes need to become more adaptive to renewables as soon as possible.

IBC with onsite RE requirement based on roof area with $200 \%$ ? EE/REC offset allowance.

Start with $\mathrm{C}+\mathrm{I}$ for RE and solar ready for everything else; create realistic and aggressive schedule for benchmarks. Weight electrical RE/thermal RE/charging stations for electrical vehicles based on climate zones and market penetration.

Voluntary requirement with energy supply structure designed to enable the use and value of renewable technologies 


\section{Response (recommendations summary)}

Require it in the building codes (ICC\&UBC) best due to a national governmental directive. Require a 30\% decrease in GHG/sf for building operations over current levels (based on building type/use) and include incremental increases over time. Also have requirements for reducing embedded GHG in building materials and methods considering cradle to grave. Tie these requirements with CEU requirements for licensed professionals (architects, contractors, plumbers, electricians, engineers, etc.) for specific education in understanding GHG and buildings and building envelopes, building systems, and renewable energy sources. Ensure that the results overall will bring GHG levels below 350 ppm by 2030.

1. Set aggressive energy end use target for all building types and situations (should be tailored to be feasible) 2. Allow project teams to determine best combination of strategies to achieve 3 . Provide a prescriptive path for those projects that choose to use it.

Introduce it as part of tradeoffs with other requirements. It should be included as part of stretch codes i.e. codes that are already designed to be stringent so that people are not shocked when they see the requirement.

Get first time costs down - systems will then make good business sense and be sought out for installation. Code would each need to have provisions as the renewable either has structural components, electrical systems, interconnection to or made up of piping or duct systems etc.

\section{6: How will people accept a renewable energy requirement? What do you think will be the response?}

(Respondents could only choose a single response)

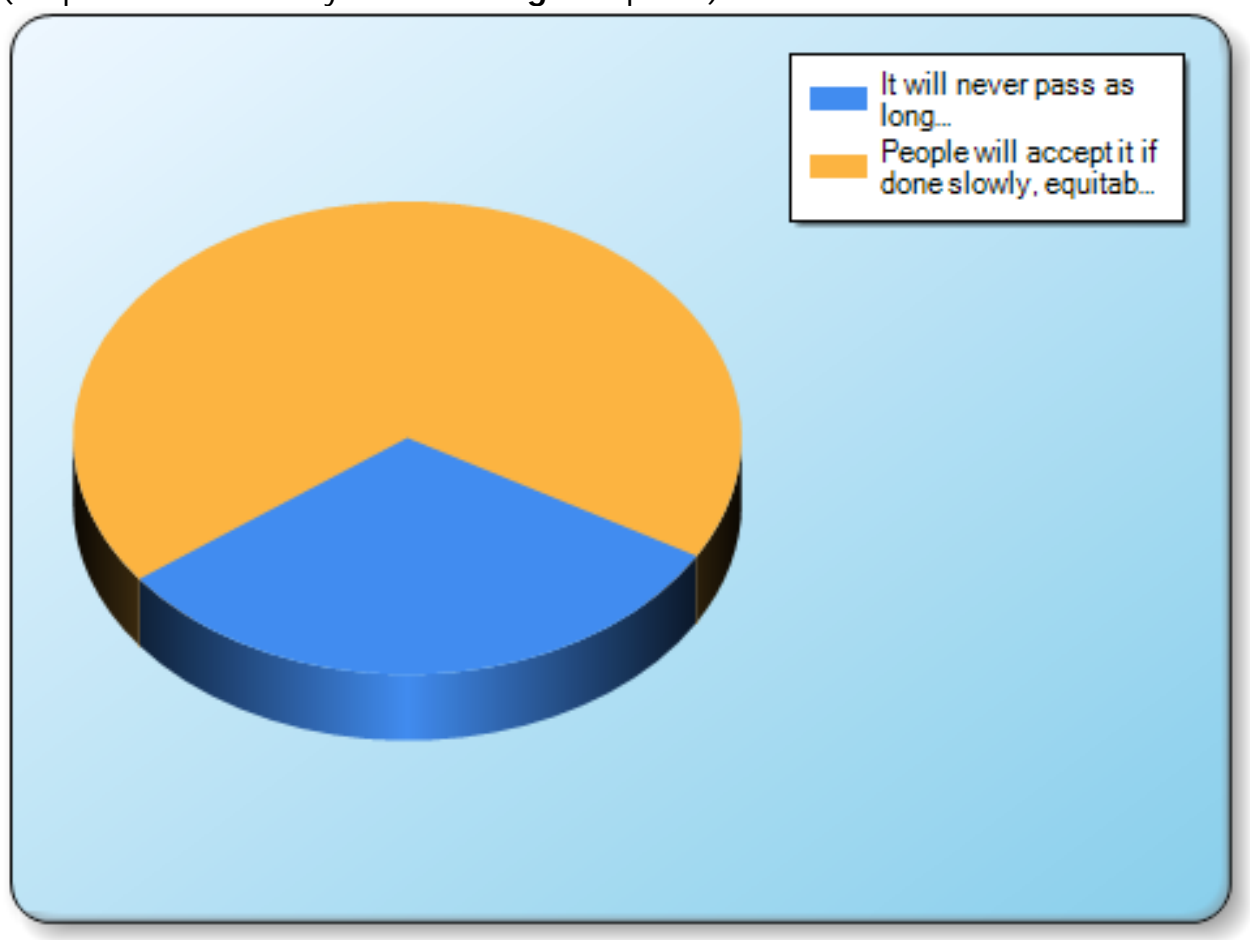


26: How will people accept a renewable energy requirement? What do you think will be the response?

(Respondents could only choose a single response)

\begin{tabular}{|c|c|c|c|c|}
\hline Response & \multicolumn{2}{|l|}{ Chart } & Frequency & Count \\
\hline $\begin{array}{l}\text { It will never pass as long as } \\
\text { renewables are not cost- } \\
\text { effective }\end{array}$ & & & $31.5 \%$ & 17 \\
\hline $\begin{array}{l}\text { People will accept it if } \\
\text { done slowly, equitably, } \\
\text { and flexibly }\end{array}$ & & & $68.5 \%$ & 37 \\
\hline \multirow[t]{5}{*}{ Not Answered } & & & & 2 \\
\hline & & \multicolumn{2}{|l|}{ Mean } & 1.685 \\
\hline & & \multicolumn{2}{|c|}{ Standard Deviation } & 0.469 \\
\hline & & \multicolumn{2}{|c|}{ Valid Responses } & 54 \\
\hline & & \multicolumn{2}{|c|}{ Total Responses } & 56 \\
\hline
\end{tabular}

\section{Elaborate on your response to question 26.}

Response to question 26

People will not accept a renewable energy requirement coming to them via building codes. These are over-arching policy determinations that need to be deployed through a broad catalog of measures, of which the codes may be a part.

See comments above in Question 25

The program is already in place and it's working.

In some places it is already moving forward, but to get the majority it must be cost effective. Work in places where RE is cost-effective and others will emulate.

Many buildings cannot do renewables for many reasons (lack of roof space, lack of site space, etc), and will resent this requirement.

Do you guys really believe that it makes sense to require renewables before more cost-effective conservation strategies? What constituencies will buy into this? I talk to audiences all over the country debunking the notion that it makes sense to add renewables before all reasonable efficiency strategies have been implemented. DOE has had to drop the term 'net zero' because it has been hijacked by the renewables industry to promote renewables ahead of efficiency. Is this where PNNL is at also?

People are not so good at calculating costs and values. If they see the system working to generate energy, they will be positive. If codes require the installation of systems which do not work due to climate or site or installation issues, they will revolt.

Unfortunately people will accept it but not because it is a good thing to do. Most have no understanding of the relationship between efficiency and renewables.

Its time has come.

Educate, demonstrate, bottom line benefit from subsidies to tax credits. 


\section{Response to question 26}

The small minority will accept it immediately. The vast majority will only do it if required (not recommended) or when cost effective.

Developers are bottom line people and generally resist being told what to do. Equitably and flexibility will soften the reality.

Someone needs to subsidize the cost/help finance until cost effective. Carbon Tax on existing sources or cap and trade would improve ROI

If the answer is no, none of this matters.

Depends upon the price of a barrel of oil. When we saw oil at $\$ 140$ a barrel people started thinking of RE and EE.

Start with low goals to gain acceptance, apply them across the board to both public and government projects, provide for design flexibility.

Make it cost effective. For example, Hawaii has significant rebates loans for solar PV systems. My brother-in-law put one in.

Cost-effective is a relative term; as the price of energy continues to soar and dominate all aspects of our economy, saving energy by using other sources will continue to become more 'cost-

effective'

See comments question 8

I believe "common sense" must prevail and towards that end, the outcome must be used as the primary metric. Additionally the community must foot some of the bill in the early years or until the full costs of coal, oil, etc are borne.

I can be done equitably and flexibly but I am less convinced on the slowly part.

As long as it is an option it can be phased in.

We quickly learned to live with minimum window sizes and double glazing requirements we will learn to live with RE requirements

The cost-effective argument is very important--however, I think that there are ways to include RE cost-effectively. 2011 CA T24 code updates \& OR energy code are good examples of starting points.

it is the approach of pushing efficiency first then renewables also encouraging distributed power

Start with a small target that few can object to.

A lot of marketing and preparation is needed. This is important stuff; the industries and stakeholders all need to find a way to buy-in and own this transition.

If "renewables" are focused on 1 or 2 technologies only, the value and benefit will be limited in many areas and buildings. Work will need to be completed on the integration of the energy supply with renewable systems before renewable requirements can be rationally defined.

People never accept change easily, but that is no reason for aiming high and pushing forward.

It's very difficult to put in more stringent ee requirements even if they are cost effective. Beyond that, it has to be done slowly, equitably and flexibly.

Money is the best motivator. 
27: Rank, in order of significance, where you think the most resistance to renewable energy requirements will come from. Rank at least three, with 1 representing the greatest resistance.

\section{Builders, contractors}

(Respondents were limited to brief text responses)

\begin{tabular}{|c|c|c|c|}
\hline Response & Chart & Frequency & Count \\
\hline No Response Recorded & & $14.3 \%$ & 8 \\
\hline 1 & & $32.1 \%$ & 18 \\
\hline 2 & & $30.4 \%$ & 17 \\
\hline 3 & & $17.9 \%$ & 10 \\
\hline 4 & & $3.6 \%$ & 2 \\
\hline \multirow[t]{3}{*}{ Other Responses } & & $1.8 \%$ & 1 \\
\hline & & Valid Responses & 56 \\
\hline & & Total Responses & 56 \\
\hline
\end{tabular}

\section{Building owners}

(Respondents were limited to brief text responses)

\begin{tabular}{|c|c|c|c|}
\hline Response & Chart & Frequency & Count \\
\hline No Response Recorded & & $3.6 \%$ & 2 \\
\hline 1 & & $41.1 \%$ & 23 \\
\hline 2 & & $32.1 \%$ & 18 \\
\hline 3 & & $12.5 \%$ & 7 \\
\hline 4 & & $8.9 \%$ & 5 \\
\hline \multirow[t]{3}{*}{ Other Responses } & & $1.8 \%$ & 1 \\
\hline & & Valid Responses & 56 \\
\hline & & Total Responses & 56 \\
\hline
\end{tabular}




\section{Code professionals}

(Respondents were limited to brief text responses)

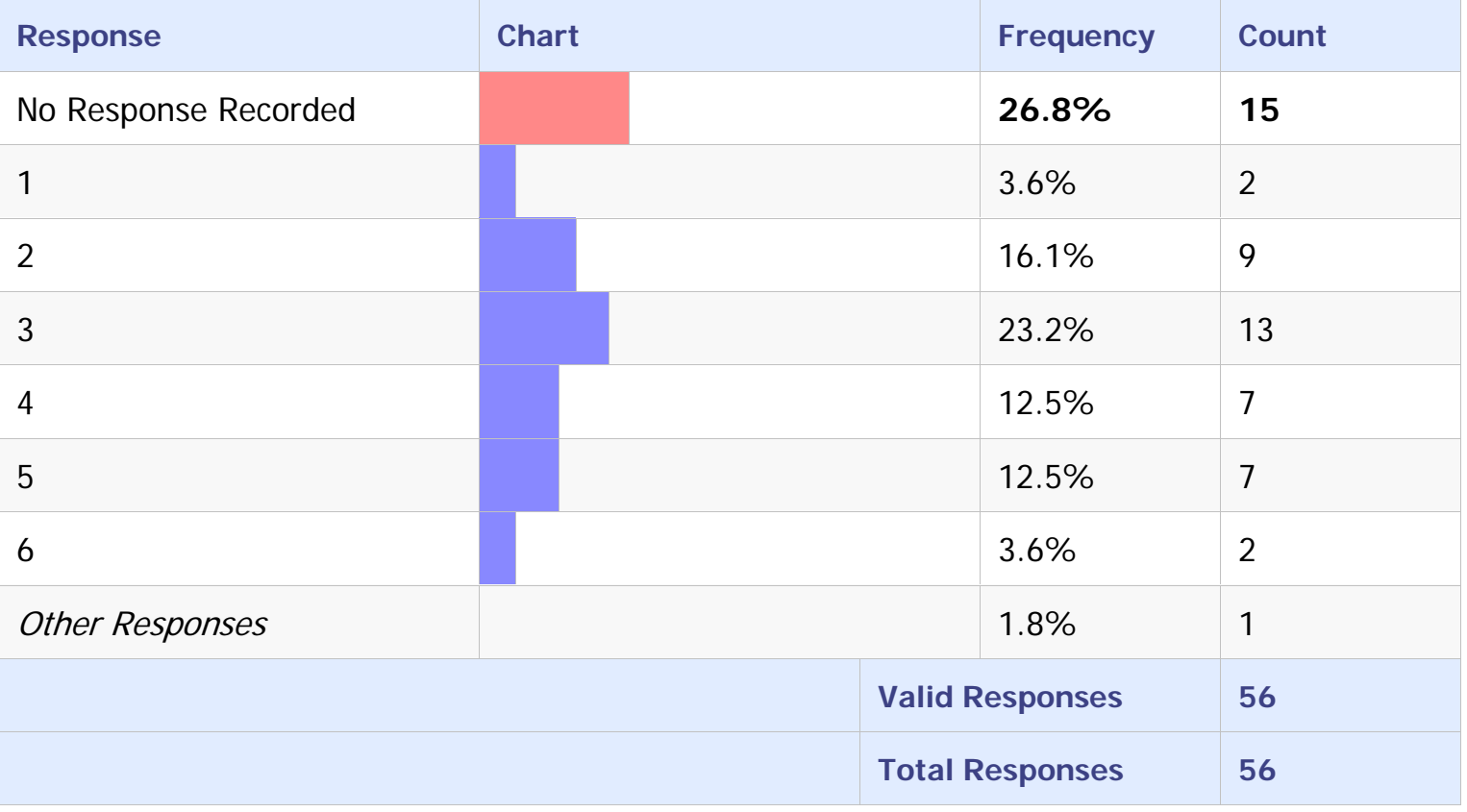

\section{Design community (A\&Es)}

(Respondents were limited to brief text responses)

\begin{tabular}{|c|c|c|c|}
\hline Response & Chart & Frequency & Count \\
\hline No Response Recorded & & $30.4 \%$ & 17 \\
\hline 2 & & $8.9 \%$ & 5 \\
\hline 3 & & $28.6 \%$ & 16 \\
\hline 4 & & $12.5 \%$ & 7 \\
\hline 5 & & $14.3 \%$ & 8 \\
\hline \multirow[t]{3}{*}{ Other Responses } & & $5.4 \%$ & 3 \\
\hline & & Valid Responses & 56 \\
\hline & & Total Responses & 56 \\
\hline
\end{tabular}




\section{Utilities}

(Respondents were limited to brief text responses)

\begin{tabular}{|c|c|c|c|}
\hline Response & Chart & Frequency & Count \\
\hline No Response Recorded & & $17.9 \%$ & 10 \\
\hline 1 & & $21.4 \%$ & 12 \\
\hline 2 & & $12.5 \%$ & 7 \\
\hline 3 & & $23.2 \%$ & 13 \\
\hline 4 & & $5.4 \%$ & 3 \\
\hline 5 & & $16.1 \%$ & 9 \\
\hline \multirow[t]{3}{*}{ Other Responses } & & $3.6 \%$ & 2 \\
\hline & & Valid Responses & 56 \\
\hline & & Total Responses & 56 \\
\hline
\end{tabular}

\section{Other (please specify and rank)}

(Respondents were limited to brief text responses)

\begin{tabular}{|l|l|l|l|}
\hline Response & Chart & Frequency & Count \\
\hline No Response Recorded & $\mathbf{7 3 . 2 \%}$ & $\mathbf{4 1}$ \\
\hline 3 & $3.6 \%$ & 2 \\
\hline Other Responses & $23.2 \%$ & 13 \\
\hline & Valid Responses & $\mathbf{5 6}$ \\
\hline & Total Responses & $\mathbf{5 6}$ \\
\hline
\end{tabular}

B.105 
Response Other (please specify and rank)

1 - customers

1

2

Code officials 4

1 economists, financiers, developers

3 (Banks, etc)

1 - NAHB

2. Banks, realtors (unless conservative, proven metrics are provided)

1-Oil and Coal Companies

3 - Depends on how codes are designed, implemented \& jurisdiction. In some cases utilities will have a big issue but not so much elsewhere...

3

3 neighbors

3

media - 1

2 local government

Responses

\section{How can resistance to integrating renewable energy requirements into codes best be overcome?}

\section{Response Renewable Energy Resistance}

By lowering the cost. Create demand among customers and builders will follow.

Make them more cost effective by correctly pricing carbon and other pollution. Don't require renewables too quickly or before cost-effective EE.

The first line of resistance will come from communities, and will be evident by the lack of willingness to adopt or enforce codes that impose requirements on the types of energy that must be used. Building owners will also resist, as the cost factor will always be the number one consideration without a broadly-supported mandate.

See Question 25 answer

Leverage the state RPS and federal tax rebate programs. Encourage and allow third party financing of renewables, but ensure project maintains the RECs (or buys them back)

The code professionals and utilities are already on board. 
Response Renewable Energy Resistance

Public perception could be a big obstacle.

\section{Cost-Effective}

By not mixing the two.

Require a small amount so that it is not costly.

Drug everyone with half a brain and a calculator.

Education, national code requirements, utility rebates and mandates.

Explain to developers that on-site renewable energy systems are a positive marketing feature for their project.

Constant public awareness of the current state of our energy situation and future

Start small. Keep it simple.

Getting a much, much cheaper product.

Slowly adding requirements

Education and information at multiple levels from PSA's to vendors.

Successful, cost-effective installations

see 26

Raise the price of traditional energy sources. Subsidize renewables via a program with nationally important goals (energy independence, climate change, sustainability)

By treating renewables as just one more way to achieve the broader goal.

Develop technologies and systems that are cost effective, promote pilot uses, and demonstrate value to building owners and those who construct buildings.

Subsidies

For builders and building owners - By placing the requirements in mandatory codes for jurisdictions to adopt. For designers - continuing education programs to make them aware of renewable design options and comfortable to introduce it into each design they work on.

The design community is ready to go there. The public will go there if they can finance it and get it to pay back. The contractors are always looking for an edge. Incentivize it!

Education; comprehensive training and learning tools for the entire construction industry (designers, builders and enforcers); sound market introduction as shown now by DOE lighting project for LED.

Phase in the integration of renewable energy. See comments question 8

By making our society bear the full costs of what we're using now!

National "ad" campaign in every TV show, every movie, every bus, every bill board, etc showing effective, beautiful RE systems. Japan did it. PV is "cool" there, and all want it, even if they cannot afford it.

The requirement has to be clear, enforceable, and a produce a meaningful amount of energy. It will need to be uniformly enforced either nationally or regionally so that some jurisdictions are not disadvantaged. 
Response Renewable Energy Resistance

\section{Education}

Tax credits for the RE work done on the building (make the credits transferable) Provide bonus credits at the beginning of the requirements (150-300\% of actual spending particularly if work done by Certified personnel

Sensible, cost-effective approaches that start slowly and can be ratcheted up.

Incentives and education

Boot on neck (again kidding) If you don't comply you are out of business. "Physics deplores a vacuum"

Reduce cost, make it easy to comply, ensure utilities are given an incentive to promote distributed generation (in CA through attribution)

See above comment

Present it in the context of an overall goal consistent with national goals

Really good outreach and education, capacity building in all industries, coordinated efforts with minimal unnecessary constraints and bureaucracy.

see 26

It has to be mandated, if only to get people's attention! Then there should be CEU requirements for all related professionals that specifically addresses greenhouse gas emissions and buildings broadly, not just renewable on the subject building.

By including it as one of several means to achieve target EUI. Efficiency, which is generally much cheaper, should always be an option.

Case studies, cost benefit data, etc.

Reducing cost (including incorporating measures that make it more cost effective such as proper net metering). Including it as a trade off option so that builders can ease into it. It should be part of commercial requirements first as these projects can better absorb the cost.

Provide provisions for safe installations and basic performance requires, but it is the owner's option to choose, whether or not to install. Leave the operating of their business to them.

Responses

\section{8: What do you regard as the key issues that must be addressed if the use of renewable energy is to be integrated into building energy codes? Include any that we missed.}

Response comments question 28

Same answer.

Make sure that all the state interconnection codes are in agreement with the new requirement and that the penetration levels will not by opposed by state or utility rules.

We must have a national energy policy before we incorporate any requirements on energy sources into the codes. We must have a national portfolio standard as part of that energy policy, requiring the utilities to invest in renewable energy. We must continue to offer incentive programs for the deployment of renewables in order to achieve market transformation. Mandates alone will not achieve our objectives quickly enough. 
Response comments question 28

See Question 25 answer

Power purchase agreements and third party financing and REC ownership. Combination of design based prescriptive requirements and outcome based energy use caps to ensure real performance and overcome the lack of energy code enforcement

The PV industry is still a "wild west" sector. We need to tighten and enforce good practice. Many installers are skirting requirements, and could give the industry a bad name.

Cost-effective; safety of wind turbine in the built environment

\section{Cost-Effective}

First cost

How much additional costs are going to be required as a percentage of total building costs, especially for smaller buildings.

How to write it in code language. If you state that it must be a certain percentage of the building load, how is that load determined? Is it through simulation or the electrical load to the panel? This is very complex.

Improve codes to typically deliver office EUI 's of 25 or below (for example) before considering renewable requirements in code.

Rank and file building officials don't buy into energy efficiency or renewable energy

Make the requirements easy to understand and enforceable. Offer options, at least at first. Educate the users of the codes and the supplier industries thoroughly.

Start small.

Value Added

An effective administration of the rules. Not just the citing of non-compliance but the ability for the code official as the administrator to support the objectives as an informed resource.

They work, they are simple to maintain.

covered in previous comments

Resistance to the cost of renewables

cost effectiveness

NAHB

The key issue is working the requirements into the codes in phases, i.e., you need a starting point that is less than the "we must save the world with bold actions" levels that some would like to start with immediately. Once you get the topic into the codes, then you increase the level of compliance with each new edition of the codes.

It has to be cost effective.

Education in basic building science for construction industry; Integrated, comprehensive checklists to learn \& use in conjunction with BIM; Growth of infrastructure to test, commission and support the maintenance and repair of the systems Turn around financing of buildings to value energy conservation and efficiency first and foremost in construction That the systems are installed properly, commissioned and that the building operators know how to operate them. 
Response comments question 28

Require the infrastructure at least. Everybody is into upgrades so if renewables are an easier upgrade then they'll be more likely. Everybody also loves their upgrades so renewables become popular and more in demand. Marketing.

Fire Hazards of Class C PV modules on/in roofs of buildings

Develop a practical level of energy use offset (e.g. 3\% of total energy use in the building)

Financing and quality assurance. A government operated and assured warranty program would be important to drive the acceptance

Don't forget renewables from planning \& entitlement!

ancient lights externalities distributed energy and arrangements what does it mean for the gov to be a power producer how do utilities keep capacity for when the cloud goes over the NZ site E building - what happens when lots of buildings are NZE?

Utility and energy regulations. We are a protectionist nation when it comes to our energy policies.

Costs need to come down

Gain support of stakeholders for broad goal, before you tell them the details.

Be firm and clear and consistent with the long-term goals and schedule, allow for some ramp-up scenarios.

It must be mandatory, not voluntary, to get address the problem and to incentivize the various industries which need to come to bear. It must be doable. Don't give in to whining, it will happen no matter what you do, in fact, if you ask, the whiners are already whining about the current codes! One size does not fit all. If you want to provide a prescriptive requirement, make sure it will result in at least the same, if not greater, greenhouse gas emission reduction results as a performance/outcome option, which I feel is preferred.

Resistance to change, which should come in the form of more aggressive performance EUI targets, rather than further prescriptive measures.

Training requirements. How will training be done? Most builders have trouble with simple items; this will add a whole new level of complexity.

Cost effective and reasonable installation standards.

Responses

\section{9: Are there other comments you wish to add regarding the integration of renewable energy requirements into codes?}

\section{Response other comments question 29}

No

The city Dept. of Planning and Permitting is a bottleneck to approving new renewables. More education and a clear set if guidelines is necessary

It is my understanding that codes provide safety and health service and global warming \& nonRE's decreasing abundance should be framed that way, but it must be made clear or integrating RE into building energy codes will be misunderstood. 
Response other comments question 29

It's a terrible idea.

Do not forget the use of geothermal resources or resources that produce methane, such as composting or anaerobic digesters.

Not viable politically, economically, or practically.

No

Keep it flexible

Make sure that we are incentivizing the behavior that we want. Don't stop at the lot line. Consider broader societal impact, like transportation energy use.

They should be done at the neighborhood/district level so they should never be put into codes for individual buildings.

None at this time.

We have to build a strong and reliable work force and US based material supply and manufacturing infrastructure.

You have accepted a noble but difficult challenge.

No

The topic has to be addressed by incorporation into existing building code review and inspection processes. In my opinion an error has been made by some by teaching the requirements of the IECC as if energy is a separate discipline handled by a specific 'energy code plan reviewer'. The renewable requirements, as the energy requirements do now, blend in with and effect the general requirements of the building and fire codes. Make a change to energy or renewable requirement in a design and you may have negatively impacted a general code requirement, to make sure compliance is consistent and complete the building design has to be reviewed as an integrated system, not as separate topics.

I don't see this as an issue. People will go there when it is to their advantage to do so. Florida's approach is to keep making the code more stringent. To get there...they can use renewables. Support the market and marketability of the systems and their components before trying to modify the model codes.

The energy code should specify an energy target for the total building load by building type and weather zones

Inspectors are not up to the technical task of inspecting PV systems. They are far more complex that typical ac load systems--at this time.

No

It seems like the survey is written assuming an ASHRAE 189-type renewable requirement. I think there are a lot more nuanced ways to get renewables in the code in different areas. Examples are current work done by CA T24 2011 development, and Oregon's energy code, California Senate Bill 1, etc. We will need creative, flexible approaches.

I probably have more but at a loss right now ... see above...

I have said enough...( kidding)

Make sure that RE requirements do not undercut EE requirements. Also avoid loopholes that would allow owners to generate a hefty revenue from $\mathrm{RE}$.

Let the opposition "keep the duck". 


\section{Response other comments question 29}

This is exciting. It's going to be bumpy and challenging, but good stuff is never easy stuff... Keep your eye on the larger picture. If greenhouse gas reduction can be made at the utility then pressure is taken off the building industry. There should be a balance and the reductions should occur where the technology/cost, etc. indicates it makes the most sense.

Please move forward with this as quickly and aggressively as possible.

Kind of have been repeating myself already. This will bloom and grow when we get the costs down - just like what happened with color TV's and many other things. Reasonable prices and quality product means people will purchase. 
30: Please indicate your willingness to answer follow-up questions by phone, approximately 30 minutes.

(Respondents could only choose a single response)

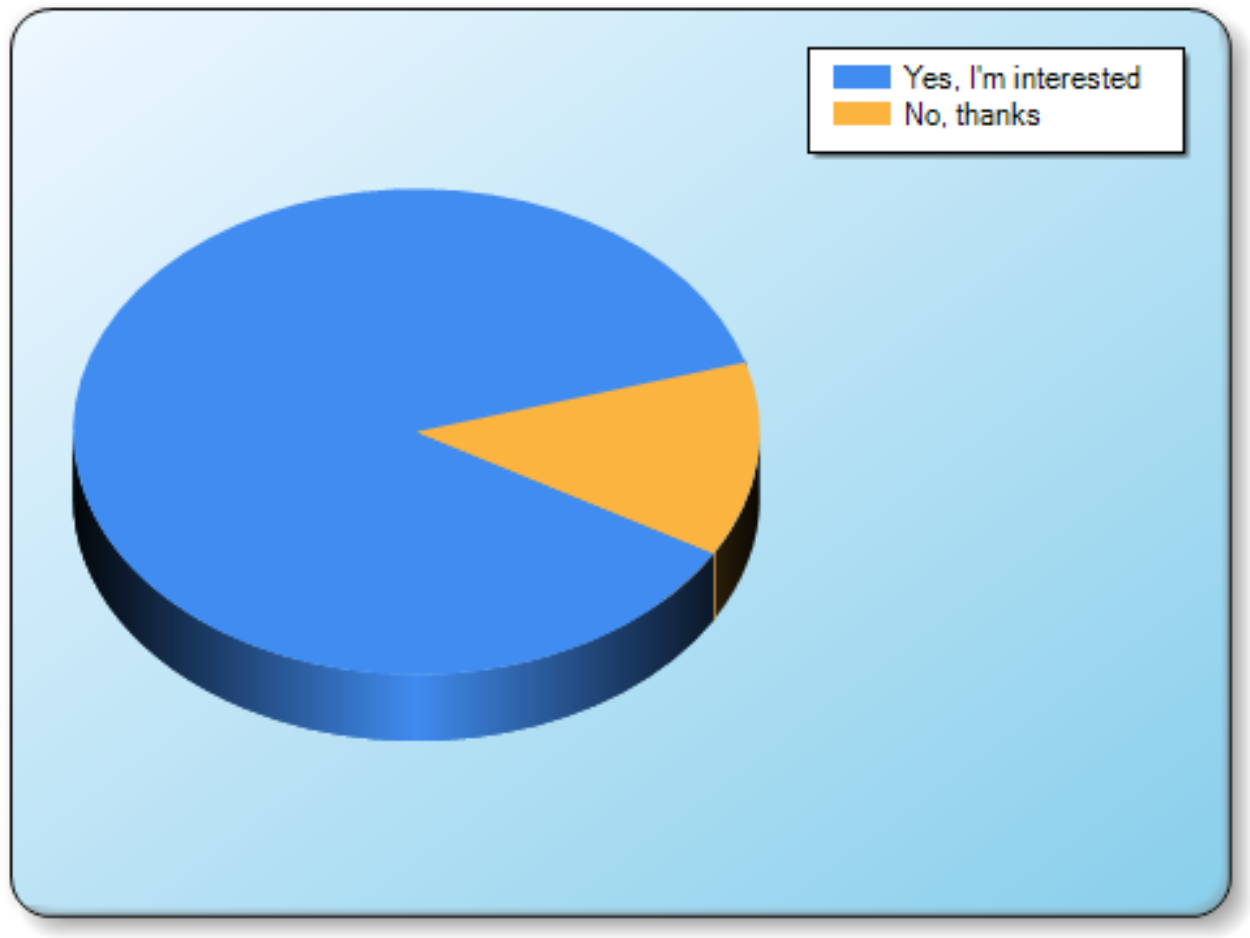

30: Please indicate your willingness to answer follow-up questions by phone, approximately 30 minutes.

(Respondents could only choose a single response)

\begin{tabular}{|c|c|c|c|c|}
\hline Response & \multicolumn{2}{|l|}{ Chart } & Frequency & Count \\
\hline Yes, I 'm interested & & & $87.0 \%$ & 47 \\
\hline No, thanks & & & $13.0 \%$ & 7 \\
\hline \multirow[t]{5}{*}{ Not Answered } & & & & 2 \\
\hline & & \multicolumn{2}{|c|}{ Mean } & 1.130 \\
\hline & & \multicolumn{2}{|c|}{ Standard Deviation } & 0.339 \\
\hline & & \multicolumn{2}{|c|}{ Valid Responses } & 54 \\
\hline & & \multicolumn{2}{|c|}{ Total Responses } & 56 \\
\hline
\end{tabular}




\section{1: Please give us your opinion of this questionnaire}

(Respondents could only choose a single response)

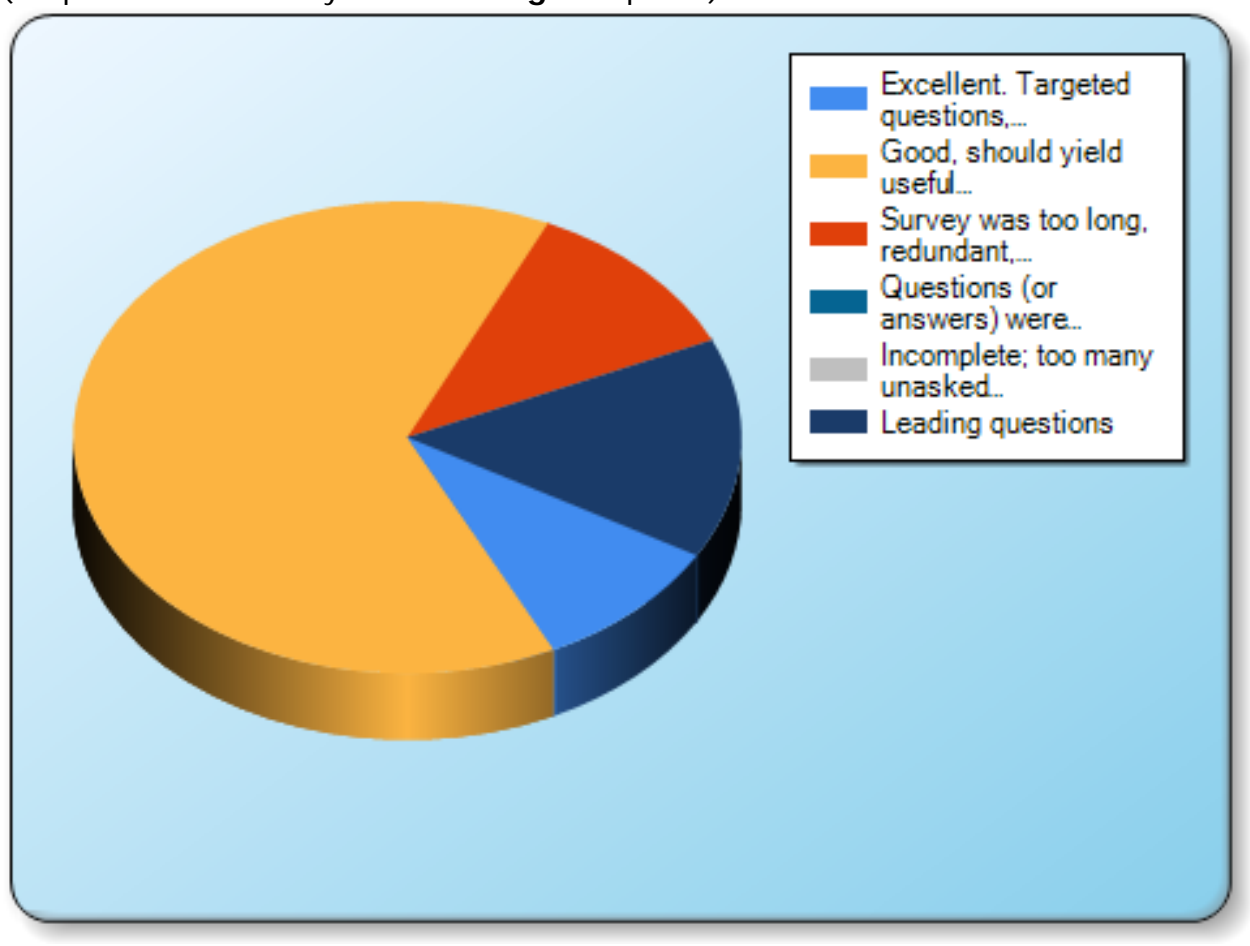

31: Please give us your opinion of this questionnaire (Respondents could only choose a single response)

\begin{tabular}{|c|c|c|c|c|}
\hline Response & \multicolumn{2}{|l|}{ Chart } & Frequency & Count \\
\hline $\begin{array}{l}\text { Excellent. Targeted questions, } \\
\text { complete and relevant } \\
\text { answers }\end{array}$ & & & $9.4 \%$ & 5 \\
\hline $\begin{array}{l}\text { Good, should yield useful } \\
\text { information }\end{array}$ & & & $64.2 \%$ & 34 \\
\hline $\begin{array}{l}\text { Survey was too long, } \\
\text { redundant, and extraneous }\end{array}$ & & & $11.3 \%$ & 6 \\
\hline $\begin{array}{l}\text { Questions (or answers) were } \\
\text { unclear or random }\end{array}$ & & & $0.0 \%$ & 0 \\
\hline $\begin{array}{l}\text { Incomplete; too many } \\
\text { unasked questions }\end{array}$ & & & $0.0 \%$ & 0 \\
\hline Leading questions & & & $15.1 \%$ & 8 \\
\hline Not Answered & & & & 3 \\
\hline & & Mear & & 2.623 \\
\hline & & Stanc & rd Deviation & 1.509 \\
\hline & & Valid & esponses & 53 \\
\hline & & Total & esponses & 56 \\
\hline
\end{tabular}




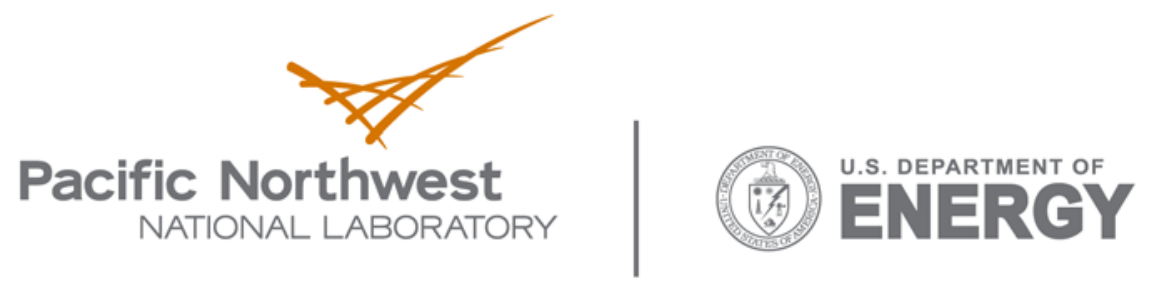

902 Battelle Boulevard

P.O. Box 999

Richland, WA 99352

1-888-375-PNNL (7665)

www.pnl.gov 